\title{
ANÁLISIS DE LA INNOVACIÓN EN PROCESO Y ESTUDIO DE LOS NON-R\&D INNOVATORS. EVIDENCIA EMPÍRICA PARA ESPAÑA.
}

Tesis Doctoral para obtener el doctorado en el Programa de Doctorado de Planificación y Gestión Empresarial.

Fecha: noviembre de 2012.

Autor:

Boronat Moll, Carles

Directores:

Hervás Oliver, José Luís (Departament d'Organització d'Empreses, UPV)

Seguí Mas, Elies (Departament d'Economia i Ciències Socials, UPV)

Departament d'Economia i Ciències Socials

Universitat Politècnica de València 



\section{Agraïments:}

Acadèmicament m'agradaria donar les gràcies a molta gent, sobretot als meus tutors, per ser tan pacients amb mi, amb els meus intensos períodes de treball en la tesi (on sempre trobaven un forat per atendre'm) continuats de períodes de desaparició quasi total, i és que compaginar la realització d'una tesi amb una feina a temps complet no serà mai fàcil.

També donar les gràcies a José Albors, a la gent de la Universitat de València per haver-me ensenyat un poc de tota la econometria que saben (sobretot a Juan Sanchis i Maria Rochina), a un revisor anònim de Industrial and corporate change que ens va obrir els ulls cap a nous horitzons i sobretot a Francisca Sempere Ripoll, segurament de tota la gent (a banda dels meus tutors) és a la persona a la que més dec haver pogut acabar esta tesi.

Personalment no puc deixar d'estar agraït a mon pare i ma mare per la seua paciència, el meu germà menut Artur pels seus consells i el meu germà major Salvador per la seua ajuda a nivell personal. Part de la realització de la tesi va coincidir amb un moment personal molt dur i tampoc puc deixar d'agrair tindre tants amics que em van donar el seu suport, sobretot Ilaria i Raul, però també Laura, Mariela, i tanta altra gent que quedaria fora de lloc posar-los a tots. Però en moments durs a la gent que et treu un somriure només li puc dir: gràcies. 



\section{RESUM}

El propòsit d'esta tesi es triple i intenta entendre un important resultat de la innovació organitzativa: la innovació de procés. Primer, l'article aborda un tema en emergent creixement: la importància dels innovadors no-I+D (innovadors sense $\mathrm{I}+\mathrm{D}$ que innoven). Segon, l'article explora i aclareix el fenomen de la innovació de procés que ha rebut menys atenció per part dels acadèmics en els últims anys, més centrats en el fenomen de la innovació de producte. En tercer lloc, l'article també busca idees per a determinar el grau en què les activitats d'innovació de procés són interdependents de la innovació organitzativa.

L'article constituïx un intent d'obtindre una fèrtil síntesi dels estímuls de la innovació de procés i els seus resultats usant diferents disciplines econòmiques per a complementar la perspectiva de la innovació organitzativa. L'estudi està basat en les dades de l'enquesta CIS d'Espanya (EUROSTAT data set, Contract on the use of Community Innovation Survey (CIS) microdata for research purposes, --CIS/2001/01 Contract number, Dr. Jose-Luis Hervas-Oliver, Louxembourg, 16-03-2011) i inclou especialment les empreses que van respondre haver introduït qualsevol tipus de resultat d'innovació en procés en sectors manufacturers i de serveis.

En general, els resultats subratllen el fet que l'activitat d'innovació de procés en contextos de mitja i baixa tecnologia, és explicada principalment pels esforços no-I $+\mathrm{D}$, mostrant una dependència del subministrament extern d'inputs, per exemple fonts externes de coneixement, la grandària resulta ser important i la combinació de la innovació en procés és interdependent de la organitzativa. La tesi presenta també importants implicacions per als polítics, sobretot enfront dels problemes de selectivitat de la mostra usualment observats en la majoria d'estudis d'innovació de procés.

\section{RESUMEN}

El propósito de esta tesis es triple e intenta comprender un importante resultado de la innovación organizativa: la innovación de proceso. Primero, el artículo aborda un tema en emergente crecimiento: la importancia de los innovadores no-I+D (innovadores sin I+D que innovan). Segundo, el artículo explora y arroja luz sobre el fenómeno de la innovación de proceso que ha recibido menos atención por parte de los académicos en 
los últimos años, más centrados en el fenómeno de la innovación de producto. En tercer lugar, el artículo también busca ideas para determinar el grado en que las actividades de innovación de proceso son interdependientes de la innovación organizativa.

La tesis constituye un intento de obtener una fértil síntesis de los estímulos de la innovación de proceso y sus resultados usando diferentes disciplinas económicas para complementar la perspectiva de la innovación organizativa. El estudio está basado en los datos de la encuesta CIS de España (EUROSTAT data set, Contract on the use of Community Innovation Survey (CIS) microdata for research purposes, CIS/2001/01 Contract number, Dr. Jose-Luis Hervas-Oliver, Louxembourg, 16-03-2011) e incluye especialmente las empresas que respondieron haber introducido cualquier tipo de resultado innovador en sectores manufactureros y de servicios (a partir de una encuesta de 32.553 empresas).

En general, los resultados subrayan el hecho de que la actividad de innovación de proceso en contextos de media y baja tecnología, es explicada principalmente por los esfuerzos no-I+D, mostrando una dependencia del suministro externo de inputs, por ejemplo fuentes externas de conocimiento, el tamaño resulta ser importante y la combinación de la innovación en proceso es interdependiente de la organizativa. La tesis presenta también importantes implicaciones para los políticos, sobre todo frente a los problemas de selectividad de la muestra usualmente observados en la mayoría de estudios de innovación de proceso.

\begin{abstract}
The purpose of this study is threefold, and it aims to provide an understanding of one important output from organizational innovation: process innovations. First, the study addresses an emerging growth: the importance of non $R \& D$ innovators (non $R \& D$ performers who innovate). Second, it explores and sheds light on the process innovation phenomenon which, in recent years, has received less attention by the Academia that has focused more on the product innovation phenomenon. Third, it seeks to provide insight to determine the extent to which process innovation activities are interdependent of organization innovation.
\end{abstract}


This study attempts to obtain a cross-fertilization synthesis of the inducements of process innovation and its outcomes using different economic disciplines to complement the organizational innovation perspective. The study is based on Spanish CIS data (EUROSTAT data set, Contract on the use of Community Innovation Survey (CIS) microdata for research purposes, CIS/2001/01 Contract number, Dr. Jose-Luis Hervas-Oliver, Louxembourg, 16-03-2011) and includes specially the firms that recorded having introduced any type of innovative output into manufacturing and service industries.

Overall, the results stress the fact that the process innovation activity in low- and medium-tech contexts is mainly explained by non R\&D efforts, with dependencies on the external provision of inputs, i.e., external knowledge sources, that size is important, and the combination of process innovation is interdependent to organization innovation. This study presents important implications for policymakers, and particularly addresses the selectivity problems in the sample that are usually observed in most studies conducted on the innovation process (from a survey of de 32.553 firms). 



\section{ÍNDICE}

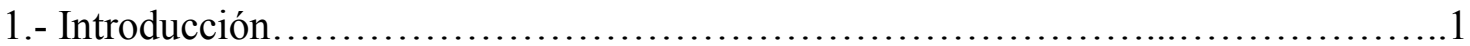

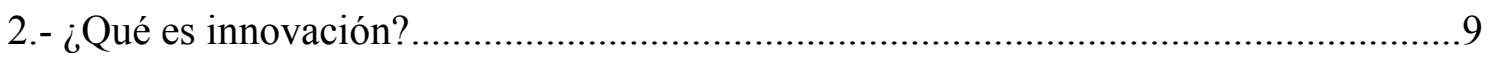

2.1.- Orígenes........................................................ 9

2.2.- Definiciones y tipos de innovación.................................. 10

2.3.- Fuentes de la innovación............................................... 11

2.4.- Normalización de indicadores de innovación y su medición...................11

2.4.1.- Manual Frascati..................................................... 11

2.4.2.- Manual de Oslo........................................................12

2.4.2.1.- Objetivos y alcance del manual...................................12

2.4.2.2.- Teoría de la innovación y necesidad de su medición.......................14

2.4.2.3.- Definiciones básicas........................................ 15

2.4.2.4.- Clasificaciones institucionales..................................... 16

2.4.2.5.- Vínculos en el proceso de innovación..............................17

2.4.2.6.- Medida de las actividades de innovación...........................17

2.4.2.7.- Objetivos, Barreras y Resultados de la Innovación...................19

2.4.2.8.- Procedimientos de encuesta..........................................20

2.4.3.- La encuesta de innovación tecnológica en las empresas del INE...........21

2.4.4.-Otros manuales.....................................................23

2.5.- Sistemas de innovación............................................24

2.5.1.- Sistemas de innovación estatales..................................24

2.5.1.1.- Sistema español de innovación........................................26

2.5.2.- Sistemas de innovación regionales..........................................27

2.5.3.- Sistemas de innovación a nivel de empresa.............................30

2.5.3.1.- Determinantes internos de la innovación............................31

2.5.3.2.- Determinantes externos de la innovación. Entorno....................39

2.5.3.3.- Otras variables explicativas....................................42

2.6.- Entendiendo la relación entre el desarrollo del proceso tecnológico y su inserción en la organización............................................43

3.- Innovación en servicios.............................................49

3.1.- Características de los servicios.........................................49

3.2.- Literatura en innovación de servicios..................................49

3.2.1.- Enfoque tecnológico o de asimilación............................50 
3.2.2- Enfoque orientado a servicios o de diferenciación.....................52

3.2.3.- Enfoque integrado o de síntesis...................................5

3.3.- Diferencias entre innovación en producción y servicios.......................59

3.4.- Medición de la innovación en servicios....................................62

3.5.- Revisión literatura sobre innovación en KIBS..................................63

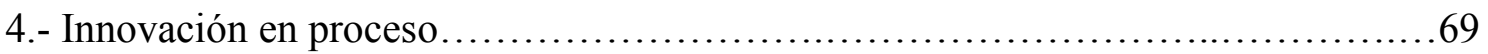

4.1.- Modelos iniciales básicos..............................................69

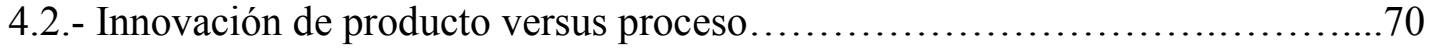

4.3.- Modelos de innovación de proceso.....................................72

5.- Innovadores no-I+D o non-R\&D innovators................................ 75

5.1.- Estudios que hacen mención a la importancia de la innovación no-

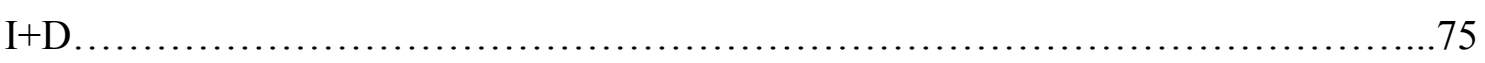

5.2- Estudios que tratan tangencialmente sobre la innovación no-I+D .............77

5.2.1.- Estudios sobre LMT (Low Medium Technology sectors)..................79

5.3.- Estudios sobre innovadores no-I+D ................................... 79

5.4. Resumen y discusión...................................................... 83

6.- Process innovation and non R\&D activities: unfolding neglected innovators in

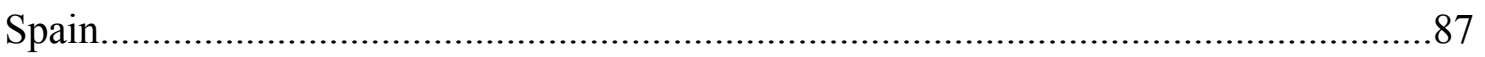

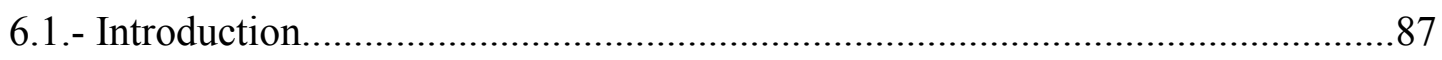

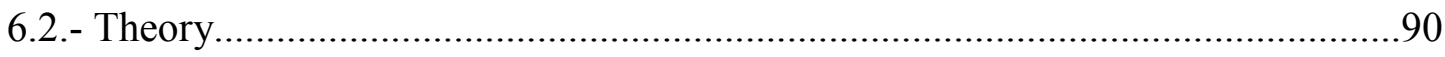

6.2.1.- Product and process innovation: different or complementary?......................90

6.2.2.- Managerial levers: the organizational determinants of innovation.................92

6.2.3.- Technological capabilities and innovation: the influence of industry on a

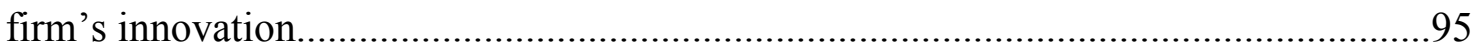

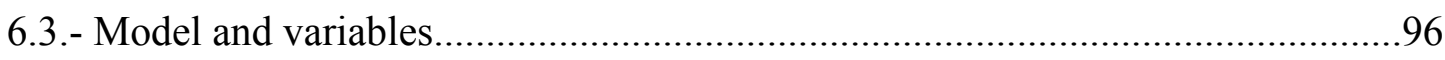

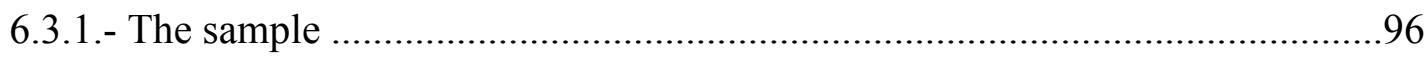

6.3.2.- Dependent variable for process performance..............................................97

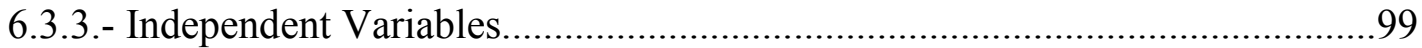

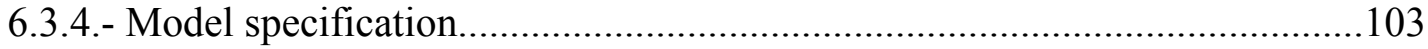

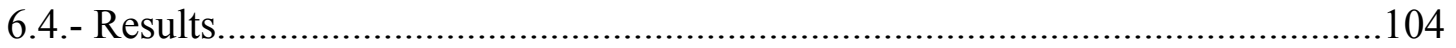

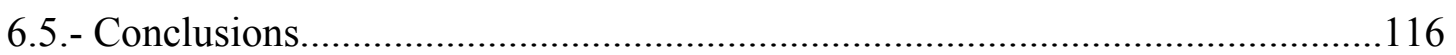

7.- Process innovation strategy and organizational synchronous adoption: complementarities and performance effects................................ 123

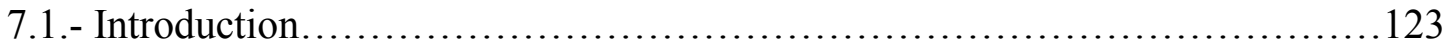


7.2.- Theory development and hypothesis.

7.2.1. Processes, technologies and organizational innovation synchronous adoption:

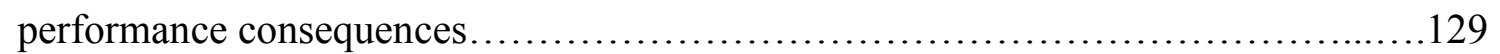

7.3. Empirical design.................................................... 132

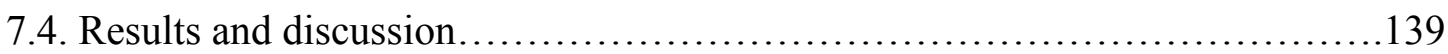

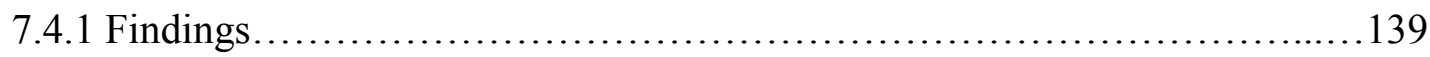

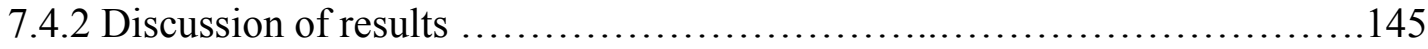

7.5. Conclusions........................................................... 148

8.- Conclusiones y trabajo futuro........................................... 151

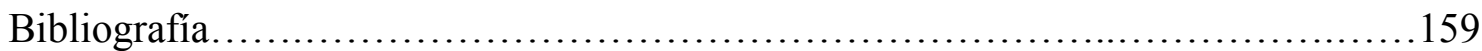

Appendix A: effects on products from new processes introduction.................... 195

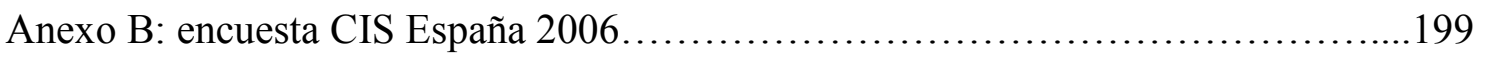





\section{ÍNDICE DE TABLAS}

Tabla 1. Revisión de estudios empíricos sobre non-R\&D innovators..................85

Table 2. Explanatory variables and their measurement and codification.......................99

Table 3. Descriptive statistics: mean, standard deviation and correlation

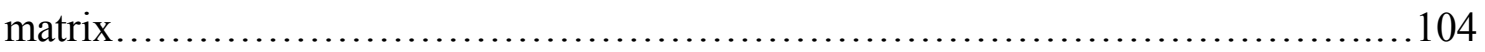

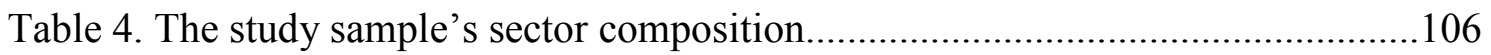

Table 5. Results from the models in the general sample (manufacturing and

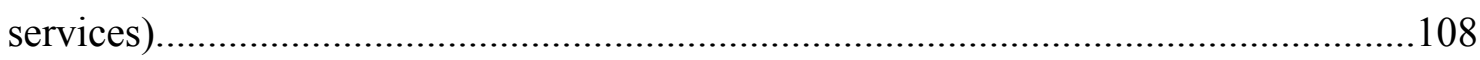

Table 6. Results from the models in the manufacturing firms sample.........................112

Table 7. Results from the models in the service firms sample...................................113

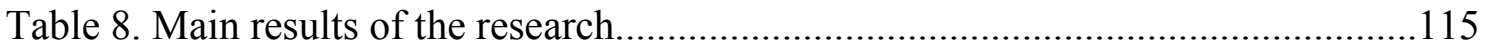

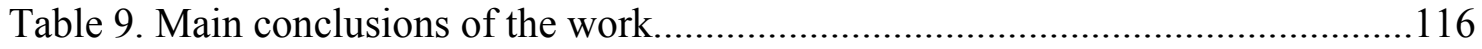

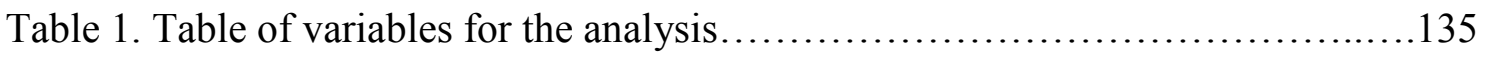

Table 2. Descriptive statistics and correlation matrix............................ 137

Table 3 Two-step Heckman procedure to control for selection problems.............139

Table 4. OLS Model. Dependent variable: Process_Effects.......................... 140

Table 5 OLS Model. Dependent variable: Process_Effects..............................143 


\section{ÍNDICE DE FIGURAS}

Figura 1. Citas de palabras............................................... 12

Figura 2. Composición de un sistema regional de innovación (SRI) $\ldots \ldots \ldots \ldots \ldots \ldots \ldots . .28$

Figura 3. Comparación entre la clasificación de Pavitt (1984) y la de Miozzo y Soete (2001)

Figura 4. Relación entre características técnicas y de servicio en el modelo Saviotti-

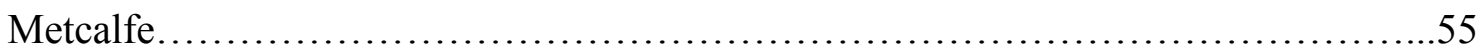

Figura 5. Representación del producto basado en características.....................56

Figura 6. Modelo mejorado de características y competencias........................58

Figura 7. Modelo dinámico de innovación de Utterback y Abernathy.................69

Figura 8. Representación estilizada de los vínculos del desempeño

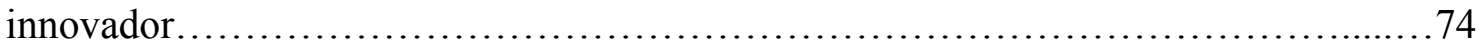




\section{1.- INTRODUCCIÓN}

Esta tesis es la culminación de un trabajo que empezó con la tesina del Diploma de estudios avanzados. Dos años después, tras muchas vicisitudes y cientos, sino miles de regresiones realizadas, el trabajo de este alumno de doctorado llega a su fin, que tal vez sea el comienzo de nuevas tareas de investigación.

En un congreso comentaba con alguien que a veces, tú no eliges los temas sino que ellos te eligen a ti. Este parece ser el caso con la innovación de proceso y esta tesis. Al realizar la revisión de la literatura una tesis que a priori iba a tratar sobre la innovación en servicios terminó tratando la innovación en proceso y como bien saben algunos no fue una cosa nada fácil, la innovación en proceso pareció resistirse a los esfuerzos de investigación de este investigador, pero la perseverancia finalmente dio sus frutos y se encontraron algunos hallazgos que se presentan en esta tesis.

El propósito de esta investigación es cuádruple y trata de proveer un mejor entendimiento de un importante resultado de la innovación organizativa: la innovación en proceso. Primero explora y arroja luz en el fenómeno de la innovación de proceso que en años recientes ha recibido menos atención por parte de los académicos (Reichstein and Salter, 2006; European Commission, 2008) comparado con el énfasis observado en la estrategia de innovación de producto o ha sido sistemáticamente explorada en tándem con la innovación de producto (Escribano et al., 2009) para predecir las firmas innovadoras. Segundo, el estudio se dirige a un emergente crecimiento de la importancia de los innovadores no- $\mathrm{I}+\mathrm{D}$ (empresas sin $\mathrm{I}+\mathrm{D}$ formal que innovan, Arundel et al., 2008, OECD, 2010; Barge-Gil et al., 2011). Tercero, también busca ideas para determinar el extremo hasta el cual la adopción de la innovación en proceso está relacionada y es por tanto interdependiente (Pisano, 1997; Damanpour, 2010) de la innovación de producto. La combinación de esos objetivos en el contexto de un país tecnológicamente bajo y medio (en el cual el estudio está basado), hacen al estudio original, mientras que también contribuye a la literatura existente explorando una de las estrategias menos investigadas cuando se estudia la innovación: la estrategia de innovación de proceso.

La innovación de proceso se define como los nuevos elementos introducidos en la producción u operación de servicio de una compañía para producir un producto o prestar un servicio (Utterback and Abernathy, 1975; Rosenberg, 1982) para el propósito 
de mejorar la productividad o calidad. Siguiendo a Reichstein and Salter (2006:655), la innovación de proceso está relacionada con nuevo capital de equipo (Salter, 1960), y aprender haciendo y aprender usando (Hollander, 1965; Cabral and Leiblein, 2001). Las actividades de innovación de proceso usualmente incluyen cambios organizativos y tecnológicos (Gopalakrishnan and Damanpour, 1997; Reichstein and Salter, 2006) que son difíciles de separar (Womack et al., 1990), como algunos académicos reivindican (Edquist et al., 2001). Citando al Manual de Oslo (OECD, 2005:55):

"Distinguir entre las innovaciones de proceso y organizativas es tal vez el caso fronterizo más frecuente para las encuestas de innovación ya que ambos tipos de innovación intentan -entre otras cosas- decrementar costes a través de nuevos y más eficientes conceptos de producción, suministro y organización interna. Muchas innovaciones por tanto contienen aspectos de ambos tipos de innovación. Por ejemplo, la introducción de nuevos procesos puede también incluir el primer uso de nuevos métodos organizativos tales como grupos de trabajo. Las innovaciones organizativas tales como la primera introducción de la gestión de la calidad total pueden incluir mejoras significativas en los métodos de producción, tales como nuevos sistemas logísticos de producción, para evitar ciertos tipos de defectos o nuevos y más eficientes sistemas de información basados en nuevo software y nuevo equipamiento TIC".

Nuestro estudio principalmente se centra en innovaciones tecnológicas de proceso. Hasta la fecha, la mayoría de la literatura basada en innovación está dedicada al entendimiento de la innovación de producto (ej.: Turner et al., 2010; Taylor, 2010; Kim and Pennings, 2009; Atuahene-Gima and Ko, 2001; Dougherty, 1992). Los estudios que se centran exclusivamente en analizar la innovación de proceso en la lietartura de gestión son escasos (Sinclair et al., 2000; Reichstein and Salter, 2006). De acuerdo a la OECD (2009:19), “Las preguntas de la encuesta sobre los efectos de la innovación de proceso (ej.: reducciones de costes, mayor productividad y flexibilidad, etc.) son necesarias para ganar una visión más completa de los efectos de la innovación en la economía. Hasta el presente, solo el porcentaje de ventas de nuevos productos sobreventas está cubierto". De hecho, existe una tendencia común a usar la adopción de innovación de proceso como una variable dependiente usando una variable ficticia para reflejar si la firma consigue o no innovación de proceso, por ejemplo, prediciendo los innovadores en proceso (Pacheco-Pires et al., 2008). Así, el problema es que el desempeño en innovación de proceso está raramente cubierto por la literatura existente. 
A la inversa, explorar como la capacidad de innovación trae resultados en innovación, y por último en el desempeño de la firma, es de extrema importancia para la gestión de la innovación de la firma (Crossan and Apaydin, 2010). Nuestro estudio arroja luz sobre este hecho estudiando la adopción de la innovación de proceso y sus consecuencias para el desempeño de esta. Hasta donde nosotros sepamos, la mayoría de artículos han usado el porcentaje de ventas de nuevos productos/servicios como medida del desempeño de la innovación (Laursen and Salter, 2006; Escribano et al., 2009). Esto es correcto siempre que la muestral este compuesta de innovadores de producto. Sin lugar a dudas, cuando el propósito del estudio consiste en medir la innovación de proceso, la muestra debería estar hecha de innovadores de proceso y la medida del desempeño no debería incluir el sobre utilizado porcentaje de ventas debido a nuevos productos. Por el contrario, como Wheelwright and Clark (1992) sugieren, que el desempeño de la innovación de proceso no puede ser medido por un porcentaje específico sobre ventas, sino que más bien requiere resultados de innovación de proceso tales como productividad laboral. En esta línea, Ettlie and Reza (1992) midieron el desempeño en la adopción de innovación de proceso usando dos categorías (flexibilidad y capacidad de proceso) y Pisano (1994) usó tiempo de suministro. Este estudio va a medir la adopción de innovación de proceso y su desempeño evitando la medida de desempeño del producto y por tanto usando un indicador adecuado compuesto de mejoras en costes laborales, costes de energía y materiales, reducción de tiempo de entrega y flexibilidad. De forma consistente con la meta anterior el estudio aplica en procedimiento de dos pasos de Heckman para validar la muestra y evitar problemas de selección. Además nuestro estudio arroja luz sobre el debate de si los procesos difieren o son complementarios a la innovación de producto. Siguiendo el artículo seminal de Damanpour (2010), existen dos asunciones diferentes, primero el proceso está considerado un fenómeno distinto (Wolfe, 1994; Damanpour and Aravind, 2006); segundo es complementario e interdependiente (Damanpour and Gopalakrishnan, 2001; Pisano, 1997; Abernathy and Utterback, 1978).

Cuando se estudia la adopción de la innovación en proceso, la literatura ha considerado también necesario la integración organizativa (Ettlie and Reza, 1992), especialmente a partir de la teoría de la organización. Por innovación organizativa en este trabajo nos referimos a "la implementación de nuevos métodos organizativos en las prácticas de negocio de la firma, organización del lugar de trabajo o relaciones externas" (OECD- 
Eurostat, 2005: 177), destacando el hecho de que es el resultado de decisiones estratégicas tomadas por la gestión. Siguiendo a Wengel et al., (2000) existen dos clases diferentes de innovación organizativa, usualmente interrelacionadas: las innovaciones estructurales (acuerdos organizativos y división del trabajo involucrado) e innovaciones de gestión (la forma en que una firma organiza sus actividades o el personal). Además, Birkinshaw et al., (2008) utilizan el término innovación de gestión para dirigirse a las nuevas estructuras organizativas, prácticas de gestión, procesos y técnicas. En esta línea, la innovación organizativa o de gestión se usa indistintamente, siempre y cuando coincidan en su significado. La evidencia empírica sobre la línea de investigación que sostiene que tecnología es una ocasión para estructurar la organización se encuentra en los casos de estudio de Barley (1986). Similarmente, Jelinek y Burstein (1982) señalaron el hecho de que la estructura productiva debe mantener una adecuación dinámica con la firma y su contexto organizativo. A partir de la literatura de gestión de operaciones se postula que la innovación en proceso está relacionada con la innovación organizativa o de gestión en el sentido que los sitemas de gestión usualmente complementan los técnicos (Womack et al., 1991). Complementariamente, la literatura de innovación también ha señalado que los cambios organizativos y tecnológicos son difusos y difíciles de separar (Edquist et al., 2001), aunque la evidencia empírica es escasa. Por tanto, este trabajo investiga también el rol complementario de la innovación de proceso y de gestión, para entender mejor la totalidad de actividades y subsistemas que envuelven la estrategia de innovación en proceso. En particular, este estudio presenta un intento de explorar los efectos que la adopción de innovación de proceso, enfatizando el rol de las complementariedades potenciales cuando, simultáneamente, se adoptan nuevos métodos organizativos para integrar la introducción de nuevas tecnologías y procesos. En este sentido, integración se entiende como un sistema de funcionamiento cruzado y sentido de la responsabilidad colectiva (Follet, 1933), en el sentido de Thompson (1967) de racionalidad limitada. Y es equivalente al de sincronización (Ettlie, 1988) o optimización conjunta de prácticas que están socialmente y técnicamente orientadas en la misma dirección (Cua et al., 2001; Damanpour et al., 2009). A pesar de toda esta heterogénea literatura señalando el mismo fenómeno, la evidencia proporcionada está basada en casos de estudio (Fleck, 1994), pequeñas muestras (Damanpour and Evan, 1984) o industrias específicas (Womack et al., 1991). En este sentido, esas complementariedades no han sido todavía empíricamente examinadas usando una gran base de datos y la literatura previa en gestión de la 
innovación no ha investigado todavía el rol de las complementariedades de gestión entre la innovación de proceso y organizativa usando datos CIS, especialmente porque la estrategia de innovación de proceso no ha sido estudiada de forma consistente.

El trabajo une los hilos desconexos de la literatura basada en adopción de innovación tecnológica con la de la innovación organizativa. Esta conexión teórica cubre un gran campo de literaturas, como la de la teoría organizativa, la gestión de operaciones y los estudios de innovación. Por tanto, las contribuciones de esta investigación se espera que conecten mejor la conversación sobre la innovación técnica con las de las teorías organizativas, abordando conjuntamente la estrategia de innovación en proceso y sus complementariedades con la de innovación organizativa.

Se ha prestado una creciente atención a la innovación no-I+D (NESTA, 2007; European Commission, 2008). En esta línea, Arundel et al. (2008) señalaron que los innovadores sin $\mathrm{I}+\mathrm{D}$ no son propiamente apoyados por las políticas, incluso cuando el cambio en el crecimiento anual de ventas entre los innovadores I+D y no-I+D es similar, y no existe razón para un sesgo en la política. De hecho cuando se compara el desempeño I+D y no- $\mathrm{I}+\mathrm{D}$, la mitad de todas las firmas innovadoras no desempeña $\mathrm{I}+\mathrm{D}$ y no existe diferencia en el desempeño, medido por el cambio en ventas (p.32). Adicionalmente, en el 2008, el Directorio de Innovación Europea (EIS), desarrollado por la Comisión de la Unión Europea medir las consecuciones de la agenda de Lisboa (Celikel-Esser et al., 2008), la metodología ha sido revisada y las nuevas categorías (facilitadores, actividades de la firma y resultados; mostrando 7 dimensiones y 29 indicadores) (ver Hollanders and van Cruysen, 2008) centrados principalmente en el prominente rol jugado por las PYMEs en Europa. Así, se han introducido indicadores tales como los gastos en innovación no-I+D (\% sobre ventas), entre otros. De forma complementaria la OCDE (OECD, Measuring Innovation, a New Perspective, 2010) dice que: “...las firmas pueden introducir nuevos productos en el mercado sin involucrarse en $I+D$. Nuevos indicadores revelan que en Australia y Noruega la propensión a introducir una innovación nueva para el mercado es similar independientemente de que la firma desempañe $I+D$. Por ejemplo, se ha citado que el $52 \%$ de firmas innovadora sin $I+D$ en Luxemburgo introdujo innovaciones nuevas para el mercado comparado a un 63\% de innovadores con I $+D$ interna” (p23). A pesar de todos esos esfuerzos para reflejar la innovación de una forma más amplia, la literatura en innovación se centra fundamentalmente en innovadores con I+D (Vega-Jurado et al., 2008; Escribano et al., 
2009) que ofrece contribuciones importantes pero tiene limitaciones significativas: restringir las actividades de innovación solamente a esfuerzos en $\mathrm{I}+\mathrm{D}$ elimina firmas de la muestra, las que innovan $\sin \mathrm{I}+\mathrm{D}$. De hecho, los gastos en $\mathrm{I}+\mathrm{D}$ presentan una evidencia bastante débil (Raymond and St. Pierre, 2009; Brouwer and Kleinkecht, 1997; Roper and Love, 2002) para explicar el desempeño innovador. Este estudio ofrece una solución a este problema: no restringir firmas a solamente los innovadores con $\mathrm{I}+\mathrm{D}$ (Máñez et al., 2005) e introducir ambos, los esfuerzos innovadores con y sin I+D (actividades input) para controlar los conductores requeridos para introducir la innovación. Así, las muestras no están restringidas y las conclusiones son más extensivas, y no solo reflejan mejor el ambiente real en los negocios, sino evitan problemas de sesgo en la selección muestral.

El trabajo está establecido a un nivel organizativo y contribuye a la existente literatura dando un análisis en profundidad de las actividades innovadoras de proceso proveyendo evidencia empírica de estrategias con y sin $\mathrm{I}+\mathrm{D}$ así como innovadores de proceso. En lugar de meramente predecir los innovadores en proceso (Baldwin et al., 2002), o simplemente entender las complementariedades ente las innovaciones de producto $\mathrm{y}$ proceso (Martinez-Ros, 2000), este estudio está basado en un entendimiento de los conductores que explican la consecución de mejoras en la productividad a través de reducciones de costes, flexibilidad y capacidad a partir de la adopción de innovaciones en proceso. Está basado también en un país seguidor tecnológicamente (España) cuyos niveles de inversión en $\mathrm{I}+\mathrm{D}$ no son altos). Los datos para llevar a cabo el análisis se originan a partir de la Encuesta de Innovación Española basada en la Encuesta de la Comunidad Eurostat de Innovación (CIS, Comunity Innovation Survey) y el Manual de Oslo (OECD, 2005).

La tesis está estructurada de la siguiente forma, en el capítulo 2 se hace un repaso genérico al concepto de innovación y a la literatura sobre el tema, centrada mayormente en la innovación de producto y en empresas manufacturing.

Posteriormente se hace una revisión de la literatura de a la innovación en servicios (capítulo 3), innovación en proceso (capítulo 4) y los innovadores no I+D (capítulo 5).

Tras toda esta revisión de la literatura académica en los capítulos 6 y 7 se acomete todo el trabajo empírico realizado. Cada uno de los capítulos está organizado internamente de forma independiente, esto se ha realizado así porque se pretende publicar los resultados 
de la tesis y facilitaba esta tarea, además podemos se puede separar mejor las distintas fases y hallazgos de la investigación realizada que comentamos en el último capítulo de conclusiones. 


\section{2.- ¿QUÉ ES INNOVACIÓN?}

\section{1.- Orígenes.}

Un principio inherente a los humanos ha sido siempre pensar en nuevas formas de hacer las cosas e intentar ponerlas en práctica. Así se ha pasado de los primitivos instrumentos de caza a las actuales armas de fuego, de la rueda y los carros a aviones supersónicos, en cualquier campo encontramos innovaciones que ayudan en parte también a explicar cómo ha evolucionado la humanidad, por qué fueron los europeos los que conquistaron América y no al revés, etc.

Sin embargo, a pesar de que la innovación explica en parte como se ha evolucionado, no se ha estudiado el proceso de la innovación hasta fechas recientes. Uno de los primeros y más influyentes autores sobre la innovación fue sin duda Joseph Schumpeter (18831850). Su teoría sobre el empresario innovador establecida en la "Teoría del Desarrollo Económico" (1934) continúa siendo estudiada en todos los manuales de economía. Su definición de innovación también lo sigue siendo y es una de las primeras definiciones universalmente aceptadas. Para Schumpeter existe equilibrio económico hasta que, debido a una innovación, este se rompe como consecuencia de la acción de un empresario innovador que tiene como función introducir nuevas combinaciones de factores productivos e incluso nuevos productos. En resumen, que innova (Schumpeter, 1934).

Posteriormente, algunos de los primeros en ocuparse del problema desde un punto de vista científico fueron los miembros de la SPRU (Science Policy Research Unit) en la Universidad de Sussex, que tuvo a Christopher Freeman como primer director. También se estableció "Research Policy" como la primera revista científica sobre el tema en 1972 (Fagerberg, Mowerry y Nelson, 2005). 


\section{2.- Definiciones y tipos de innovación.}

Según Schumpeter (1934) innovación es la introducción en el mercado de una nueva combinación de factores productivos que podría adoptar las siguientes formas:

a) Introducción de nuevos productos o productos de nuevas calidades.

b) Introducción de un nuevo proceso productivo, que no se derive de un descubrimiento científico o de una nueva forma de distribuir un producto comercialmente.

c) Apertura de nuevos mercados.

d) Nuevas fuentes de aprovisionamiento.

e) Nueva organización de una determinada industria.

Según el Manual de Oslo (OECD, 2005), una innovación es la introducción de un nuevo o significativamente mejorado producto (bien o servicio), de un proceso, de un nuevo método de comercialización o de un nuevo método organizativo, en las prácticas internas de la empresa, la organización del lugar de trabajo o las relaciones exteriores. De forma más restrictiva, el propio manual dice que se puede restringir el concepto de innovación tecnológica a innovación de producto o proceso.

En cuanto a los tipos de innovación el manual de Oslo distingue:

- Innovación de producto: introducción de un bien o servicio nuevo o significativamente mejorado, en cuanto a sus características o en cuanto a su uso.

- Innovación de proceso: introducción de un nuevo o significativamente mejorado, proceso de producción o distribución. Implicando cambios significativos en las técnicas, materiales y/o programas informáticos

- Innovación de mercadotecnia: aplicación de un nuevo método de comercialización que implique cambios significativos del diseño o envasado del producto, su posicionamiento, su promoción.

- Innovación de organización: introducción de un nuevo método organizativo en las prácticas, en la organización del lugar de trabajo o las relaciones exteriores de la empresa. 
Normalmente se distingue entre invención e innovación. Así, hay veces que son dos hechos íntimamente relacionados (como sucede en la biotecnología), pero otras veces hay un considerable retraso de incluso décadas entre la invención y la innovación (Rogers, 1995). Además, mientras que las invenciones pueden suceder en cualquier lado, como en las universidades, las innovaciones suceden de forma mayoritaria en compañías. También hay que tener en cuenta que si asumimos que invención es igual a patente nos encontramos con un gran número de innovaciones que no resultan patentables. Sin embargo, el uso de patentes para medir la innovación es una práctica muy extendida (pero con limitaciones).

\section{3.- Fuentes de la innovación.}

La innovación tiene como origen diversas fuentes. Se pueden identificar fuentes internas y externas (Veugelers, 1997; Padmore, 1998).

1.- Fuentes internas. Surgen dentro de la empresa, serían: directivos, departamento de $\mathrm{I}+\mathrm{D}$, departamento de marketing, empleados, etc.

2.- Fuentes externas. Se dan fuera de la empresa. Se pueden distinguir dos grandes tipos:

- Científicas, son las también denominadas Organismos Públicos de Investigación (OPIS): laboratorios de investigación, universidades, institutos tecnológicos.

- No científicas: proveedores, clientes, competidores y empresas de consultoría relacionadas con la valorización de tecnología, información general disponible como conferencias, encuentros y revistas profesionales o ferias y exhibiciones.

\section{4.- Normalización de indicadores de innovación y su medición.}

\subsection{1.- Manual Frascati.}

Desde el principio, en la OCDE se observó la importancia de la innovación para conseguir un desarrollo económico sostenido y sostenible. El Manual Frascati fue el 
primero en establecer un conjunto de principios básicos respecto de la medición de las actividades científicas y tecnológicas.

El Manual Frascati define la I+D y marca cuales son los indicadores para medir la innovación, estableciendo una base homogénea para posteriormente poder hacer comparaciones entre distintos países (OECD, 2002).

\subsection{2.- Manual de Oslo.}

El sector servicios representa en los países desarrollados cerca de un $65 \%$ de la economía (Miles, 2005). Es por ello que el Manual de Oslo ha hecho un notable esfuerzo respecto a su adaptación en la última edición para contemplar la innovación en servicios. Aún así, la palabra 'servicio' o 'servicios' se cita 170 veces en el manual mientras que la palabra 'producto' o 'productos' se cita un total de 439 veces. Esto es, la palabra servicio se cita un $62 \%$ menos que la palabra producto (fuente: elaboración propia). Hay que hacer la salvedad de que muchas veces la palabra producto está utilizada en el sentido de que implica también el significado de servicio, dada la dificultad de tener en cuenta esto, solo se indica este hecho para señalar que falta un largo recorrido en el estudio de los servicios, como se verá más adelante.

Figura 1. Citas de palabras.

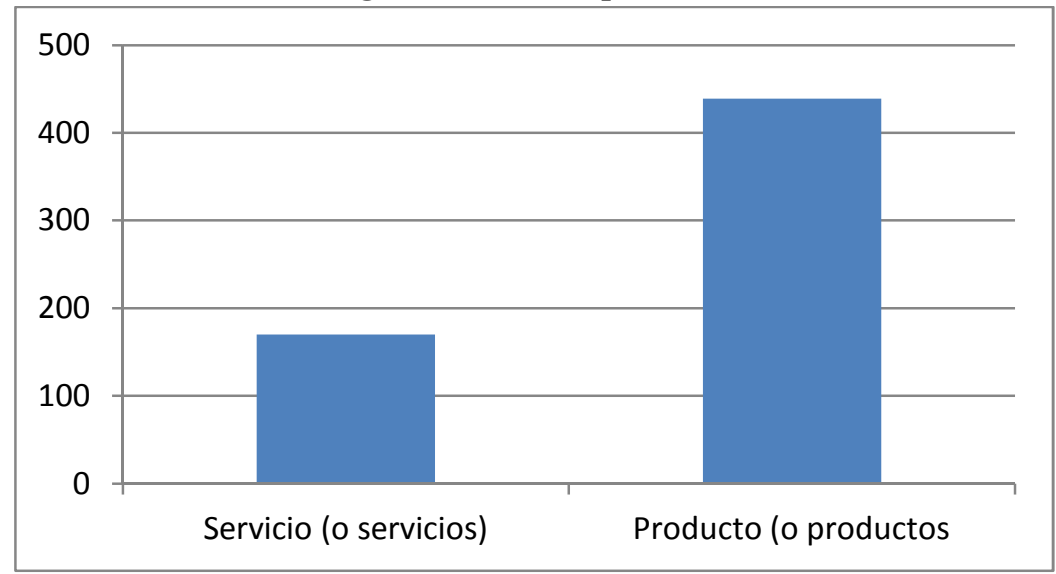

Fuente: elaboración propia.

\subsubsection{1.- Objetivos y alcance del manual.}

El Manual de Oslo (OECD, 2005) proporciona las definiciones y metodología para diseñar las encuestas que recojan los datos sobre fuentes de ideas innovadoras, 
inversiones e impacto de la innovación, de forma homogénea, así como los obstáculos para la misma.

El Manual de Oslo trata específicamente de la innovación, estableciendo qué se puede considerar así y que no. Fundamentalmente trata cuatro tipos básicos de innovación: de producto, de proceso, de mercadotecnia y de organización. El Manual no trata sobre la innovación en servicios tales como la salud o la educación, trata solamente la innovación en el sector empresarial.

Entiende por difusión de la innovación, el modo en el cual estas se extienden a través de circuitos comerciales (u otros) a los diferentes consumidores, países, mercados, sectores o empresas. Sin esta difusión, una innovación no tiene ningún impacto económico.

La novedad de las innovaciones puede ser de tres tipos: nuevo para la empresa, nuevo para el mercado, nuevo para el mundo y, por último, innovaciones que suponen una ruptura. Así mismo, durante un período de tiempo las actividades de innovación de una empresa pueden obtener diversos resultados: exitosas, en curso o abandonadas.

El manual considera empresa innovadora la que ha introducido una innovación en un período de tiempo considerado. El impacto de esta innovación puede ser medido fundamentalmente como el porcentaje de ventas atribuido a los productos nuevos o mejorados.

Las actividades innovadoras de una empresa dependen en parte de los vínculos que mantiene con otros agentes del sistema innovador. Así el manual identifica tres tipos de vínculos externos: fuentes de información de libre acceso, adquisición de conocimiento y tecnología, y finalmente, cooperación en cuanto a innovación.

El Manual de Oslo describe dos tipos principales de encuesta para la recogida de datos sobre innovación: una sobre una innovación en concreto y otra sobre las diversas actividades innovadoras de la empresa o sujeto del estudio. Para que las encuestas sean comparables a nivel internacional el manual intenta armonizar los métodos de muestra. 


\subsubsection{2.- Teoría de la innovación y necesidad de su medición.}

El manual examina las teorías y la investigación sobre innovación, y las cuestiones políticas relacionadas, tratando de ver como las encuestas sobre innovación pueden facilitar datos que ayuden a entender mejor estos temas.

El marco en el que se basa el manual para la integración de las diferentes teorías de la innovación presenta las siguientes características: innovación en la empresa, vínculos con otras empresas e instituciones públicas de investigación, marco institucional en el que funcionan las empresas y el papel de la demanda.

Innovación según el Manual, implica incertidumbre en cuanto a resultados, inversión en activos materiales e inmateriales, está sujeta a spillovers (rara vez las ventajas de la innovación creativa se quedan de forma íntegra en la empresa innovadora) y tiene como objeto la mejora de los resultados de la empresa mediante la obtención de ventajas competitivas.

Las actividades específicas de innovación no solo incluyen la I+D sino que son muchas más, como por ejemplo: definición de nuevos conceptos de servicios, compra de información técnica, etc. En las encuestas se intenta determinar la importancia de cada tipo de insumo para la innovación.

El marco institucional de la empresa se refiere a sistema universitario y educativo, financiero, legislativo, etc.

En los sectores de alta tecnología, la I+D desempeña un papel central en las actividades de innovación, mientras que otros sectores se apoyan en mayor grado en la adopción del conocimiento y de la tecnología.

Las actividades de innovación en el sector servicios son normalmente continuas y la diferencia entre innovación de servicio y de proceso resulta mucho menos clara que la distinción entre innovación de producto y proceso.

Las encuestas sobre innovación permiten definir los motivos y las barreras a la innovación, los cambios en el método de funcionamiento de las empresas, la naturaleza de las actividades de innovación que desarrollan y los tipos de innovaciones que introducen, aunque presentan limitaciones. 
Las encuestas tratan también de determinar cuáles son los vínculos que establecen las empresas innovadoras y cuál es el papel de la difusión en la innovación. Intentan establecer cuál es el impacto de la innovación en términos de productividad, producción y empleo.

Las encuestas sobre innovación también intentan medir los diferentes obstáculos con las que se encuentra esta: económicos (altos costes o ausencia de demanda), factores específicos de una empresa (carencia de personal experto o conocimiento necesario), factores legales (reglamentaciones o las normas fiscales) y también la capacidad de las empresas para proteger o apropiarse de las mejoras de las actividades de innovación (patentes, modelos de utilidad, secreto industrial, etc.). Intentan medir y analizar el papel de la demanda en la innovación, de los recursos humanos y la influencia de la legislación y la normativa.

\subsubsection{3.- Definiciones básicas.}

Para distinguir las innovaciones de producto o servicio de la innovación de proceso, el manual hace hincapié en los siguientes puntos según sea la innovación:

- Si presenta características nuevas o mejoradas del servicio ofrecido, se trata de innovación de producto.

- Si implica la utilización de métodos, equipos, y/o conocimientos nuevos o mejorados para presentar el servicio, es innovación de proceso.

- Si presenta a la vez que las características del producto ofrecido o servicio prestado, los métodos, equipos y/o conocimientos utilizados para esa prestación, se trata de una innovación de producto y proceso.

Para distinguir las innovaciones de servicio de innovaciones de mercadotecnia el manual asevera que el principal factor para distinguirlas es si la innovación implica un método de comercialización o un servicio. Así, para una empresa de ventas de determinados productos, la introducción de la venta por internet implica una innovación de mercadotecnia. En cambio para una empresa de comercio electrónico, un cambio en su website, es una innovación de servicio. 
Hay determinados cambios que el Manual de Oslo no considera innovaciones: cese de la utilización de un proceso, método de comercialización o de organización, o de la comercialización de un producto; la simple sustitución o ampliación de equipos; variaciones solamente del precio de los factores; producción personalizada (en tanto que un mismo producto para un nuevo cliente no es considerada innovación); modificaciones estacionales regulares y otros cambios cíclicos (moda); comercialización de productos nuevos o significativamente mejorados (si el mayorista o minorista solamente lo venden no se puede considerar que introduzcan una innovación).

Toda innovación debe tener un elemento de novedad, pero esta puede tener un diferente grado de novedad, el mínimo requerido es que sea nueva para la empresa, una innovación puede ser nueva para el mercado si es la primera vez que se utiliza en ese sector de actividad, o nueva para el mundo si es nueva en cualquier sector de actividad o mercado.

El manual considera empresa innovadora a aquella que ha incluido al menos una innovación durante el periodo estudiado (normalmente 3 años).

\subsubsection{4.- Clasificaciones institucionales.}

Se define la unidad estadística primaria como la unidad empresa. Para grupos de empresas, la decisión de si tomarlas como grupo o individualmente se debería de basar en donde se realiza la toma de decisiones en cuanto a las actividades innovadoras. Para empresas multinacionales, las encuestas solo se referirían a las unidades que se encuentren en el mismo estado, incluso la adquisición de conocimiento de otra empresa del grupo, pero si es de otro estado debe tenerse en cuenta como adquisición externa de conocimiento.

Se define una unidad estadística secundaria, menor que una empresa y que se referiría a una empresa o parte de empresa que realiza una única actividad productiva.

Las empresas se clasifican para su estudio según su actividad económica y número de empleados principalmente, pero también según la forma de actividad, tipo de institución, tipos de bienes producidos, intensidad de actividad exportadora, situación geográfica, intensidad de la innovación y cooperación. 


\subsubsection{5.- Vínculos en el proceso de innovación.}

El manual habla sobre los vínculos en el proceso de innovación que relacionan a la empresa innovadora con los agentes del sistema de innovación. En las encuestas se debe tratar de identificar estos vínculos, que normalmente dependerán de la naturaleza de la empresa y su mercado (Dierkes, 2003).

Los vínculos varían según la fuente (con quien o con qué se establece el vínculo), el coste (importe de la inversión requerida) y el nivel de interacción (sentido del flujo de la información y nivel de los contactos interpersonales). De este modo, es importante determinar si el desarrollo la innovación se ha realizado mayormente dentro de la empresa o no.

Tenemos que hablar de difusiones "entrantes", entender cómo se difunde desde la primera vez que aparece hacia otras empresas y mercados. El manual establece tres tipos: fuentes de información de libre acceso (que no implican ni compra de conocimiento y tecnología, ni interacción entre la empresa y la fuente), la compra o la adquisición de conocimiento y tecnología, y la cooperación en materia de innovación. También es importante conocer la naturaleza del conocimiento obtenido por medio de un vínculo: si era público o privado, si estaba incorporado o no, si era tácito o estaba catalogado, si estaba basado en la I+D, específica o genérica, y cuál era su grado de novedad.

Difusión "saliente" puede producirse por la venta de un nuevo bien o servicio a los consumidores o a otras empresas, pero va más allá e incluye como se comparte la información y la difusión de innovaciones organizativas y de mercadotecnia. La gestión del conocimiento ayuda a la innovación y a la difusión de la misma.

\subsubsection{6.- Medida de las actividades de innovación.}

La información sobre las actividades de innovación es útil porque permite saber qué tipos de actividades realizan las empresas: efectúan $\mathrm{I}+\mathrm{D}$, compran conocimiento y tecnología en forma de $\mathrm{I}+\mathrm{D}$ externa (máquinas $\mathrm{y}$ equipos, $\mathrm{u}$ otras formas de 
conocimiento externo), incluyen la formación en el desarrollo e introducción de innovaciones o están implicadas en actividades para modificar su organización.

Para garantizar que los resultados de las encuestas sobre innovación sean comparables, el manual divide todas las actividades de innovación distintas de las de $\mathrm{I}+\mathrm{D}$, en actividades de innovación de producto y proceso por una parte, e innovaciones de mercadotecnia y organización, por otra.

- Actividades de innovación de producto y proceso: adquisición de conocimientos en el exterior; adquisición de máquinas, equipos y otros bienes de capital; otros preparativos destinados a las innovaciones de producto y proceso; preparación del mercado para las innovaciones de producto; y formación.

- Actividades relativas a las innovaciones de mercadotecnia y organización: preparación destinada a las innovaciones de mercadotecnia (preparación para la introducción de nuevos métodos de comercialización en el diseño o envasado del producto, en los métodos de tarificación, en la colocación del producto y en su promoción) y preparación destinada a las innovaciones de organización (elaboración y la planificación de nuevos métodos de organización así como las actividades necesarias para su aplicación).

El manual puntualiza sobre la investigación y desarrollo experimental, que todas las actividades de $\mathrm{I}+\mathrm{D}$ deben considerarse como innovación. Se considera $\mathrm{I}+\mathrm{D}$ el desarrollo de programas informáticos. El desarrollo de servicios se considerará como I+D si da lugar a un nuevo conocimiento o implica la utilización de nuevos conocimientos para elaborar nuevas aplicaciones. La construcción y prueba de un prototipo se considera como I+D si su primer objetivo consiste en aportar nuevas mejoras.

Todas las actividades de diseño para el desarrollo y la introducción de innovaciones de producto (incluso las referentes a la forma y el aspecto del producto) e innovaciones de proceso deben incluirse o en $\mathrm{I}+\mathrm{D}$, o en otros preparativos destinados a las innovaciones de producto y de proceso. En cambio las actividades vinculadas a cambios de diseño del producto que constituyan innovaciones de mercadotecnia (cuando las características funcionales o las utilizaciones previstas para el producto en cuestión no se mejoran significativamente) deben incluirse en preparativos destinados a las innovaciones de mercadotecnia. 
La recogida de datos sobre innovación puede recoger tanto aspectos cuantitativos como cualitativos. Se deben evitar las imputaciones dobles de gastos. El manual desglosa los gastos según su tipo: gastos corrientes de innovación (mano de obra y otros gastos corrientes) e inversiones en capital fijo.

El manual considera importante como se financia la innovación. Para eso desglosa el origen de fondos: fondos propios, fondos procedentes de empresas participadas, fondos procedentes de otras empresas no financieras, fondos procedentes de sociedades financieras (préstamos bancarios, capital riesgo, etc.), fondos públicos (préstamos, subvenciones, etc.), fondos procedentes de organismos supranacionales e internacionales (UE, etc.), y otros orígenes.

Los enfoques a la hora de elaborar las preguntas sobre gastos de innovación pueden ser de dos tipos: objeto, donde se preguntan gastos totales sobre una innovación específica y sujeto, donde se preguntan gastos totales en un período de tiempo dado.

\subsubsection{7.- Objetivos, barreras y resultados de la innovación}

Los objetivos y las barreras para la innovación son distintos según el tipo de innovación. Como ejemplo, los objetivos de las innovaciones de producto o de mercadotecnia se refieren principalmente a la demanda (mejora de la calidad de los productos, aumento de la cuota de mercado, penetración en nuevos mercados), mientras que las innovaciones de proceso o las organizativas tratan más bien de la oferta (la reducción de costes, el aumento de la capacidad de producción). También algunas barreras afectan a todos los tipos de innovación (por ejemplo, los factores de coste) mientras que otras solo inciden en una combinación de los tipos de innovación.

Las empresas pueden emprender actividades de innovación por múltiples motivos, mejora de eficiencia, de calidad, de nuevos o mejorados productos, conquista de nuevos mercados, etc. Los datos sobre esos objetivos pueden aportar información sobre las distintas fuerzas que originan la información y los distintos resultados a los que se llega. La competencia, la demanda y los mercados son los principales motores de las innovaciones de producto y, en algunos casos, de las innovaciones de mercadotecnia. 
El éxito y el impacto de las innovaciones pueden ser muy diferentes. El manual recomienda medir este impacto por ejemplo, por el tiempo transcurrido desde que se produce la innovación, las exportaciones, el margen comercial, la cifra de negocios o el empleo generado.

La capacidad de las empresas para recoger los frutos de sus actividades de innovación es un factor que afecta mucho a la innovación. Se sugieren los siguientes métodos de protección:

- Métodos formales: patentes, registro de modelos, marcas registradas, derechos de autor, acuerdos de confidencialidad y secreto comercial.

- Métodos informales: secretos no cubiertos por acuerdos jurídicos, complejidad del diseño del producto, ventaja en el plazo de introducción con relación a los competidores.

Los datos relativos a las patentes, tanto solicitudes como concesiones, sirven como un indicador de resultados intermedios para la actividad de innovación y facilitan también información sobre la capacidad de innovación de la empresa.

Sin embargo, diversos estudios demuestran que la efectividad de las patentes para proteger los derechos sobre las inversiones en $\mathrm{I}+\mathrm{D}$ ha disminuido a pesar una legislación más exigente y amplia (Cohen y Nelson, 2000), tendiendo las empresas a preferir el secreto.

\subsubsection{8.- Procedimientos de encuesta.}

Se recomienda realizar encuestas a las unidades de cómo mínimo diez empleados. Se considera población marco a aquella sobre la que se extrae la muestra. Las técnicas para seleccionar la muestra son: muestreo aleatorio simple, muestreo estratificado, muestreo por conglomerados $\mathrm{y}$ el muestreo con probabilidades proporcionales al tamaño. También pueden utilizarse técnicas combinadas. Ciertos subconjuntos de la población pueden revestir un especial interés, a estos se les denomina dominios. Los métodos de encuesta son: postales y entrevistas personales (se incluyen aquí las telefónicas dirigidas por ordenador). Los cuestionarios deben de probarse antes de ponerse en práctica. 
Deberían ser lo más simples y breves posible, tener una estructura lógica y tener definiciones e instrucciones claras.

Si se hacen de forma combinada, una encuesta sobre innovación e I+D generará diferentes ventajas (menor carga de trabajo, mayor posibilidad de analizar las relaciones entre I+D e innovación, entre otras) e inconvenientes (cuestionario más largo, marcos de las dos encuestas diferentes y otros).

Los resultados de los sondeos deben ponderarse para poder obtener información representativa de la población objetivo, existiendo una serie de programas informáticos para la calibración de los resultados. El manual hace algunas recomendaciones para el tratamiento de las no-respuestas como hablar con el encuestador, inferir las respuestas y otras. Los resultados sobre innovación pueden utilizarse tanto para hacer un análisis descriptivo como para realizar un análisis deductivo. El manual recomienda realizar encuestas sobre innovación cada dos años.

\subsection{3- La encuesta de innovación tecnológica en las empresas del INE}

La encuesta de innovación tecnológica facilita información sobre la estructura del proceso de innovación ( $+\mathrm{D}$ y otras actividades innovadoras) y permite mostrar las relaciones entre dicho proceso y la estrategia tecnológica de las empresas, los factores que influyen (o dificultan) en su capacidad para innovar y el rendimiento económico de las empresas.

Además, proporciona el marco base para posteriores estudios específicos sobre aspectos concretos del proceso de innovación (por ejemplo, utilización de tecnología punta en la fabricación, pagos e ingresos tecnológicos, estudios sobre patentes, etc.).

El Instituto Nacional de Estadística (INE) realizó esta encuesta en los años: 1998, 2000, 2002, 2003, 2004, 2005, 2006, 2007 y 2008. Es decir, a partir del año 2002, toma un carácter anual.

La encuesta se realiza siguiendo las directrices metodológicas definidas en el Manual de Oslo de la OCDE, que inspiraron su primera realización en España en 1994. 
La encuesta va dirigida a las empresas agrícolas, industriales, de la construcción y de los servicios de 10 o más asalariados, cuya actividad económica principal se corresponde con: agricultura, ganadería, silvicultura y pesca; industrias extractivas; industria manufacturera; suministro de energía eléctrica, gas, vapor y aire acondicionado, suministro de agua, actividades de saneamiento, gestión de residuos y descontaminación; construcción; comercio; transporte y almacenamiento; hostelería; información y comunicaciones; actividades financieras y de seguros; actividades inmobiliarias; actividades profesionales, científicas y técnicas; actividades administrativas y servicios auxiliares; actividades sanitarias y de servicios sociales; actividades artísticas, recreativas y de entretenimiento; y otros servicios.

Desde el año 2002 este estudio se realiza de forma coordinada con la Estadística sobre actividades en Investigación Científica y Desarrollo Tecnológico (I+D). El directorio está formado por una parte por un directorio de empresas potencialmente investigadoras (bien porque así consta de años anteriores o bien porque han solicitado financiación pública para proyectos propios de investigación), y por las empresas de más de 200 empleados; y por otra parte de una muestra aleatoria extraída del DIRCE (Directorio Centralizado de Empresas), obteniéndose una muestra final de más de 33.363 empresas para el año 2005. El método de recogida de la información es un sistema mixto que comprende la realización de envíos por correo y la participación de entrevistadores, con un importante apoyo telefónico en la recogida de la misma.

Con carácter general se solicita información de la actividad innovadora de la empresa durante el año de referencia, si bien, para aquellas variables relacionadas con los productos y procesos innovadores se requiere información para un período de tres años con objeto de facilitar la comparación internacional.

La información solicitada se refiere a adquisición de nuevas tecnologías, innovaciones tecnológicas, actividades de $\mathrm{I}+\mathrm{D}$, gastos en innovación, regionalización de los gastos de innovación, impacto económico de la innovación tecnológica, objetivos de la actividad innovadora, fuentes de ideas innovadoras, obstáculos a la innovación y otras innovaciones no tecnológicas.

En el cuestionario se hacen una serie de preguntas descriptivas sobre las características de la empresa, sobre las actividades internas de $\mathrm{I}+\mathrm{D}$, sobre la compra de servicios de $\mathrm{I}+\mathrm{D}$, actividades para la innovación tecnológica realizadas por la empresa, innovación 
de productos y procesos en un periodo de tres años (año de la encuesta y los dos años anteriores), factores que dificultan las actividades de innovación, derechos de propiedad intelectual o industrial, ingresos y pagos por tecnología desincorporada, innovaciones organizativas, innovaciones de comercialización y sobre deducciones fiscales para I+D e innovación.

\subsection{4.- Otros manuales.}

Existen otros manuales relacionados con innovación que tienen diferentes objetivos. Se procede a comentar brevemente los mismos:

- Manual de Camberra (OECD, 1995). Este manual está destinado a proveer de una guía para la medición de recursos humanos dedicados a la ciencia y tecnología, y al análisis de dichos datos.

- Manual para la medida e interpretación de pagos tecnológicos. Balanza de pagos tecnológicos (BPT) (OECD, 1990). Registra el flujo financiero que se produce en un país debido a las transacciones comerciales internacionales de sus empresas, relativas a la transferencia de tecnología, para un periodo dado. Comprende compra y venta de tecnología «no incorporada», en la forma de derechos de propiedad industrial, incluyendo los derechos al uso de las patentes, licencias, diseños, know-how, así como asistencia técnica y servicios técnicos en ingeniería, agricultura, etc., y de asesoría informática, entre otros. Los datos de la BPT permiten medir la difusión internacional de la tecnología no incorporada, contabilizando todas las operaciones relativas a intercambios de conocimientos técnicos y de servicios con contenido tecnológico, entre socios de diversos países. Es decir, mide la diferencia entre gastos y retornos de un país, por exportar o importar conocimientos o servicios técnicos.

- Manual de Patentes (OECD, 1994). Trata la utilización de los datos de patentes como indicadores de Ciencia y Tecnología. La finalidad de este manual es ofrecer información básica sobre los datos de patentes que se utilizan para medir la ciencia y la tecnología y construir indicadores de actividad tecnológica, así como ofrecer directrices para la recopilación e interpretación de indicadores en materia de patentes. Las limitaciones de la medición de la innovación son diversas: una empresa puede optar por el secreto industrial como mejor forma de proteger la innovación 
(Cohen y Nelson, 2000), hay numerosas innovaciones que no son patentables, algunas patentes no son explotadas comercialmente después, etc. Además, muchas patentes tienen un valor tecnológico y económico nulo, mientras que otras tienen un enorme valor.

- Manual de Bogotá (RYCIT y OEA, 2001). Este manual trata de adaptar el Manual de Oslo a las características de los países de América Latina y el Caribe, considerados países emergentes o en vías de desarrollo. Trata de normalizar los indicadores de innovación tecnológica en América Latina.

\subsection{Sistemas de innovación.}

\subsection{1.- Sistemas de innovación estatales.}

La expresión "sistema nacional de innovación" fue usada por primera vez por Freeman (1987). Él lo definió como la red de instituciones en el sector público y privado, cuyas actividades e interacciones inician, importan y difunden nuevas tecnologías. En el trabajo se usará la expresión sistema estatal de innovación en vez "sistema nacional de innovación“, que es la que utiliza mayoritariamente en la literatura. La mayoría de autores al referirse a este sistema se refieren al sistema estatal y por tanto no realizan ninguna diferencia entre el concepto de nación y de estado, diferencias que en esta investigación si se realizan por ser estos dos conceptos diferentes (Taylor y Flint, 2002).

Las dos obras más importantes sobre los sistemas estatales de innovación son Lundvall (1992) y Nelson (1993), quienes emplean diferentes aproximaciones. Nelson (1993) hace más énfasis en los casos de estudio empíricos que en el desarrollo teórico y algunos de esto estudios se focalizan en los sistemas estatales de innovación. En cambio Lundvall (1992) es más conceptual y hace hincapié en la interacción mutua de aprendizaje entre el productor-usuario y la innovación.

Una definición más amplia de sistema estatal de innovación es la proporcionada por Edquist (1997): “todos los factores importantes de tipo económico, social, político, organizacional, institucional y otros que influencian el desarrollo, difusión y uso de las innovaciones". 
De acuerdo con diversos autores (Pérez, 1996) existen dos formas de interpretar la definición de sistema estatal de innovación. Una más estrecha, en donde este concordaría con el sistema científico tecnológico, siendo este el enfoque utilizado por la OCDE en los estudios sobre políticas científicas y tecnológicas. Y en el sentido más amplio, como veíamos en la anterior definición de Edquist (1997), que englobaría a todos los agentes y espacios relacionados con el progreso técnico en el ámbito productivo.

Fagerberg y Srholec (2008), analizan los datos del PIB para distintos países, y encuentran que hay 4 factores que pueden explicar el 74\% de la varianza del desarrollo económico de un país. El primer factor descansa de forma muy importante en diferentes aspectos de la capacidad tecnológica como: patentes, publicaciones científicas, infraestructura en TIC, certificaciones ISO 9000 y acceso a financiación. Sin embargo, también está altamente correlacionado con la educación que es más bien una variable de tipo social. Se propone una definición de factor como "las capacidades que influyen en el desarrollo, difusión y uso de las innovaciones" y etiquetan este factor como "sistema de innovación". Existe una fuerte correlación entre este factor y el PIB de cada país. Una de las pocas desviaciones viene de países con economías ricas en recursos que muestran mayor PIB del que cabría esperar en función de su sistema de innovación. El segundo factor se basa en diversos aspectos que reflejan la calidad del "gobierno", tales como respeto a los derechos de propiedad, un sistema judicial que funcione bien, poca corrupción y un entorno favorable para los negocios. La relación de este factor, a pesar de ser positiva no es tan fuerte como en el caso anterior, principalmente debido a la existencia de un grupo de países (sobre todo en África) que son mucho más pobres que lo que indica la calidad de su gobierno. El tercer factor se basa en el carácter del "sistema político". En países pequeños con sistemas cercanos a los del mundo occidental tienen un alto rango en este factor, mientras que países que difieren de los ideales democráticos de los países occidentales tienen un bajo valor. En contraste con los dos factores anteriores, no existe una gran correlación, dado que algunos países con regímenes autoritarios se desarrollan bastante bien económicamente (como los países del golfo pérsico y China). El cuarto factor está formado por dos indicadores, importaciones de bienes y servicios, e inversión directa extranjera. Por lo tanto este factor explica el grado de "apertura" al comercio exterior y al capital extranjero. Esta variable no muestra una correlación con el desarrollo económico. Los autores creen que 
se deberían tener en cuenta también la apertura a las personas y a las ideas (a pesar de no haber sido capaz de encontrar información relevante para su estudio), y que estas no están necesariamente correlacionadas con la apertura al comercio exterior o al capital extranjero.

Finalmente, la introducción de indicadores que reflejan diferencias en la naturaleza, geografía e historia muestra una ligera mejoría en el poder explicativo de las variables.

Como conclusión cabe decir que la posibilidad de que un país alcance a los otros en términos de desarrollo económico aumenta principalmente al mejorar el sistema de innovación y el gobierno.

\subsubsection{1.- Sistema español de innovación.}

En esta parte se realiza una breve descripción del sistema español de innovación. Para ello se toma la aproximación menos amplia al concepto de sistema estatal de innovación. Esta descripción está basada en el Plan Nacional de Investigación Científica, Desarrollo e Innovación Tecnológica 2008-2011 de la Comisión Interministerial de ciencia y Tecnología (2007). Así, los componentes del sistema español de innovación son:

- Organismos públicos de I+D

- Universidades

- Otros centros públicos de I+D

- Centros públicos y privados de I+D sin ánimo de lucro

- Empresas

- Centros tecnológicos

- Agrupaciones o asociaciones empresariales

- Agrupaciones empresariales innovadoras (clústeres innovadores) y plataformas tecnológicas.

- Organizaciones de apoyo a la transferencia tecnológica, difusión y divulgación tecnológica y científica. Incluye parques científicos y tecnológicos, OTRIs, CEIs y los centros de innovación y tecnología. 


\subsection{2.- Sistemas de innovación regionales.}

El concepto de sistema regional de innovación es empleado por primera vez por Cooke (1992, p. 299). No existe una definición de sistema regional de innovación plenamente aceptada, se puede definir un sistema regional de innovación (Asheim y Gertler, 2005) como "la infraestructura institucional que apoya a la innovación en la estructura productiva de una región".

Cooke y Memedovic (2003) señalan que el sistema regional de innovación estaría integrado por dos subsistemas de actores implicados en un aprendizaje interactivo: un subsistema de generación de conocimiento (o infraestructura de apoyo regional), compuesta por laboratorios de investigación públicos y privados, por universidades, agencias de transferencia tecnológica, organizaciones de formación continua, etc.; y un subsistema de explotación de conocimiento (o estructura de producción regional), compuesto mayormente por empresas. Sobre ambos subsistemas actuarían las organizaciones gubernamentales y las agencias de desarrollo regional, que según Trippl y Tödtling (2007) constituirían a su vez otro subsistema del sistema regional de innovación. Estos subsistemas estarían insertos en un marco socioeconómico y cultural común regional. Dicho sistema de innovación regional (SRI) no debe entenderse como una unidad autosuficiente, sino que es un sistema abierto que se encuentra ligado a otros sistemas de innovación regionales, nacionales y globales. 
Figura 2. Composición de un sistema regional de innovación (SRI).

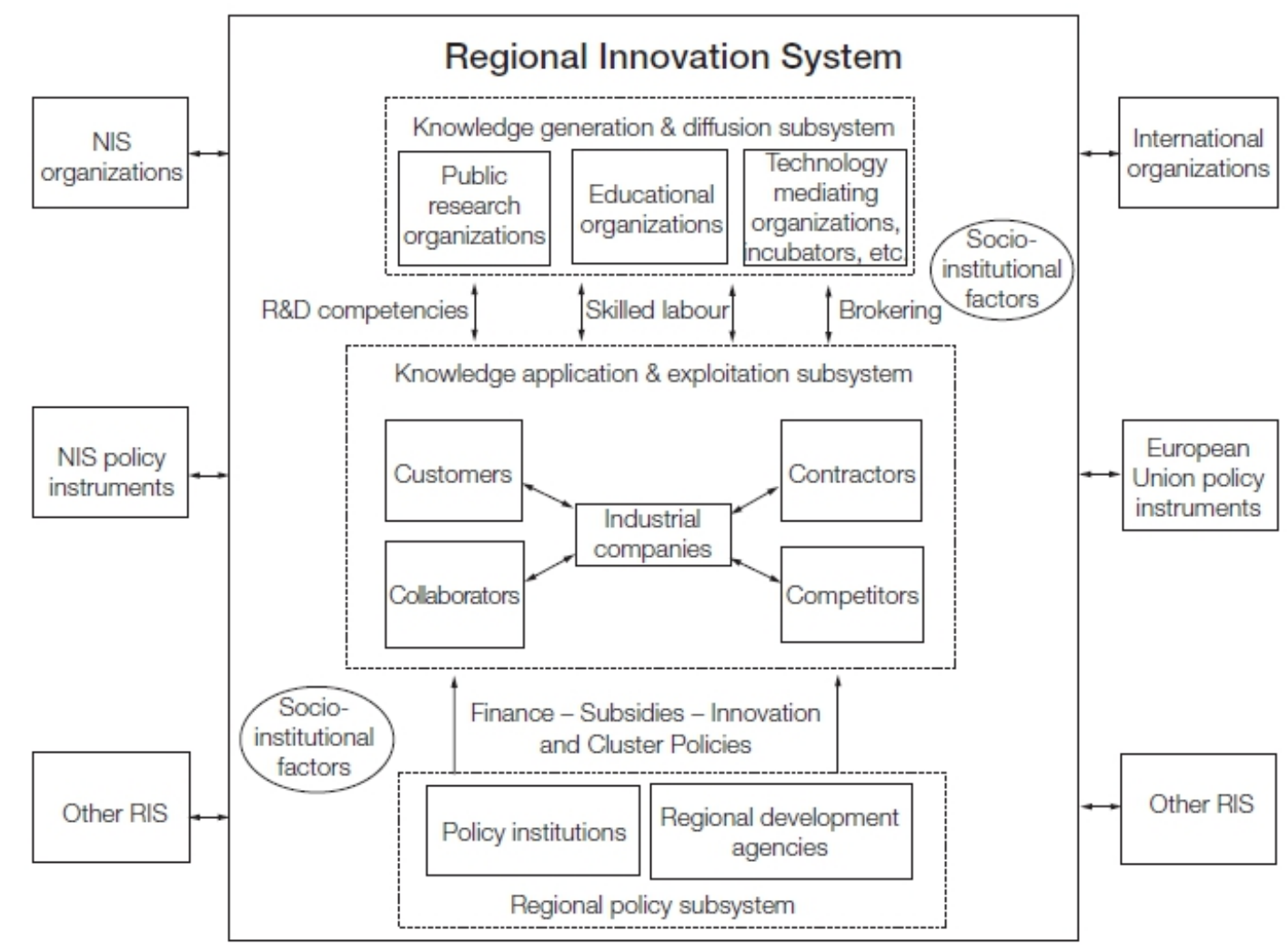

Fuente: Tödtling y Trippl (2005).

Así como señalan Olazaran y Otero (2009). La perspectiva de los SRI parte de la premisa de que las redes formales e informales entre agentes (empresas, gobierno, agentes de $\mathrm{I}+\mathrm{D}$, otros agentes del entorno) en un contexto de confianza permiten minimizar los costes de transacción, facilitando el intercambio de conocimientos tácitos de carácter innovador (Cooke, Gómez y Etxebarria, 1997). El capital social contribuye a la innovación al reducir los costes transaccionales en las relaciones entre empresas (y entre éstas y otros actores), los costes de investigación e información, los costes de negociación y decisión y los costes de implementación de políticas y programas (Maskell, 2001; OECD, 2001).

La confianza, la reciprocidad, los valores compartidos, las redes y las normas aceleran la transferencia de información y el desarrollo de nuevo conocimiento. Los "fallos del mercado" para el intercambio de conocimiento entre empresas pueden superarse si las relaciones puramente económicas son reemplazadas por acuerdos de intercambio recíprocos y estables basados en la confianza. 
Las redes de colaboración inter-empresarial (clústeres, distritos industriales, milieux) son particularmente importantes en el caso de las pymes, que conforman la gran mayoría del tejido empresarial europeo (Crouch, Le-Galés, Trigilia y Voelzkow, 2004).

Iammarino (2005) destaca los contextos culturales y locales para la innovación a través de un estudio de las diferencias en la evolución de distintas regiones italianas.

Holbrook y Wolfe (2005) estudiaron como varía la innovación en las diferentes regiones de Canadá y encontraron que el capital social en forma de redes de investigación incentiva las innovaciones radicales. También descubrieron que el impacto de la globalización afecta de diferente forma a las firmas según si son indígenas (mayor tendencia a realizar $\mathrm{I}+\mathrm{D}$ a nivel regional o local) o multinacionales (se apoyan más en sus homólogas, y realizan un menos esfuerzo en $\mathrm{I}+\mathrm{D}$ a nivel local o regional). Además las industrias intensivas en conocimiento tienden a estar geográficamente concentradas, como resultado de los derrames que generan, y necesitan establecer grupos comunes con investigadores de las universidades para que se dé también intercambio de conocimiento tácito.

Estos autores terminan concluyendo que el aprendizaje resulta ser la clave de los procesos económicos en todos los casos (como otras firmas, instituciones de investigación, asociaciones industriales y elementos relacionados del clúster), que la fuerza de trabajo capacitada es el activo local más importante y que la masa crítica de la misma también parece ser importante, ya que hasta que es conseguida, las empresas luchan entre ellas intentando retener o atraer la fuerza de trabajo cualificada que necesitan. Una vez alcanzada una determinada masa crítica de fuerza de trabajo altamente cualificada en un determinado sector, se establece un circulo positivo y autoreforzado a través del cual estas regiones son capaces de atraer a incluso más trabajadores de este tipo. El liderazgo dentro de la empresa es crucial para explicar las diferentes aproximaciones estratégicas tomadas por las firmas en la misma industria y región, y su posterior éxito competitivo (este liderazgo también está expresado a nivel de escala social). La legislación, leyes y laboratorios también tienen un papel sutil pero penetrante en la innovación. Al hablar de innovación, mientras el estudio parte de la premisa de que la geografía importa, se reconocen los peligros de presuponer la importancia de lugar, más que escogerlo a través de un estudio sistemático. 
Buesa, Heijsa y Baurmert (2010) a través del estudio de los sistemas regionales de innovación de 146 regiones europeas concluye que los principales determinantes de la innovación (siendo esta medida solamente a través de las patentes, con todas las restricciones que esto conlleva) son a nivel absoluto (número total de patentes), en primer lugar el entorno regional de innovación y en segundo lugar las empresas innovadoras. A nivel relativo (patentes por habitantes), el primer factor explicativo son las empresas innovadoras y el segundo el entorno regional. Esto es así porque el entorno regional es una variable de carácter absoluto que refleja entre otras cosas el tamaño de la economía y del sistema innovador de la región. Como conclusión se deriva de los resultados que las ventajas de escala son un importante factor explicativo de la innovación. El entorno regional representa el tamaño absoluto y en este caso muestra la importancia de las ventajas de escala. Las actividades de I+D muestran importantes efectos de escala, y esos efectos causan un efecto de concentración de esas actividades.

\subsection{3.- Sistemas de innovación a nivel de empresa.}

Una de las teorías que trata de explicar la innovación es la teoría evolucionista que tiene como obra seminal la de Nelson y Winter (1981). Estos autores realizan una analogía entre la biología y la economía, proponiendo un modelo evolutivo de innovación tecnológica en el ámbito empresarial, donde los mecanismos de selección de las empresas en ambientes competitivos determinan la supervivencia de las organizaciones. Para estos autores las rutinas junto con la creatividad y la inventiva constituyen el fundamento esencial para la innovación tecnológica. Consideran que las organizaciones poseen características hereditarias (capacidades y reglas de decisión) y otras nuevas capacidades que desarrollan mediante una actuación ante la adversidad o respuesta a los acontecimientos aleatorios que se presentan. Por tanto, la empresa puede ser concebida como un ser vivo en constante evolución como consecuencia del aprendizaje colectivo. Las rutinas (entendidas como patrones de comportamiento) serían como los genes de la organización, conformando una memoria corporativa con características duraderas.

En este apartado se trata de describir los diferentes factores que según la literatura afectan a la capacidad de innovación de una empresa. Para la investigación se ha basado en gran medida en el artículo de Becheikh, Landry y Amara (2006) que revisa la literatura sobre la innovación técnica en productos y procesos. 
Entre las fuerzas conducentes de las innovaciones tecnológicas, encuentran que son principalmente de dos tipos: aquellas que afectan a los determinantes internos de innovación y las que afectan al entorno (externos).

\subsubsection{1.- Determinantes internos de la innovación.}

La teoría de recursos y capacidades intenta explicar la ventaja competitiva y el crecimiento asumiendo que las empresas son heterogéneas dado a que poseen recursos y capacidades diferentes y únicas, además de que estas no son perfectamente trasladables entre las empresas (Barney, 1991; Peteraf, 1993; Grant, 1996). La ventaja competitiva se puede desarrollar a partir de la explotación de las oportunidades que la empresa encuentra en su entorno, y evitando las amenazas (Barney, 1991). Así, el tipo, magnitud y naturaleza de los recursos y capacidades que la empresa posea, serán determinantes importantes de la rentabilidad (Amit y Schoemaker, 1993). La empresa con esos recursos y capacidades debe ser capaz de generar y apropiarse de rentas. No es suficiente que la empresa se encuentre en un determinado sector industrial para que logre generar beneficios, sino que debe poseer una serie de atributos que le permitan producir de forma eficaz y eficiente. Sin embargo, un sector industrial no va permanecer bajo las mismas condiciones indefinidamente. Ante un entorno cambiante, la organización corre el riesgo de quedarse obsoleta, tanto en recursos, como en capacidades, por lo que la constante renovación le permitirá seguir obteniendo resultados óptimos. La teoría de recursos y capacidades es una herramienta que permite determinar las fortalezas y debilidades internas de la organización. El desarrollo de capacidades distintas de las de la competencia es la única forma de conseguir ventajas competitivas sostenibles según esta teoría.

En este apartado tratamos de resumir los determinantes internos de la innovación clasificados por Becheikh et al. (2006):

1.- Características generales de la firma (tamaño, edad y estructura de la propiedad de la empresa, actuación pasada).

2.- Estrategias globales de la firma: definición de la estrategia (la firma tiene una orientación estratégica definida); estrategia corporativa (estrategia de diversificación, exportación/internacionalización, crecimiento interno vs externo); estrategia de 
negocio (estrategia de diferenciación, estrategia de reducción de costes, mecanismos de protección).

3.- Estructura de la firma: formalización (estructura formal, estructura flexible), centralización (centralización del poder de decisión, poder de los empleados), interacción (interacción entre unidades de la firma).

4.- Control de actividades: control financiero versus control estratégico.

5.- Cultura de la firma: resistencia al cambio, control total de la calidad o mejora continua, cultura de soporte a la innovación.

6.- Equipo directivo: variables de liderazgo (presencia de un líder de proyecto, características del CEO, cambio del CEO); relacionadas con el mánager (cualificación y experiencia, percepción del coste/riesgo relacionado con la innovación).

7.- Activos funcionales y estrategia: I+D (activos de I+D y estrategias); recursos humanos (cualificación/experiencia del personal, estrategias de recursos humanos); operación y producción (equipos avanzados/tecnologías, grado de capacidad de utilización); márketing (estrategias de márketing, seguimiento de la competencia); finanzas (autonomía financiera, resultados/beneficios, presupuesto/disponibilidad de fondos).

(1) Variables relacionadas con las características generales de la firma. Comprenden cuatro variables: (1) tamaño, (2) edad, (3) estructura de propiedad y (4) actuación pasada.

(1) La mayoría de estudios (55\%) encuentran una relación positiva y significativa entre la innovación y el tamaño de la firma. Entre aquellos que no lo hacen, se explican estas diferencias al estar afectados por otros factores como, condiciones de la industria, estructura de mercado, etc. También parece que pequeñas compañías son fuentes de innovación más importantes al ser más eficientes en sus esfuerzos innovadores.

(2) Respecto al efecto de la edad de una firma, se postulan dos hipótesis. La primera dice que con la edad, una compañía acumulará la experiencia y conocimiento necesario para innovar, lo cual sugiere una relación positiva entre la edad de la firma y la innovación y que también que las innovaciones de viejas compañías tendrán más influencia que las de las compañías jóvenes. La segunda asunción sugiere que firmas 
más viejas desarrollan procedimientos establecidos y rutinas que crean una resistencia a la integración de avances externos mayores y que representan una barrera para la innovación. Los pocos estudios en este campo no hacen posible establecer conclusiones.

(3) Los resultados son mixtos en lo que concierne al efecto de la propiedad en innovación. Algunas investigaciones mantienen que la propiedad extranjera es positiva y está significativamente relacionada con la innovación, otros estudios encuentran que esta relación es más bien negativa o no significativa. Los argumentos para una relación negativa parecen basarse solamente una relativa falta de una gestión fuerte y de funciones operacionales (especialmente I+D) en una firma de propiedad extranjera. Sin embargo, los oponentes a esta posición argumentan que, en este caso, la transferencia de recursos científicos (ej.: tecnologías, conocimiento, resultados de $\mathrm{I}+\mathrm{D}$ ) y no científicos (finanzas, márketing, etc.) de un matriz extranjera compensará esta falta y hará posible para la compañía aumentar su capacidad innovadora.

(4) Un buen desempeño en el pasado parece proveer a las compañías con los recursos necesarios y animarles a innovar para reforzar su posición competitiva e incrementar su porcentaje del mercado y sus beneficios.

(2) Variables relacionadas con la estrategia global de las firmas y las actividades de control. Se distinguen cuatro variables: (1) Definición de la estrategia (la firma tiene una orientación estratégica definida); (2) Estrategia corporativa (estrategia de diversificación, exportación/internacionalización, crecimiento interno vs externo); (3) Estrategia de negocio (estrategia de diferenciación, estrategia de reducción de costes, mecanismos de protección).

(1) Definición de la estrategia, los autores solo encuentran un estudio empírico que responda a esta cuestión, los resultados muestran que una estrategia bien definida distingue a las firmas más innovadoras en las industrias de proveedores especializados, como la pequeña ingeniería mecánica y de instrumentación.

(2) Respecto a la estrategia de crecimiento corporativo (concentración / especialización versus diversificación). Los resultados no parecen dar soporte a la estrategia de diversificación. Todos los estudios han encontrado una relación significativa y negativa de las estrategias de diversificación con la innovación. Sin embargo se encuentra una 
relación positiva entre concentración e innovación. Distintos argumentos tratan de explicar esto, por ejemplo, en las estrategias de concentración distintas unidades pueden estar compitiendo para encontrar más rápidamente la solución a un problema. En la diversificación, los controles financieros y de otro tipo pueden desalentar la innovación.

También la empresa podría limitar sus actividades al mercado local o ser más internacional y podría buscar su crecimiento internamente o externamente (ej.: desarrollar alianzas tales como subcontratación, fusiones y adquisiciones). Con respecto a la primera elección, la investigación es casi unánime: exportación e internacionalización tienen un efecto significativo y positivo en la innovación. Para permanecer competitivo en el mercado internacional, una compañía no tiene otra elección que innovar constantemente.

Para la segunda elección, los resultados parecen estar divididos entre una asociación significativa bien positiva o negativa entre crecimiento externo e innovación. Una positiva relación se explica por el acceso a nuevas tecnologías que el crecimiento externo provee, donde se explica la relación negativa por la caída en productividad tras una adquisición, por la disrupción de las rutinas en la firma adquiridas y la complejidad de gestión de la post-adquisición.

(3) Para las estrategias de negocio, uno de las más amplias tipologías es aquella desarrollada por Porter (1990). De acuerdo a la fuente de la ventaja competitiva de la firma, Porter distingue entre dos estrategias competitivas genéricas: diferenciación y liderazgo en costes. Los resultados de la revisión sistemática muestran que la estrategia de diferenciación está positivamente correlacionada con la innovación. Tal estrategia estimula a las compañías a innovar intensamente y acelerar su ratio de innovación para estar a la cabeza de sus competidores y alcanzar una mayor ventaja competitiva. Contrariamente, una estrategia de líder en costes, parece estar negativamente asociada con la innovación. Para no incrementar sus costes, las compañías que adoptan esta estrategia a menudo limitan sus esfuerzos innovadores y tan solo imitan las innovaciones realizadas por los diferenciadores. Este resultado parece relacionado con el desproporcionado interés concedido a los productos sobre las innovaciones en procesos. Una empresa que busca minimizar costes podría ser muy dinámica desarrollando nuevos procesos eficientes, pero se ha realizado poca investigación al respeto. 
Un tema crítico relacionado con las estrategias de negocio es la protección de una ventaja competitiva. Los estudios revisados son casi unánimes sobre el efecto significativo y positivo de la protección contra la imitación en innovación. Ciertamente, la protección puede ser a través de patentes, tecnología, complejidad, secreto industrial, mantener a la gente clave en la firma, mantener un tiempo de espera sobre competidores $\mathrm{u}$ otros mecanismos que conduzcan a las firmas rivales a abandonar su carrera por la innovación tecnológica. Esto mejora la apropiación de los beneficios de la innovación de una firma lo cual a su vez alimenta la compañía con los necesarios recursos para innovar más.

(3) Variables relacionadas con la estructura, cultura y equipo de gestión. Se encuentran pocos estudios que hayan estudiado variables relacionadas con la estructura de la organización, su cultura y su equipo directivo como determinantes de la capacidad innovadora. Se distinguen aquí cinco variables: (1) Formalización (estructura formal, estructura flexible), (2) Centralización (centralización del poder de decisión, poder de los empleados), (3) Interacción (interacción entre unidades de la firma), (4) Cultura de la firma (resistencia al cambio, control total de la calidad o mejora continua, cultura de soporte a la innovación), (5) Equipo directivo: variables de liderazgo (presencia de un líder de proyecto, características del CEO, cambio del CEO); relacionadas con el mánager (cualificación y experiencia, percepción del coste/riesgo relacionado con la innovación).

(1) El efecto del formalismo estructural y decisiones centralizadas haciendo innovación es poco claro. Según algunos autores, el formalismo permite a las compañías jóvenes clarificar los roles y reducir ambigüedad. De ese modo, les permite concentrar sus esfuerzos y recursos limitados. Esto a su vez, promueve la efectividad, mejora la moral, e incrementa la innovación.

(2) En el mismo sentido, la centralización en estas compañías que se distinguen de otras por la ausencia de jerarquía burocrática, darán al emprendedor la necesaria libertad de ser asertivo y comprometer recursos. Por otra parte, en una compañía más vieja, la ampliación del espectro de actividad, y el establecimiento de un relativamente largo canal de mando debilita la capacidad innovadora de la firma, a través de un sofisticado formalismo e incrementa la centralización de decisiones. 
(3) La misma lógica podría también explicar el significativo efecto positivo en innovación de la flexibilidad de la estructura, el otorgamiento de poderes y la interacción entre las diversas unidades funcionales de una firma. Ciertamente, si las jóvenes PYMEs pueden ser innovadoras cuando formalicen sus reglas y procedimientos y centralizar su poder de decisión en las manos del emprendedor, una compañía más vieja debe estar segura que su estructura permanece flexible, y que el poder de decisión descentralizado es posible y la comunicación cruzada y la coordinación deben ser estimuladas si quiere ser innovadora.

(4) Más allá, los nuevos estudios publicados sobre determinantes de la cultura de la organización, sugieren que la innovación está significativamente y positivamente correlacionada con la implementación de una gestión de la calidad total y cultura de mejora continua dentro de la firma. Otros dos estudios encontraron que el efecto de la resistencia al cambio de la innovación y la percepción de los empleados del soporte dado a la innovación es negativo en el primer caso y positivo en el segundo.

(5) La literatura sobre los determinantes de la innovación del equipo directivo, nos permiten distinguir dos tipos de variables: (1) variables relacionadas con el liderazgo, y (2) relacionadas con los directivos. En general, la mayoría de estas variables están significativamente y positivamente correlacionadas con la innovación. La presencia de un líder del proyecto en la compañía representa un factor crucial que favorece la innovación. El líder del proyecto es una persona que de forma entusiasta apoya a los proyectos de innovación y que está personalmente comprometida con ellos.

Otros estudios han encontrado un efecto significativo y positivo de influencia de las características de los consejeros delegados (CEO) en la capacidad innovadora de la firma. Un CEO emprendedor con un liderazgo transformador y una alta necesidad de logros a menudo establece metas desafiantes, siempre busca hacer las cosas mejor y no duda a embarcarse en proyectos de innovación. La importancia atribuida por el CEO a que las metas de la compañía se traduzcan en reputación y poder, se ha encontrado que está positivamente correlacionado con innovación, ya que la innovación es una poderosa herramienta para que la compañía consiga esas metas. Las calificaciones del manager y su experiencia acumulada son de gran manera importantes determinantes para la innovación. Finalmente, la percepción del manager de las repercusiones de la innovación (incluyendo beneficios esperados, apropiación, reducción de coste, mejora 
de la posición competitiva de la firma, etc.), es un poderoso factor que les alienta a innovar.

\section{(4) Variables relacionadas con los activos funcionales y estrategias}

Hoy en día se admite que la investigación y desarrollo interno, es uno de los factores determinantes de la innovación. Más de la mitad de los estudios incluían I+D como variable explicativa y casi el $80 \%$ de ellos encontraron una relación significativa positiva entre las dos variables. El papel que la I+D interna juega como determinante de la innovación es diverso. Ayuda a las compañías a crear, explotar y trasformar nuevo conocimiento en nuevos productos y/o procesos. Les ayuda a absorber (adquirir, asimilar, transformar y explotar) nuevas tecnologías que aparecen en el mercado y atraer colaboradores. También, realizar I+D interno es particularmente importante para la innovación en el establecimiento de nuevas tecnologías, donde es muy costoso y particularmente difícil, incluso imposible, adquirir nuevas tecnologías producidas por los competidores.

El efecto positivo de la I+D en la innovación ha hecho que los investigadores hablaran de la conocida como teoría de innovación de "empuje tecnológico". En esta teoría, la investigación básica y la $\mathrm{I}+\mathrm{D}$ industrial son las fuentes de nuevos servicios y productos. Los resultados de estos esfuerzos de investigación entonces siguen un proceso lineal permitiendo a las firmas definir, diseñar, producir y vender sus innovaciones. Sin embargo, los límites de esta teoría, condujeron una visión alternativa conocida como “empuje de la demanda/mercado", que establece que la idea para soluciones también se originan en el mercado. Varios estudios empíricos han encontrando un relación

significativa y positiva entre innovación y estudios de mercado con el propósito de recoger feedback y detectar la evolución de las necesidades de los clientes. Monitorear las estrategias de márketing de los competidores como publicidad y la gestión de los pares (productos/mercados), también se ha demostrado beneficioso para la innovación. En general, una buena estrategia de márketing contribuye al éxito comercial, e incluso a la exportación de nuevos productos/procesos, alentando así a las firmas a innovar más.

Estar a la búsqueda de nuevas tecnologías y adquirir equipamiento sofisticado $\mathrm{y}$ tecnologías productivas tiene un efecto significativo y positivo en la innovación. Una 
compañía debería medir el grado en el cual utiliza su capacidad de producción si quiere permanecer innovadora. El grado de utilización de la capacidad y la innovación están correlacionadas positivamente, pero instalaciones usadas más allá del $95 \%$ de su capacidad máxima, por el contrario, reducen la innovación.

Compañías con un staff altamente formado, técnicamente cualificado y personal experimentado con diversos backgrounds es también un determinante importante de la innovación. Otras estrategias de recursos humanos como entrenamiento, motivación vía los sistemas de compensación, y la flexibilización del tiempo de trabajo han probado estar positivamente correlacionadas con innovación. Todos estas estrategias de recursos ayudan a las compañías a tener un personal cualificado y motivado, incluyendo a los empleados, ingenieros y responsables técnicos capaces de crear nuevas tecnologías y absorber las desarrolladas externamente.

Finalmente, la autonomía financiera (cantidad de capital comparado con la deuda), disponibilidad de fondos y presupuesto relacionadas con actividades de innovación parecen tener un efecto positivo en innovación. La autonomía financiera y la rentabilidad, incrementan la probabilidad de llevar a cabo inversiones, de hacer I+D interno y de generar innovaciones internas más que importarlas de fuera. Las actividades innovadoras son también actividades de riesgo. Una gran deuda, incluso si no rebaja el desarrollo de las innovaciones incrementales, desalienta seriamente el desarrollo de las innovaciones radicales. Algunos resultados sugieren que los fondos disponibles son un determinante para la innovación, pero demasiado nivel de disponibilidad puede crear un ambiente relajado alentando a los directivos a descuidar los esfuerzos en innovación, se concluye que la relación entre disponibilidad de fondos e innovación tiene forma de campana más que de línea.

En sus contribuciones seminales, Cohen y Levinthal $(1989,1990)$ subrayan el factor que las empresas no pueden beneficiarse del flujo de información externa simplemente estando expuestas a él. En cambio, éstas deben desarrollar la habilidad de reconocer el valor del conocimiento externo, y asimilar y utilizar ese conocimiento para fines comerciales. Deben desarrollar "capacidad de absorción”. Dado el significante papel jugado por el flujo de información externa en años recientes, la capacidad de absorción se ha convertido gradualmente en un factor clave de ventaja competitiva para la empresa (Henderson y Cockburn, 1996). Así, Escribano, Fosfuri y Tribó (2009), 
encuentran que una alta capacidad de absorción de una empresa puede ayudar a gestionar mejor los flujos externos de información y estimular las salidas de la innovación.

Vega-Jurado, Gutierrez-Gracia, Fernández-de-Lucio y Manjarrés-Henríquez (2008) analizan la complementariedad entre la competencia tecnológica de las empresas (derivadas de las actividades de desarrollo e investigación (I+D) internas de la empresa) y las oportunidades técnicas disponibles de la cooperación con agentes externos (para desarrollar nuevos productos). Los resultados del estudio demuestran que a mayores capacidades técnicas, mayor colaboración con agentes científicos, dando soporte a la idea que el hecho de tener un departamento propio de $\mathrm{I}+\mathrm{D}$, no solo produce conocimiento propio, sino que contribuye a la utilización de fuentes externas de conocimiento científico. Además para el caso español, se encuentra que la cooperación con agentes científicos no constituye un aspecto clave para desarrollar nuevos productos, especialmente cuando las empresas ponen mucho esfuerzo en su I+D interno.

\subsubsection{2.- Determinantes externos de la innovación. Entorno.}

Becheikh et al. (2006) agrupan los determinantes externos de la innovación en seis categorías, esto es, variables relacionadas con: (1) la industria a la cual la firma pertenece, (2) la región donde está localizada, (3) la red de relaciones con varios actores de su entorno, (4) la adquisición de conocimiento y tecnologías, (5) gobierno y políticas del sector público, y (6) la cultura circundante.

El efecto significativo de la industria y de las características regionales sobre la capacidad innovadora de las firmas está aceptado de una de forma amplia en la literatura. La gran mayoría de estudios que examinan estas dos variables encuentran una significativa relación con la innovación. Por parte de la industria, las tres principales características investigadas en la literatura han sido: (1) dinamismo tecnológico, (2) crecimiento de la demanda, y (3) estructura de la industria. Los resultados sugieren que las primeras dos variables tienen un efecto significativo en la innovación. Con respecto a dinamismo tecnológico, algunos estudios (Evangelista, Perani, Rapiti y Archibugi, 1997; Kalantariridis y Pheby, 1999; Kam, Kiese, Singh y Wong, 2003) encontraron que las industrias high-tech (ej.: telecomunicaciones, aeroespacial, farmacéutica) son más 
innovadores que las tradicionales (ej.: textil, madera, comida). Otros estudios (Souitaris, 2002) usaron la taxonomía sugerida por Pavitt (1984) para mostrar que la habilidad de una firma para innovar y los determinantes de su comportamiento innovador varían de acuerdo a si la compañía pertenece a uno u otra de las cuatro categorías sugeridas por Pavitt. Esto es, dominado por los proveedores, intensivas en escala, proveedores especializados o firmas basadas en la ciencia. El positivo y significativo efecto del crecimiento de la demanda en la innovación ha sido probado por varios estudios (Baptista y Swann, 1998; Michie y Sheehan, 2003; Zahra, 1993) confirmando una vez más la hipótesis de la teoría de innovación del "tirón de la demanda".

Para el efecto de la estructura de la industria en innovación, no hay un único resultado. Resultados significativos sugieren que la concentración de la industria tiene un efecto negativo en la innovación (Blundell, Griffith y Van Reenen, 1999; Koeller, 1995, 1996; Zahra, 1993). Sin embargo, dos estudios (Nielsen, 2001; Smolny, 2003) encontraron una relación positiva entre las dos variables, y otras investigaciones concluyeron que hay una forma de campana (Debackere, Clarysse y Rappa, 1996) o una insignificante relación (Baptista y Swann, 1998; Beneito, 2003; Love y Ashcroft, 1999). Se debería resaltar que este debate ha empezado por Schumpeter, cuyas dos proposiciones fueron bautizadas como Schumpeter Mark I y Schumpeter Mark II. Las industrias de la Mark I (también llamadas de destrucción creativa) están caracterizadas por bajas barreras de entrada tecnológica y un alto nivel de competición. En estas industrias, nuevas empresas emprendedoras son las mayores innovadores (Schumpeter, 1934). En las industrias Mark II (también llamadas de acumulación creativa), las economías de escala aumentan las barreras de entrada, favoreciendo a las firmas grandes establecidas que usan su poder monopolístico y fuentes de conocimiento acumulado, recursos y competencias para ponerse al frente del proceso de innovación (Schumpeter, 1942).

A la luz de los resultados anteriores, se puede afirmar que la investigación empírica en el sector de producción da soporte el efecto positivo sobre la innovación del patrón de destrucción creativa. Sin embargo, en el caso del patrón de acumulación creativa, parece que una industria concentrada en las manos de un limitado número de compañías conduce gradualmente a un mercado estable donde las porciones del mercado son armoniosamente negociadas y atribuidas. Por lo que es contraproducente y menos deseable introducir nuevos productos en el mercado ya que molestaran el equilibrio alcanzado (Zahra, 1993). Esta situación se mantendrá hasta la introducción de una 
innovación radical por una firma nueva. Esto moverá la industria a un patrón de destrucción creativa favorable al desarrollo innovador (Breschi, Malerba y Orsenigro, 2000)

La región donde una firma está establecida también tiene un significativo efecto en su capacidad innovadora (Brouwer, Budil-Nadvornikova y Kleinknecht, 1999; Evangelista et al., 1997; Kaufmann y Tödling, 2001). Este efecto responde a varios factores, en particular infraestructura y fuerza de trabajo especializada (Baptista y Swann, 1998; Blind y Grupp, 1999; Koberg, Uhlenbruck y Sarson, 1996; Sternberg y Arndt, 2001). Igualmente, la proximidad a socios potenciales como proveedores, clientes, universidades, instituciones de $\mathrm{I}+\mathrm{D}$ y financieras, influye de forma significativa $\mathrm{y}$ positiva en la innovación (MacPherson, 1998; Romijn y Albaladejo, 2002; Uzun, 2001). La proximidad facilita la transferencia de conocimiento tácito (Cooke, Gómez y Etxebarría, 1997, Storper y Harrison, 1991), reduce los costes de comunicación, da soporte las interacciones interpersonales, (Dicken, Forsgren y Malmberg, 1994) y desarrolla confianza y capital social entre socios, lo que reduce el riesgo e incertidumbre relacionada con la innovación (Landry, Amara y Lamari, 2002; Lundvall, 1992; Romijn y Albadalejo, 2002).

Finalmente, es importante enfatizar el excepcional desempeño del trabajo en red como determinante de la innovación. Ninguno de los estudios encontró que el trabajo en red tuviera un efecto significativo y negativo en la innovación. Todos los estudios revelaron que la correlación entre innovación y la interacción con clientes, proveedores, universidades, centros de investigación y otros actores del entorno de la firma es positivo (Beugelsdijk y Cornet, 2002; Coombs y Tomlinson, 1998; Kaufmann y Tödling, 2001; Landry et al. 2002; Ritter y Gemünden, 2003; Souitaris, 2002) o insignificante (Debackere, Clarisse y Rappa, 1996; Freel, 2000, 2003; Love y Roper, 2001; Papadakis y Bourantas, 1998). Estas interacciones ayudan a la firma a rellenar huecos en su información, conocimiento científico, recursos y competencias (Romijn y Albaladejo, 2002). Estos resultados corroboran la idea ampliamente aceptada de que los procesos de innovación no son necesariamente lineales sino que son a menudo evolutivos, no-lineales e interactivos entre los departamentos de una organización y la organización y su entorno (Dosi, Freeman, Nelson, Silverberg y Soete, 1988; Kaufmann y Tödling, 2001; Kline y Rosemberd, 1986; Malecki, 1997). 
Se debería señalar que este efecto probado de la industria y de las características regionales de la industria, del trabajo en red y la proximidad en la innovación ha jugado un papel inductor del desarrollo en muchos países de clústeres geográficos, los "milieux innovateurs" y sistemas nacionales y regionales de innovación para la promoción de la innovación (Asheim y Isaksen, 1997; Kaufmann y Tödling, 2001; Romijn y Albaladejo, 2002).

\subsubsection{3.- Otras variables explicativas.}

Como se ha sugerido en la literatura, la adquisición de conocimiento y tecnologías, el gobierno y las políticas del sector público y la cultura del país donde la firma está establecida son todas determinantes potenciales de la innovación. El conocimiento y la adquisición de tecnología pueden tomar diversas formas, como la compra de equipo, licencias y acuerdos de patrocinio, asistencia a conferencias y ferias especializadas, o simplemente los intercambios informales con varios actores del entorno de una firma. De acuerdo a esta variable, los resultados están divididos entre un efecto significativo y positivo (Ahuja y Katila, 2001; Koschatzky, Bross y Stavnovnik, 2001; Love y Roper, 1999; Souitaris, 2001; Uzun, 2001) y un efecto no significativo sobre la innovación (Kaufmann y Tödling, 2001; Lee, 1995; Liu y White, 1997; Love y Roper, 2001). Esta falta de consenso podría ser explicada por el hecho de que la efectividad con que la adquisición de tecnología y conocimiento actúa como determinante de la innovación tiene un gran peso en la práctica por la capacidad de absorción de la firma (Landry et al., 2002; Lee, 1995; Liu y White, 1997). Las organizaciones que son capaces de asimilar, adaptar y transformar el conocimiento y la tecnología adquiridos, tienen más oportunidades de usarlos para innovar que aquellas que son incapaces de hacerlo.

Las políticas del gobierno, como por ejemplo, el fomento de ciertos sectores, la sustitución de importaciones y la promoción del cambio en el entorno de gestión tienen también un efecto positivo importante en la innovación (Coombs y Tomlinson, 1998; Lanjouw y Mody, 1996; Oyelaran-Oyeyinka, Laditan y Esubiyi, 1996). Igualmente, el soporte financiero concedido por el gobierno, organismos profesionales y las instituciones financieras orientadas a la industria fomentan que las firmas innoven más (Beugelsdijk y Cornet, 2002, Caird, 1994; Keizer, Dijkstra y Halman, 2002; Romijn y 
Albaladejo, 2002, Souitaris, 2001). Este soporte financiero puede tomar la forma de subsidios, becas, premios o préstamos.

Finalmente, con respecto a la cultura que rodea a la firma, la investigación empírica es extremadamente inusual. Esos estudios que han examinado este determinante hacían operativa esta variable usando las dimensiones de Hofstede (Hofstede, 1980; Franke, Hofstede y Bond, 1991). Es decir: (1) jerarquía distante, (2) control de la incertidumbre, (3) individualismo versus colectivismo, (4) masculinidad versus feminidad, y (5) orientación del tiempo. Los resultados son bastante variados y a menudo no significativos. Los pocos resultados sugieren que la innovación tiene más oportunidad de desarrollarse dentro de una cultura individualista marcada por la aceptación de la incertidumbre y una orientación a largo plazo (Shane, 1993; Wu, Chiang y Jiang, 2002). Con respecto a la distancia de la jerarquía, dos estudios (Rhyne, Teagarden y Van den Panhuyzen, 2002; Shane, 1993) conducen a conclusiones opuestas. Excepto por estos resultados todos las otras pruebas demostraron ser no-significativas.

\section{6.- Entendiendo la relación entre el desarrollo del proceso tecnológico y su inserción en la organización}

En grandes líneas, la idea importante que queremos señalar en esta sección consiste en acentuar el estrecho vínculo y relación que existe entre la introducción de nuevas tecnologías o actividades vinculadas al proceso y su acople en el sistema organizativo de la empresa. En este sentido, dicha relación ha sido resaltada en diversas corrientes de la literatura. En todas ellas, sin embargo, se reconoce el hecho de que los efectos sinérgicos o complementarios de crear un sistema de activos (tecnología y organización) interrelacionados conlleva la generación de activos estratégicos complejos que posibilitan: (1) una dificultad de imitación por parte de la competencia, lo que conlleva unas ventajas competitivas sostenibles en el tiempo o más difíciles de erosionar y, (2) un mayor rendimiento económico debido al sistema en sí, esto es, la suma total lograda a través de la integración técnico-organizativa es mayor que la suma de las partes por separado.

Con respecto a la literatura de estrategia de gestión, esta idea de adopción síncrona está reflejada en el uso de complementariedades, y se reconoce como una influencia clave en 
la innovación de la firma (Stieglitz y Heine, 2007). Así, Teece (1986) define activos complementarios como aquellos que elevan el valor de las innovaciones tecnológicas de la compañía. Dierickx and Cool (1989), usando la teoría de la visión basada en recursos (RBV, Resource Based View) se refiere a los activos complementarios destacando la sostenible ventaja competitiva que ofrecen al interconectar activos para prevenir la imitación. De forma similar, Milgrom y Roberts (1995:81) defienden la idea de complementariedades como los retornos marginales de una variable que incrementan los niveles de las otras variables. Ichniowski et al. (1997) también afirman que complementariedad entre prácticas implica que la magnitud del efecto en el desempeño en todo el sistema es mayor que la suma de los efectos marginales de adoptar cada práctica por separado. Como Milgrom y Roberts (1990) señalan, las actividades que son mutuamente complementarias necesitan ser adoptadas conjuntamente. Si no, entonces la falta de coordinación o integración puede reducir los retornos. Por ejemplo, si una nueva máquina más flexible se instala, los gestores de márketing, sn coordinación, pueden subestimar el impacto en la descripción de trabajos (Milrom y Roberts, 1995). Evidencia empírica sobre este punto viene dada por Ettlie y Reza (1992) que afirman que la adopción con éxito de innovaciones de proceso, mayormente al adquirir nuevas tecnologías para operaciones, son complementadas por mecanismos de integración y coordinación para capturar totalmente el valor de las innovaciones de proceso y proteger de las imitaciones, sosteniendo la ventaja competitiva a partir de una reestructuración. Milgrom y Roberts (1995) y Ichniowski et al. (1997) igualmente se centran en la noción de complementariedad como los cambios sistémicos entre las prácticas de organización, ampliando de esta manera la teoría de la contingencia (Donaldson, 1996), en el sentido de que la complementariedad requiere ajuste entre las principales variables de la organización.

Además y complementariamente a las anteriores teorías, el sistema socio-técnico (Trist y Bamforth, 1951) describe un método de ver las organizaciones enfatizando la interrelación del funcionamiento de los subsistemas social y técnico. Dicho de otra manera, la visión socio-técnica sostiene que las organizaciones están hechas de gente y tecnología (Trist, 1978; Pasmore et al., 1982). El sistema social, por una parte se refiere a la gente que trabaja en la organización y las relaciones entre ellos, aunque esta perspectiva es mayor y considera actitudes, expectaciones y otros patrones de comportamiento que están más allá de los límites de alcance de este trabajo. El sistema 
técnico por otra parte consiste de técnicas, procedimientos o conocimiento usado por el sistema social para conseguir metas organizativas (Trist y Bamforth, 1951). Los sistemas socio-técnicos establecen que la relación entre los subsistemas de la organización representa una relación correlativa que representa un "acoplamiento de diferencias" donde el cambio de cada subsistema requiere cambios en los otros subsistemas (Trist y Murray, 1993). Con todo, esta idea de la complementariedad constituye la idea básica para describir la estrategia de innovación de proceso y la necesaria integración de otras innovaciones gerenciales y organizativas.

En particular, las actividades de innovación de proceso involucran cambios organizativos y tecnológicos (Gopalakrishnan and Damanpour, 1997; Reichstein and Salter, 2006) difuminados y difíciles de separar (Edquist et al., 2001; Ettlie and Reza, 1992; Womack et al., 1990). Edquist et al., (2001) incluye dentro de las actividades de innovación de proceso dos actividades distintas pero relacionadas: la innovación tecnológica de proceso y la innovación organizativa de proceso. Las innovaciones tecnológicas de proceso son nuevos bienes que son usados en el proceso de producción e incluyen bienes de inversión y bienes intermedios tales como máquinas de procesamiento, robots industriales y equipamiento TIC. Complementariamente, las innovaciones organizativas de proceso son nuevas formas de organizer las actividades de negocios tales como la producción y no tienen elementos tecnológicos sino la coordinación de recursos humanos y prácticas de trabajo, tales como producción justo a tiempo, gestión total de la calidad o producción ajustada. En conjunto, la literatura sobre la gestión ha evidenciado que la aplicación de la tecnología de proceso en industrias depende de cambios en la estructura y las prácticas administrativas (Ettlie, 1988; Nabseth and Ray, 1974; Thompson, 1967). La coincidencia sistemática de la innovación organizativa y proceso también es recalcada sistemáticamente en la literatura de gestión de operaciones (ej.: White and Ruch, 1990; Duguay et al., 1997), aunque la mayoría de esta literatura está basada en casos de estudios o industrias específicas (ej.: Womack et al., 1990; Ettlie, 1988). En esta línea, Luria (1987) demostró que los cambios en la estructura organizativa o la tecnología de procesos solamente no dio lugar a ninguna reducción de costes significativa en las plantas de componentes de automoción, mientras que las ganancias positivas en el desempeño a partir de la co-adopción están reconocidas en la literatura (ej.: Battisti \& Stoneman, 2010; Damanpour et al., 2009). 
En general, se reconoce que la innovación de proceso en pequeña firmas está mucho más relacionada con el "cambio tecnológico incorporado" en la formación del capital físico más que en inversiones intangibles en I+D (Conte and Vivarelli, 2005; Santarelli and Sterlacchini, 1990; Vaona and Pianta, 2008). Específicamente, la innovación tecnológica de proceso está relacionada con la incorporación de nuevo capital de equipo (Salter, 1960) máquinas de procesamiento, robos industriales o equipamiento TIC (Edquist, 2001: OECD, 2005; Heidenreich, 2009) o solo capital de tecnología incorporada (Rouvinen, 2002) frecuentemente obtenida de la compra de maquinaria avanzada o la combinación de hardware y software (Huang et al., 2010; OECD, 2005). Esta idea responde al hecho de que las nuevas tecnologías y por lo general en forma de tecnología incorporada constituyen uno de los principales impulsos para una empresa al renovar sus procesos. Entonces, la adquisición de tecnología a través del conocimiento incorporado requiere la integración dentro de los límites organizativos de la empresa. En esta línea, Flowers (2007) afronta este proceso estudiando la adquisición, implementación y explotación de nuevas tecnologías desde la vista de la demanda o la perspectiva del comprador, más que la tan investigada visión centrada en el proveedor. Esto es, cuando se vende/compra equipamiento o infraestructura (un software como un ERP Enterprise Resource Planning, MRP, Manufacturing Resource Planning, u otros sistemas TIC para propósitos en la producción u organización) la mayoría del trabajo en el cambio tecnológico se centra en la dinámica del lado del proveedor (Adner and Levinthal, 2001; Dosi, 1992; Flowers, 2007) más que en el lado de la demanda (comprador), esto es, el adquiriente de nueva tecnología. En esta línea, el comprador/usuario, que compra bienes de capital tecnológicos y servicios para su propia infraestructura operativa, requiere adecuar la nueva tecnología a la organización. Esta implementación de nuevo equipamiento o conocimiento incorporado es un proceso de aprendizaje organizativo (Voss, 1998) que constituyes un componente clave del proceso de innovación (Leonard-Barton and Deschamps, 1988) y especialmente del proceso de adopción de la innovación (Ettlie and Reza, 1992). En esta línea, Fleck (1994) ha descrito la implementación como un proceso de "aprender intentándolo" o "aprender peleándose para hacer que funcione", es decir, que las mejoras y modificaciones hechas en los componentes constituyentes antes de la configuración pueden trabajar como una entidad integrada. El punto es entender que la adquisición de nueva tecnología requiere una mutua adaptación de tecnología organización (Ettlie, 1988; Ettlie and Reza, 1992; Fleck, 1994; Leonard-Barton and Deschamps, 1988; Voss, 1988), esto es, que la 
adaptación de la transferencia de tecnología a través del la implementación del proceso requiere que los manager reconozcan y asuman su responsabilidad para los cambios organizativos y técnicos (Leonard-Barton y Deschamps, 1988), de forma similar nos hemos referido arriba a la integración, complementariedades o adopción síncrona. Por ejemplo, Ettlie (1988) encontró que las organizaciones con mejor desempeño sincronizan la adaptación de las políticas administrativas con la introducción de tecnología. Fleck (1994) también reconoció la necesaria adaptación de los procedimientos de gestión a la nueva tecnología implementada y Voss (1988) explícitamente se dirigió a los efectos complementarios de integrar nueva tecnología con la perspectiva organizativa para adoptar con éxito nueva tecnología para la innovación de proceso. Considerándolo todo, la tecnología es una ocasión para estructurar y los resultados actuales dependen de cómo los nuevos procesos comprados a partir de nueva tecnología son acoplados a la organización (Barley, 1986; Cohen and Zysman, 1987; Damanpour, 1991; Ettlie and Reza, 1992). Por tanto, capturar valor de las nuevas tecnologías necesita hacer la adopción de innovación de proceso una ocasión única para reestructurar y crear acuerdos de acoplamiento (Cohen and Zysman, 1987; Ettlie and Reza, 1992). Por lo tanto, esperamos que los resultados de la adopción de nueva tecnología a partir de la adopción de nuevas innovaciones en proceso serán ampliados cuando le sigan cambios organizativos, es decir sea complementada y acoplada la introducción de la nueva tecnología. 


\section{3.- INNOVACIÓN EN SERVICIOS.}

\section{1.- Características de los servicios.}

Jaw, Lo y Lin (2010) y Dolfsma (2004), a partir de una revisión de la literatura establecen que las características inherentes de los servicios son:

- Intangible: no se pueden poseer físicamente.

- Heterogeneidad: la estandarización total de un servicio es imposible, ya que depende de una interacción humana para su prestación, o bien variará el proveedor del servicio o el consumidor o las condiciones de su prestación.

- Inseparabilidad. Simultaneidad entre producción y consumo: la mayoría de servicios no pueden presarse a menos que el cliente esté presente o directamente involucrado en el proceso de producción. En muchos casos es fundamental la participación del cliente para su prestación (producción), hablamos en este caso de una coproducción del servicio.

- Perecedero: no se puede almacenar

\section{2.- Literatura en innovación de servicios.}

Gallouj (1994, 1998) propone una clasificación ampliamente adoptada (Gallouj y Weinstein, 1997; Miles, 2002, 2005; Tether 2005; Howells 2006; Gallouj y Saviona; 2009) para reclasificar la literatura sobre innovación en servicios, que puede ser clasificada en tres grandes aproximaciones:

1.- Aproximación tecnológica o de asimilación. Según esta teoría, la innovación en servicios equivale a la adopción y uso de la tecnología (por ejemplo, nuevas tecnologías de comunicación e información, TIC). Las contribuciones en esta línea intentan asimilar la innovación en servicios dentro del marco usado para la clasificación de innovación en productos o de producción.

2.- Un enfoque orientado a servicios o de diferenciación que busca identificar cualquier posible particularidad en la naturaleza y organización de la innovación en 
servicios. El conjunto de autores de este enfoque intentan desarrollar un marco específico para la innovación en servicios, a la vez que subrayan los aspectos específicos de los servicios respecto de la innovación en productos o procesos de producción.

3.- Un enfoque integrado o de síntesis, que intenta desarrollar un marco conceptual común para innovación en servicios y productos. Este último enfoque parece estar en una fase creciente de interés dado que ayuda a resolver problemas encontrados en los otros dos, como se verá más adelante.

\subsection{1.- Enfoque tecnológico o de asimilación.}

Este enfoque intenta clasificar la innovación en servicios dentro de las taxonomías existentes para la innovación de productos. Para estos autores la innovación va siempre ligada al cambio tecnológico. Su principal argumento es que los servicios se están volviendo cada vez más tecnológicos, debido sobre todo a la difusión de las TIC, y considera las innovaciones no tecnológicas como marginales. Lo que no tienen en cuenta es que a menudo la adopción de las TIC está complementada por actividades de ingeniería de la organización.

Basándose en observaciones de más de 2000 innovaciones significativas a través de diversas firmas y sectores, Pavitt (1984) hace una clasificación de los innovadores identificando cinco categorías: dominada por el proveedor, intensiva en producción, (dentro de la cual se distingue: intensiva en escala y proveedores especializados), basada en la ciencia e intensiva en información, una categoría añadida después (Pavitt, Robson y Townsend, 1989). Esta aproximación está centrada en buscar "cosas innovadoras" (medicamentos, software), como la mayoría servicios no tienden a producir productos directamente, la mayoría de innovaciones eran atribuidas al proveedor. Así Pavitt termina clasificando a los servicios como mayoritariamente dominados por el proveedor.

El intento más remarcable de asimilar servicios dentro de la investigación en innovación usando las herramientas conceptuales derivadas de los estudios de producción fue el de Miozzo y Soete (2001) que intentaba adaptar la taxonomía de Pavitt para abarcar a los servicios. Así, Miozzo y Soete identificaron diversas clases de actividades tecnológicas: 
sectores dominados por el proveedor (bienes públicos o colectivos y servicios personales), sectores de producción intensiva (entre los cuales hay dos subtipos: intensivos en escala y sectores en red), y sectores especializados en tecnología y basados en ciencia (software y servicios de consultoría de negocios entre otros). A continuación, se muestran las dos clasificaciones:

Figura 3. Comparación entre la clasificación de Pavitt (1984) y la de Miozzo y Soete (2001).

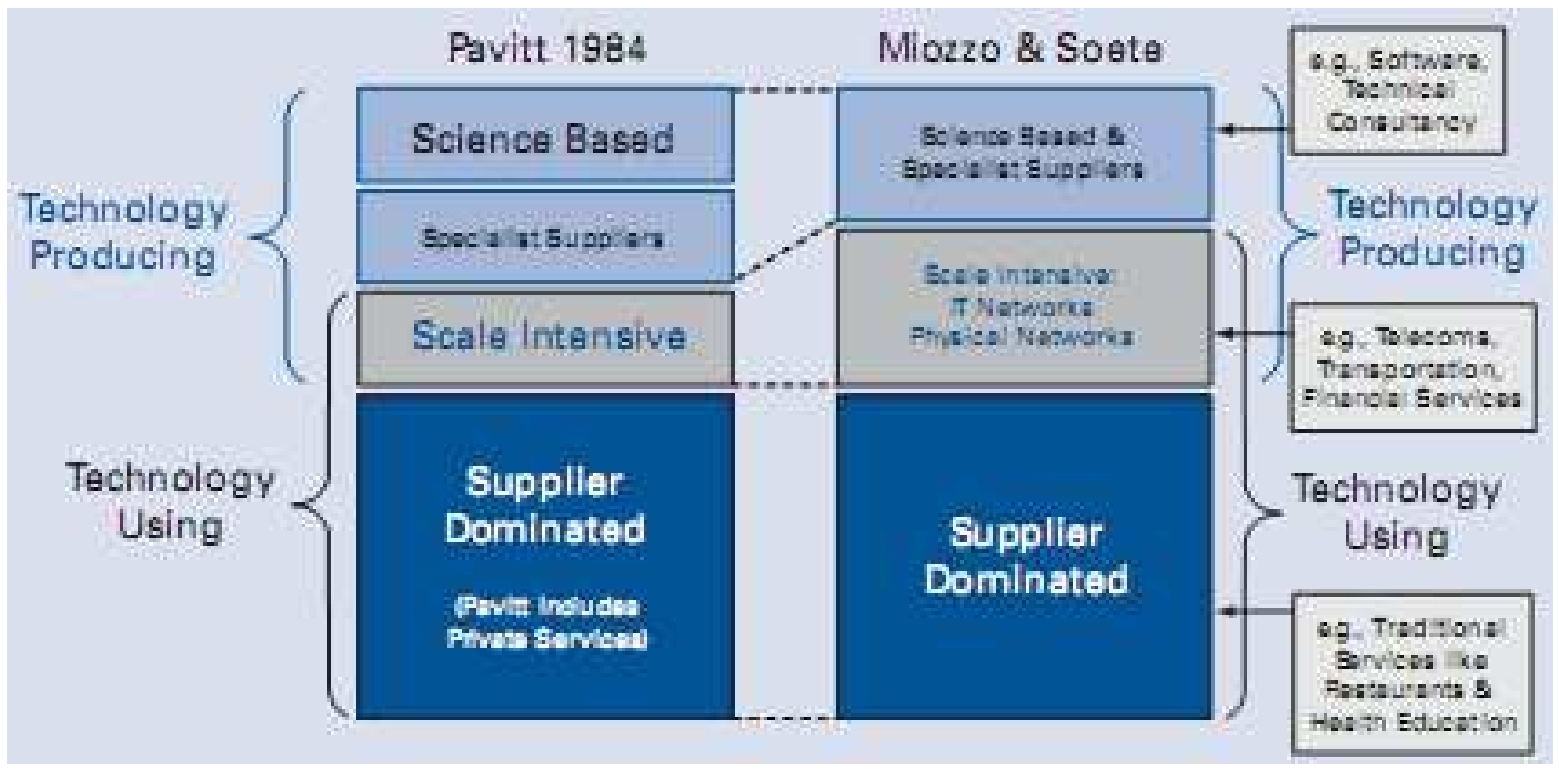

Fuente: Tether y Howells, 2007.

Evangelista (2000) explotó los datos de la encuesta de innovación italiana y clasificó las firmas de servicios en cuatro grupos:

- Usuarios de tecnología

- Servicios interactivos

- Servicios basados en ciencia y tecnología

- Servicios de consultoría tecnológica.

Evangelista encontró que la aproximación de Pavitt podría ser válida. A pesar de ser menos del 5\% de los empleos en servicios, los servicios intensos en tecnología "servicios basados en ciencia y tecnología" representaban el $30 \%$ del gasto del total de las firmas en innovación. Las empresas del tipo "usuarios de tecnología" tenían una pequeña porción de gastos de innovación, a pesar de que constituían un $80 \%$ del total de compañías, y más de la mitad del empleo en el sector servicios incluido en el análisis. Concluye en su artículo que la innovación en servicios tiene más similitudes que diferencias con la innovación de producción. 
Surgen diversas críticas (Sundbo, 1998; Gallouj, 2002) que siguiendo la aproximación de distinción, argumentan que estos hallazgos se basan en una aproximación que usa las herramientas conceptuales y empíricas derivadas de los estudios de producción. Se le presta poca atención a la interacción (por ejemplo a través de la innovación prestada, importante a veces en servicios), a las habilidades (Tether, Mina, Consoli y Gagliardi, 2005) y el foco está todavía en la producción más que en el uso de tecnologías.

\subsection{2- Enfoque orientado a servicios o de diferenciación.}

Una segunda línea de investigación ha argumentado que la innovación en servicios sigue diferentes patrones de la innovación en producción. En primer lugar Abernathy y Utterback (1978), desarrollaron un modelo genérico de la naturaleza de la innovación relacionado con las características de la firma, según este modelo, en las primeras etapas del ciclo de vida de un producto, las empresas tienden a mejorar la calidad de los productos, a medida que los mercados se saturan y se da un diseño óptimo, las firmas tienden a adoptar este diseño y realizan estrategias de minimización de costes a través de procesos de estandarización de la producción.

Un intento posterior fue el realizado por Barras (1986, 1990), a través de la investigación de los servicios financieros, contrariamente a los autores anteriores, Barras observa que en los servicios bancarios se pone el foco de atención en primer lugar en la mejora de la eficiencia de los procesos (principalmente a través de la adopción de TIC) y que el desarrollo de los productos y su adaptación al consumidor vienen después. A este proceso lo llamó "ciclo inverso del producto".

El modelo de Barras ha estado sujeto a varias críticas (Uchupalanan, 2000; Gallouj, 2002; Miles, 2005; Gallouj y Saviona, 2009). La mayoría de ellas señalan que iguala la innovación a innovación tecnológica. También que más que un modelo de innovación en servicios se asemeja a un modelo de difusión y adopción de la innovación. De cualquier forma y aunque algunos autores califican a Barras como perteneciente al enfoque tecnológico (Gallouj y Saviona, 2009), sí está reconocido como el precursor de los modelos diferenciadores que aparecieron en la década de los 90 (que ya no privilegiaban la innovación tecnológica). 
Sundbo (1997) estudió una amplia variedad de servicios, rechazando la centralidad de la innovación tecnológica. Para él, la estrategia seguida por una empresa es lo más importante para la innovación. Mientras muchas innovaciones estratégicas son facilitadas por la tecnología, su desarrollo no necesariamente ha dependido de tecnologías punta o de mantener una ventaja competitiva sobre los competidores, y por lo tanto concluyó que el papel desempeñado por las tecnologías hard es menos importante que en el sector manufacturero.

Los enfoques de diferenciación propiamente dichos consisten en una investigación en la cual se enfatizaban las diferencias de las actividades de innovación de servicios, aunque también señalan su utilidad para la innovación de productos. Así tenemos a Gadrey, Gallouj y Weinstein (1994); Den Hertog (2000); Djellal y Gallouj (2001). De este modo Djellal y Gallouj buscan contribuir a un concepto autónomo de innovación en servicios. Den Hertog toma una perspectiva conceptual de innovación de servicios, presentando una taxonomía de los patrones de innovación y un marco para entender mejor que partes de los servicios están más sometidas a procesos de innovación.

Se enfatizaron las peculiaridades de los servicios y como los servicios se diferencian de los productos. Los servicios son intangibles, producidos y consumidos al mismo tiempo, a menudo con la involucración directa del consumidor. Algunos servicios, como el control del tráfico aéreo son co-producidos por el proveedor y usuario trabajando juntos (Tether y Metcalfe, 2003). Esto quiere decir que es mucho más difícil definir un servicio y observar un momento en el cual el servicio es cambiado significativamente (las innovaciones en servicios son más difíciles de identificar que las innovaciones en bienes). Tampoco los procesos de servicios son todos internos a la empresa en la cual se desarrolla la innovación, lo cual crea dificultades con la dicotomía generalmente aceptada de innovación de producto y de proceso. Existe también una cierta confusión sobre como diferenciar innovaciones de proceso y de organización en servicios.

Los investigadores desarrollan herramientas empíricas y conceptuales que son más sensibles a las peculiaridades de los servicios (intangibilidad, gran dependencia de la gente, y grandes niveles de interacción) (Tether, 2005).

Sundbo y Gallouj (2000) identifican varios modos de patrones en la innovación en servicios: 
- Patrón clásico, donde la innovación está basada en el modelo lineal de avance tecnológico y se desarrolla principalmente través de departamentos dedicados a $\mathrm{I}+\mathrm{D}$.

- Patrón de los servicios profesionales, este modo está basado en servicios profesionales que no venden productos y sus soluciones a menudo son ad-hoc.

- Patrón neo-industrial, este es un híbrido entre el patrón clásico de I+D y el patrón de servicios profesionales, en el cual la empresa tiene un departamento de $\mathrm{I}+\mathrm{D}$, pero la innovación está más distribuida e involucra a más profesionales que los del propio departamento de I+D (ej.: servicios de salud y grandes consultoras de ingeniería).

- Patrón de estrategia organizada de innovación, en este modo no suele existir un departamento de $\mathrm{I}+\mathrm{D}$, y en su lugar la innovación es más distribuida con proyectos particulares y equipos multidisciplinares.

- Patrón emprendedor, se basa en firmas tipo start-up que ofrecen innovaciones radicales o modelos de negocios nuevos.

- Patrón artesanal, se encuentra este modo en servicios como la limpieza y el cátering, donde la innovación suele darse a pequeña escala y que a menuda no se repite. A menudo las innovaciones vienen de fuera a través de regulaciones o nuevas tecnologías.

- Modelo en red, está basado en una red de firmas actuando juntas, más que en una única compañía actuando sola.

\subsection{3.- Enfoque integrado o de síntesis.}

Los límites entre bienes y servicios se han vuelto cada vez más difusos, y además ninguna de las teorías generadas había satisfecho plenamente a los investigadores. Así, las componentes inmateriales de un producto son cada vez más importante y también es cada vez más fácil estandarizar algunas actividades de servicios.

Las primeras contribuciones integradoras en su naturaleza son de Belleflamme, Houard y Michaux (1986) y Barcet, Bonamy y Mayère (1987). Estos trabajos comparten una aproximación funcional a la actividad económica, de acuerdo a la cual, una necesidad o función puede ser satisfecha a través del consumo de un bien o servicio. Desde esta 
perspectiva, la distinción entre bien y servicio se vuelve redundante. Estos autores consideran el acto de consumo como el acto de satisfacer una necesidad.

La definición de un producto (bien o servicio) basado en sus características o competencias, materiales o inmateriales propuesta por Saviotti y Metcalfe (1984), y basada a su vez en Lancaster (1966) es sin duda el trabajo más influyente de este enfoque.

Las firmas compiten ofreciendo combinaciones particulares de características de servicios que creen que serán más atractivas para los consumidores que las de sus rivales. Esas combinaciones de características de servicio están relacionadas con un conjunto de características técnicas. El conjunto de características técnicas está directamente relacionado con las tecnologías en las que están basados los productos. La innovación es el medio por el cual las empresas mejoran el conjunto de características técnicas y por tanto, las características de los servicios en los que los consumidores están interesados. Las características de proceso están determinadas por los bienes de equipo y las tecnologías de proceso que les dan soporte, extendidas para incluir activos tangibles (como maquinaria y equipo), intangibles (como marca, copyright y patentes), recursos humanos (como educación, entrenamiento, experiencia y habilidades del staff individual) y recursos organizativos (tales como cultura corporativa, estructura organizativa, reglas y los procesos de la firma) que varían desde el diseño a producción o márketing.

Figura 4. Relación entre características técnicas y de servicio en el modelo Saviotti-Metcalfe.

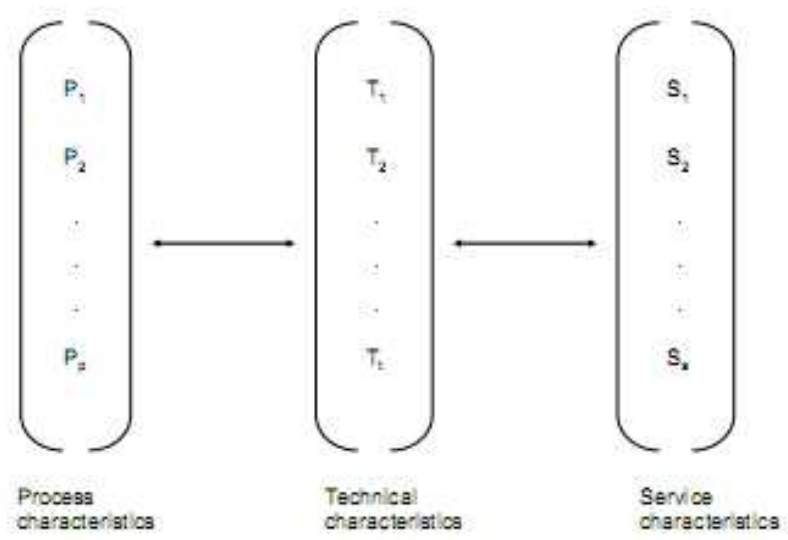

Figura 4. Fuente: Windrum y García-Goñi (2008).

En la figura siguiente se tiene una representación de una adaptación de este modelo por Gallouj y Weinstein (1997), donde el vector Y representa las características de servicio (el valor dado al usuario final). El vector T representa las características técnicas del 
producto, bien sean estas materiales o inmateriales. Los vectores $\mathrm{C}$ y C'representan las competencias de los proveedores y de los clientes-usuarios respectivamente. Por ejemplo, un servicio puro vendría representado por los vectores $C-Y$, la relación T-Y representaría un bien material puro, y finalmente la relación entre C-T-Y identifica una relación de autoservicio.

También señalan que en servicios a menudo es difícil separar las características de proceso de las características de producto. Por tanto, algunas características de proceso de Saviotti-Metcalfe se convierten en características tangibles e intangibles del producto en el modelo de Gallouj y Winstein (1997), mientras que las características del proceso estaban a parte del producto en el modelo de Saviotti-Metcalfe.

Figura 5. Representación del producto basado en características.

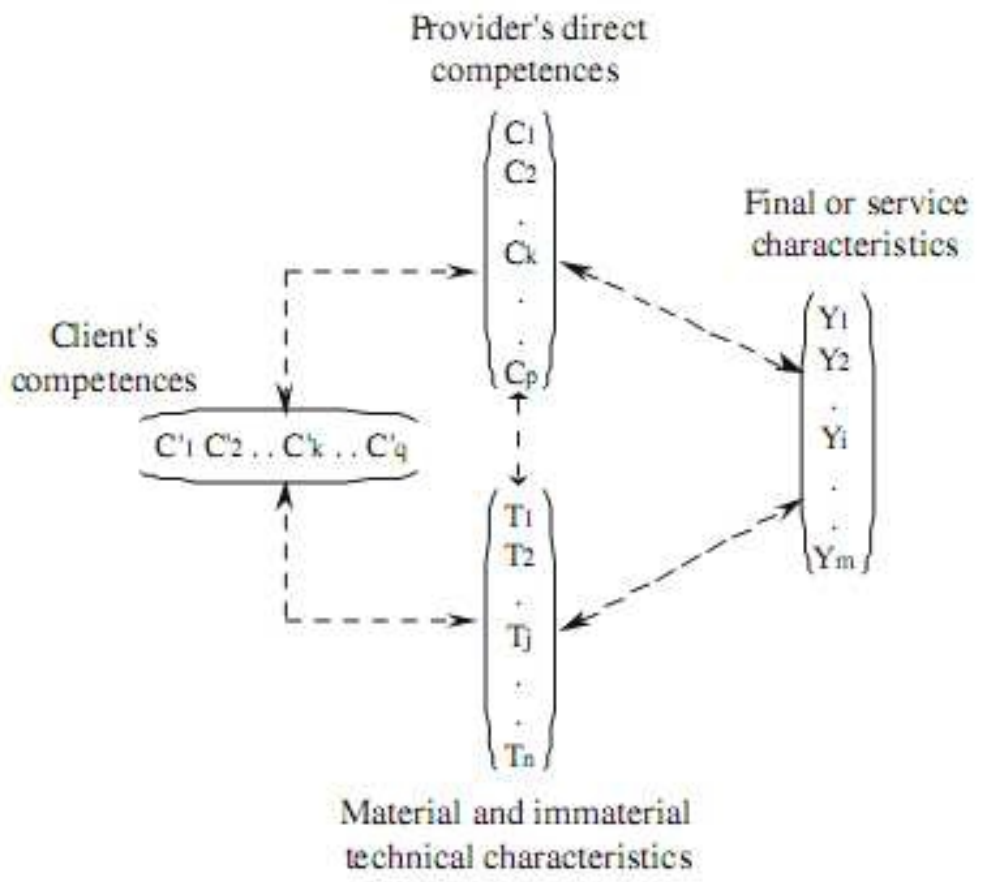

Fuente: Gallouj y Weinstein, 1997.

La innovación puede ser definida de acuerdo a los cambios que afectan a uno o más elementos de uno o más vectores de características (técnicas y de servicio) o de competencias. Estos cambios están destinados a ser definidos por uno o más mecanismos básicos: evolución o variación, salida o entrada de uno o más elementos, y asociación, disociación o formación de uno o más elementos. Estos pueden ser planeados o intencionales, como los resultados de las actividades de investigación y 
desarrollo, o no intencionales. Esto es, emergentes de un proceso de descubrimiento por inercia por los agentes involucrados.

La innovación, por tanto es definida no como un resultado, sino como un proceso. Más que identificar tipos de innovación, este marco permite identificar y dar cabida a diferentes modelos de innovación como resultado del dinamismo de sus características. Algunos son, según la taxonomía de Gallouj y Savona (2009):

- Innovación radical, está definida por la creación de un nuevo conjunto de vectores, de características técnicas y de servicio.

- Mejora de la innovación, ocurre cuando el conjunto de vectores de características permanece inalterado, pero el valor cualitativo de sus componentes individuales incrementa.

- Innovación incremental: ocurre cuando una nueva característica es añadida, eliminada o sustituida, dejando el conjunto total de vectores incambiado.

- Innovación Ad hoc, implica un significativo cambio en el vector de competencias y también principalmente en los elementos inmateriales del vector de características técnicas.

- Recombinación de la innovación, implica una asociación diferente o disociación de servicio y características técnicas. Por ejemplo, creación de nuevos productos como combinación (o asociación) de características de uno o más productos o la creación de un nuevo producto por medio de la fragmentación (o disociación) de características de un producto preexistente (Bresand y Nicolaïdis, 1988).

- Innovación formal ocurre cuando uno o más características están formadas o estandarizadas.

Los distintos autores siguiendo este modelo integrador son: Saviotti y Metcalfe (1984); Gallouj y Weinstein (1997); Bitran y Pedrosa (1998); Coombs y Miles (2000); Hollenstein (2003); Drejer, 2004; Hipp y Grupp (2005); Miles (2005); Salter y Tether (2006); Windrum y Garcia-Goñi (2007); Froehle y Roth (2007); Gallouj y Savona (2009), entre otros.

Esto conduce a la necesidad de futuros estudios para validar este desarrollo teórico de modelos para la innovación en servicios y productos. En particular el modelo de Gallouj y Weinstein (1997) ha sido solamente testeado en las industrias de servicios (DeVries, 
2006) aunque ha sido explícitamente diseñado como un modelo de innovación aplicable a industrias de productos y servicios.

DeVries establece que las competencias del proveedor y los vectores de características necesitan ser mejorados para tomar en cuenta explícitamente la posibilidad de interacción entre vectores de competencias y tecnologías de distintos proveedores en una red de organizaciones. Introduce también un vector de tecnología del cliente para hacer explicito que los clientes interactúan con los proveedores a través de su propia tecnología, para entender las innovaciones recientes como sistemas de información inter-organizacional, internet, e-business, telefonía celular y otros canales tecnológicos para interactuar con clientes. Restringe los tipos de innovación a cuatro: radical, incremental, ad hoc e innovación recombinativa. No se hace distinción entre innovación mejorada e incremental y se usa el término incremental para ambos tipos dado que la diferencia entre ambas es empíricamente difícil de establecer según este autor.

Figura 6. Modelo mejorado de características y competencias.

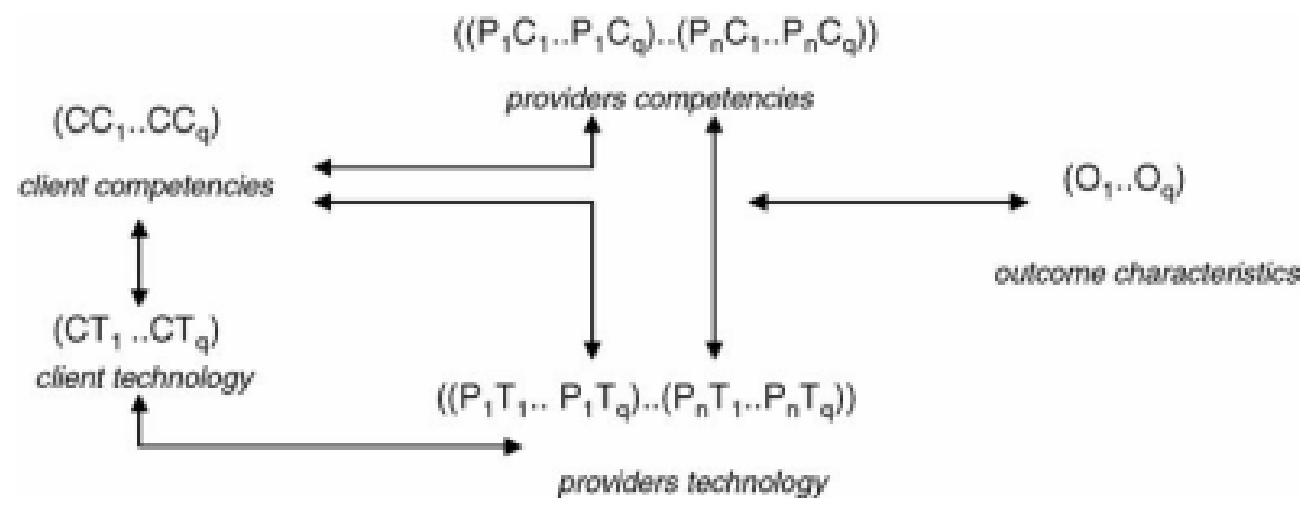

Fuente: DeVries (2006)

Windrum y García-Goñi (2008) desarrollan un modelo evolutivo de innovación en servicios de salud. Introducen las características del responsable de las políticas públicas con la finalidad de abarcar los modos de innovación con independencia de la propiedad (pública o privada). Los autores se basan en la aproximación basada en características para dirigirse al problema de la medida de innovación en servicios. En su modelo todas las dimensiones de la innovación de Schumpeter (organización, producto, proceso, mercado y entrada), así como la diferencia entre incremental y radical, son reelaboradas en términos de cambios en características. 
Estudios empíricos que testeen este modelo en ambos sectores podrían ser un área interesante para la investigación futura.

\section{3.- Diferencias entre innovación en producción (productos y proceso) y servicios.}

Según el Manual de Oslo (2005), la innovación en servicios puede diferir de la innovación en los sectores orientados a fabricación, organizándose a menudo de forma menos formal teniendo una naturaleza más incremental y menos tecnológica. Para tratar de medirla de una forma más adecuada el manual cambia algunas definiciones de la versión anterior y también incluye dos nuevos tipos de innovación: organizativa y de mercadotécnica. También se hace eco de la dificultad en distinguir en el sector servicios entre las innovaciones de producto (servicio) y proceso, ya que la producción y el consumo ocurren simultáneamente. Al ser además la actividad de innovación en servicios un proceso continuo se hace muy difícil la definición de la innovación como un acontecimiento específico. Concluye el manual que para los servicios, los inputs de la innovación más frecuentes son distintos de la I+D.

La relación con clientes constituye uno de los elementos básicos y típicos de innovación de servicios. Como resultado de su naturaleza coproducida, la fuerte interacción entre productor y consumidor parcialmente desdibuja la distinción entre innovación en productos e innovación en procesos (Sirilli y Evangelista, 1998). Esta interacción requerida por el servicio coproducido puede implicar que la innovación tiene sus propias características, conductas y necesidades. Esto explica la gran importancia de los factores humanos y organizativos como elementos competitivos cuando se compara con la producción (manufacturing). La innovación de servicios requiere una alta consideración de aspectos organizativos más allá de los métodos tradicionales de innovación de producto y proceso (Gallouj, 1994, 2002; Gadrey, Gallouj y Weinstein, 1994; Sundbo, 1998). Esto es debido al alto contenido de intangibilidad y elementos informativos asociados con aquellos productos y procesos de los servicios, y a la alta relevancia de innovación no incorporada.

Así, las formas de obtener innovación en servicios son más variadas y complejas en comparación con la innovación en bienes. Desde la perspectiva de las entradas, el papel de $\mathrm{I}+\mathrm{D}$ como fuente de innovación es mucho más bajo que en la innovación industrial 
clásica (de producto y proceso) (Rubalcaba, 2006). En ausencia de procesos de I+D formal, no es fácil para las compañías de servicios identificar sus actividades de innovación como I+D. Aunque algunas de las compañías europeas más innovadoras están basadas en servicios, el nivel total I+D es demasiado bajo y poco estructurado. En los servicios, una parte de I+D no está estadísticamente registrada (por ejemplo, no es llevado a cabo en el departamento de I+D, o este tipo de departamento no existe), y muchas inversiones para la innovación no están referidos como I+D.

Debido a su naturaleza interactiva, los resultados de la innovación en servicios son menos visibles que los resultados de la innovación en bienes. Además los métodos de apropiación en servicios (preferiblemente copyright) difieren de los de los bienes (Howells, 2001). Cabe destacar que la naturaleza distinta de la innovación en servicios no excluye a los bienes. Así la innovación en bienes puede incluir elementos de los servicios y viceversa. La innovación en servicios es útil para la innovación en bienes por medio de un proceso de encapsulación, descrito por Howells (2004). Por tanto para este tipo de innovación, los factores no técnicos y los intermediarios de la información y el conocimiento ganan gran importancia.

Baumol $(1967,1985)$ encontró que el crecimiento de los servicios en la economía y los bajos niveles de productividad estaban positivamente relacionados. Más recientemente, sin embargo el mismo autor (Baumol, 2000) ha revisado los hallazgos previos tomando en cuenta los problemas respecto a la medición estadística de los servicios y el efecto indirecto y positivo que una variedad de servicios (particularmente los llamados KIBS, Knowledge Intensive Business Services) generan en las empresas que los usan (Windrum y Tomlinson, 1999; Rubalcaba y Kox, 2007) y su competitividad (Rubalcaba, di Meglio, Visintin, Maroto y Gallego, 2008).

La innovación en servicios transciende más allá de los límites individuales de la firma (Ark, Inklaar, McGuckin y Timmer, 2003a). El impacto de la innovación en servicios provoca una reacción que va más allá de un efecto directo y afecta a la forma en la cual los subsiguientes procesos de innovación están construidos. El impacto de la innovación en servicios puede ser estimado por las necesidades del cliente, dado que existen muchos equipos mixtos de proyectos en los cuales el cliente y la firma de servicios contratantes coproducen soluciones a problemas específicos. Consecuentemente, los servicios innovan en la base de necesidades específicas que están articuladas por sus 
clientes, incluso aunque esto sea más explicito para algunas innovaciones particulares que para otras.

Hipp, Kukuk, Licht y Muent (1996), Tether (2005), Howells y Tether (2004) enfatizan el rol de las redes colaborativas como fuentes de innovación, entre los cuales destaca la colaboración con clientes y proveedores. Más aún, en algunos casos, la firma de servicios es incluida en los procesos de innovación que tiene lugar en la firma del cliente, tales casos son principalmente representados por KIBS, Den Hertog, 2000.

Tether y Tajar (2008) exploran los modos de innovación entre las empresas europeas y establecen tres grupos: las empresas que innovan en productos, las que desarrolla innovaciones técnicas de proceso y las que innovan de un modo que denomina innovación organizativa de cooperación. La primera es conocida en la literatura y las firmas high-tech tienden más a estar involucradas en ella, mientras que las firmas de producción con baja tecnología es más probable que estén involucradas en tecnologías de proceso. El modo de innovación organizativa de cooperación, que implica más a la cadena de suministro que las prácticas basadas en cooperación en la innovación, es particularmente prominente en servicios, especialmente en servicios de comercio y distribución. Esto concuerda con la visión de que la innovación en servicios es más bien de tipo soft.

Tomlinson (2000) y Drejer (2002) encontraron un efecto significativo y positivo de los KIS en los resultados de las empresas clientes. Los KIBS evidentemente no son las únicas actividades de servicio que positivamente afectan a la productividad, pero su distintivo rol está asociado con efectos de derrame en la totalidad del sistema productivo. A este respecto, Ark, Inklaar, McGuckin y Timmer (2003b) demostraron que la introducción de las TIC daba como resultado importantes efectos de mejora en la productividad en muchas industrias de servicios. También Antionelli (1998) y Tomlinson (2000) reportaron la positiva correlación entre TIC y la importancia de los negocios de servicios dentro de una economía dada. Otros autores (Licht y Moch, 1999; OECD, 2004; Gago y Rubalcaba, 2007, entre otros) han destacado el rol de las TIC como fuente de innovaciones. 


\section{4.- Medición de la innovación en servicios.}

Existen varias formas de medir la innovación en servicios, estas han ido cambiando y actualizándose, en función de la disponibilidad de datos. Van a estudiarse a continuación todas las posibilidades manifestadas en la literatura.

Un factor clave para la medida de innovación en servicios ha tenido que ver con la investigación y desarrollo (I+D), sobre todo a partir del Manual Frascati a principios de los 60. Las estadísticas en $\mathrm{I}+\mathrm{D}$ tienen la ventaja de que cuentan con unas grandes series temporales y la posibilidad de comparación entre países, aunque los críticos sostienen que la diferencia en los incentivos para llevar a cabo I+D (eliminación de impuestos a la I+D y otros) y las diferencias en la recolección de los datos, hace que la posibilidad de comparación de estos datos sea menor de lo que cabría esperara a priori. También cada vez se está haciendo más difícil medir la $\mathrm{I}+\mathrm{D}$, a medida que las practicas en investigación se han vuelto más difusas y menos dependientes de los laboratorios centrales de I+D de las grandes compañías. A pesar de todo, la principal crítica de tomar la medición de I+D como medida de innovación es que se trata de un input, no de una salida, y las compañías pueden diferir de forma muy grande en su habilidad para convertir esta $\mathrm{I}+\mathrm{D}$ en resultados exitosos en el mercado.

El otro tradicional indicador de la innovación tecnológica son las patentes. Las patentes son muy usadas por la disponibilidad de grandes bases de datos (sobre todo de las oficinas de Estados Unidos y Europa). Para patentar, las firmas tienden a desarrollar resultados patentables. Esto varía entre países, sobre todo en lo que refiere a las patentes de software y de modelos de negocio. También es sabido que las firmas e industrias difieren en gran manera en su propensión a patentar, y que las patentes son solo un mecanismo de defensa en la industria química y farmacéutica. Las patentes son más un mecanismo de invención que de innovación, ya que muchas patentes no son comercializadas. Son también solo una medida parcial de la invención, ya que muchas invenciones no son patentadas, debido a que las empresas pueden optar por el secreto industrial $\mathrm{u}$ otros modos de protección o que algunas empresas no son proclives a patentar por la complejidad y coste del proceso.

Más tarde, en los 80 se desarrollaron nuevos enfoques, dada la falta de satisfacción con estas medidas de innovación. Uno es el llamado "enfoque basado en objetos", que está basado en identificar innovaciones directamente, preguntar a expertos en varias 
industrias para que identifiquen las innovaciones, o usar revistas de comercio para identificar y clasificar nuevos anuncios de productos. Aunque estas aproximaciones mostraron una gran innovación que no fluía de la inversión en $\mathrm{I}+\mathrm{D}$, tendían a favorecer industrias que producían cosas tangibles, más que prácticas o procedimientos.

La otra gran aproximación para medir la innovación es la "aproximación basada en el sujeto", que está basada en preguntar a una firma (el sujeto) si han introducido innovaciones. Aunque se usa en el Innobarómetro Europeo, entre otras encuestas, el principal instrumento que usa la "aproximación basada en el sujeto" es el CIS (Community Innovation Survey, Encuestas de innovación de la Unión Europea). En principio, este enfoque es igualmente aplicable a producción y servicios, pero en la práctica, ha tendido a favorecer más a producción. En la primera edición del Manual de Oslo se puso el foco de atención en la innovación técnica y de procesos. La literatura científica en servicios sostiene que esto es poco apropiado para los servicios, cuya innovación se cree que es más continua. En sucesivas ediciones del manual se incluyeron las innovaciones de organización y mercadotecnia, también se hizo una mayor incidencia en servicios.

El CIS ha producido un número de valiosas revelaciones en servicios, pero está todavía focalizado en el hecho de la comercialización de nuevos productos y procesos. Esta limitación no ayuda a la hora de entender la difusión de tecnologías y su práctica (como las tecnologías se integran en las organizaciones a la vez que otros cambios en capacidades, relaciones y estructura de la organización). La conexión entre innovación y estrategia de la firma está también poco desarrollada. Otras críticas sugieren que la encuestas no son capaces de medir toda la innovación, permaneciendo oculta una parte de ella a pesar de los esfuerzos realizados (Tether y Tajar, 2008).

\section{5.- Revisión literatura sobre innovación en KIBS (Knowledge Intensive Business}

\section{Services).}

Miles, Kastrinos, Flanagan, Bilderbeek y den Hertog (1995) definieron los KIBS como servicios que involucran actividades económicas que están destinadas a lograr la creación, acumulación o diseminación de conocimiento. Den Hertog (2000) los definió como compañías privadas $\mathrm{u}$ organizaciones que descansan de gran manera en 
conocimiento profesional o técnico para proveer productos intermedios y servicios basados en el conocimiento. Miles et al. (1995) encontraron que las características de estos servicios son:

- Están basados en servicios profesionales de conocimiento

- Ellos mismos son también fuentes primarias de información y conocimiento (informes, consultoría de formación, etc.).

- Usan sus conocimientos para producir servicios intermedios para los procesos de producción de sus clientes. (ej.: comunicación y servicios de computación).

- Son de importancia competitiva y se suministran principalmente a las empresas.

Miles et al. (1995) encontraron que algunos son servicios profesionales tradicionales (PKIBS) y en cambio otros nuevos servicios basados en la tecnología (T-KIBS). También algunos servicios que responden a características de KIBS normalmente no están clasificados como KIBS, como pueden ser los servicios relacionados con el cuidado de la salud entre otros. A continuación presentamos la clasificación de servicios realizada por Miles et al. (1995):

\section{Sectores tradicionales:}

- Márketing/publicidad.

- Formación y entrenamiento (distinto de aquel en nuevas tecnologías).

- Diseño (otro que no sea involucrar a nuevas tecnologías).

- Algunos servicios financieros (por ejemplo: actividades relacionadas con valores y el mercado de acciones).

- Servicios de oficina (que no involucren nuevo equipamiento de oficina y se excluye servicios físicos como limpieza).

- Servicios de construcción (ej.: arquitectura, de inspección, ingeniería de construcción, pero excluyendo servicios que involucren nuevos equipamiento en IT como construcción de sistemas de gestión de energía).

- Consultoría de negocio (cualquiera que no involucre nuevas tecnologías).

- Contabilidad y gestión de cuentas.

- Servicios legales.

- Servicios medio ambientales (no involucrando nuevas tecnologías, ej.: leyes medio ambientales, y no basados en vieja tecnología, ej.: servicios elementales de eliminación de residuos. 


\section{Basados en nuevas tecnologías:}

- Redes de computación/telemática.

- Telecomunicaciones (especialmente nuevos negocios de servicios).

- Software.

- Otros servicios relacionados con los ordenadores, ej.: gestión de instalaciones.

- Entrenamiento y formación en nuevas tecnologías.

- Diseño que involucre nuevas tecnologías.

- Servicios de oficinas que involucre nuevo equipamiento de oficina

- Servicios de construcción (que involucres nuevo equipamiento en IT como construcción de sistemas de gestión de la energía).

- Consultoría de negocio que involucre nueva tecnología.

- Ingeniería técnica.

- Servicios de medioambiente que involucren nueva tecnología; ej.: remediar, vigilar, servicios científicos y de laboratorio.

- Consultoría en I+D y tiendas de alta tecnología.

\section{No se consideran servicios KIBS:}

- Servicios médicos o de salud.

- De correos, transporte y distribución (aunque algunos servicios especializados podrían ser incluidos).

- Servicios de financiación al cliente y servicios inmobiliarios.

- Servicios de educación (que no sea entrenamiento especializado para la industria).

- Difusión y otros medios de masas (con posibles excepciones cuando esos medios se usan también para prestación especializada de servicios de negocio en emisión de datos o negocios de transmisión de video codificados.

- Administración pública (con posibles excepciones en esquemas de soporte a la industria.

- Administración pública (con posibles excepciones en planes de soporte a la industria).

- Reparación/mantenimiento (con la excepción de actividades relacionadas con IT avanzada).

- Venta al por mayor y al por menor.

- Servicios de asistencia social. 
- Hostelería y catering.

- Ocio/turismo.

- Servicios de consumo personal.

- Entretenimiento.

Así según Miles et al. (1995) y Hauknes (1998), los KIBS juegan tres funciones en los sistemas de innovación:

(1) Facilitador de innovación, cuando una firma KIBS da soporte a una empresa cliente en su proceso de innovación, pero la innovación no se origina de una firma KIBS.

(2) Portador de innovación, cuando una firma KIBS transfiere innovación existente de una firma o industria a una firma de un cliente o industria.

(3) KIBS como fuentes de de innovación, cuando una firma KIBS juega un gran papel en iniciar y desarrollar la innovación en la firma de un cliente.

La investigación en KIBS primero tuvo una fase teórica con poca preocupación empírica. En una fase posterior, se analizaron los KIBS de una forma más profunda, intentando responder a grandes cuestiones ¿Innovan los KIBS? ¿Innovan los KIBS de forma diferente a producción? ¿Innovan de forma diferente al resto de servicios? ¿Innovan de forma diferente entre ellos?

Con respecto a la primera, el desarrollo más importante que ha contribuido al entendimiento de los procesos de innovación ha sido la implementación de CIS (Community Innovative Surveys). Los estudios basados en datos CIS se concentran sobretodo en temas como patrones de innovación y fuentes de competitividad (Camacho y Rodríguez, 2005; Evangelista, 2000; Hollenstein, 2003; Tether, 2003; Tether y Hipp 2002), en innovación y la actuación de un sector (Cainelli, Evangelista y Savona, 2004; Cainelli, Evangelista y Savona, 2002, 2003) e innovación y colaboración entre firmas (Tether, 2003). Cuando se dirigen a las KIBS, estos artículos se concentran esencialmente en las actividades innovadoras de KIBS dentro de marcos estatales.

En paralelo, algunos académicos han desarrollado su propia base de datos basada en grandes encuestas dirigidas a KIBS y subsectores para tener una visión más amplia de los patrones innovadores en KIBS (Balaz, 2003; Djellal y Gallouj, 2001; Freel, 2006; Koch y Stahlecker, 2006; Koschatzky, 1999; Leiponen, 2005; Muller 2001; Tether, 
2005; Wong y Singh, 2004). Estas encuestas se basan en los manuales de la OCDE y la metodología CIS. Los estudios empíricos sobre KIBS están todavía lejos de ser concluyentes en lo que respecta a las características de la innovación en estos sectores. Sin embargo, los resultados de la literatura revelan que son grandes innovadores.

Para la cuestión de si innovan de forma diferente de la producción, existe un reconocimiento de que las actividades innovadoras en KIBS son distintas de las de producción (Camacho y Rodriguez, 2005; Gallaher y Petrusa, 2006; Sundbo y Gallouj, 2000; Tether, 1999; Tödtling, Lehner y Trippl, 2006). Wong y He (2005) mostraron que los KIBS están más intensamente involucrados en innovación y actividades de formación y entrenamiento que las actividades de producción. Freel (2006) mostró que la innovación en KIBS está fuertemente asociada con empleados muy cualificados y una intensa colaboración con clientes y proveedores, en comparación a las firmas de producción.

Respecto a la tercera pregunta, Tether y Hipp (2002), establecieron que los KIBS tendían a gastar más en innovación (por empleado) de lo que lo hacían las otras firmas de servicios menos intensivas en conocimiento, sugiriendo una dedicación más grande a la innovación entre ellos. Distinguían entre lo que llamaban firmas de servicios con alta intensidad técnica y otras firmas de servicios con alta intensidad en conocimiento. Observaron que la I+D parecía ser particularmente importante para los KIBS técnicos comparado con los KIBS no técnicos observando sus gastos de innovación. Como evidencia de los patrones de inversión relacionada con innovación, si los KIBS tendían a gastar más en TIC que los servicios en general (por empleado), tendían a invertir menos (por empleado) en nueva maquinaria y equipamiento que los servicios en general. Notaron que los KIBS eran más propensos a identificar fuentes externas de información y estaban también más propensos a estar involucrados en acuerdos cooperativos para la innovación que las firmas de servicios en general.

Para la pregunta de si los diferentes sectores KIBS innovan de forma diferente, Doloreux y Shearmur (2010) encuentran diferencias significativas relativas a la prevalencia de diferentes tipos de innovación, fuentes de información, estrategias de innovación y obstáculos percibidos. Según su estudio, cada uno de los sub-sectores KIBS analizados está sobrerrepresentado en uno o dos perfiles de innovación, y un perfil particular puede ser asociado a cada subsector. Así, arquitectura, ingeniería, y 
servicio relacionados, son innovadores y tienden a percibir menos obstáculos para innovar. Diseño de sistemas de ordenadores y servicios relacionados son también innovadores pero más sensibles a los obstáculos financieros. Se sugiere que esto puede ser atribuible a la naturaleza más especulativa de la innovación en este último sector. Servicios de consultoría de gestión, científica y técnica son menos innovadores, pero se focalizan más en recursos internos y empleados. 


\section{4.- INNOVACIÓN EN PROCESO.}

\section{1.- Modelos iniciales básicos.}

Los primeros estudios sobre modelos de innovación mencionaban la innovación de producto y proceso. Utterback y Abernathy (1975) postularon que el proceso innovador de la firma estaba influenciado por el entorno de la misma y su estrategia para competir y crecer, y por el estado de desarrollo de la tecnología de proceso usada por la firma y sus competidores. Estos autores clasificaron las etapas de desarrollo del proceso en tres dependiendo básicamente del grado de competencia en el mercado: no coordinada, departamental y sistémica. El mismo proceso evolucionaría desde una naturaleza orgánica hacia una mecánica y posteriormente sistémica, tendiendo bien hacia el declive o hacia cambios revolucionarios. El modelo incluye y relaciona la innovación de producto y proceso ya que una innovación de producto evoluciona desde una mejora del desempeño del producto hacia una minimización de costes del mismo, incluyendo proceso de fabricación, distribución u otro.

Figura 7: Modelo dinámico de innovación de Utterback y Abernathy.

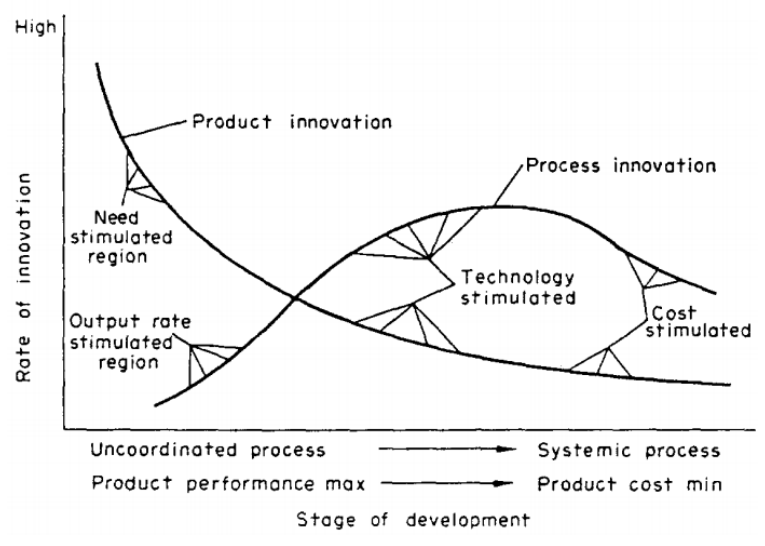

Fuente: Utterback y Abernathy (1975)

Aberthany y Utterback (1978) extendieron el modelo en una posterior publicación analizando diversas industrias y aplicándoles el modelo. El modelo relacionaba los patrones de la innovación (de producto y proceso) con la estrategia competitiva de la firma, las capacidades de producción y las características organizativas.

Más tarde Aberthany y Clark (1985) analizando la historia de la industria del automóvil, postularon su modelo de transiliencia en un esfuerzo por explicar la capacidad de la 
innovación para influir en los sistemas establecidos de producción y márketing. Así las innovaciones fueron categorizadas en cuatro tipos: arquitectónicas (debidas a un clima de gestión y organizativo propicio, que usa nuevos conceptos tecnológicos para formar nuevos mercados), de nicho de mercado (nuevos mercados a través de tecnología existente), regulares (innovaciones casi imperceptibles) y revolucionarias (debido a nuevas opciones técnicas o nuevas aplicaciones que no tienen respuesta con la tecnología existente). De nuevo, dentro de este modelo, las innovaciones de producto y proceso se alternarían dependiendo del entorno competitivo de la industria. Las diferentes clases de innovación requerirían diferentes tipos de habilidades de gestión y organización por parte de las firmas involucradas.

Bresson y Townsend (1981) desafiaron el modelo de Utterback y Aberthany demostrando que algunas industrias no se ajustan a este modelo. Algunas firmas están orientadas hacia sus usuarios y adaptan su comportamiento innovador, y su trabajo organizativo está más vinculado a los sectores industriales que las etapas evolutivas de la firma. Otras firmas parten directamente de innovaciones de proceso. De acuerdo a estos autores, el modelo no explica tampoco la aparición de la innovación radical en las industrias tradicionales.

\section{2.- Innovación de producto versus proceso.}

Existe un gran número de artículos que han discutido el dilema de la innovación en producto versus la innovación en proceso al nivel de la firma. Un primer bloque todavía sigue el modelo de Utterback y Abernathy. Kraft (1990) comparó el grado de novedad de las innovaciones tecnológicas de proceso y producto, encontrando una fuerte dependencia del proceso de la innovación de producto y que la innovación de producto era más dependiente de la estructura del mercado. Bayus (1995) concluye que la innovación incremental de producto y proceso a lo largo de la vida de un producto es resultado de una función interdependiente de las mejoras de producto y proceso, aunque da soporte solo en parte el modelo de Utterback y Abernathy. Este autor midió los gastos en $\mathrm{I}+\mathrm{D}$ sobre las actividades de proceso y de producto a través del ciclo de vida del producto en el caso de la industria de automóvil. Etienne (1981) postuló la necesidad de integrar márketing, proceso e $\mathrm{I}+\mathrm{D}$ a la hora de formular una estrategia de producto. 
Bhoovaraghavan et al. (1996) insisten en una aproximación integradora de la innovación de producto y proceso desde una perspectiva de la demanda del cliente. Klepper (1996) da soporte al modelo de Utterback y Abernathy destacando la relevancia de la innovación de proceso en las últimas fases del ciclo de vida de un producto. En la misma dirección, Stumpfe (2001) confirmó la dependencia de la innovación del proceso de fabricación del ciclo de vida del producto. Rouvinen (2002) indicó que aunque la innovación interrelacionada de producto y proceso fuera impulsada por diversos factores, la tecnología incorporada afectaba al proceso mientras que la tecnología no incorporada afectaba a la innovación de producto.

Lim et al. (2006) propusieron una nueva perspectiva donde la tecnología era un factor clave para entender la gestión del desarrollo de la innovación de producto y proceso en empresas del sector biofarmacéutico con una visión modificada del modelo de Utterback y Abernathy. Cabagnols (1999) estudió la dinámica de la innovación de producto versus proceso y viceversa tomando en cuenta su continuidad y consistencia, encontrando que la continuidad era mayor en el primer caso y la consistencia mayor en el segundo. Martínez-Ros (2000) analizó una gran muestra de firmas españolas y encontró que la innovación de producto y proceso era complementaria y dependía básicamente del mercado y de las características de la firma. Damanpour y Gopalakrishnan (2001), siguiendo esta escuela de pensamiento, encontraron que la innovación de producto era adoptada en mayor medida que la de proceso y que era más probable que la innovación de proceso viniera después de la innovación de producto que al revés.

Bogers y Lhuillery (2010) estudiaron el rol de la apertura de la firma y establecieron que las firmas se basan más en conocimiento externo que en interno mientras llevan a cabo innovación de producto versus la de proceso. Finalmente, Reichstein y Salter (2006) analizaron una gran muestra de empresas manufactureras (manufacturing) del Reino Unido y encontraron que la innovación de producto y proceso eran interdependientes. La innovación de proceso era responsable de mejoras de productividad y cambio industrial y estaba asociada con nuevos equipos, el uso de las TIC y prácticas de gestión innovadora. Los proveedores eran una fuente de conocimiento externo asociado a la innovación de proceso y los innovadores radicales de producto tendían a ser también innovadores radicales de proceso. 
Una segunda corriente de la literatura académica tiende también a considerar producto y proceso como actividades interdependientes o a analizarlas interdependientemente. Scherer (1983) estudió una gran base de datos de patentes de la industria norteamericana y encontró que la influencia de la concentración de la industria y el porcentaje del mercado en la intensidad de $\mathrm{I}+\mathrm{D}$ de producto y proceso era relevante para el fomento del crecimiento de la productividad de las empresas. Lunn (1987) analizó las patentes de innovación de producto y proceso y encontró que la concentración de la industria afecta a las dos actividades de innovación de forma diferente dependiendo de las oportunidades tecnológicas afrontadas por las firmas así como su régimen tecnológico. La diversificación fomenta las patentes de proceso y producto pero sus efectos son mayores en el último caso. Se encontró que el tamaño de la firma no era un factor determinante en la actividad de patentar. Cohen y Klepper (1996) analizaron el efecto del tamaño de la firma en la localización del esfuerzo de I+D entre innovación de producto y proceso y encontraron que dependía del tamaño de la unidad de negocio. El mismo argumento fue confirmado por Fritsch y Meschede (2001), especialmente en el caso de la innovación de proceso. Para Weiss (2003) la tendencia de una firma a involucrarse en innovación de producto o proceso puede ser atribuida a la intensidad de competición, el grado de diferenciación del producto y los costes de la innovación. En el caso del entorno industrial, Cleff y Renning (1999) señalaron como la innovación de proceso y producto tiene claramente diferentes determinantes.

\section{3.- Modelos de innovación de proceso.}

Un tercer conjunto de autores han analizado la innovación de proceso desde un punto de vista distinto. Skinner (1992) abordó el concepto de innovación de proceso de forma independiente de la innovación de producto y señaló el rol de la innovación de proceso en industrias de proceso y de no proceso como contribuidor a la ventaja competitiva de la firma. Vonortas y Xue (1997), siguiendo la aproximación de Bhoovaraghavan, estudiaron la influencia de los clientes en el caso de la innovación de proceso mientras Bonnano y Haworth (1998) propusieron que la decisión de una firma de buscar la innovación de producto o la de proceso dependía del régimen de competición de la industria. En esta dirección, Yin y Zuscovitch (1998) eran partidarios de la escuela que atribuye un papel relevante al tamaño de la firma a este respecto, mientras Damanpour 
(2010) no asociaba el tamaño de la firma a la predominancia de la innovación de proceso y señalaba que ya que el ciclo de vida de un producto tiende a recortarse, las firmas requerirán cada vez más habilidades para desarrollar innovaciones de proceso de forma continua. Llorca-Vivero (2002) después de su estudio de una gran muestra de firmas españolas manufactureras distinguió entre los roles de innovación de proceso y producto en el desempeño de una firma y demostró que el desempeño en la innovación de proceso era estable, consistente y de efecto permanente en el ratio de crecimiento de su productividad laboral. Huergo y Jaumandreu (2004) y Rochina-Barrachina et al. (2010) confirmaron empíricamente esta hipótesis mientras que Becker y Egger (2009) encontraron que las actividades de innovación de proceso son relevantes para asegurar la posición competitiva en el mercado de la compañía. Freel y Harrison (2006) encontraron una correlación entre la tendencia de una firma a involucrarse en innovación de proceso y su cooperación con proveedores y universidades. Ornaghi (2006) indicaron que los derrames de la innovación de proceso a las otras firmas aumentan su eficiencia relativa, mientras que la difusión tecnológica de la innovación de producto aumenta la demanda. También encuentran que la innovación de producto tiene una mayor difusión tecnológica que las innovaciones de proceso, tanto en magnitud como en presencia.

Desde el punto de vista de la influencia de las capacidades internas Ettlie y Reza (1992) estudiaron la adopción con éxito de la innovación de proceso y encontrado que la integración organizativa de proveedores y clientes junto con las capacidades internas tales como diseño y producción afectan positivamente a la productividad de los nuevos sistemas de producción. Hatch y Mowery (1998) atribuyen a la influencia de las capacidades internas de la firma la tendencia de las mismas a innovar en proceso. Muvorec y Prodan (2008) y Bogers y Lhuillery (2010) han revelado la influencia de la capacidad de absorción de una firma en su desempeño de la innovación de proceso. Para Baer y Frese (2003) las actividades de innovación de proceso necesitan estar acompañadas por climas internos que complementen la adopción e implementación de tales innovaciones.

Finalmente, Evangelista y Vezzani (2010) a partir de un estudio basado en datos de la encuesta CIS italiana estudian los determinantes tecnológicos y no tecnológicos de la innovación y su impacto en el desempeño innovador, incluyendo la dimensión organizativa de la misma, lo que les da una mejor comprensión de la innovación en 
empresas manufactureras y de servicios. Concluyendo que una forma de innovación compleja (producto, proceso y organizativa) da un mejor resultado entre las empresas manufactureras y de servicios.

Figura 8. Representación de los vínculos del desempeño innovador.

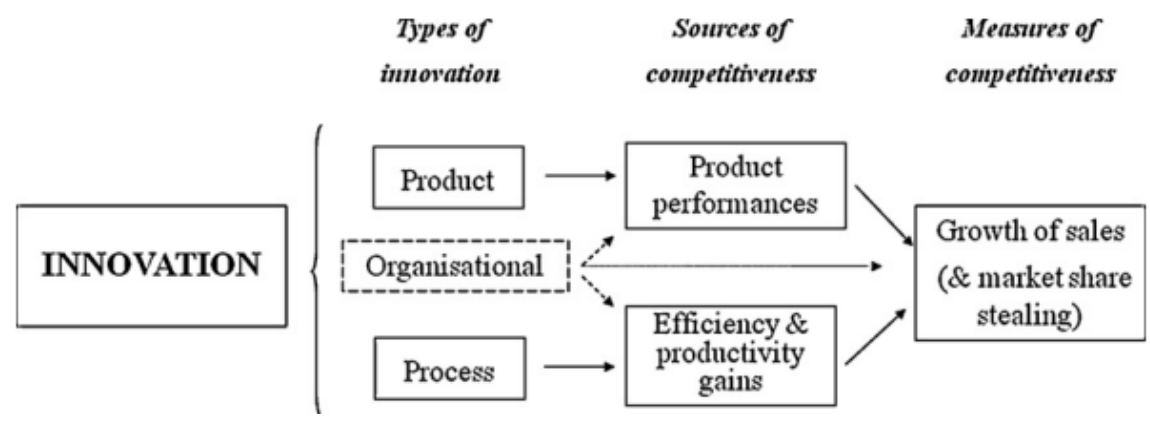

Fuente: Evangelista y Vezzani (2010) 


\section{5.- INNOVADORES NO I+D O "NON-R\&D INNOVATORS"}

En la literatura sobre innovadores sin $\mathrm{I}+\mathrm{D}$ se han encontrado y clasificado numerosas referencias. Primero encontramos un conjunto de estudios que señalan que a parte de la I+D existen otros gastos importantes para la innovación. Se clasifican como estudios que hacen mención a la importancia de la innovación no-I+D.

Existen también un numeroso número de autores que estudian alguno de estos inputs (diseño, marketing, etc.), aunque no se refieren a la innovación sin I+D específicamente. Dentro de este grupo diferenciamos concretamente a los autores que realizan estudios sobre sectores de tecnología baja (LMT) porque se acercan al tema de nuestro interés de manera más directa. Hemos clasificado a estos estudios como aquellos que estudian tangencialmente la innovación y se ha decidido asignar una categoría a los estudios sobre LMT dada su relevancia.

Por último se a partir del artículo seminal de Arundel et al. (2008) surgen una serie de autores que empiezan a tratar la innovación sin $\mathrm{I}+\mathrm{D}$ como tema central. Llamamos a este tercer conjunto de artículos como específicos de no-I+D.

\section{1.- Estudios que hacen mención a la importancia de la innovación no-I+D.}

Pavitt (1982) sugiere que las estadísticas de patentes subestiman las actividades de innovación en grandes firmas y que las estadísticas en $\mathrm{I}+\mathrm{D}$ hacen lo propio con las firmas pequeñas. Posteriormente el mismo autor (Pavitt, 1984) sugiere que las estadísticas sobre I+D no miden bien dos importantes fuentes de cambio tecnológico: la producción de los departamentos de ingeniería de las firmas intensivas en producción y las actividades de diseño y desarrollo de proveedores especializados de fabricación de equipos. Así, las empresas intensivas en producción producían la mayor parte de su propia tecnología de proceso a la que dedicaban una gran parte de sus propios recursos de innovación (suelen tener grupos especializados de ingeniería capaces de identificar desequilibrios técnicos y cuellos de botella, que corregidos permiten mejoras en productividad y a veces son capaces de diseñar nuevos equipos que mejoran todavía más la productividad). Los proveedores especializados en fabricación de equipos también producían una gran parte de su propia tecnología de proceso, pero centraban sus actividades innovadoras en innovaciones de producto para usar en otros sectores. 
También encontró que las firmas dominadas por los proveedores presentaban débiles capacidades de ingeniería e $\mathrm{I}+\mathrm{D}$ y que se basaban más en diseño estético, marcas y publicidad.

Kleinknecht (1987) a través de una encuesta sobre innovación a 3.000 empresas holandesas observó importantes desviaciones respecto a la encuesta oficial CIS del mismo año, mientras que los datos sobre R\&D concuerdan para empresas de más de 500 trabajadores. Se encuentran importantes diferencias sobre el porcentaje de I+D en empresas menores. Su principal conclusión es que las encuestas CIS no son capaces de medir bien la I+D en PYMEs.

Grilliches (1990) sugiere que otros gastos de innovación no contabilizados como I+D son probablemente importantes, especialmente para pequeñas firmas. Posteriormente Kleinknecht y Reijnen (1991) y Santarelli y Sterlacchini (1990) confirman lo anterior, y los últimos encuentran que las PYMEs italianas es más probable que se involucraran en actividades de $\mathrm{I}+\mathrm{D}$ menos sistemáticas (intermitentes) que las grandes empresas. Además encuentran que las encuentran sesgos importantes en las encuestas en $\mathrm{I}+\mathrm{D}$ y cambian la forma de preguntar sobre la misma, haciendo notar que existe una gran parte de I+D informal no medida adecuadamente.

Brouwer y Kleinknecht (1997) se plantean medir los gastos en innovación que no son I+D como patentes, licencias, diseño, prototipos para producción, equipamiento, formación de la mano de obra, investigación de mercado e inversiones en activos fijos entre otros. Encuentran que I+D representaba tan solo una cuarta parte de los gastos en innovación. También Sterlacchini (1999) se plantea la medición de dichos inputs en PYMEs como fuentes de innovación dada la desviación de las anteriores mediciones de los determinantes de la innovación en tales firmas (aunque en su artículo Sterlacchini los utilice como determinantes de la propensión a exportar). Encuentra que la intensidad de esas actividades de no-I+D es particularmente alta en pequeñas firmas especialmente en aquellas clasificadas como "dominadas por los proveedores" y "proveedores especializados" (Pavitt, 1984).

Mairesse y Mohnen (2004) comparan las medidas de los resultados de la innovación de diferentes indicadores y no encuentran grandes diferencias entre una muestra de innovadores que realizan $\mathrm{I}+\mathrm{D}$ de forma continua y de firmas que innovan (tanto si han 
realizado $\mathrm{I}+\mathrm{D}$ de forma continua como si no), aunque no se centran en la innovación no$\mathrm{I}+\mathrm{D}$.

En los trabajos anteriores vemos como estos autores se replantean que tal vez la medición de la I+D en las PYMEs por parte de las encuestas CIS no es la adecuada, y empiezan a replantearse que puede haber innovadores sin I+D (ej.: Pavitt, 1984; Grilliches, 1990) o la posibilidad de medir las actividades de no-I+D.

\section{2- Estudios que tratan tangencialmente sobre la innovación no-I+D.}

Von Hippel (1986) estudia el papel de los clientes como fuente de innovación de productos innovadores. En su trabajo sobre los factores que influyen en como las firmas innovan de Veugelers y Cassiman (1999), examinan la elección entre innovar a través de I+D interno o comprar conocimiento externo (o una combinación de ambas); pero sin hacer mención a actividades internas no-I+D que afectan a la innovación.

Chuang y Lin (1999) encuentran que la inversión extranjera y la I+D tienen un impacto positivo o efecto derrame en la productividad. También hallan que la inversión directa extranjera, la compra de tecnología local y la inversión en el extranjero son sustitutas de la actividad en I+D. Estos hallazgos aún siendo importantes se tienen que tomar con cautela al estar referidos a una economía en desarrollo (Taiwan).

Love y Roper (1999) encuentran que el trabajo en red y la transferencia de tecnología son sustitutos de la $\mathrm{I}+\mathrm{D}$ más que complementario y que por lo tanto se deberían tener en cuenta en los estudios sobre innovación.

Bah y Dumontier (2001) estudiaron si las firmas involucradas de forma intensa en actividades de $\mathrm{I}+\mathrm{D}$ exhibían un comportamiento financiero determinado teniendo en cuenta su estructura de capital, vencimiento de la deuda, pagos de dividendo y caja. Comparando una muestra de firmas intensivas en $\mathrm{I}+\mathrm{D}$ con una de no- $\mathrm{I}+\mathrm{D}$ en Europa, Japón, UK y USA, encontraron que las firmas intensivas en I+D exhibían un significativo menor nivel de deuda y niveles de pago de dividendo, pero mayores vencimientos de deuda y mayores niveles de caja que los no-I+D (excepto en Japón). 
Ofek y Sarvary (2003) observa para el mercado de alta tecnología, el líder tiende a invertir más en publicidad y marketing (no-I+D) mientras que el seguidor por el contrario centra sus esfuerzos en I+D.

Freel (2003) encuentra que las PYMEs que invierten más en formación tienden a innovar más. Marsili y Salter (2006) investigan la relación entre el diseño y la innovación de producto en la industria danesa.

Schmidt y Rammer (2007) investigan la influencia de las innovaciones de marketing y organizativas para la consecución de innovaciones de producto y proceso, además de la clásica I+D, y encuentran que tienen efectos muy parecidos. La combinación de la innovación tecnológica y no-tecnológica tiene un positivo impacto en los resultados de ventas, pero este efecto solo se encuentra en la combinación de innovación de producto y organizativa.

Hall y Bagchi-Sen (2007) estudian las empresas biotecnológicas y encuentran que las firmas con poca intensidad en $\mathrm{I}+\mathrm{D}$ atribuyen su desempeño innovador en estrategias que se centran en el acceso a los mercados, capacidades de marketing y relaciones con los clientes.

Schubert (2010) analiza la influencia del marketing y los cambios organizativos en la innovación de proceso y producto. También estudia si las características de mercado espolean ciertas innovaciones estratégicas y si la innovaciones de marketing y organizativas son complementarias a las innovaciones de producto y proceso o si son sustitutas. Sugieren que las firmas eligen estrategias amplias, que combinan ambas (organizativas y de proceso) si tienen grandes recursos internos y un cierto poder de mercado. También hallan que las innovaciones de marketing hacen que las innovaciones de producto y proceso tengan más éxito.

Mothe y Thi (2010) comprobaron el impacto de las innovaciones organizativas y de marketing en la decisión de innovar en producto y su desempeño innovador, encontrando que tanto la innovación en marketing como la actividad innovadora no tecnológica era importante para la propensión a innovar, pero en cambio no influía en el desempeño innovador. Todo ello referido a la innovación en producto.

Cuervo-Cazurra y Un (2010) estudian la frecuencia de la inversión formal en I+D. Proponen que una empresa a la que le faltan recursos de conocimiento internos es 
probable que nunca invierta en $\mathrm{I}+\mathrm{D}$, una firma que tenga los dos tipos de recursos de conocimiento (internos y externos es probable que a veces invierta en $\mathrm{I}+\mathrm{D}$, mientras que una que tenga recursos de conocimiento interno pero le falten recursos de conocimiento externo es más probable que siempre invierta en $\mathrm{I}+\mathrm{D}$.

\subsection{1.- Estudios sobre LMT (Low medium technology sectors).}

Los procesos de innovación en sectores de tecnología baja y media (Low and Medium Technology, LMT) son a menudo menos formales y más relacionados con cambios incrementales, diseño y optimización de procesos, más que a $\mathrm{I}+\mathrm{D}$ formal (Hansen y Serin, 1997).

Kearns y Ruane (2001) a partir de un estudio de empresas irlandesas manufactureras encuentran que las pérdidas de empleo fueron mayores y la persistencia del trabajo menor en los sectores low-tech (de baja tecnología) y entre los las empresas sin gastos de $\mathrm{I}+\mathrm{D}$ comparadas con las que tenían gastos de $\mathrm{I}+\mathrm{D}$.

Heidenreich (2009) encuentra que existe un patrón de innovación específico de las firmas LMT caracterizado mayormente por innovaciones de proceso, organizativas y débiles capacidades internas en innovación y una fuerte dependencia de la provisión externa de máquinas, equipamiento y software. Un amplio rango de productos $\mathrm{y}$ servicios y el acceso a nuevos mercado son menos importantes que la mejora de flexibilidad en producción o la reducción de costes laborales. El rol de los clientes tampoco parece muy importante. En cambio no encuentran que este patrón sea la base de un comportamiento de éxito, ya que las firmas LMT presentan con menores tasas de crecimiento.

\section{3.- Estudios sobre innovadores no-I+D.}

Laestadius et al. (2005) clasifican a las empresas según su intensidad en I+D y son los primeros en hablar específicamente sobre empresas no-I+D (hasta donde sabemos), encontrando que se dan incluso en los sectores de tecnología alta (30\% de las ventas del sector high-tech son debidos a empresas sin I+D). Propone un conjunto de cinco indicadores de la actividad innovadora que además de la convencional medida de 
intensidad en $\mathrm{I}+\mathrm{D}$ incluye intensidad en diseño, intensidad tecnológica (maquinaria y equipo), intensidad en habilidades (formación y entrenamiento del personal) e intensidad en innovación (innovación de producto o proceso, porcentaje de productos nuevos o innovadores).

Arundel et al. (2008) encuentran que la mitad de los innovadores no desempeñan I+D, pero que no hay diferencias en los resultados respecto de las ventas entre ambos grupos. Los innovadores no-I+D gastan menos en innovación y tienen menores capacidades innovadoras, pero introducen en proporción más innovaciones producto o proceso a través de la adopción de tecnología (estas diferencias no son tan importantes como se esperaba en un principio) y que las empresas sin $\mathrm{I}+\mathrm{D}$ basaban mayormente sus innovaciones en desarrollos internos. Las empresas con I+D colaboraban más para la innovación que las otras. Los innovadores no-I+D se centraban más en la innovación de proceso y era menos probable que se basaran en la experiencia de los ingenieros de producción y diseño. Observaron también que los innovadores no-I+D se dan en pequeñas empresas, son activos en sectores de baja tecnología (sobre todo en servicios) y que se localizan en países con bajas capacidades innovadores.

Huang et al. (2008), muestran que la mitad de las firmas europeas innovadoras no llevaban a cabo $\mathrm{I}+\mathrm{D}$ interna o externa y en lugar de invertir en $\mathrm{I}+\mathrm{D}$, adquirían maquinaria avanzada, compraban patentes y licencias o llevaba a cabo actividades de formación o marketing para desarrollar innovaciones de producto o proceso. Demuestran como la productividad inicial de las firmas, el porcentaje de sus gastos en actividades de innovación no- $++\mathrm{D}$, y la potencial reducción de costes conseguido por la aplicación de tecnologías existentes o el desarrollo de nuevas tecnologías afectaría a los gastos de las empresas para innovar. Así, una firma que este lejos de la frontera tecnológica debería incrementar sus gastos de innovación adquiriendo tecnologías existentes, así podría mantener su competitividad con un menor presupuesto en innovación.

Santamaria et al. (2009) estudian una base de datos de empresas manufactureras españolas para explorar como las actividades no-I+D en empresas de sectores de baja tecnología ayudan a explicar el comportamiento innovador de las mismas. Así, el diseño, el uso de maquinaria avanzada y la formación son cruciales para entender la innovación de cualquier firma y en particular de las firmas en industrias de baja 
tecnología, especialmente en lo que se refiere a las innovaciones de producto. Los autores también estudian la consecución de patentes y si la firma se involucra o no en innovación de proceso. También observan la importancia de las fuentes externas para la innovación como el uso de consultores, la contratación de personal, los acuerdos de colaboración y la I+D externa, con grandes diferencias entre las empresas de baja tecnología y las de alta tecnología en lo que se refiere a innovación de proceso.

Rammer et al. (2009) basándose en la encuesta CIS alemana analizan si las PYMEs que no tienen $\mathrm{I}+\mathrm{D}$ interno pueden sustituir el $\mathrm{I}+\mathrm{D}$ por prácticas de gestión para conseguir un éxito similar y cuáles serían estas prácticas. Utilizan una variable dependiente que mide si la empresa ha introducido innovaciones de producto o proceso que hayan cambiado significativamente la posición competitiva de la empresa. Encuentran que las PYMEs capaces de aplicar un conjunto amplio de herramientas de gestión efectivamente (gestión de recursos humanos, equipo multifuncional de trabajos y acuerdos de cooperación logran un desempeño innovador similar a los que realizan $\mathrm{I}+\mathrm{D}$. La estrategia de $\mathrm{I}+\mathrm{D}$ parecía especialmente efectiva cuando se combinaba con fuentes de conocimiento externo.

Som et al. (2010) a partir de una revisión de la literatura sobre innovadores sin $\mathrm{I}+\mathrm{D}$ concluye que la mayoría de autores los consideran un grupo homogéneo. Som et al identifican diferentes patrones de comportamiento innovador entre una muestra de empresas manufactureras alemanas que innovan pero no realizan $\mathrm{I}+\mathrm{D}$ y tampoco lo compran, estableciendo los siguientes tipos:

- Desarrolladores de producto intensivos en conocimientos, de forma sorprendente son similares a los intensivos en I+D. Presentan un alto porcentaje de desarrollo de productos, a menudo acompañados de servicios relacionados. Utilizan múltiples fuentes de conocimiento, la mayoría de ellas se basadas en fuentes de conocimiento internos y en personal altamente cualificado. También organizaciones externas como universidad y laboratorios de $\mathrm{I}+\mathrm{D}$ son una fuente importante de conocimiento para la innovación. Caracterizadas por un alto nivel de innovación no-técnica de proceso, utilización intensiva de innovación organizativa del trabajo y producción, además demuestran una elevada intensidad en cooperación para la innovación. Principalmente se dan en sectores 
de tecnología alta (pero un $25 \%$ de ellos en los de baja tecnología), además son los más numerosos entres los innovadores sin $\mathrm{I}+\mathrm{D}$.

- Basados en el cliente (especialistas técnicos en el proceso), muestran una alta intensidad innovadora en lo que se refiere a la personalización, innovación técnica de proceso y están probablemente basados en una mezcla de conocimiento interno basado en la experiencia y $\mathrm{I}+\mathrm{D}$ externa relacionada con conocimiento experto que proviene de la demanda.

- Desarrolladores ocasionales de productos desde el negocio al consumidor, la mayor parte del conocimiento para sus innovaciones es interno (a pesar de un menor porcentaje de trabajadores altamente formados). Ninguna de esas firmas desarrollan sus productos de acuerdo a especificaciones del cliente, y los servicios relacionados con los productos rara vez juegan un importante papel. Tal vez otras dimensiones de innovación como diseño o marketing son de importancia para ellos.

- No innovadoras, manufactureras intensivas en producción. Presentan un alto número de empresas que personalizan sus productos de acuerdo a especificaciones externas, pero casi nunca desarrollan nuevos productos. Esta falta de innovación no está compensada ni por la innovación de servicios ni por la innovación de proceso. De forma sorprendente, no existe fuente de conocimiento o propensión a colaborar de forma significativa. Reportan un alto porcentaje de trabajadores en producción y alto porcentaje de trabajadores altamente formados.

- Volumen flexible, proveedores especializados. Parecen ser proveedores especializados en personalización que se basan en un conocimiento a partir de la experiencia propia, intensidad innovadora media, que realizan innovación de proceso no-técnica y con pocos trabajadores altamente cualificados.

Huang et al. (2010) estudian las fuentes de innovación de producto y proceso para empresas manufactureras y de servicio encontrando que para las firmas sin $\mathrm{I}+\mathrm{D}$, los proveedores y los competidores son una importante fuente de información, pero no para las firmas que contratan fuera la I+D o para las que simplemente adoptan la tecnología. Para la innovación en producto, las empresas tienden tener I+D interno, y para proceso también encuentran que es necesario ciertas capacidades internas (los autores usan una variable denominada capacidad innovadora interna que consiste en si la empresa ha 
introducido nuevas innovaciones de producto o proceso principalmente desarrolladas por la empresa u otros miembros del grupo de empresas, sin la participación de otras firmas). Concluyen que un simple contraste entre firmas innovadoras que no realizan $\mathrm{I}+\mathrm{D}$ interna no es suficiente para entender la innovación en las mismas.

Barge-Gil et al. (2011) estudian las fuentes de innovación de las empresas no-I+D, observan que las empresas no-I+D no crean resultados de innovación por casualidad, sino que se basan en diseño, formación promoción de la tecnología y uso de tecnología avanzada. Así el diseño y promoción de tecnología avanzada son relevantes para explicar la innovación en ambos grupos (I+D y no-I+D), la formación solo afecta a la innovación de producto positivamente para las empresas no-I+D, y por último el uso de tecnología avanzada es muy importante explicando la innovación de proceso. También las actividades no-I+D pueden ayudar a explicar los resultados de innovación de algunas firmas que si tienen I+D.

Hervas-Oliver et al. (2011) estudian como las actividades de I+D difieren en innovación de las no-I+D, especialmente en el contexto LMT donde la mayoría de las firmas son PYMEs. Encuentran que los gastos en I+D pueden explicar solamente la innovación en producto, mientras que la innovación en proceso, es explicada por variables no-R\&D como marketing, diseño o la contratación de empleados con estudios terciarios avanzados. También encuentras que las firmas con mayores recursos internos se involucran más en acuerdos de cooperación y acceden más a flujos externos de conocimientos.

\subsection{Resumen y discusión.}

Cuando alguien quiere solucionar un problema lo primero es darse cuenta de que lo tiene. Así podemos establecer que si el problema era medir adecuadamente la innovación, lo primero era darse cuenta de que no se estaba haciendo correctamente, así la innovación que era medida mayormente a través de indicadores de $\mathrm{I}+\mathrm{D}$ tales como gastos internos en $\mathrm{I}+\mathrm{D}$ o concesión de patentes. Un conjunto amplio de autores empiezan a señalar que la innovación no solamente es debida a I+D y que deben existir otros determinantes importantes para la misma (ej.: Pavitt, 1982; Grilliches, 1990). 
Sobretodo observan importantes sesgos al medir la innovación en PYMEs (ej.: Kleinknecht, 1987; Grilliches, 1990; Santarelli y Sterlacchini, 1990).

También entre otros Hansen and Serin (1997) se replantean que la innovación en contextos de baja tecnología responde a otros inputs además de la I+D. Así Brouwer y Kleinknecht (1997) encuentran que I+D representaba tan solo una cuarta parte de los gastos en innovación de las empresas.

Una vez determinado el problema, se producen una serie de acercamientos al origen de la innovación sin- $\mathrm{I}+\mathrm{D}$, aunque de forma tangencial, así unos autores se centran en la compra de conocimiento externo (Veugelers y Cassiman, 1999), otros en la inversión extranjera (efecto derrame, Chuang y Lin, 1999), transferencia de tecnología (Love and Roper, 1999), clientes como fuente de innovación (von Hippel, 1986; Hall y BagchiSen, 2007), formación (Freel, 2006), diseño (Marsili y Salter, 2006), marketing (Schmidt y Rammer, 2007; Hall y Bagchi-Sen, 2007, Mothe y Thi, 2010) o innovaciones organizativas (Schmidt y Rammer, 2007; Mothe y Thi, 2010).

Laestatius et al. (2005) proponen una serie de indicadores que van más allá de la I+D, pero es el Manual de Oslo (OECD, 2005) que incluye las innovaciones de marketing y organizativas el que marcará la existencia de datos no-I+D comparables entre países gracias a las encuestas CIS. Por lo tanto y siguiendo con nuestro análisis, se propusieron indicadores para medir apropiadamente la innovación tratando de reducir el sesgo que se había producido hacia la I+D. A pesar de ello las variables input en las encuestas CIS continúan siendo prácticamente las mismas que se usaban para la innovación tecnológica (Evangelista y Vezzani, 2010).

Posteriormente y con estos datos en la mano, la Comisión Europea (EC, 2008) señala que es importante entender si existen diferentes comportamientos y necesidades entre los innovadores no-I+D y los I+D para mejorar la efectividad de las políticas públicas para estimular la innovación (EC, 2008: p.6). Es más, destaca que la encuesta sobre innovación muestra que casi la mitad de los innovadores europeos no llevo a cabo I+D interno. Tales innovaciones no-I+D incluyen la compra de maquinaria avanzada y hardware específicamente comprado para implementar nuevos o significativos mejorados productos o proceso, la compra de derechos de uso de patentes, licencias, know-how, marcas y software, actividades internas o externas de formación para el personal con el propósito de desarrollar o introducir innovaciones e innovaciones de 
marketing internas y externas con el propósito de introducir en el mercado nuevos o significativamente mejorados productos. El porcentaje de innovaciones no-I+D tiende a ser mayor en los nuevos estados miembros (normalmente países del este). Descomponiendo datos por sectores, encuentran que los innovadores no-I+D están concentrados en los sectores de producción y servicios de baja tecnología, y que la distribución de esos innovadores no-I+D presenta un sesgo hacia empresas pequeñas y medianas PYMEs (EC, 2008: p. 25 y 26).

Tal vez al ser todavía relativamente recientes las observaciones de la Comisión Europea sobre innovadores no-I+D, los artículos cuantitativos sobre el tema son escasos.

Tabla 1. Revisión de estudios empíricos sobre non-R\&D innovators.

\begin{tabular}{|c|c|c|c|c|c|c|c|}
\cline { 2 - 7 } \multicolumn{1}{c|}{} & AÑO & PAIS & SECTOR & N & Año & TIPO INNO & VBLE DEP \\
\hline $\begin{array}{c}\text { Arundel, Bordoy y } \\
\text { Kanerva }\end{array}$ & 2008 & EU (27) & $\begin{array}{c}\text { producción } \\
\text { servicios }\end{array}$ & 4395 & $2005-6$ & $\begin{array}{c}\text { producto, proceso, } \\
\text { marketing, } \\
\text { organizativa }\end{array}$ & $\begin{array}{c}\text { Firmas innovan sin R\&D 0-1 } \\
\text { Declive o sin cambio en crecimiento } \\
\text { ventas }\end{array}$ \\
\hline $\begin{array}{c}\text { Barge-Gil, Nieto y } \\
\text { Santamaria }\end{array}$ & 2011 & Spain & producción & $\begin{array}{c}6500=1300 \\
\text { firmx5years }\end{array}$ & $98-2002$ & producto y proceso & $\begin{array}{c}\text { Innovación de producto 0-1 } \\
\text { Innovación de proceso 0-1 }\end{array}$ \\
\hline $\begin{array}{c}\text { Huang, Arundel y } \\
\text { Hollanders }\end{array}$ & 2008 & EU(18) & producción & 14430 & $98-2000$ & $\begin{array}{c}\text { producto y proceso } \\
\text { como variables } \\
\text { indep. }\end{array}$ & $\begin{array}{c}\text { Intensidad de los gastos en } \\
\text { innovación }\end{array}$ \\
\hline $\begin{array}{c}\text { Santamaria, Nieto, } \\
\text { Barge-Gil }\end{array}$ & 2009 & Spain & producción & $\begin{array}{c}6500=1300 \\
\text { firmx5years }\end{array}$ & $98-2002$ & $\begin{array}{c}\text { producto y proceso } \\
\text { innovación de producto, innovación } \\
\text { de proceso, propensión a patentar }\end{array}$ \\
\hline $\begin{array}{c}\text { Rammer, Czarnitzki } \\
\text { y Spielkamp }\end{array}$ & 2009 & Germany & producción & $\begin{array}{c}1049 \\
\text { servicio }\end{array}$ & SME & $2000-2$ & $\begin{array}{c}\text { producto y proceso } \\
\text { efficiency innovations, quality } \\
\text { innovations (generated quantitative } \\
\text { innovation success) 0-1 }\end{array}$ \\
\hline $\begin{array}{c}\text { Som, Dreher y } \\
\text { Maloca }\end{array}$ & 2010 & Germany & producción & 1474 & 2009 & $\begin{array}{c}\text { producto (incluye } \\
\text { servicio) y proceso }\end{array}$ & Análisis clúster \\
\hline $\begin{array}{c}\text { Huang, Arundel y } \\
\text { Hollanders }\end{array}$ & 2011 & EU (15) & producción & 12766 & $98-2000$ & producto y proceso & porcentaje de gastos en no-I+D \\
\hline $\begin{array}{c}\text { Hervas-Oliver, } \\
\text { Albors y Gil- } \\
\text { Pechuan }\end{array}$ & 2011 & Spain & producción & 2023 & $2005-6$ & producto y proceso & innovación en producto 0-1 \\
innovación proceso 0-1
\end{tabular}

Fuente: elaboración propia.

Teniendo en cuenta la escasa literatura empírica sobre el tema encontramos varios problemas en los estudios sobre innovadores non-I+D:

- No existe una definición común de innovadores no-I+D. Si en los estudios lowtech a veces se utiliza un porcentaje de los gastos de $\mathrm{I}+\mathrm{D}$, en la literatura específica sobre no-I+D el problema se centra en si un innovador no-I+D es 
aquel que innova sin gastos de I+D (Rammer et al., 2009; Barge-Gil et al., 2010; Huang et al., 2011; Hervas-Oliver et al., 2011) y si los innovadores no-I+D son aquellos que además de no tener $\mathrm{I}+\mathrm{D}$ interna no compran $\mathrm{I}+\mathrm{D}$ externa (Som et al., 2010). Aquí los últimos autores a pesar de señalar este problema, difieren de la mayoría de estudios. Creemos en la definición más amplia de innovadores noI+D es la que se debería aplicar en este momento, dada la falta de estudios sobre el tema y que se debería buscar un nombre para las empresas que no realizan $\mathrm{I}+\mathrm{D}$ interna y además no compran I+D externa (¿tal vez "innovadores sin $\mathrm{I}+\mathrm{D}$ absolutos"?).

- La gran mayoría de autores no estudian el sector servicios, solamente Arundel et al. (2008) y Rammer et al. (2009) lo hacen, a pesar de que según Arundel et al. los innovadores no-I+D se dan especialmente en servicios.

- Los estudios españoles sobre el tema están basados en una encuesta (SBSS) que no es una encuesta CIS y presenta problemas de cara a realizar comparaciones internacionales.

- Realizan comparaciones entre las formas de innovación de los sectores high-tech y low-tech (Arundel et al., 2008; Heidenreich, 2009).

- La mayoría de autores estudia solamente variables que presentan valores discretos de $0-1$, si la empresa ha realizado una innovación de producto o proceso o no y no en cambio la importancia de estas (porcentaje sobre ventas de productos nuevos para el mercado por ejemplo). Solamente Arundel et al (2008) y Rammer et al. (2009) estudian los efectos de las innovaciones de alguna forma.

- Solo un estudio trata la capacidad de absorción en firmas sin I+D (Hervas-Oliver et al. 2011).

Básicamente y en resumen, actualmente la literatura científica se encuentra investigando como innovan las empresas sin I+D y además se está replanteando todavía si esta innovación está todavía bien medida en las encuestas CIS. 


\section{6.- PROCESS INNOVATION AND NON R\&D ACTIVITIES: UNFOLDING NEGLECTED INNOVATORS IN SPAIN.}

\section{1.- Introduction.}

The purpose of this study is threefold, and it aims to provide a better understanding of one important output from organizational innovation: process innovation strategy. First, it explores and sheds light on the process innovation phenomenon which, in recent years, has received less attention by the Academia (cfr. Reichstein and Salter, 2006; European Commission, 2008) compared to the emphasis observed in the product innovation strategy, or has been systematically explored in tandem with product innovation (e.g., Escribano et al., 2009) in order to predict innovators. Second, the study addresses an emerging growth of the importance of non R\&D innovators or "neglected" innovators (non R\&D performers who innovate, Arundel et al., 2008, OECD, 2010; Barge-Gil et al., 2011). Third, it also seeks insights to determine the extent to which process innovation adoption is related and is, thus, interdependent (e.g., Pisano, 1997; Damanpour, 2010) of product innovation. The combination of these objectives and the context of low and medium technology country in which the study is set, make this study original, while it also contributes to the existing literature by exploring one of the strategies less researched when studying innovation: process innovation strategy.

Process innovation is defined as the new elements introduced into a firm's production or service operation to manufacture a product or render a service (e.g., Utterback and Abernathy, 1975; Rosenberg, 1982) for the purpose of improving productivity or quality. Following Reichstein and Salter (2006:655), process innovation is related to new capital equipment (Salter, 1960), and to learning-by-doing and learning-by-using (Hollander, 1965; Cabral and Leiblein, 2001). Process innovation activities usually involve both organizational and technological changes (Gopalakrishnan and Damanpour, 1997; Reichstein and Salter, 2006) which are difficult to separate (e.g., Womack et al., 1990), as some scholars claim (e.g., Edquist et al., 2001). Quoting the Oslo Manual (OECD, 2005:55):

"Distinguishing between process and organisational innovations is perhaps the most frequent borderline case for innovation surveys since both types of innovation attempt- 
among other things - to decrease costs through new and more efficient concepts of production, delivery and internal organisation. Many innovations thus contain aspects of both types of innovation. For example, the introduction of new processes may also involve the first use of new organisational methods such as group working. Organisational innovations such as the first introduction of a total quality management system may involve significant improvements in production methods, such as new production logistic systems, to avoid certain types of flaws or new and more efficient information systems based on new software and new ICT equipment."

Our study mainly centers on technological process innovations. To date, most of the literature based on innovation is devoted to the understanding of product innovation (e.g., Turner et al., 2010; Taylor, 2010; Kim and Pennings, 2009; Atuahene-Gima and Ko, 2001; Dougherty, 1992). Studies that focus exclusively on analyzing process innovation in the innovation management literature are scarce (e.g., Sinclair et al., 2000; Reichstein and Salter, 2006). According to the OECD (2009:19), "Survey questions on the effects of process innovation (e.g., cost reductions, greater productivity and flexibility, etc.) are needed in order to gain a more complete view of the effect of innovation on the economy. At present, only the share of new products in turnover is covered". In fact, there is a common tendency to use the process innovation adoption as a dependent variable using a dummy variable to reflect whether or not the firm achieves process innovation, i.e. predicting process innovators (Pacheco-Pires et al., 2008). Then, the problem is that the process innovation performance is rarely covered by existing literature. Conversely, exploring how innovation capability delivers innovation outcomes, and ultimately firm performance, is paramount to manage firm innovation (Crossan and Apaydin, 2010). Our study sheds light on this fact by studying the process innovation adoption and its performance consequences. To the best of our knowledge, most of the papers have used the percentage of sales from new products/services as a performance measure to measure innovation performance (cfr. Laursen and Salter, 2006; Escribano et al., 2009). This is correct as long as the sample is only made of product innovators. Nevertheless, when the purpose of the study consists on measuring process innovation, the sample should be made of process innovators and the performance measure should not be the over-researched percentage of sales due to new products. On the contrary, as Wheelwright and Clark (1992) suggest, process innovation performance cannot be measured by a specific share of turnover, but rather it requires 
process innovation outputs such as labor productivity. In this line, Ettlie and Reza (1992) measured process adoption performance using two categories (process capacity and flexibility) and Pisano (1994) uses lead time. This study is going to measure process innovation adoption and its performance consequences avoiding the product performance measure and thus using proper process performance indicators such as those referred to production, flexibility and costs reduction. Consistently with the previous goal, the study applies a two-step Heckman procedure to validate the sample and avoid selection problems. In addition, our study sheds light on the debate about whether the process differs or is complementary to product innovation. Following Damanpour's (2010) seminal paper, there are two different assumptions; first, the process is considered a distinct phenomenon (Wolfe, 1994; Damanpour and Aravind, 2006); second, it is both complementary and interdependent (Damanpour and Gopalakrishnan, 2001; Pisano, 1997; Abernathy and Utterback, 1978).

Increasing attention has been paid to the role of non R\&D innovation (NESTA, 2007; European Commission, 2008). In this vein, Arundel et al. (2008) pointed out that neglected innovators are not properly policy-supported, even when the change in the growth of annual revenues between $\mathrm{R} \& \mathrm{D}$ and non $\mathrm{R} \& \mathrm{D}$ ("neglected) innovators is similar, and there is no reason for policy bias. In fact when comparing R\&D and non R\&D performers, half of all innovative firms do not perform $R \& D$ and there is no difference in performance, measured by a change in revenues (p.32). Additionally, in the 2008 European Innovation Scoreboard (EIS), developed by the European Union Commission to measure Lisbon Agenda achievements (Celikel-Esser et al., 2008), the methodology has been revised and the new categories (enablers, firm activities and outputs; displaying 7 dimensions and 29 indicators) (see Hollanders and van Cruysen, 2008) focus mainly on the prominent role played by SMEs in Europe. Thus, indicators such as the Non R\&D innovation expenditures ( $\%$ of turnover), among others, have been introduced. In a complementary manner, the OECD (OECD, Measuring Innovation, a New Perspective, 2010) states that: “...firms may introduce new products on the market without engaging in $R \& D$. New indicators reveal that in Australia and Norway the propensity to introduce a new-to-market product innovation is similar whether or not the firm performs $R \& D$. For instance, it has been cited that $52 \%$ of non $R \& D$ performers in Luxemburg introduced new-to-market innovations if compared to just 63\% of in-house R\&D performers" (p.23). Despite all these efforts to reflect 
innovation as a broader nature, the innovation literature mainly focuses on $R \& D$ innovators (e.g., Vega-Jurado et al., 2008; Escribano et al., 2009) which offer important contributions, but have important limitations: restricting innovation activities to just $R \& D$ efforts eliminates firms from the sample, which is innovative without performing R\&D. In fact, $R \& D$ expenditures present rather weak evidence (Raymond and St. Pierre, 2009; Brouwer and Kleinkecht, 1997; Roper and Love, 2002) to explain innovative output. This study offers a solution to this problem: non restricting firms to just R\&D performers (cfr. Mañez et al., 2005), and introducing both R\&D and non $\mathrm{R} \& \mathrm{D}$ efforts (input activities) to control for the drivers required to introduce innovation. Thus, samples are not restricted and the conclusions are more extensive, and not only better reflect the real-life business environment, but avoid bias selectivity.

The work is based at organizational level and contributes to the existing literature by giving its in-depth analysis of process innovation activities by providing empirical evidence of $R \& D$ and non-R\&D strategies along process innovators. Instead of merely predicting process innovators (e.g., Baldwin et al., 2002), or simply understanding complementarities between product and process innovations (Martinez-Ros, 2000), this study is based on an understanding of the drivers which explain the achievement of productivity improvements through cost reductions, flexibility and capacity improvement from process innovation adoption. It is also based on a technologyfollower country (Spain) whose R\&D investment levels are not high. The data to carry out the analysis originates from the Spanish Innovation Survey based on both the Eurostat Community Innovation Survey (CIS) and the Oslo Manual (OECD, 2005). This study is arranged as follows: after this Introduction, there is a chapter devoted to theory and another one to the empirical design. Then, at the end provides the results are described while the final section offers conclusions and discussion.

\section{2.- Theory.}

\subsection{1.- Product and process innovation adoption: different or complementary?}

A body of papers has discussed the product versus process innovation adoption dilemma at the firm level. The first block still follows the model of Utterback and 
Abernathy (1975). Kraft (1990) compared the process and product technology innovations' degrees of innovativeness to find that the process strongly depends on product innovation and that product innovation depends more on market structure. Bayus (1995) concluded that incremental product and process innovations over product life are an interdependence function of product and process improvements. He measured R\&D expenditures in process and product activities through the product life cycle in the automotive industry. Etienne (1981) postulated the need for integrating marketing, process and R\&D when formulating a product strategy. Bhoovaraghavan et al. (1996) insisted on an integrative process and product innovation approach from a customer demand perspective. Klepper (1996) supported Utterback and Abernathy's model by outlining the relevance of process innovation in later product life cycle phases. In the same direction, Stumpfe (2001) confirmed the dependence of manufacturing process innovation on product innovation cycle. Rouvinen (2002) outlined that although interrelated product and process innovation are driven by diverse factors embodying a technology-affected process, disembodied technology affects product innovation. Cabagnols (1999) studied the dynamics of product versus process innovation, and vice versa, by taking into account its continuity and consistency, to find that continuity is higher in the former, and that consistency is similar in both. Martinez-Ros (2000) analyzed a large sample of Spanish firms to find that product and process innovation are complementary and basically depend on the market's and firm's characteristics. In this line, Damanpour and Gopalakrishnan (2001) discovered that product innovation is adopted at a higher rate than process innovation, and that it is more likely for process innovation to follow product innovation than vice versa. Bogers and Lhuillery (2010) studied the role of the firm's openness and established that firms rely more on external than internal knowledge while conducting product versus process innovation. Finally, Reichstein and Salter (2006) analyzed a large sample of UK manufacturing firms, and found that product and process innovation are interdependent. All in all, it seems that product and process innovation adoption are complementary. Therefore, the first hypothesis is as follows:

HYPOTHESIS 1: Product and process innovation adoption is complementary and interdependent. 


\subsection{2.- The organizational internal and external drivers of innovation}

Organizational drivers are often operational using dynamic capabilities (e.g., Teece et al., 1997) view and the resource-based view (RBV, e.g., Barney, 1991), both drawing on evolutionary economics (Nelson and Winter, 1982). Following these perspectives, it is said that the different resource bases among firms provide variation source for innovations. Overall, an organization's propensity to innovate is a type of dynamic capability which improves performance through building up competitive advantages (Helfat et al., 2007). Thus, innovation capabilities reside in managerial levers that enable innovation (Crossan and Apaydin, 2010; Mumford et al., 2002). Usually the organizational capabilities which drive innovation are both internal and external activities or sources of knowledge.

Regarding the former, Hatch and Mowery (1998) attributed the influence of internal firm organizational capabilities to firms' tendency to innovate in process. Murovec and Prodan (2008) and Bogers and Lhuillery (2010) revealed the influence of firms' absorptive capacity (Cohen and Levinthal, 1990) in their process innovation performance. After studying a large sample of Spanish manufacturing firms, LlorcaVivero (2002) distinguished the roles of both process and product innovation on a firm's performance, and demonstrated that process innovation performance has a stable, consistent and permanent effect on the labor productivity growth rate. Huergo and Jaumandreu (2004) and Rochina-Barrachina et al. (2010) empirically confirmed this hypothesis, while Becker and Egger (2008) found that process innovation activities are relevant to secure a firm's market competitive position. For Baer and Frese (2003), process innovation activities need to be accompanied by internal climates which complement the adoption and implementation of such innovations. The RBV stresses that a firm's unique internal resources determine its performance, at least in part. The RBV also establishes a correspondence between a firm's unique set of resources and capabilities and its level of performance. From this internal perspective, innovation stems from better organizational routines and other core functions. Barney (1991) referred to the RBV with a broad definition of resources, such as all types of assets, organizational processes, knowledge capabilities and other potential advantage sources. Tidd (2000) classified internal competences into three categories: (a) organizational competences (managerial systems, skills, etc.), (b) market competences, and (c) technological competences, mainly deriving from in-house R\&D activities. This study 
refers to process innovation and its technological dimension. Regarding the technological capabilities or competences, studies based on process innovation have evidenced that $R \& D$ does not suffice to measure the innovation process. While Mairesse and Mohnen (2005) found a strong relationship between process innovation and R\&D intensity, Rouvinen (2002) observed no relationship between a firm's level of R\&D and process innovation. All in all, most of the literature relating R\&D and process innovation has been made on adoption. Nevertheless, our study focuses on the process innovation performance from process adoption. Thus, our proposition is that a firm's unique stock of internal resources is positively associated with a firm's process innovative performance, but the literature does not provide clear variables to link process adoption and performance. Therefore, the second hypothesis is that which follows:

HYPOTHESIS 2a. A firm's investments on technical capabilities related to $R \& D$ form a unique stock of internal resources positively associated with process innovation performance.

HYPOTHESIS $2 \boldsymbol{b}$. A firm's investments on technical capabilities related to non-R\&D form a unique stock of internal resources positively associated with process innovation performance.

Addressing external sources of knowledge, the learning environment which supports innovation for organizational capabilities also accounts for search strategies developed (Cebon and Newton, 1999) with universities (Atuahene-Gima, 1995), customers (Lee et al., 1996) or suppliers (Bessant, 2003). Nevertheless, the relational view (Dyer and Singh, 1998; Lee et al., 2001; Capaldo, 2007) can expand and reinforce external linkages at the organizational level. The relational view argues that a firm's critical resources go beyond a firm's boundaries, and that interfirm collaborative linkages generate further relational returns (Dyer and Singh, 1998). These strategic assets (Gulati et al., 2000), embedded in their surrounding social context (Gulati, 1998), are claimed to have an impact on innovation by facilitating knowledge sharing and an interactive learning process (Powell et al., 1996; McEvily and Zaheer, 1999; Rowley et al., 2000; Lee et al., 2001), although debate on relational capabilities is still in its very early stages (Capaldo, 2007). External knowledge as a technological opportunity 
improves innovation capacity and can be found in sources such as firm-university linkages, or in relationships with suppliers or customers (e.g., Klevorick et al., 1995; Lee et al., 2001).

Literature on innovation reflects a dramatic increase in firms' systematic use of external networks (Hagedoorn, 2002; Zeng et al., 2010). Interactions and networks are key factors for innovation (Doloreux, 2004). External innovation search sources aim to identify valuable impulses from customers, suppliers, competitors or universities, and from other public research organizations, to orientate innovation efforts (von Hippel, 1988; Katila and Ahuja 2002; Laursen and Salter 2006).

Ettlie and Reza (1992) studied the successful adoption of process innovation and found that suppliers and customers' organizational integration, along with internal capabilities such as design and manufacturing, positively affect the productivity of new manufacturing systems. Specifically for process innovation, the literature confirms some important points about the influence of these external knowledge sources. Von Hippel (1988) suggested that process innovators work closely with external suppliers. Similarly, Freel and Harrison (2006), Rouvinen (2002) and Cabagnols and Le Bas (2002) found a correlation between a firm's tendency to engage in process innovation and its cooperation with suppliers and universities. Similarly, Vonortas and Xue (1997) followed the approach of Bhoovaraghavan and studied customers' influence in a process innovation case. In short, customers, suppliers and university cooperation increased the chances of achieving process innovation, as the literature suggests (Cabagnols, 1999; Bogers and Lhuillery, 2010; Vonortas and Xue, 1997, Bhoovaraghan et al, 1996; Ettlie and Reza, 1992). Therefore, the third hypothesis is as follows:

HYPOTHESIS 3. A firm's search strategy to tap into industry and non industry knowledge sources is positively associated with a firm's process innovative performance.

In addition, if we focus on a firm's organizational complexity, it is claimed that size is a key determining factor for process innovation achievement (Kraft, 1990; Martinez-Ros, 2000; Cohen and Klepper, 1996), although other studies assume that size does not determine innovation (Camison-Zornoza et al., 2004) given the differences in its 
measurement. In this vein, Yin and Zuscovitch (1998) were advocates of the school that attributes a relevant role to firm size, while Damanpour (2010) associated firm size with process innovation predominance and pointed out that as product life cycles tend to shorten, firms will require more skills to develop process innovation on a continuous basis. The overall claim is that large-sized firms can better achieve process innovation because they possess more technical and financial resources, and that all these assets better absorb the costs associated with the innovation process (Chandy and Tellis, 2000; Nord and Tucker, 1987). In line with this, and following Damanpour's (2010) suggestions, the fourth hypothesis is put forward below:

HYPOTHESIS 4: There is a positive relationship between firm size and process innovative performance.

\subsection{3.- Technological capabilities and innovation: the influence of industry on a firm's innovation.}

A number of academics have analyzed process innovation from a differentiated point of view. Bonanno and Haworth (1998) proposed that the firm's decision to pursue either process or product innovation depends on the industry competition regime. Therefore, technological opportunities are also crucial in this debate. Cohen and Levinthal (1990) referred to technological opportunities as the amount of knowledge to be assimilated and exploited: the more there is, the greater the incentive to invest in absortive capacity. In other words, the technological opportunities concept relates to the probability of the resources used to foster innovation generating technological advances (e.g., Dosi et al., 1988; Nelson and Winter, 1982). Indeed, this idea is based on the differences in a firm's innovation across different sectors. This external driver from the original concept has been corroborated in subsequent re-conceptualizations (e.g., Todorova and Durisin, 2007). To date, and following Nieto and Quevedo (2005:3), most of the work done on the stimulus to undertake innovative activities arising from the presence of technological opportunities highlights there is a positive linkage between the technological opportunity level available to a firm and the firm's efforts to innovate (Scherer, 1965; Levin et al., 1985; Jaffe, 1986, 1988, 1989; Geroski, 1990; Klevorick et al., 1995; Nieto and Quevedo, 2005). In order to analyze the industry variations related to the effect of external and internal factors on a firm's innovative performance, firms 
were classified into broad sectoral categories (Arundel et al., 1995; Cesaretto and Mangano, 1992; Souitaris, 2002). Technological opportunities and appropriability conditions (e.g., patents, lead effect or the learning curve) are considered relevant factors that affect the dynamics of market structure and innovation (Winter, 1984; Levin et al. 1985; Lin and Huang 2008). Specifically when addressing process innovation, Pacheco-Pires et al. (2008), and Bogers (2009), along with Escribano et al. (2009) and Mothe and Nguyen-Thi (2010), all suggested for both process and product that sector heterogeneity needs to be considered. Thus, these effects are captured in this hypothesis to address the industry type to which firms belong. Thus, the sixth hypothesis is that which follows:

HYPOTHESIS 5. The level of technological opportunities and appropriability conditions embedded in a firm's industry impact on a firm's process innovation performance.

\section{3.- Model and variables}

\subsection{1.- The sample.}

The data to be used for the analysis originate from the Spanish Innovation Survey (the Technology Innovation Survey is its official name), administered by EUROSTAT and based on the core Eurostat Community Innovation Survey (CIS) of innovation, as basically described in the Oslo Manual (2005). The original dataset contained around 33,000 firms, with innovators and non innovators across all the available industries. We selected those firms which recorded being service o manufacturing industries $(32,553)$, and after the ones which recorded having adopted process innovation $(10,755)$. Therefore, this study works only with process innovators for the OLS regression. Nevertheless, the sample is controlled with two important steps. First, one aspect of the sample is that the study avoids biases as it employs a proper selection of variables, which influences the sample. Thus, the sample presents firms with R\&D and non R\&D expenditures without biasing the study toward those firms which perform only R\&D activities. Second, the study runs a two-step Heckman procedure in order to avoid selection. Thus, the technological innovators (either product or process adopters) which adopted process innovation are treated using a Probit model in order to obtain the 
inverse Mills' ratio (lambda variable) in order to control coefficients in the OLS regression, as explained below. Overall, CIS questionnaire data have been used in a large number of studies (e.g., Tether, 2002; Reichstein and Salter, 2006), especially for Spanish cases (e.g., Vega-Jurado et al., 2008; Escribano et al., 2009).

It is necessary to stress that the sample contains manufacturing and service firms. This work splits the sample in manufacturing and service process innovators. Nevertheless, following Gallouj and Savona (2009), the way of measuring manufacturing and services innovation is similar and their differences blur. We cite this work:

"An integrative or synthesizing approach, which, taking as a starting point the trend towards convergence between manufactured goods and services, attempts to develop a common conceptual framework, able to account for an enlarged view of innovation which is applicable to any tangible or intangible product... (pp.155); ...we believe that such a synthesis is becoming more necessary as the boundaries between goods and services become more blurred. On the one hand, the immaterial components of goods are becoming important, while on the other the standardization of certain service activities is becoming easier and cheaper. This process of convergence is a symptom of the advanced economies moving from service economies to economies based on service relationships or new modes of coordination amongst agents" (p.162)

\subsection{2.- Dependent variable for process performance.}

A majority of the empirical studies conducted to study process innovation included as a dichotomic dependent variable whether the firm pointed out process innovation (1) or otherwise (0). Thus, these papers conducted logit or probit analysis to tackle the studied phenomena. In this case, the main problem lies on the fact that innovation process adoption is itself the activity and not the result that the company achieves through process innovation. In other words, when measuring product innovation most of the studies use the percentage of new (to the firm or the market) products sold on the firm sales or the radical versus incremental change in the company's portfolio of products. Then, why not to look for a similar measure to capture the benefits or achievements obtained through process innovation? This work solves this problem through selecting an appropriate variable to capture the effects of conducting process innovation. Ettlie 
and Reza (1992) proposed a construct with seven performance measures of process innovation into two categories:

- Contribution to manufacturing process capacity: system performance measures; scrap and rework rates, cycle time achieved, utilization, and throughput time reduction.

- Flexibility: changeover time, the number of part families scheduled on a system, and reduction in service calls to customers.

Even that, the majority of authors considers process innovation a search for lower costs (Pisano, 1997; Bonano and Haworth, 1998; Yin and Zuscovitch, 1998; Martinez-Ros, 2000; Baldwin, Hanel and Sabourin, 2001; Llorca-Vivero 2002; Cabagnol and Le Bas, 2002). Other authors (Reichstein and Salter, 2006) incorporate quality or flexibility (Simonetti, Archibugi, Evangelista, 1995) to the main objectives of process innovations.

The empirical research of Quadros, Furtado, Bernardes and Franco (2001) concludes that cost reduction is the second most important firms' objective for innovation after quality improvement (based in a sample of Brazilian firms of Saõ Paulo innovation survey). Furthermore, Murovec and Prodan (2008) found, through a factor analysis, that reduced labor cost per unit/transaction produced, reduced materials and energy per unit/transaction were the second and the third more important components for process innovations.

Consequently, we propose a new dependent variable which takes 4 values, depending on whether the firm states that they reduces costs as a consequence of organizational innovation ( 0 , not answered or not; 1 , limited; 2 , intermediate, 3 high). It is worth noting that in the Spanish CIS 2006, the question referring to output is as follows: "Please, indicate the impact or effect that your innovation activities have had on your enterprise in the period 2004-2006". It is perceived because the output is measured on a scale from 0 to 3, where 0 is equal to none and 3 the highest impact ( 1 means low and 2 means medium). The impact or effect from technological innovation adoption addresses three different groups of aspects: perceived production performance (labor cost reduction, production flexibility, improving capacity or the reduction of materials), perceived market performance (wider range of products or services, increasing the market share or obtaining higher quality products or services) and perceived environmental performance. This work focuses on the innovative output from process 
innovation strategies. We therefore focus primarily on production performance from process innovation adoption, although certain robustness tests are carried out in order to ensure the appropriate selection of the sample and the outputs, as explained below ${ }^{1}$.

\subsection{3.- Independent Variables.}

Table 2. Explanatory variables and their measurement and codification.

\begin{tabular}{|c|c|}
\hline Hypothesis & Variables and coding \\
\hline H1. & $\begin{array}{l}\text { INNPRODUCT. Whether the firm introduces, or not, a new or significantly improved good } \\
\text { or service into the market. } \\
0-1 \text { discrete }\end{array}$ \\
\hline $\begin{array}{l}\text { H2a: } \\
\text { H2b. }\end{array}$ & $\begin{array}{l}\text { R\&D-based: } \\
\text { RDINTEXPENDITURE: Internal research and development expenditures divided by sales } \\
\text { and multiplied per } 100 \\
0 \text {, if the firm spent nothing on R\&D in the year } 2006 \\
1 \text {, if R\&D spent/sales in the year } 2006 \text { is more than } 0 \text { and less than } 1 \% \\
2 \text {, if R\&D spent/sales in the year } 2006 \text { is greater or equal to } 1 \% \text { and less than } 5 \% \text {. } \\
\text { 3, if R\&D spent/sales in the year } 2006 \text { is greater or equal to } 5 \% \text { and less than } 10 \% \text {. } \\
\text { 4, if R\&D spent/sales in the year } 2006 \text { is greater or equal to } 10 \% \text {. } \\
\text { RDADQ: Expenditures on acquisition of external knowledge for innovation divided by sales } \\
\text { and multiplied per } 100 \\
0 \text {, if RDADQ equal to } 0 \text { in the year } 2006 \\
\text { 1, if RDADQ is more than } 0 \text { and less than } 1 \% \\
2 \text {, if RDADQ is greater or equal to } 1 \% \text { and less than } 5 \% \text {. } \\
3 \text {, if RDADQ is greater or equal to } 5 \% \text { and less than } 10 \% \text {. } \\
4 \text {, if RDADQ is greater or equal to } 10 \% \text {. } \\
\text { Non-R\&D based: } \\
\text { BUYEQUIP: Expenditures on acquisition of advanced machinery, equipment or computer } \\
\text { hardware or software to produce new or significantly improved products (goods or services) } \\
\text { or processes divided by sales and multiplied per } 100 \\
0 \text {, if BUYEQUIP equal to } 0 \text { in the year } 2006 \\
1 \text {, if BUYEQUIP is more than } 0 \text { and less than } 1 \% \\
2 \text {, if BUYEQUIP is greater or equal to } 1 \% \text { and less than } 5 \% \text {. } \\
3 \text {, if BUYEQUIP is greater or equal to } 5 \% \text { and less than } 10 \% \text {. } \\
4 \text {, if BUYEQUIP is greater or equal to } 10 \% \text {. } \\
\text { BUYKNOWnonRD: Expenditures on acquisition of other external knowledge for innovation } \\
\text { (not included in R\&D) divided by sales } \\
0 \text {, if BUYKNOWnonRD equal to } 0 \text { in the year } 2006 \\
1 \text {, if BUYKNOWnonRD is more than } 0 \text { and less than } 1 \% \\
2 \text {, if BUYKNOWnonRD is greater or equal to } 1 \% \text { and less than } 5 \% \text {. } \\
3 \text {, if BUYKNOWnonRD is greater or equal to } 5 \% \text { and less than } 10 \% \text {. } \\
4 \text {, if BUYKNOWnonRD is greater or equal to } 10 \% \text {. }\end{array}$ \\
\hline
\end{tabular}

\footnotetext{
${ }^{1}$ The same applies for the UK questionnaire (CIS3 and CIS4). Nevertheless, since 2008, the Spanish questionnaire modified and changed the variable in order to capture the idea of objectives (similar to "innovation goals", related to technological trajectories in the sense of Dosi, (1982) or factors for the decision to innovate. The same approach is observed in the CIS for the UK questionnaire: CIS5 and CIS6 versions mentioned factors or objectives, while the previous third and fourth version mentioned effects. Therefore, we used 2006 data and observed that innovation performance of innovation activities are treated coherently as output from the innovation strategy. Finally, it is important to notice that, although the CIS is standardized for Europe, each country has some peculiarities.
} 


\begin{tabular}{|c|c|}
\hline & $\begin{array}{l}\text { TRAINING: expenditures on internal or external training for employees, with the aim of } \\
\text { developing new products or processes or significantly improved ones divided by sales } \\
0 \text {, if TRAINING equal to } 0 \text { in the year } 2006 \\
1 \text {, if TRAINING is more than } 0 \text { and less than } 1 \% \\
2 \text {, if TRAINING is greater or equal to } 1 \% \text { and less than } 5 \% \text {. } \\
3 \text {, if TRAINING is greater or equal to } 5 \% \text { and less than } 10 \% \text {. } \\
4 \text {, if TRAINING is greater or equal to } 10 \% \text {. } \\
\text { INTROINN: Expenditures on introduction of innovations in the market divided by sales } \\
0 \text {, if INTROINN equal to } 0 \text { in the year } 2006 \\
1 \text {, if INTROINN is more than } 0 \text { and less than } 1 \% \\
2 \text {, if INTROINN is greater or equal to } 1 \% \text { and less than } 5 \% \text {. } \\
3 \text {, if INTROINN is greater or equal to } 5 \% \text { and less than } 10 \% \text {. } \\
4 \text {, if INTROINN is greater or equal to } 10 \% \text {. } \\
\text { DESIGNPROCESS: processes and preparations for making new products or processes o } \\
\text { improved significantly, } \\
0 \text {, if DESIGN equal to } 0 \text { in the year } 2006 \\
1 \text {, if DESIGN is more than } 0 \text { and less than } 1 \% \\
2 \text {, if DESIGN is greater or equal to } 1 \% \text { and less than } 5 \% \text {. } \\
3 \text {, if DESIGN is greater or equal to } 5 \% \text { and less than } 10 \% \text {. } \\
4 \text {, if DESIGN is greater or equal to } 10 \% \text {. }\end{array}$ \\
\hline H3: & 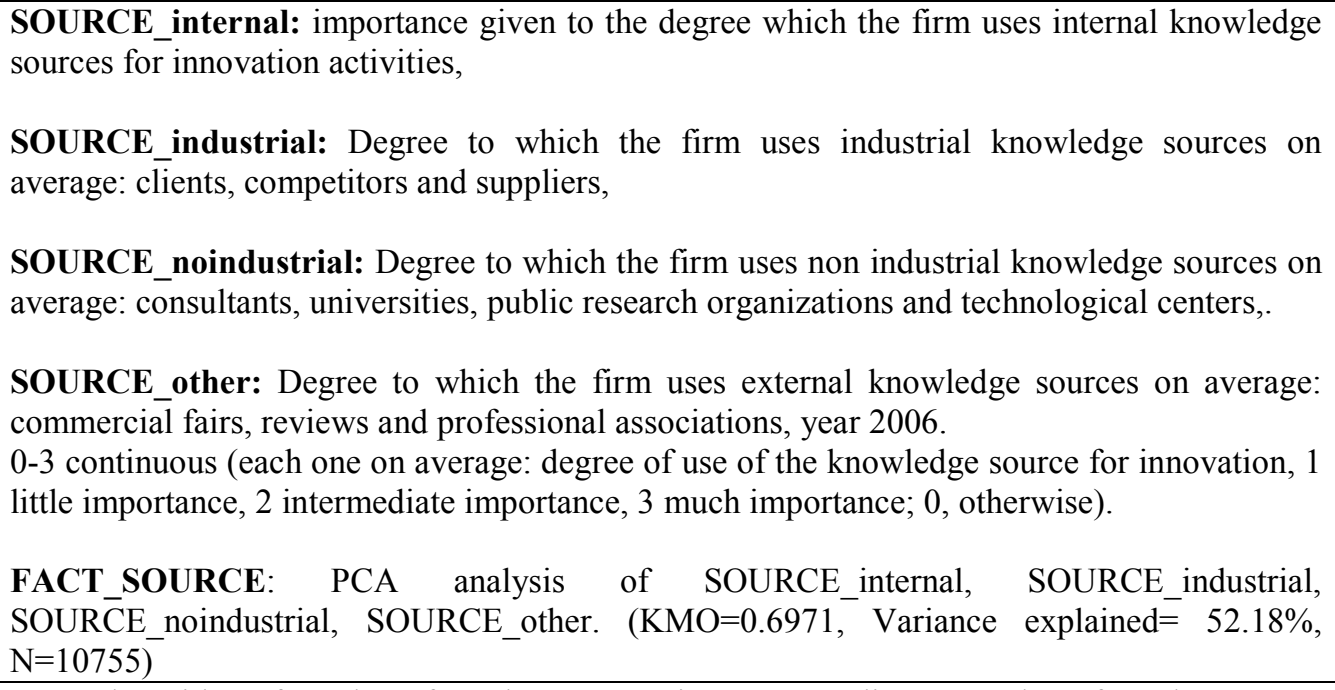 \\
\hline H4: & SIZE: logarithm of number of employees, Continuous according to number of employees. \\
\hline H5: & $\begin{array}{l}\text { MANUFACTURING: dummy variable representing if the firm belongs to the manufacturing } \\
\text { sector. } \\
0 \text {-1 discrete. } \\
\text { SECTORTECH: a dummy variable representing the firm's technological sector. } \\
0 \text { if the firm is a low technological service, } 1 \text { low technological manufacturing, } 2 \text { medium } \\
\text { technological manufacturing, } 3 \text { high technological manufacturing and } 4 \text { high technological } \\
\text { service. } \\
\text { MANUFACTURINGSECTOR: a dummy variable representing the firm's technological } \\
\text { sector. } \\
0 \text { if the firm is a low technological manufacturing, } 1 \text { medium technological manufacturing, } 2 \\
\text { high technological manufacturing. } \\
\text { SERVICESECTOR: a dummy variable representing the firm's technological sector. } \\
0 \text { if the firm is a low technological service, } 1 \text { high technological service. } \\
\text { SECTOR: industrial dummies representing the sectors in Table } 3 \text {. }\end{array}$ \\
\hline
\end{tabular}


In Table 2 the variables addressing $\mathrm{H} 2$ and $\mathrm{H} 3$ were set to investigate the organizational capabilities from internal and external knowledge sources in technological innovation activities. These variables were separated into three groups. $R \& D$ and non-R\&D activities, addressing internal knowledge sources (H2); the external knowledge (H1). $R \& D$ activities reflect a firm's $R \& D$ expenditures, $R \& D$ personnel and external $R \& D$ acquisition $^{2}$. These three variables capture the technical dimension of a firm's process innovation. To specifically address technological process innovation activities, this study also used the BUYEQUIP variable, which reflects acquisition of advanced machinery, equipment and computer hardware or software to produce new or significantly improved products and processes. This variable is important due to the fact that process innovation has been mainly defined as the introduction of new technologies and equipment (see Section 1). Then, the classic variables addressing internally and externally generated R\&D (variables, RDINTEXPENDITURE, and RDADQ, respectively). Considering the work of Gopalakrishan and Damanpour (1997), innovation can be initiated in an organization by either generation or adoption. The former is measured in RDINTEXPENDITURE, while the latter is addressed in BUYEQUIP and RDADQ. Other technological non-R\&D based variables used are BUYKNOWnonRD (expenditures on acquisition of other external knowledge for innovation), TRAINING (expenditures on internal or external training for employees), INTROINN (expenditures on introduction of innovations in the market), DESIGNPROCESS (processes and preparations for making new products or processes o improved significantly).

Regarding the third hypothesis, organizational capabilities based on external knowledge sources or a firm's search strategies, are captured broadly through a range of different information and knowledge sources (i.e., suppliers, customers, consultants, competitors, universities and other research centers, etc). This is done by aggregating the 4-point Likert scale and obtaining four variables that acts as a 4-point Likert scale for four types of sources (internal, industrial, non-industrial and others), where $0=$ no use of external knowledge sources, $3=$ the highest level of use of external knowledge sources; all the available information sources are in use. In this respect, questions asked respondents

\footnotetext{
${ }^{2}$ In order to maintain the sample, the variables without innovative activities were recorded as zero.
} 
whether their firm uses the following as an external provider of knowledge and information: (i) client firms, (ii) supplier firms and (iii) main competitor firms, (iv) consultants and the scientific sources (v). The resulting variables are named SOURCE_internal, SOURCE_industrial, SOURCE_noindustrial, SOURCE_other. They provide different specifications in which the individual variables and the aggregated ones are all used. This is done because the use of the all original variables from the same construct may cause multicolinearity problems in the model, as Hair et al. (2007) suggested and because not all of them have the same implications.

In relation to $\mathrm{H} 1$, the INNPRODUCT variable is included to control for a firm's innovative outputs that differ from process, i.e., firms that adopted product and/or service innovation. Thus, this variable reflects the interdependent or complementary character expected between product innovation and process innovation. Then, the SIZE variable (H4) is measured through the logarithm of the annual average of full-time employees. In order to address H5, a set of dummies was used, which takes the value of 1 in accordance with the firm's sector classification following the OECD classification. Thus, firms in the manufacturing sector are coded as: MANUFLOWTECH, low-tech firms; MANUFMEDTECH, medium-tech firms; MANUFHIGHTECH, high-tech firms; in the service sector: SERVHIGHTECH, high-tech firms and SERVLOWTECH, medium- and low-tech firms. In addition, the study introduces sector classification in order to control for industry differences (SECTOR variable), including the 58 2-digit NACE-93 industry classification as dummies, ranging from the 14 to 74 2-digit NACE93 codes (59 industries) (see table 4). Lastly, interaction effects were also obtained by multiplying the main variables addressing internal knowledge sources with the SOURCE_industrial variable because is the one with a major coefficient and FACT_SOURCE (pca analysis of the variables SOURCE_internal, SOURCE_industrial, SOURCE_nonindustrial, and SOURCE_other).

This study takes the process innovation output as a mediator rather than a dependent variable, as Crossan and Apaydin (2010) suggested. Our dependent variable is based on a factor analysis (principal component analysis, PCA) which reduced (59.54\% of the variance explained, $\mathrm{KMO}=0.7068, \mathrm{p}<0.01$ ) four output variables to one dimension, which address the effects obtained by a firm by introducing process innovation activities (measuring reduced labor costs per unit output; improved flexibility of production or service provision; increased production capability or service provision). 
The four original variables were ordered responses, which fell in a scale from 0 to 3 , where 3 represents the highest ranking and 0 the lowest (absence) of cost reduction, flexibility, capacity or materials and energy reduction. The dependent variable used in the analysis came about from the factor scores obtained with the PCA. So the dependent variable reflects a multi-item construct based on improvements in costs (labor and energy/inputs), flexibility and capacity from the process innovation activities introduced by the firm. Ordinary least squares (OLS) were used to run the model. Perceived Production Performance, from PCA application to the samples (three PCA, one for each sample: total, manufacturing, services), resulting from the following variables measuring the effects of the innovation activities on:

Higher production flexibility

Higher production capacity

- Lower labor cost per unit

Fewer materials and energy per produced unit

See table 2 for a full description of the variables.

\subsection{4.- Model specification.}

Results could suffer from additional selection bias when selecting process innovators. Heckman's two-stage analysis (Heckman, 1979) is run in order to tackle these selection problems. The two steps are divided into a first stage in which, after a Probit analysis (first model), an inverse Mills' ratio is obtained for use in a second step (OLS), as an additional independent variable, so as to explain the variation in innovation performance of the selected sample of process innovators. One inverse Mills ratio is obtained from the Probit, including it as an additional independent variable in order to run the OLS (see Heckman, 1979; Mothe and Thi, 2010).

\section{$\underline{\text { First model (Probit) }}$}

Process innovation $\mathrm{i}=$ Const + organizational capabilities [Internally originated and adopted knowledge resources (through $R \& D$ and non $R \& D$ activities)] + SIZE + INNPRODUCT + EXPORT + SECTORS + $i$. 
Second model (OLS):

Productivity improvement (cost reduction, flexibility, capacity, PCA)i $=$ Const $+\beta 1$ Internal non R\&D resources [INNMANUF, INNLOGIST, INNSUPPORT; BUYEQUIP ]$i+\beta 2$ Internal resources $R \& D[R \& D E X P E N D I T U R E S ; B U Y R D] i+\beta 3$ External knowledge sources [customers + suppliers + competitors + universities + consultants + reviews...] $i+\beta 4$ Product innovation [INNOPRODUCT] + Size $($ SIZE) $i+\beta 5$ sector [SECTOR, OECD classification] $+\varepsilon i$.

In the first model we decide to take into account the SOURCE variables and the internally originated and adopted knowledge resources even they affect only for the innovative companies, because they are independent of the introduction of the process innovation. In other words, they are exclusive for innovators but not only for process innovators.

Following this model, the work reports six different specifications in three different subsamples: the complete sample, that addressing only manufacturing firms and another for services.

\section{4.- Results.}

Table 3. Descriptive statistics: mean, standard deviation and correlation matrix.

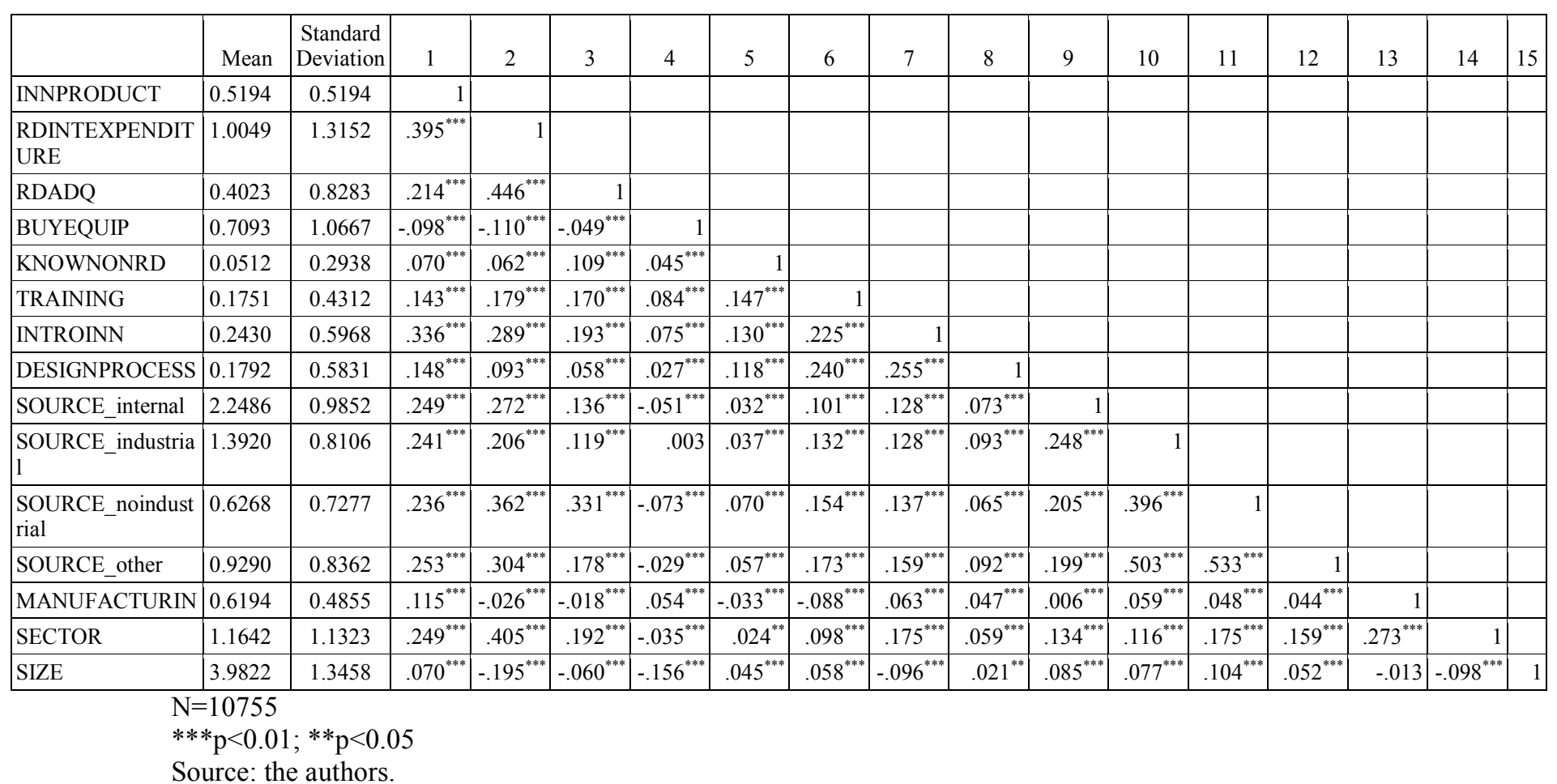


The sample contains 6662 manufacturing and 4093 service firms.

The sample contains 6662 manufacturing and 4093 service firms which are process innovators. Table 3 shows the main descriptive statistics of the 10755 firms which recorded having introduced process innovation ${ }^{3}$. One relevant remark is that 9355 firms are SMEs (87\% of the sample), i.e., firms with less than 250 employees, and that 5759 (53.54\%) did not carry out R\&D activities, whereas 4996 (46.45\%) did. Moreover, only 2028 firms (18.85\%) answered yes to the question about there being a formal R\&D department. In general, it is quite interesting to observe how innovative (process) firms in Spain are mainly non-R\&D innovators. Other descriptive statistics ${ }^{4}$ reveal for knowledge sources that: internal sources are used by $90.72 \%$ of the firms included in the sample, that $81.23 \%$ used suppliers, $68.00 \%$ reported using customer's knowledge sources, $61.61 \%$ used competitors, $49.21 \%$ employed consultants, and only $35.89 \%$ resorted to scientific knowledge sources (universities). These results are in line with other studies which highlighted that suppliers are the key source of external knowledge (Reichstein and Salter, 2006). Table 4 shows the sample's sector composition; of the whole sample, $70.64 \%$ are low-tech or medium tech manufacturing or services companies, while only $29.35 \%$ are firms in high-tech industries. Industries were coded following the OECD classification, as previously mentioned. Once again, these data also confirm Spain's aforementioned role of a technology-follower country.

\footnotetext{
${ }^{3}$ Potential collinearity is tested and the results clearly show (VIF and condition number) there is no problem of collinearity in the regressions. In addition, OLS regressions are run by making a collinearity correction, and the standard coefficients errors do not change significantly. We have also avoided collinearity problems by introducing just one variable into each specification in each construct. Most collinearity problems are based on the fact that scholars introduce more than one variable from each construct into the equation. Each construct is measured with variables or dimensions of theoretical validity (they measure what is supposed to be measured, following theory) and reliability (applying a PCA Analysis or Cronbach's Alpha techniques; see Hair et al., 2007). Following the same procedure carried out by Tomlinson (2010:767), and based on Campbell and Fiske (1959) and Hair et al. (2007), the paper addresses the possible methodological issues raised from using perception scale-based measures. Besides the nomological validity, which considers the theoretical justification by using particular scale items and assesses the extent to which the constructs, the paper also tackles the convergent validity, where the items used in a specific construct should be related or share a high proportion of variance in common, using Cronbach's alpha indicators which basically exceeded the level of 0.70 in each construct. Then, the work also used discriminant validity. This is the extent to which a construct is distinct, i.e., unique, and it captures phenomena that other measures do not. Hair et al. (2007) suggest testing for this by comparing the variance-extracted estimates for any two constructs with the square of the correlation estimate between these two constructs. We used PCA to obtain evidence that discriminant validity was present. All these results are available upon request.
}

\footnotetext{
${ }^{4}$ Available upon request
} 
Table 4. The study sample's sector composition.

\begin{tabular}{|c|c|c|}
\hline Industries & No. of firms & $\%$ \\
\hline Low and medium technology service sectors & 3305 & $30.73 \%$ \\
\hline $\begin{array}{l}\text { Sale, maintenance and repair of motor vehicles and motorcycles, retail of motor } \\
\text { vehicle fuel }\end{array}$ & 206 & $1.92 \%$ \\
\hline Wholesale trade and commission trade, except motor vehicles and motorcycles & 730 & $6.79 \%$ \\
\hline $\begin{array}{l}\text { Retail trade, except motor vehicles and motorcycles, repair of personal and household } \\
\text { goods }\end{array}$ & 0 & $0.00 \%$ \\
\hline Hospitality & 146 & $1.36 \%$ \\
\hline Transport & 180 & $1.67 \%$ \\
\hline Travel agencies & 140 & $1.30 \%$ \\
\hline Finance and insurance & 256 & $2.38 \%$ \\
\hline Real estate & 103 & $0.96 \%$ \\
\hline $\begin{array}{l}\text { Renting of machinery and equipment without operators and of personal and household } \\
\text { goods }\end{array}$ & 50 & $0.46 \%$ \\
\hline Other business activities & 919 & $8.54 \%$ \\
\hline Education & 36 & $0.33 \%$ \\
\hline Health and social work, social service & 289 & $2.68 \%$ \\
\hline Sanitation and similar activities & 64 & $0.60 \%$ \\
\hline Associated activities; recreational, cultural, sports; and other service activities & 39 & $0.36 \%$ \\
\hline Leisure, cultural and sports activities & 131 & $1.22 \%$ \\
\hline Diverse personal services activities & 17 & $0.16 \%$ \\
\hline Low-technology manufacturing sectors & 4442 & $41.30 \%$ \\
\hline Manufacture of food products, beverages and tobacco & 938 & $8.72 \%$ \\
\hline Manufacture of textiles, apparel, furs, leather and footwear & 420 & $3.91 \%$ \\
\hline $\begin{array}{l}\text { Manufacture of wood and wood products, pulp, paper and paper products; publishing } \\
\text { and printing }\end{array}$ & 653 & $6.07 \%$ \\
\hline Manufacture of coke, refined petroleum products and nuclear fuel & 7 & $0.07 \%$ \\
\hline Manufacture of rubber and plastic products & 402 & $3.74 \%$ \\
\hline Manufacture of other non metallic mineral products & 449 & $4.17 \%$ \\
\hline Manufacture of basic metals & 203 & $1.89 \%$ \\
\hline Manufacture of fabricated metal products, except machinery and equipment & 828 & $7.70 \%$ \\
\hline Manufacture of furniture and similar products & 398 & $3.70 \%$ \\
\hline Scrap metal and other waste & 35 & $0.33 \%$ \\
\hline Production and distribution of electricity, gas, steam and heat water & 49 & $0.46 \%$ \\
\hline Collection, purification and water distribution. & 60 & $0.56 \%$ \\
\hline Medium-technology manufacturing sectors & 1733 & $16.11 \%$ \\
\hline Chemical industry, except pharmaceutics & 523 & $4.86 \%$ \\
\hline Machinery and mechanical equipment & 652 & $6.06 \%$ \\
\hline
\end{tabular}




\begin{tabular}{|c|c|c|}
\hline Machinery and electrical devices & 242 & $2.25 \%$ \\
\hline Automotive industry & 236 & $2.19 \%$ \\
\hline Manufacture of transport equipment, except vehicles & 80 & $0.74 \%$ \\
\hline High-technology manufacturing sectors & 487 & $4.53 \%$ \\
\hline Pharmaceutics industry & 143 & $1.33 \%$ \\
\hline Office machinery and computer equipment & 22 & $0.20 \%$ \\
\hline Electronic components, radio, TV and communication devices & 124 & $1.15 \%$ \\
\hline Medical, precision, optical and watchmaking & 169 & $1.57 \%$ \\
\hline Aircraft and spacecraft & 29 & $0.27 \%$ \\
\hline High-technology services & 788 & $7.33 \%$ \\
\hline Post and telecommunication & 80 & $0.74 \%$ \\
\hline Computer services & 522 & $4.85 \%$ \\
\hline Research and development services & 186 & $1.73 \%$ \\
\hline Total & 10755 & $100.00 \%$ \\
\hline
\end{tabular}

Source: the authors. 
Table 5. Results from the models in the general sample (manufacturing and services).

\begin{tabular}{|c|c|c|c|c|c|c|c|c|}
\hline & $\begin{array}{l}\text { Probability to innovate } \\
\text { in process Model } 1\end{array}$ & $\begin{array}{l}\text { Innovative } \\
\text { performance Model } 2\end{array}$ & $\begin{array}{l}\text { Innovative performance } \\
\text { Model } 3\end{array}$ & $\begin{array}{l}\text { Innovative performance } \\
\text { Model } 4\end{array}$ & $\begin{array}{l}\text { Probability to innovate } \\
\text { in process Model } 5\end{array}$ & $\begin{array}{l}\text { Innovative performance } \\
\text { Model } 6\end{array}$ & $\begin{array}{l}\text { Probability to innovate } \\
\text { in process Model } 7\end{array}$ & $\begin{array}{l}\text { Innovative } \\
\text { performance } \\
\text { Model } 8\end{array}$ \\
\hline Constant & $-2.2390 * * *$ & & & & $-2.0986^{* * *}$ & & $-2.1641 * * *$ & \\
\hline INNPRODUCT & \begin{tabular}{|l|l|}
0.0128 \\
\end{tabular} & 0.0018 & \begin{tabular}{|l|}
0.0018 \\
\end{tabular} & 0.0018 & 0.0406 & 0.0173 & 0.0291 & 0.0039 \\
\hline RDINTEXPENDITURE & $-0.1389 * * *$ & $\begin{array}{l}-0.0143 \\
\end{array}$ & \begin{tabular}{|l|}
-0.0144 \\
\end{tabular} & -0.0144 & $-0.1399 * * *$ & -0.0202 & $-0.1015^{* * *}$ & 0.0069 \\
\hline RDADQ & $0.0310^{* *}$ & -0.0045 & \begin{tabular}{|l|l|}
-0.0047 \\
\end{tabular} & -0.0046 & $0.0294 * *$ & -0.0056 & $0.0301 * *$ & -0.0073 \\
\hline BUYEQUIP & $0.6461 * * *$ & $0.1020 * * *$ & $0.1018 * * *$ & $0.1019 * * *$ & $0.6508^{* * *}$ & $0.1004 * * *$ & $0.6415^{* * *}$ & $0.0965^{* * *}$ \\
\hline KNOWNONRD & 0.0069 & -0.0074 & \begin{tabular}{|l|}
-0.0074 \\
\end{tabular} & -0.0074 & 0.0028 & -0.0102 & 0.0104 & -0.0069 \\
\hline TRAINING & $0.1195^{* * * *}$ & 0.0103 & 0.0104 & 0.0104 & $0.0975 * * *$ & -0.0013 & $0.1285^{* * *}$ & $0.0114 * * *$ \\
\hline INTROINN & $-0.0569 * * *$ & -0.0063 & -0.0062 & -0.0062 & $-0.0619 * * *$ & -0.0100 & $-0.0529 * * *$ & $-0.0036^{* * *}$ \\
\hline DESIGNPROCESS & 0.0239 & 0.0149 & 0.00149 & 0.0149 & 0.0339 & $0.0210^{* *}$ & 0.0249 & 0.0146 \\
\hline SOURCE_internal & $0.5332 * * *$ & $0.1620 * * *$ & $0.1619 * * *$ & $0.1620 * * *$ & $0.5364 * * *$ & $0.1510 * * *$ & $0.5306^{* * *}$ & $0.1589 * * *$ \\
\hline SOURCE_industrial & $0.4278^{* * *}$ & $0.2589^{* * *}$ & $0.2589^{* * *}$ & $0.2589^{* * *}$ & $0.4368^{* * *}$ & $0.2562^{* * *}$ & $0.4314 * * *$ & $0.2530^{* * *}$ \\
\hline SOURCE_noindustrial & \begin{tabular}{|l|}
-0.0098 \\
\end{tabular} & 0.0143 & 0.0144 & 0.0143 & -0.0048 & 0.0200 & -0.0157 & 0.0171 \\
\hline SOURCE_other & $0.0993 * * *$ & $0.1570 * * *$ & $0.1570 * * *$ & $0.1570 * * *$ & $0.0999 * * *$ & $0.1568 * * *$ & $0.0985 * * *$ & $0.1606^{* * *}$ \\
\hline EXPORT & -0.0002 & & & & 0.0012 & & 0.0002 & \\
\hline MANUFACTURING & $0.1946^{* * *}$ & $0.0987 * * *$ & $0.0986^{* * *}$ & $0.0986^{* * *}$ & & & & \\
\hline SECTORTECH & & & & & $-0.0337 * * *$ & 0.0017 & & \\
\hline SECTOR & & & & & & & Non significant & Non significant \\
\hline SIZE & $0.1362 * * *$ & $0.0334 * * *$ & $0.0450 * * *$ & $0.0450 * * *$ & $0.1282 * * *$ & $0.0385 * * *$ & $0.1362 * * *$ & $0.0435 * * *$ \\
\hline Inverse mills ${ }^{5}$ & & \begin{tabular}{|l|}
0.0780 \\
\end{tabular} & 0.0365 & 0.0365 & & 0.0198 & & 0.0708 \\
\hline BUYEQUIPx & & & 0.0039 & & & & & \\
\hline BUYEQUIPxFACT_SOURCE & & & & 0.0025 & & & & \\
\hline Log likelihood & -10942.657 & & & & -10983.588 & & -10859.156 & \\
\hline Pseudo R2 & 0.4702 & & & & 0.4682 & & 0.4742 & \\
\hline R2 adjusted & & 0.1962 & 0.1961 & 0.1961 & & 0.1875 & & 0.2006 \\
\hline $\mathrm{N}$ & 32553 & 10755 & 10755 & 10755 & 32553 & 10755 & 32553 & 10755 \\
\hline
\end{tabular}

$\mathrm{N}=32553$ firms of all sectors. $\mathrm{N}=10755$ firms which innovate in technical processes and/or products

Dependent variable. A PCA factor score of cost reduction, flexibility improvement and capacity upgraded $(\mathrm{KMO}=0.7068, \mathrm{Variance}$ explained $=59.54 \%$, $\mathrm{N}=10755)$

$* * * \mathrm{p}<0.01 ; * * \mathrm{p}<0.05$

Source: the authors.

${ }^{5}$ The inverse Mill's ratio is entered here as an independent variable in correct possible sample selection, it is calculated from the Probit and used in the OLS models. 
In each table (5, 6 and 7) there are two types of methods. First, probit regressions to control for selection problems when the decision to innovate is endogenous, that is, the firms decide whether innovate or not in process and thus are part of the sample. Probit techniques are the first step of the Heckman procedures to control for selection problems. Second, in each table there are OLS (ordinary least squares) to specifically answer the stated hypothesis, while applying the second step of the Heckman procedures. In all the OLS the Inverse Mills ratio is showed in order to correct the coefficients when selection problems are evidenced. When the Inverse Mills ratio or lambda is significant $(\mathrm{p}<0.05)$, then the presence of its coefficient corrects the rest of the coefficients in the OLS. When the lambda is not significant, the coefficient has not any role in correcting the rest of them. The probit regression show a pseudo R2 of 0.4702 for model 1 (table 5 ) and the biggest significant coefficients corresponds to the BUYEQUIP variable (acquisition of embodied knowledge; 0.64, $\mathrm{p}<0.01$ ), then the use of sources (SOURCE variable) of information ( 0.5332 for internal, 0.4278 for industrial sources), after those the most important are being a manufacturing firm, size and training of employees for innovation, all of them for the probability of innovate in process. The internal expenditures in research and development seems have a negative and significant coefficient indicating that the effort in R\&D probably is focused more in other types of innovation (new products) and process is more a innovation not based in R\&D but in other activities.

According to Table 5, which contains the OLS results for the whole sample of innovative firms (N $=10755)$, the various specifications representing the model, as explained above, offer a fit of $\mathrm{R}^{2}$ adjusted from 0.1962 in Model 2 to 0.2006 in Model 6. The results in Table 5, corresponding to Model 2, indicate that the buy of equipment, the use of internal, industrial and other sources (coefficients, $0.1020,0.1620,0.2589$ and 0.1570 respectively, all of which are significant at $\mathrm{p}<0.01$ ) are important drivers to explain productivity gains (in costs, flexibility and capacity).

Following model 2 in table 5, belonging to a manufacturing sector also increases the gains in productivity (coefficient 0.0987 significant at $\mathrm{p}<0.01$ ), and also the size (number of employees) of the company helps in some way (coefficient 0.0334 significant at $p<0.01$ ). In the model 4 we observe that belonging to a higher technological sector (SECTORTECH variable, $-0.0337, \mathrm{p}<0.01$ ) is negative for having increases in the effects of process innovation, in other terms if the firm is a low manufacturing or service firm will obtain more productivity gains of process innovations reflected in the perceived production performance. All in all, the use of external knowledge sources, the SOURCE_industrial variable (clients, competitors and suppliers) and the SOURCE_others (commercial fairs, reviews and professional associations), is significant and increases the chances of a firm being able to improve its productivity through process innovation 
activities (coefficients 0.2589 and 0.1570 respectively and significant at $\mathrm{p}<0.01$ ). In other words, it is not merely an in-house or internally-focus process, but it also requires some strategic openness. In addition, this study also separates the different types of sources, and the supply chain comes over as being important, but universities are not; nonetheless, source suppliers are the most important ${ }^{6}$ according to the strength of their coefficient. Model 2 shows how R\&D activities of any kind (R\&D EXPENDITURES, or BUYRD) do not improve a firm's chances of improving its productivity through process innovation activities; i.e., R\&D efforts are not proper drivers to explain increased productivity achieved by process innovation activities. However, $\mathrm{R}^{2}$ adjusted does not increase in any point. These are very interesting results as most studies in the literature review have used only $R \& D$ activities as key internal determining factors to understand process innovation, as mentioned earlier.

Next if we look at the results of Model 2, we note that control variable SIZE, measured as the logarithm of number of employees, is important; i.e., firm's size confers betters chances of improving productivity through process innovation activities. Thus, both SMEs and large-sized firms have not the same propensity to achieve productivity gains through process innovation investments. Industry differences (the SECTOR variable in dummies) in Model 6 is non significant effect $(-0.033, \mathrm{p}<0.01)$;

Models 1 to 6 (table 5) contain the INNPRODUCT variable to control for those firms recording product innovation (to address the first hypothesis). The non significant coefficient for INNPRODUCT (Model 1; 0.0128, p >0.05; model 2, $0.0018 \mathrm{p}>0.05$ ) is not significant and cannot help us to explain if the technical innovation outcome from its innovative investments presents a positive relationship with productivity gains, achieved through process innovation activities if compared to the firms that only achieved process innovation outcome. Put differently, all models in table 5 show that the introduction of new products is not a driver to explain the adoption of process innovation (from the probit results) and, similarly, the introduction of new products do not yield any return on production performance (in better costs, capacity or flexibility). Therefore, explaining process innovation adoption and production-process performance does not require the simultaneous introduction of new products. In addition, the marketing activities (INTROINN variable) are not significant in any model. This is consistent with the idea that process innovation

\footnotetext{
${ }^{6}$ Different types of sources are shown to avoid multi-collinearity. The separate effects of the SOURCE variable are: Internal $0.146^{* * *}$, Suppliers $0.151^{* * *}$, Clients $0.062^{* * *}$, Competitors $0.095^{* * *}$, Consultants $0.052^{* * *}$, Universities $-0.013^{* * *}$, Technological centers $0.033^{* *}$, conferences $0.108^{* * *}$, reviews $0.0526^{* * *}$. Public centers and associations are not significant; ${ }^{* *} p<0.05,{ }^{* * *} p<0.01$.
} 
does not require the "entrance" to the market and its related marketing activities as the product innovation could demand. Similarly, the rest of technological non-R\&D activities (TRAINING or DESIGNPROCESS variables) show no significant values (except for TRAINING in the probits and the model 6 and DESIGNPROCESS in the model 4, coefficient $0.0210, p<0.05$ ). Only in model 4 the inverse Mills ratio is significant $(0.0198, \mathrm{p}<0.05)$ and corrects the rest of coefficients.

In model 6, similar results are observed. All in all, the drivers of production-process performance in the process innovators sample is made up of the acquisition of embodied knowledge (BUYEQUIP variable, 0.0965, $\mathrm{p}<0.01$ ), training activities to improve the firm's skills (TRAINING variable, $0.0114, \mathrm{p}<0.01$ ), the use of sources of knowledge (SOURCE variables), the size of the firms (SIZE variable) and the use of training (TRAINING variable) activities to support innovation. In short, and addressing the results from the OLS models, the outcomes indicate that the expenditures in (embodied knowledge) equipment, machinery, software or hardware together with the use of internal and external non-scientific knowledge sources, increase a firm's chances of obtaining higher productivity levels through reducing costs, and improving flexibility and capacity in process innovation activities. Neither R\&D efforts nor external (extra-mural) R\&D increase or alter the chances a firm has to reduce costs through process innovation adoption. Also being a firm that belongs to the manufacturing sector (MANUFACTURING variable) and the size of the company matters in a positive way. Nor industry differences are obtained. All in all, the process innovation adoption and its performance consequences are mainly explained by weak internal capabilities and a high dependence on external sources of knowledge (mainly from the industry and from the acquisition of embodied knowledge). In addition, the less technology-intensive industries are the ones which host those non-R\&D process innovators. 
Table 6. Results from the models in the manufacturing firms sample.

\begin{tabular}{|c|c|c|c|c|c|c|c|c|}
\hline & $\begin{array}{l}\text { Probability to innovate } \\
\text { in process Model } 9\end{array}$ & $\begin{array}{l}\text { Innovative performance } \\
\text { Model } 10\end{array}$ & $\begin{array}{l}\text { Innovative performance } \\
\text { Model } 11\end{array}$ & $\begin{array}{l}\text { Innovative } \\
\text { performance Model } 12\end{array}$ & $\begin{array}{l}\text { Probability to innovate } \\
\text { in process Model } 13\end{array}$ & $\begin{array}{l}\text { Innovative } \\
\text { performance Model } 14\end{array}$ & $\begin{array}{l}\text { Probability to innovate } \\
\text { in process Model } 15\end{array}$ & $\begin{array}{l}\text { Innovative performance } \\
\text { Model } 16\end{array}$ \\
\hline Constant & $-2.1375 * * *$ & & & & $-2.097 * * *$ & & $-2.1023 * * *$ & \\
\hline INNPRODUCT & $0.0699 * *$ & -0.0060 & -0.0060 & -0.0060 & $0.0822 * *$ & -0.0044 & $0.0881 * * *$ & -0.0029 \\
\hline RDINTEXPENDITURE & $-0.0884 * * *$ & -0.0094 & \begin{tabular}{|l|}
-0.0094 \\
\end{tabular} & -0.0094 & $-0.0569^{* * *}$ & 0.0011 & $-0.0536^{* * *}$ & 0.0033 \\
\hline RDADQ & 0.0208 & -0.0043 & \begin{tabular}{|l|l|}
-0.0047 \\
\end{tabular} & -0.0046 & 0.02309 & -0.0029 & 0.0181 & -0.0063 \\
\hline BUYEQUIP & $0.6379 * * *$ & $0.1098^{* * *}$ & $0.1095 * * *$ & $0.1096^{* * *}$ & $0.6336^{* * *}$ & $0.1050^{* * *}$ & $0.6314 * * *$ & $0.1003 * * *$ \\
\hline KNOWNONRD & 0.0210 & -0.0059 & -0.0058 & -0.0058 & 0.0372 & -0.0048 & 0.0293 & -0.0039 \\
\hline TRAINING & $0.1066^{* *}$ & 0.0165 & 0.0166 & 0.0166 & $0.1265^{* *}$ & 0.0183 & $0.1197 * *$ & 0.0154 \\
\hline INTROINN & -0.0495 & -0.0173 & -0.0172 & -0.0172 & \begin{tabular}{|l|l|}
-0.0448 \\
\end{tabular} & -0.0164 & -0.0385 & -0.0145 \\
\hline DESIGNPROCESS & 0.0339 & 0.0133 & 0.0133 & 0.0133 & 0.0326 & 0.0130 & 0.0366 & 0.0139 \\
\hline SOURCE_internal & $0.4880^{* * *}$ & $0.1629 * * *$ & $0.1628^{* * * *}$ & $0.1629 * * *$ & $0.4902 * * *$ & $0.1604 * * *$ & $0.4861 * * *$ & $0.1597 * * *$ \\
\hline SOURCE_industrial & $0.3767^{* * *}$ & $0.2510^{* * *}$ & $0.2510^{* * *}$ & $0.2510^{* * *}$ & $0.3825^{* * *}$ & $0.2497 * * *$ & $0.3906^{* * * *}$ & $0.2471^{* * *}$ \\
\hline SOURCE_noindustrial & 0.0144 & 0.0049 & 0.0049 & 0.0049 & 0.0121 & 0.0044 & 0.0027 & 0.0074 \\
\hline SOURCE_other & $0.1310^{* * *}$ & $0.1654^{* * *}$ & $0.1654 * * *$ & $0.1654 * * *$ & $0.1273 * * *$ & $0.1641^{* * *}$ & $0.1252 * * *$ & $0.1677 * * *$ \\
\hline EXPORT & -0.0007 & & & & 0.00003 & & 0.0001 & \\
\hline MANUFSECTOR & & & & & $-0.1945 * * *$ & $-0.0346^{* * *}$ & & \\
\hline SECTOR & & & & & & & Two significants $^{7}$ & Non significant \\
\hline SIZE & $0.1689^{* * *}$ & $0.0462 * * *$ & $0.0464^{* * *}$ & $0.0463 * * *$ & $0.1676^{* * *}$ & $0.0456^{* * *}$ & $0.1628 * * *$ & $0.0435 * * *$ \\
\hline Inverse mills & & 0.0246 & 0.0244 & 0.0245 & & 0.0189 & & -0.0007 \\
\hline $\begin{array}{l}\text { BUYEQUIPx } \\
\text { SOURCE industrial }\end{array}$ & & & 0.0050 & & & & & \\
\hline BUYEQUIPXFACT_SOURCE & & & & 0.0031 & & & & \\
\hline Log likelihood & -6100.8134 & & & & -6063.3684 & & -6044.3006 & \\
\hline Pseudo R2 & 0.4548 & & & & 0.4581 & & 0.4598 & \\
\hline $\mathrm{R} 2$ adjusted & & 0.1820 & 0.1819 & 0.1819 & & 0.1827 & & 0.1870 \\
\hline $\mathrm{N}$ & 16616 & 6662 & 6662 & 6662 & 16616 & 6662 & 16616 & 6662 \\
\hline
\end{tabular}

$\mathrm{N}=16,616$ manufacturing firms. $\mathrm{N}=6,662$ Manufacturing firms which innovate in processes

Dependent variable. A PCA factor score of cost reduction, flexibility improvement and capacity upgraded $(\mathrm{KMO}=0.723$, Variance explained $=61.29)$

$* * * \mathrm{p}<0.01 ; * * \mathrm{p}<0.05$ Source: the authors.

${ }^{7}$ The two significant are: Electronic components, radio, TV and communications devices; Medical, precision, optical and watch making. 
Table 7. Results from the models in the service firms sample.

\begin{tabular}{|c|c|c|c|c|c|c|c|c|}
\hline & $\begin{array}{l}\text { Probability to innovate } \\
\text { in process Model } 17\end{array}$ & $\begin{array}{l}\text { Innovative } \\
\text { performance Model } 18\end{array}$ & $\begin{array}{l}\text { Innovate performance } \\
\text { Model } 19\end{array}$ & $\begin{array}{l}\text { Innovate performance } \\
\text { Model } 20\end{array}$ & $\begin{array}{l}\text { Probability to innovate } \\
\text { in process Model } 21\end{array}$ & $\begin{array}{l}\text { Innovate performance } \\
\text { Model } 22\end{array}$ & $\begin{array}{l}\text { Probability to innovate } \\
\text { in process Model } 23\end{array}$ & $\begin{array}{l}\text { Innovate performance } \\
\text { Model } 24\end{array}$ \\
\hline Constant & $-2.1462 * * *$ & & & & $-2.1382 * * *$ & & -2.1029 & \\
\hline INNPRODUCT & -0.0734 & 0.0153 & 0.0153 & 0.0145 & -0.0632 & 0.0176 & -0.0627 & 0.01568 \\
\hline RDINTEXPENDITURE & $-0.1846^{* * *}$ & -0.0183 & -0.0182 & $\mid-0.0174$ & $-0.1684 * * *$ & 0.0012 & $-0.1543 * * *$ & 0.0181 \\
\hline $\begin{array}{l}\text { RDADQ } \\
\end{array}$ & $0.0373 * *$ & -0.0080 & -0.0077 & -0.0077 & $0.0363 * *$ & -0.0090 & $0.0371^{* *}$ & -0.0123 \\
\hline BUYEQUIP & $0.6600^{* * * *}$ & $0.0742 * * *$ & $0.0744 * * *$ & $0.0742 * * *$ & $0.6559 * * *$ & $0.0728 * * *$ & $0.6578^{* * *}$ & $0.0728^{* * *}$ \\
\hline KNOWNONRD & -0.0058 & $\mid-0.0101$ & -0.0093 & -0.0090 & -0.0058 & -0.0104 & -0.0052 & -0.0114 \\
\hline TRAINING & $0.1229 * * *$ & 0.0015 & 0.0013 & 0.0013 & $0.1261 * * *$ & 0.0030 & $0.1270^{* * *}$ & 0.0054 \\
\hline INTROINN & -0.0547 & 0.0108 & 0.0106 & 0.0111 & -0.0516 & 0.0137 & $-0.0554 * *$ & 0.0131 \\
\hline DESIGNPROCESS & 0.0042 & 0.0187 & 0.0186 & 0.0181 & 0.0032 & 0.0174 & 0.0019 & 0.0172 \\
\hline SOURCE_internal & $0.5842 * * *$ & $0.1464 * * *$ & $0.1465^{* * *}$ & $0.1466^{* * *}$ & $0.5852 * * *$ & $0.1470 * * *$ & $0.5822 * * *$ & $0.1415^{* * *}$ \\
\hline SOURCE_industrial & $0.4850^{* * *}$ & $0.2654 * * *$ & $0.2653^{* * *}$ & $0.2666^{* * *}$ & $0.4862 * * *$ & $0.2667^{* * *}$ & $0.4787^{* * *}$ & $0.2545^{* * *}$ \\
\hline SOURCE_noindustrial & -0.0340 & 0.0322 & 0.0319 & 0.0300 & -0.0365 & 0.0301 & -0.0333 & 0.0356 \\
\hline SOURCE_other & $0.0645 * *$ & $0.1418^{* * *}$ & $0.1421^{* * *}$ & $0.1415^{* * *}$ & $0.0642 * *$ & $0.1417 * * *$ & $0.0675^{* *}$ & $0.1468^{* * *}$ \\
\hline EXPORT & -0.0004 & & & & -0.0004 & & -0.0004 & \\
\hline SERVICESECTOR & & & & & $-0.1380 * * *$ & $-0.0419 * *$ & & \\
\hline SECTOR & & & & & & & Non significant & Non significant \\
\hline SIZE & $0.1061 * * *$ & $0.0418^{* *}$ & $0.0417 * *$ & $0.0420 * *$ & $0.1055^{* * *}$ & $0.0411^{* *}$ & $0.1105^{* * *}$ & $0.0420 * *$ \\
\hline Inverse mills & & 0.0268 & 0.0268 & 0.0253 & & 0.0250 & & \\
\hline $\begin{array}{l}\text { BUYEQUIPx } \\
\text { SOURCE_industrial }\end{array}$ & & & -0.0040 & & & & & \\
\hline $\begin{array}{l}\text { BUYEQUIPXFACT_SOURC } \\
\text { E }\end{array}$ & & & & -0.0041 & & & & \\
\hline Log likelihood & -4803.9559 & & & & -4798.8541 & & -4781.5114 & \\
\hline Pseudo R2 & 0.4709 & & & & 0.4715 & & 0.4734 & \\
\hline $\mathrm{R} 2$ adjusted & & 0.1864 & 0.1862 & 0.1868 & & 0.1880 & & \begin{tabular}{|l|l|}
0.1899 \\
\end{tabular} \\
\hline $\mathrm{N}$ & 15937 & 4093 & 4093 & 4093 & 15937 & 4093 & 15937 & 4093 \\
\hline
\end{tabular}

$\mathrm{N}=4,093$ Service firms which innovate in processes

Dependent variable. A PCA factor score of cost reduction, flexibility improvement and capacity upgraded $(\mathrm{KMO}=0.704$, Variance explained $=53.39)$

$* * * \mathrm{p}<0.01 ; * * \mathrm{p}<0.05$

Source: the authors. 
Table 6 presents the results for the manufacturing firms in the sample, while Table 7 provides the results for the service industries firms. Table 6 (manufacturing firms) offers the results for the sub-sample with 6662 manufacturing firms, which is similar to the general results presented in Table 5. In fact, the $\mathrm{R}^{2}$ adjusted values range around 0.18 for the models 8,10 and 12 . Therefore, for the decision of innovate in process the results provide three distinct insights: first, the INNPRODUCT variable is positive and statistically significant (0.0669 in Model 7 and similar values in Model 9; $<0.01$ ), this means that innovate in product for manufacturing has to do with the decision of innovating in process, which differs to the general case (whole sample, i.e., manufacturing and services) in which product innovation is not a driver to predict process innovators; second, the expenditures in acquisition of external R\&D (RDADQ), is not significant, third the expenditures in the marketing activities (INTROINN) are not significant. While TRAINING remains significant in the decision to adopt process innovation (models 7, 9 and 11, table 6). Nevertheless, the stated results in table 6 are interpreted from the probit results, that is, the decision to adopt process innovation (for Heckman procedures), whereas the performance consequences from process innovation adoption (in the models 8,10 and 12 showing the OLS specifications) present a different outcome. In fact, the introduction of new products and the R\&D (intra and extra mural) investments do not yield any return in the production-process performance. Again, the results from the manufacturing sample (table 6) are similar to the general ones showed in table 5, that is, the process innovation pattern is depicted by weak internal resources and high dependence on external knowledge (embodied one and sources of information, mainly from the industry) and positively moderated by the size of the firms, together with a better perceived performance of process effects in the less-intensive tech industries (MANUFSECTOR, $-0.0346, \mathrm{p}<0.01$, Model 10). In this case industry heterogeneity is also found (SECTOR variable).

The table 7 shows the results for the service companies. For the OLS regressions in services the results show similar results to manufacturing (table 6), with the similar tendency to identify productivity gains in the case of the less-intensive service industries (SERVICESECTOR variable, $-0.0419, \mathrm{p}<0.01$, Model 16). So for services, again, low technological sector companies have better perceived performance of process effects, they have bigger gains of productivity or production performance. Therefore, it can be stated that both manufacturing and service perform similarly, and can be assessed with analogous inputs or variables, which confirms Gallouj and Savona's (2009) and Forsman and Rantanen's (2011) more recent results.

Basically, process innovation adoption in low- and medium-tech contexts is mainly explained by non $R \& D$ efforts, these being in-house weak internal technological innovation capabilities (referring to the lack of R\&D expenditures), and by high dependencies on the external provision of inputs, i.e. external knowledge. Size matters and performing other technical innovative 
activities relating to product development doesn't help to increase returns from process innovation.

Table 8. Main results of the research.

\begin{tabular}{|c|c|}
\hline \multicolumn{2}{|c|}{ OBJECTIVES } \\
\hline \multicolumn{2}{|r|}{$\begin{array}{l}\text { - First, the study attempts to understand drivers to explain production process innovation } \\
\text { performance in process innovators. Process innovation is under-researched and the } \\
\text { majority of innovation studies focus on product and its related outcome measured as \% } \\
\text { of sale from new products/services. Therefore, unfolding the process innovation } \\
\text { strategy, its antecedents and performance consequences is capital. }\end{array}$} \\
\hline \multicolumn{2}{|r|}{ The study controls for: } \\
\hline \multicolumn{2}{|r|}{$\begin{array}{l}\text {-The non-R\&D based activities to innovate. Importantly, the sample contains } R \& D \text { and } \\
\text { non-R\&D performers. }\end{array}$} \\
\hline \multicolumn{2}{|r|}{$\begin{array}{l}\text {-The complementary or interdependence role between product innovation and process } \\
\text { innovation adoption. }\end{array}$} \\
\hline \multicolumn{2}{|c|}{ RESULTS } \\
\hline \multicolumn{2}{|r|}{$\begin{array}{l}\text { - R\&D activities do not explain the drivers of process innovation strategy, nor its } \\
\text { performance consequences. }\end{array}$} \\
\hline \multicolumn{2}{|r|}{$\begin{array}{l}\text { - Non R\&D activities are important as drivers to explain innovative outcome. Thus, the } \\
\text { results strongly support the view that non R\&D activities are crucial to understand the } \\
\text { innovation process of any firm, at least in this low-medium tech context. }\end{array}$} \\
\hline \multicolumn{2}{|r|}{$\begin{array}{l}\text { - There is no evidence that support that product and process innovation are } \\
\text { complementary (firms which achieve product innovation have more chances of } \\
\text { obtaining productivity gains through process innovation activities). }\end{array}$} \\
\hline \multicolumn{2}{|r|}{$\begin{array}{l}\text { - Size is a determining factor; thus, productivity improvement through the production } \\
\text { performance from process innovation adoption is key. }\end{array}$} \\
\hline \multicolumn{2}{|r|}{$\begin{array}{l}\text { - The level of technological opportunities, measured by the sector classification, is } \\
\text { important and influences the process innovation performance. }\end{array}$} \\
\hline & $\begin{array}{l}\text { Overall, we can summarize that process innovation strategy and its performance in low- } \\
\text { and medium-tech contexts are mainly explained by non R\&D efforts (buy of } \\
\text { equipment), with high dependencies on the use of the (external) industrial sources of } \\
\text { information; size is also important (more size more process innovation performance). } \\
\text { Thus, it can be said that the process innovators, in general, are too dependent of } \\
\text { external knowledge due to the lack of internal resources. }\end{array}$ \\
\hline
\end{tabular}

Source: the authors.

Table 8 contains a summary of the main results obtained with the analysis. 


\section{5.- Conclusions.}

The study's goal consists of exploring and depicting the process innovation strategy and its performance consequences, which academia has paid less attention to. It especially sheds light on the almost neglected measurement of the process innovation performance, rather than the over-researched product innovation one. The study, following that key objective presents two interesting elements of novelty. First, the work addresses an emerging topic: the importance of non R\&D innovators or "neglected" innovators, together with the non-R\&D technological activities to explain innovation. Second, it seeks insights to determine the extent to which process and product innovation activities are related or interdependent. The combination of these elements with the objective makes this study original and contributing to the literature on innovation. Instead of merely predicting process innovators or simply understanding complementarities between product and process innovations, this study is based on understanding the drivers that explain: the process innovation strategy and its performance consequences through productivity improvements from cost reductions, flexibility and capacity improvement from process innovation adoption, controlling for R\&D and non R\&D activities. Based on 10,755 firms from the Spanish CIS data-based innovation survey for 2006, the main conclusions are as follow. Table 8 contains a summary of the main conclusions of this study. In general, hypothesis 1 and $2 \mathrm{a}$ are rejected and the rest are confirmed. This means that product innovation adoption and R\&D activities do not improve production-process performance. In addition, the size, the access to external sources of knowledge and the non-R\&D resources are related positively to the process adoption performance, while the industry differences also matter.

Table 9. Main conclusions of the work.

\begin{tabular}{|l|l|l|l|}
\hline Hypothesis & Expected & $\begin{array}{l}\text { Result (sign; hypothesis } \\
\text { and meaning) }\end{array}$ & Conclusions \\
\hline $\begin{array}{l}\text { H1: Product and process } \\
\text { innovations are } \\
\text { complementary and } \\
\text { interdependent. }\end{array}$ & Positive & Rejected & $\begin{array}{l}\text { There is no evidence that supports } \\
\text { that product and process innovation } \\
\text { adoption are complementary or } \\
\text { interdependent (rejecting } \\
\text { Damanpour, 2010; Reichstein and } \\
\text { Salter, 2006). In addition, the } \\
\text { introduction of product innovations } \\
\text { does not act as spur for process }\end{array}$ \\
\hline
\end{tabular}




\begin{tabular}{|c|c|c|c|}
\hline & & & innovation performance. \\
\hline 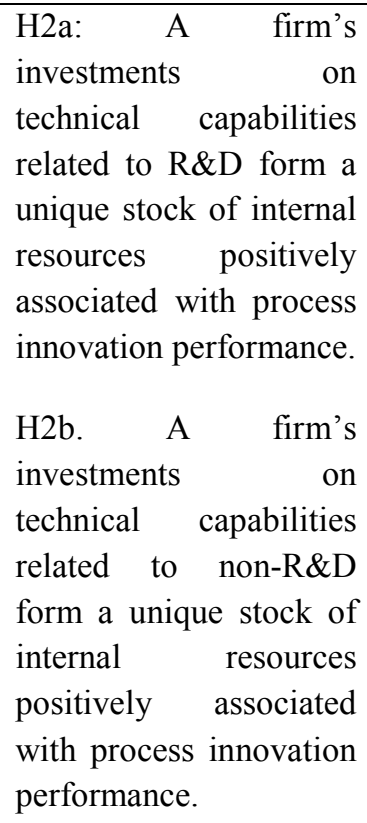 & Positive & $\begin{array}{l}\text { Hypothesis 2a is rejected, } \\
\text { as R\&D activities do not } \\
\text { increase production- } \\
\text { process innovation } \\
\text { performance. } \\
\text { Hypothesis } 2 \mathrm{~b} \text { is accepted } \\
\text { as there are non-R\&D } \\
\text { based activities (Training) } \\
\text { or technology acquisition } \\
\text { which explains } \\
\text { production-process } \\
\text { performance. }\end{array}$ & $\begin{array}{l}\text { A firm's R\&D activities are not } \\
\text { main drivers of process innovation } \\
\text { performance, rejecting Reichstein } \\
\text { and Salter (2006). Nevertheless, due } \\
\text { to the scarcity of works measuring } \\
\text { process performance, most of the } \\
\text { literature for innovation and R\&D is } \\
\text { due to the study of product } \\
\text { innovation. } \\
\text { In addition, the non-R\&D activities } \\
\text { explaining performance is } \\
\text { confirmed (Barge-Gil et al., 2011) } \\
\text { but again only for product } \\
\text { innovation. }\end{array}$ \\
\hline $\begin{array}{l}\text { H3: A firm's search } \\
\text { strategy to tap into } \\
\text { industry and non- } \\
\text { industry knowledge } \\
\text { sources is positively } \\
\text { associated with a firm's } \\
\text { process innovation } \\
\text { performance. }\end{array}$ & Positive & $\begin{array}{l}\text { Positive; hypothesis } \\
\text { accepted. A firm's search } \\
\text { strategy to tap into } \\
\text { external knowledge is } \\
\text { related with a firm's } \\
\text { production-process } \\
\text { performance }\end{array}$ & $\begin{array}{l}\text { A firm's search strategy to tap into } \\
\text { external knowledge is related to } \\
\text { achieving productivity improvement } \\
\text { through process innovation } \\
\text { activities. This confirms (Von } \\
\text { Hippel, 1988; Freel and Harrison, } \\
\text { 2006) literature, although most of it } \\
\text { is based again in product innovation. }\end{array}$ \\
\hline $\begin{array}{l}\text { H4: There is a positive } \\
\text { relationship between } \\
\text { firm size and process } \\
\text { innovative performance. }\end{array}$ & Positive & $\begin{array}{l}\text { Significant, positive, } \\
\text { hypothesis accepted. Size } \\
\text { affects the process } \\
\text { innovation outcome. }\end{array}$ & $\begin{array}{l}\text { Large- and small-sized firms differ } \\
\text { in terms of the process innovation } \\
\text { activities outcome. This scenario } \\
\text { confirms Damanpour (2010); } \\
\text { Reichstein and Salter (2006), among } \\
\text { others. }\end{array}$ \\
\hline $\begin{array}{l}\text { H5: The level of } \\
\text { technological } \\
\text { opportunities and } \\
\text { appropriability } \\
\text { conditions embedded in } \\
\text { a firm's industry } \\
\text { positively relates to a } \\
\text { firm's innovative } \\
\text { performance process }\end{array}$ & Positive & $\begin{array}{l}\text { Negative: hypothesis } \\
\text { rejected. Technological } \\
\text { opportunities influence the } \\
\text { achievement of } \\
\text { productivity } \\
\text { improvements through } \\
\text { process innovation } \\
\text { activities in a negative or } \\
\text { indirect relationship for } \\
\text { manufacturing and service } \\
\text { firms. }\end{array}$ & $\begin{array}{l}\text { The technological opportunities } \\
\text { measured by the sector classification } \\
\text { influences the process innovation } \\
\text { outcome inversely; i.e. presents an } \\
\text { indirect relationship. This } \\
\text { contradicts innovation papers in } \\
\text { general, Escribano et al. (2009); } \\
\text { Nieto and Quevedo, 2005; } \\
\text { Klevorick et al., 1995; Geroski, } \\
\text { 1990), and process innovation paper } \\
\text { in particular, Pacheco-Pires et al. } \\
\text { (2008), and Bogers (2009), }\end{array}$ \\
\hline
\end{tabular}

Source: the authors. 
First, the study has found evidence about the process innovation patterns, its drivers and performance consequences. All in all, it can be said that the process innovation strategy and its production performance is mainly explained, not by R\&D efforts, by a highly intensive process of dependence on external sources of knowledge, including the formal and pecuniary acquisition of embodied technology and informal sources of knowledge sourced mainly from the industry. In short, the results indicate that introducing acquired embodied knowledge, together with the use of external and internal (to the firm) sources of knowledge, increase a firm's overall production performance from its process innovation strategies, reducing costs and materials per produced unit and improving flexibility and capacity in process/production activities. This high dependence on external sources indicates clearly the weak stock of in-house capabilities of those process innovators and, consequently, the low absorptive capacity expected.

Second, neither intramural R\&D efforts, nor extramural ones improve production performance. Traditional R\&D indicators do not capture the full impact of innovation activities on a firm's performance, as previous works also evidenced (e.g., Hall et al., 2009; Rammer et al., 2009; Arundel et al., 2008). In this line, process innovation performance is explained by using non $\mathrm{R} \& \mathrm{D}$ variables. In the innovation management literature, different scholars have worked without considering R\&D intensity (Bougrain and Haudeville, 2002; Freel, 2003, 2007; Muscio, 2007) and by confirming how the innovation process in low- and medium-tech contexts can be captured using non R\&D activities (e.g., Santamaria et al., 2009). Put differently, the variables upon which the study is based are beyond those of intramural $\mathrm{R} \& \mathrm{D}$, and the results show that "doing, using and interacting" (Jensen et al., 2007) is a way for firms to rely on the processes and experience-based know-how in downstream activities (marketing, design, etc.) (OECD, 2005). This mainly refers to the low- and medium-tech sectors that use “...incremental problem solving and experimentation [which] take[s] place on the shop floor and are closely associated with production beyond well-defined $R \& D$ programmes..." (Albaladejo and Romijn, 2000:4-5). Thus, innovation is not an exclusive technological effort, but a strategic, market-driven perspective (e.g., Bessant and Tidd, 2007; Terziovski, 2010). Therefore, in contradiction to a large stream of research (e.g., Reichstein and Salter, 2006; Mairesse and Mohnen, 2005; Baldwin et al., 2002), R\&D efforts are not important to explain process performance, confirming the study of Rouvinen (2002). In this particular case of a technology-follower country, this 
result was expected provided the percentage of firms in the sample did not present conscious R\&D efforts (in whatever form, R\&D expenditures RDEXPENDITURES or outsourcing R\&D, BUYRD).

Third, production-process performance is not optimized when process innovators also introduce new products. The predicted complementary or interdependent role of process and product innovation has not been confirmed, in spite of an important stream of literature (e.g., Damanpour, 2010; Reichstein and Salter, 2006; Pisano, 1997). Nevertheless, and in contrast with the above ideas, this study does not only measure the product-process interdependence, but the effect of introducing new product innovation on the process performance, which is not a frequent debate in the academia. As observed, the results completely contradict conventional wisdom on product innovation strategies, which are by far the most widely propagated in the literature. Put differently, firms do not need to adopt product innovation in order to improve its production performance, that is, process innovation and its performance consequences seems detached from the introduction of new product innovations. Thus, the production performance is not increased when the company also introduces new products into the market, as is consistently showed in the INNOPRODUCT insignificant coefficients in the OLS models. Therefore, to some extent it can be pointed out the no interdependence between both technological innovations, at least when referring to the production (process) performance. Therefore, the results confirm Kraft (1990) which suggests that introducing process innovation does not act as a spur to product innovation.

Fourth, external knowledge sources are positive and significant, and in line with other studies (Escribano et al., 2009; Barge-Gil, 2010; Vega-Jurado et al., 2008; Reichstein and Salter, 2006; Rouvinen, 2002; Cabagnols and Le Bas, 2002; Von Hippel, 1988). Specifically, when different external knowledge sources are presented in the various specifications, suppliers are seen as the most important knowledge source. This result contradicts Bogers (2009) and Von Hippel's (1998) customer focus and confirms the view that suppliers are key drivers for process innovators because they are key knowledge sources when addressing technological process innovation (e.g., Reichstein and Salter, 2006), while customers are a key source when using non technological activities in process innovation activities (e.g., Bogers, 2009). More research is needed since the majority of studies on innovation nor address the non R\&D activities. In addition, most results are biased owing to sample selection; i.e., most papers employ 
$\mathrm{R} \& \mathrm{D}$ as the main inducement, which actually restricts the sample and the results may not be properly set, for example, in a different non R\&D sample. Size has been found to be an important driver to explain inducements to process innovation in the literature (Damanpour, 2010; Reichstein and Salter, 2006; Keppler, 1996, Cohen and Klepper, 1996; Nord and Tucker, 1987) and to predict a positive relationship. Despite the contradicting predictions, our study reports that size is important to improve productionprocess performance. This idea implies that large-sized firms have the better chances of increasing productivity through cost reductions, flexibility and capacity improvement as process innovators, a fact which can be explained by economies of scale related to production-process activities.

Overall, one of the most important points raised in this study is based on the fact that $R \& D$ and non $R \& D$ efforts were used to measure the potential drivers to explain a better productivity level by conducting process innovation activities as part of a firm's managerial levers. In fact, given this (almost neglected) chance of measuring innovation (input) drivers or activities beyond $\mathrm{R} \& \mathrm{D}$ is one way of helping open up the literature to understand innovation with and without R\&D efforts. In this vein, Arundel et al. (2008) pointed out that "neglected" (non R\&D performers) innovators are not properly policysupported, even when the change in the growth of annual revenues between R\&D and non $R \& D$ ("neglected) innovators is similar and there is no reason for policy bias. In fact, when comparing R\&D and non R\&D performers, half of all innovative firms do not perform $R \& D$ and there is no difference in performance, measured by a change in revenues (p.32). Similarly, the OECD (2010:23) states that “...firms may introduce new products on the market without engaging in $R \& D$. New indicators reveal that in Australia and Norway the propensity to introduce a new-to-market product innovation is similar whether or not the firm performs $R \& D$. It seems, however, that most studies measuring innovation have made severe mistakes and that the most relevant one capable of distorting the results is the following: if the sample is made up of R\&D performers, then the majority of firms in the sample are large-sized ones. This can distort the results and bias the reality. In this study particular case, almost $60 \%$ of the firms did not carry out $R \& D$ activities. If the study had included only R\&D performers, what sample would have been displayed? What would the results and implications have been? Including $R \& D$ and non $R \& D$ activities to measure innovation is a more balanced way to understand this effect. However more research is needed in this area, especially into not 
only non R\&D innovators, but non R\&D activities, in order to properly measure these neglected innovators, which are frequently omitted from the selectivity process. Finally, as the results evidence, services are performed in a roughly similar way to manufacturing firms, and both can be measured with similar variables, which confirms the works of Forsman and Rantanen (2011) and Gallouj and Savona (2009).

The study has its limitations. First, the sample is set in a technology-follower country (Spain) and it cannot be extended to other more technology advanced nations. Second, As Qian and Li (2003) pointed out, it is impossible to determine causality at a single time point. Nonetheless, this study assumes that independent variables cannot have a causal relationship with the firm's innovative performance due to the lack of a lag period considered between the independent and dependent variables, but it shows important relationships between variables. For future studies, a more in-depth analysis of the role of non R\&D innovators should be done by especially comparing European Union countries. 


\section{7.- PROCESS INNOVATION STRATEGY AND ORGANIZATIONAL SYNCHRONOUS ADOPTION: COMPLEMENTARITIES AND PERFORMANCE EFEECTS.}

This research provides depth on the study of the process innovators, i.e. the process innovation strategy, its patterns and performance consequences, whose study has been systematically under-researched by scholars who traditionally are devoted to product innovation. Using large-scale database, the effects that the process innovation strategy exerts on a firm's performance are analyzed, unfolding the role of the potential complementarities when, simultaneously, adopting new organizational methods to integrate the introduction of new processes technologies. Based on 28,649 firms using Spanish CIS data for 2006, and checking potential selection by two-step Heckman procedures, the process adoption pattern is pictured and the findings suggest that the introduction of new management or organizational practices is positively related to the process adoption performance, observing also an important implementation effect in which the acquisition of new technology requires that the organization is reprocessed to couple it. Results are in line with the idea of synchronous adoption or complementarities. The work constructs a comprehensive framework linking the differing conversations about the synchronous adoption of technical and organizational innovations across diverse organizational disciplines. The work presents important implications for managers, scholars and policymakers.

\section{1.- Introduction.}

Despite the recognition than firms have specific types of innovation objectives within "technical goals" (Cohen and Malerba, 2001:590), there is an excessive concentration of the innovation literature on product innovation and its effects on sales (e.g., Leiponen and Helfalt, 2010; Vega-Jurado et al., 2008), to the extent that the existing literature has paid less attention to an important strategy or objective which also develops and sustains a firm's competitive advantage: process innovation adoption or process development (e.g. Lager, 2011, European Commission, 2008; Niehaves, 2010; Reichstein and Salter, 2006; Hatch and Mowery, 1998), with some exceptions (e.g., Pisano, 1997; Womack et al., 1991). Each strategy or technological objective is quite distinct from each other, despite recognizing the product and process interrelationship. 
In general, it is claimed that product innovations are pursued to respond to customers' demand for new products or executives' desire to capture new markets, whereas process innovations are pursued to reduce delivery lead-time or decrease operational costs (Knight, 1967; Martinez-Ros, 2000; Schilling, 2005) and thus increase productivity. In addition, and in order to remark the obvious differences with product strategies, as Clausen et al., (2011) pointed out analyzing innovation persistence on the long term, process is less persistent, compared to product, less strategic option, focused on engineering knowledge (e.g., Kirner et al., 2009) and is rather based on learning by doing (Pisano, 1997). This confirms literature stressing the fact that process innovation requires less technological advancement and strategic decision-making (Rosenberg, 1982; Thusman and Rosenkopf, 1992). Therefore, there is no reason to analyze only or more extensively the product innovation, fact which occurs extensively in the innovation management literature and the technology strategy one. This research provides depth on the process innovators, i.e. the process innovation strategy, its patterns and performance consequences.

Process innovation is defined as the introduction of new elements into a firm's production or service operation to produce a product or render a service (e.g. Rosenberg, 1982; Utterback and Abernathy, 1975) with the aim of improving productivity, capacity, flexibility, quality, reducing costs, rationalizing production processes (Edquist, 2001; 2001; Simonetti et al., 1995) and lowering labor costs (Vivarelli and Toivanen, 1995; Vivarelli and Pianta, 2000). Complementary, Reichstein and Salter (2006) refers to process innovation as new capital equipment (Salter, 1960) and the practices of learning-by-doing and learning-by-using (Cabral and Leiblein, 2001; Hollander, 1965). Similarly, the OECD (2005:49) defines process development as:

"the implementation of new or significantly improved production or delivery methods. This includes significant changes in techniques, equipment and/or software".

In this vein, this research explores and sheds light on process innovation adoption, that is, process innovators. To the best of our knowledge, most of literature on process innovation has been conducted on predicting the adoption of new processes (Pires et al., 2008) or predicting incremental versus radical process innovation accomplishment (Reichstein and Salter, 2006), usually in tandem with product innovation adoption (e.g. 
Santamaría et al., 2009). Put differently, most of the literature is based on finding the predictors which explain whether the firm engages in product, process or both technological modes of innovation simultaneously, and not on the specific effects that new process adoption exerts on a firm's performance. In parallel, most of the innovation management literature has been devoted to the understanding of product innovation (e.g. Taylor, 2010; Turner et al., 2010). In fact, the performance consequences from introducing new processes are less explored in the innovation literature, compared with the typical percentage of annual sales that comprises new or substantially improved products introduction. Utilizing the latter measurement biases the study of technological performance towards product innovation, and mostly on product innovators, in detriment of the process innovation and the process innovators ${ }^{8}$. Therefore, the work presents an attempt to offer new insights on understanding the introduction of new processes in firms, its innovation patterns and performance consequences. In particular, we use the term innovation strategy in the terms of Clausen et al., (2011), as a mix of innovation inputs or sources of knowledge a firm uses, i.e., the innovation pattern based on the strategic choices (e.g., invest on $\mathrm{R} \& \mathrm{D}$ or maintaining cooperative relationships for innovation ) made by firms (in the sense of Nelson and Winter, 1982). Therefore, selecting process innovators, we want to disentangle their process innovation strategy and their effects on processes.

Nevertheless, when studying process innovation adoption, the literature has also considered the necessary organizational integration (Ettlie and Reza, 1992), especially from the organization theory and strategy strand. By organizational innovation in this work we refer to "the implementation of a new organizational method in the firm's business practices, workplace organization or external relations" (OECD-Eurostat, 2005:177), stressing the fact that is the result of strategic decisions taken by management (pp.179). Following Wengel et al., (2000) there are two different kinds of organizational innovation, usually inter-related: structural innovations (organizational arrangement and division of labor within it) and managerial innovations (they way a firm organizes its activities or the personnel). In addition, Birkinshaw et al., (2008) uses the term management innovation addressing the new organizational structures,

\footnotetext{
${ }^{8}$ Conducting a search on WOK (Web of Knowledge, June 2012) about "product innovation" as topic within "innovation" in the title (for articles in management, business, operations research management and economics) show 694 results, while doing the same about "process innovation" as topic showed 269 results. Noticeable, the search was using quoting "topic" (product and process separately) to reduce and filter. Without quoting the topics thousands of documents pop up.
} 
administrative systems, management practices, processes and techniques. In this vein, management or organizational innovation are indistinctively used, as long as they coincide in meaning. Empirical evidence about the line of enquiry which sustains that technology is an occasion for structuring is found in Barley's (1986) case studies. Similarly, Jelinek and Burstein (1982) pointed out the fact the productive structure musts maintain a dynamic fit with the firm and its organizational context. From the operations management literature it is also claimed that process innovation is related to management or organizational innovation, in the sense that the management systems usually complement the technical ones (e.g., Womack et al., 1991). Complementary, the innovation literature has also pointed out that both organizational and technological changes are blurred and difficult to separate (Edquist et al., 2001), although the empirical evidence is scarce. Therefore, this work also investigates the complementary role of the process and the management innovation, in order to fully address the realm of activities and sub-systems which involve the process innovation strategy. In particular, this study presents an attempt to explore the effects that the process innovation adoption exerts on a firm's process performance, emphasizing the role of the potential complementarities when, simultaneously, adopting new organizational methods to integrate the introduction of new technologies and processes. In this sense, integration is understood a system of cross-functioning and a sense of collective responsibility (Follet, 1933:66), in the sense of Thompson's (1967) bounded rationality, and it is equivalent to the synchronous (Ettlie, 1988) or joint optimization of practices that are socially- and technically-oriented (Cua et al., 2001; Damanpour et al., 2009). Despite all this heterogeneous literature pointing the same phenomenon, the evidence provided is mostly based at case studies (e.g., Fleck, 1994), small samples (Damanpour and Evan, 1984) or specific industries (Womack et al., 1991). In this sense, those complementarities has not yet been empirically examined using a large-scale dataset and the previous literature on innovation management has not yet investigated the role of managing complementarities between process and organizational innovation using CIS data, especially because process innovation strategy is not consistently studied.

The work contributes to literature in the following ways. First, providing depth and insight about the patterns of adoption of the process innovation and its results on a firm's performance, contributing to extend the knowledge about the process-production perspective which has been less studied in the organization theory and technology 
strategy literature. Second, the work links the disconnected strands of literature based on technical innovation adoption with that of the organizational innovation ${ }^{9}$. This theoretical connection covers a cross-field variety of literatures, as the organization theory and strategy, the operations management one and the innovation studies. Therefore, this research's contributions are expected to connect better the conversation about the technical innovation with those organizational theories, by addressing jointly process innovation strategy and its complementarities with the organizational innovation.

In general, our findings point out that the process innovation performance (based on production flexibility, production capacity improvement, lower labor costs or materials and energy reduction) from new processes adoption is not linked to R\&D (either internal or external). On the contrary, process adoption performance is highly influenced by search strategies to source external knowledge, mainly from the acquisition of new technologies through embodied knowledge and knowledge from the industry. In addition, the performance effects on processes are amplified by the simultaneous adoption of new management or organizational practices, finding a significant and positive relationship in the synchronous introduction of new technological processes and organizational innovations. Finally, the combination of the acquisition of new technology in the form of embodied knowledge, together with the adoption of new organizational practices yields significant returns from new process development, that is, an interaction effect is captured.

The study is based on 28,649 firms available for the Spanish Community Innovation Survey (CIS) data based on Eurostat and the Oslo Manual (OECD, 2005). Then, we selected two samples 8,977 and 4,608 firms, which developed the process innovation strategy, in order to capture the differing specificities and subtleties of the process innovation strategy, including when firms co-adopt product innovation. Two-step Heckman procedure is utilize to check for potential selection. The structure of the work is as follows. In the second section literature is revised and the hypotheses are formulated. Then, in the third section the empirical design is presented, while in the

\footnotetext{
${ }^{9}$ As a matter of proof depicting this disconnection of the literatures, Birkinshaw and Mol (2006:82) point out that "a recent search of the Business Source Premier database yielded 12,774 peer-reviewed articles discussing "technical innovation" but only 114 on "management innovation".
} 
fourth section findings are showed and discussed. Finally, the conclusion is presented in the last section.

\section{2.- Theory development and hypothesis.}

Different perspectives have provided similar points about the idea of synchronous coadoption of technological and organizational innovations. In the strategic management literature, this idea of synchronous adoption is also traced by the use of complementarities, and it is recognized its key influence on a firm's innovation (e.g., Stieglitz and Heine, 2007). Thus, Teece (1986) defines complementary assets as those which raise the value of a firm's technological innovations. Dierickx and Cool (1989), using the resource-based view of the firm (RBV) refers to the complementary assets by highlighting the sustainable competitive advantage they offer by interconnecting assets to prevent imitation. Similarly, Milgrom and Roberts (1995:81) define de idea of complementarities as the marginal returns to one variable are increasing in the levels of the other variables. Ichniowski et al. (1997) also state that complementarity among practices implies that the magnitude of the performance effect of the entire system is larger that the sum of the marginal effects of adopting each practice solely. As Milgrom and Roberts (1990) points out, the activities which are mutually complementary need to be adopted together. If not, then the lack of coordination or integration may diminish returns. For instance, if a new flexible machine is installed, the marketing managers, without coordination, may underestimate the impact on job descriptions (Milgrom and Roberts, 1995). Empirical evidence on this point is provided by Ettlie and Reza (1992) which state that successful adoption of process innovation, mostly acquiring new technologies for operations, are complemented by integration and coordination mechanisms in order to fully capture the value from process innovations and protect form imitation, sustaining with unique significant restructuring the competitive advantage. Milgrom and Roberts (1995) and Ichniowski et al. (1997) alike focus on the notion of complementarities as systemic changes among organizational practices, extending this way the contingency theory (Donaldson, 1996), in the sense that complementarities require fit between key organizational variables.

In addition and complementing the former theories, the socio-technical system (Trist and Bamforth, 1951) describes a method of viewing organizations emphasizing the 
interrelatedness of the functioning of the social and technological subsystems. Put differently, the socio-technical view contends that organizations are made up of people and technology (Trist, 1978; Pasmore et al., 1982). The social system, in the one hand, refers to people who work in the organanization and the relationships among them, although this perspective is broader and considers attitudes, expectations and other patterns of behavior are beyond this work's realm. The technical system, on the other hand, consists of techniques, procedures or knowledge used by the social system to achieve organizational goals (Trist and Bamforth, 1951). Socio-technical systems (STS) establish that the relationship between organizational subsystems represents a correlative relationship representing a "coupling of dissimilarities" where each subsystem change requires changes in the other subsystems (Trist and Murray, 1993). All in all, this idea of complementarities constitutes the basic idea to describe the process innovation strategy and its necessary integration of other managerial and organizational innovation. Thus, this work's hypotheses are developed as follows.

\subsubsection{Processes, technologies and organizational innovation synchronous adoption: performance consequences.}

In particular, process innovation activities involve both organizational and technological changes (Gopalakrishnan and Damanpour, 1997; Reichstein and Salter, 2006) blurred and difficult to separate (Edquist et al., 2001; Ettlie and Reza, 1992; Womack et al., 1990). Edquist et al., (2001) includes within process innovation activities two distinct but related activities: technological process innovation and organizational process innovation. Technological process innovations are new goods that are used in the process of production and include investment goods and intermediate goods such as processing machines, industrial robots and IT equipment. Complementary, organizational process innovations are new ways to organize business activities such as production and have no technological elements but with the co-ordination of human resources and work practices, such as just-in-time production, total quality management or lean production. All in all, literature on management has evidenced that the application of process technology in industries depends on changes in structure and administrative practices (Ettlie, 1988; Nabseth and Ray, 1974; Thompson, 1967). The systematic overlap of the organizational and process innovation is also systematically stressed in the operations management literature (e.g., White and Ruch, 1990; Duguay et al., 1997), although most of this literature is based on case studies or specific 
industries (e.g., Womack et al., 1990; Ettlie, 1988). In this vein, Luria (1987) evidenced that the changes in organizational structure or process technology alone did not yield any significant cost reductions in automobile component plants, while the positive gain in performance from co-adoption is recognized in the literature (e.g., Battisti and Stoneman, 2010; Damanpour et al., 2009). Thus, the first hypothesis is stated as follows:

HYPHOTESIS 1: The simultaneous adoption of process and organizational innovation is a part of the process innovation strategy and it is positively related to process performance.

In general, it is recognized that process innovation in small firms is much more related to the "embodied technological change" incorporated in the physical capital formation rather than in intangible investment in R\&D (Conte and Vivarelli, 2005; Santarelli and Sterlacchini, 1990; Vaona and Pianta, 2008). Specifically, technological process innovation is related to the incorporation of new capital equipment (Salter, 1960), processing machines, industrial robots or IT equipment (Edquist, 2001: OECD, 2005; Heidenreich, 2009) or just capital embodied technology (Rouvinen, 2002) usually obtained from the purchase of advanced machinery or computer hardware and software (Huang et al., 2010; OECD, 2005). This idea addresses the fact that new technologies and usually in the form of embodied technology constitute one of the main drivers in which a firm renew its processes. Then, the technology acquisition through embodied knowledge requires integration into the firm's organizational boundaries. In this vein, Flowers (2007) tackles this process by studying the acquisition, implementation and exploitation of new technologies from the demand-side or the buyer perspective, rather than the extensively researched supplier-centricity. That is, when selling/purchasing equipment or infrastructure (a software like an ERP, Enterprise Resource Planning, MRP, Manufacturing Resource Planning, or other IT systems for production or organizational purposes) most of the work on technological change is focused on the supply-side dynamics (Adner and Levinthal, 2001; Dosi, 1992; Flowers, 2007) rather than on the demand (buyer) side, that is, the acquirer of the new technology. In this vein, the buyer/user, which buys technology capital goods and services for its own operational infrastructure, requires to fit the new technology into the organization. This 
implementation of new equipment or embodied knowledge is an organizational learning process (Voss, 1988) which constitutes a key component of the innovation process (Leonard-Barton and Deschamps, 1988) and especially the process innovation adoption (Ettlie and Reza, 1992). In this vein, Fleck (1994) has described the implementation as a process of "learning by trying" or "learning by struggling to get it to work" that is, improvements and modifications done to the constituent components before the configuration can work as an integrated entity. The point is to understand that the acquisition of new technology requires a mutual adaptation of technology and organization (Ettlie, 1988; Ettlie and Reza, 1992; Fleck, 1994; Leonard-Barton and Deschamps, 1988; Voss, 1988), that is, the adaptation of the technology transfer through the implementation process requires that managers recognize and assume responsibility for both technical and organizational change (Leonard-Barton and Deschamps, 1988), in a similar way that we have referred above to integration, complementarities or synchronous adoption. For instance, Ettlie (1988) found that better performing organizations synchronize the adaptation of administrative policies with the introduction of technology. Fleck (1994) also recognized the necessity to adapt the management procedures to the new technology implemented and Voss (1988) explicitly addressed the complementary effects of integrating new technology with the organizational perspective in order to successfully adopt new technology for process innovation. All in all, technology is an occasion for structuring and actual outcomes depend on how the new processes brought from new technology are coupled with the organization (Barley, 1986; Cohen and Zysman, 1987; Damanpour, 1991; Ettlie and Reza, 1992). Thus, capturing value from new technologies needs to make process innovation adoption an unique occasion for restructuring and creating coupling arrangements (Cohen and Zysman, 1987; Ettlie and Reza, 1992). Therefore, we expect that the returns on new technology adaptation from process innovation adoption are amplified when organizational changes follow, complement and couple the introduction of new technology. Thus, the second hypothesis is stated as follows:

HYPOTHESIS 2. The process performance effects of new processes adoption by technology acquisition on performance are positively moderated by simultaneous adoption of organizational innovations. 


\subsection{Empirical design}

The data is sourced from the Spanish (Eurostat) Community of Innovation Survey (CIS) for 2006 and it consists of 28,649 firms. The method and types of questions in CIS are described in the Organisation for Economic Co-operation and Development (OECD, 2005). CIS was widely piloted and tested before implementation, and since their first use in the early 1990s, the questions have been continuously revised. CIS are often described as "subject-oriented" because they ask firms directly whether they were able to produce an innovation. The CIS questionnaire draws from a long tradition of research on innovation, including the Yale survey and the SPRU innovation database (e.g., Cohen and Levinthal, 1990; Klevorick et al., 1995) and it is extensively used in UK, France, Spain, Italy and other countries.

Following Schumpeter (1912) innovation is made up of inputs and outputs. The idea of input is related to the previously commented innovation strategy. The output, referred to our work, is related to the effects from technological process innovation. In the Spanish CIS referred to 2006 the question about the performance effects on products and processes from adoption of technological innovation, defined as an output, in the following sense: "Please, indicate the impact or effect that your innovation activities have had on your enterprise in the period 2004-2006". The answers are referred to process, product and environmental effects. The same apply for the UK questionnaire (CIS3 and CIS4). Nevertheless, since 2008, the Spanish questionnaire modify and change the variable in order to capture the idea of objectives (similar to "innovation goals", related to technological trajectories in the sense of Dosi, 1982) or factors for the decision to innovate. The same approach is observed in the CIS for the UK questionnaire: CIS5 and CIS6 versions mentioned factors or objectives, while the previous third and fourth version mentioned effects. Therefore, we used 2006 data and the performance effects are treated coherently as output from the innovation strategy.

In particular, we are interested on the performance effects on processes or production (labor cost reduction, production flexibility, improving capacity or the reduction of materials) caused by technological innovators which introduce new processes as part of their process innovation strategy, despite recognizing (and controlling) the fact that new processes introduction may also yield effects on products, see below. Thus, we concentrate on two samples, assuring that all selected companies introduced, at least, 
new processes (1st simple, regardless new products) or solely processes (2nd sample, "pure process innovators"), that is, the firms are all of them process innovators, regardless of some companies, in the first sample, which also introduced new products due to the simultaneous co-adoption. The first sample ("process innovators") contains 8,977 firms having introduced at least new processes during 2004-2006, controlling also for those which also introduced products. Two-step Heckman procedures check for potential selection problems (using the whole population available, 28,649 firms) when restricting sample to just technological process innovators and the process effects as the dependent variable. In this first sample, the most interesting output is the performance effects on processes. Nevertheless, we take into account that the introduction of new products (by firms which are also process innovators) can also influence the process effects. In order to isolate the impact on process effects from process innovation, we control with dummy variable the firms which additively introduce new products. We also recognize that process innovation impact on products, i.e., product effects from new processes. This is controlled in the second sample

Then, the second sample, made up of pure process innovators, is also used as a robustness check. Pure process innovators are defined as those companies which technologically only have introduced new processes (nor products). The second sample consists of 4,608 firms and it presents two advantages and two cautions. Regarding the advantages, the sample only contains process innovators so the technological effects, both on product and process, are directly and solely caused by new processes introduction. Therefore, product effects from process innovation can also be tested as an additional dependent variable (Appendix A). This was impossible in the first sample, as some companies also introduce new products together with new processes and the product effects could be caused by either or both introductions. In addition, for this second sample two-step Heckman procedures are also used to check for potential selection problems regarding both product and process effects as dependent variables.

The sample contains manufacturing and service firms. Following Gallouj and Savona (2009), the way of measuring manufacturing and services innovation is similar and their differences blur. For instance, Forsman (2011) stated that there are only slight differences between those manufacturing and service industries that address innovation. 
Process performance is obtained from four variables addressing the effects on processes, fact which is different from a firm's overall performance or productivity, and permits us to isolate better the effect of adopting process innovation activities. The resulting punctuations from the principal component analysis (PCA) represent the (Process_effects variable) dependent variable. These effects on processes include "improved production flexibility," "reduced unit labor costs", "increased capacity" and "reduced materials and/or energy per produced unit." The four original variables were ordered responses, represented on a scale from zero (absence, no effect) to 3 (maximum). Following this procedure, one single component from the analysis, through its punctuations, represents the dependent variable which explains $60.21 \%$ of the variance $(\mathrm{KMO}=0.7172, \mathrm{p}<0.01)$. See table 1 .

The independent or explicative variables, on the other hand, comprise a wide range of information sources of innovation, $R \& D$ internal and external expenditures, product and organizational innovations, together with industry and size as control variables. Then, the internal sources of information to innovate (Int_sources) represents those which arise from the firm's own departments, staff, firms from the same group, etc. The importance of that information has been measured in a four-point scale (not used $=0$; poor, value $=1$; medium, value $=2$; high, value $=3$ ). Addressing the external sources of knowledge that a firm taps into, those are captured across a wide range of external information sources: suppliers, customers, competitors, consultants, commercial laboratories, private $\mathrm{R} \& \mathrm{D}$ firms, universities, technological centres, public research centres, commercial events, scientific journals and papers and professional associations. All these variables have been reduced to two factors through a PCA (KMO of 0.8607 and a $56.6 \%$ of explained variance), see Table 1 . The first component obtained from this PCA (Ext_sources_fact_industrial) corresponds to the sources related with the industrial agents from the value chain as customers, suppliers or competitors and other sources also related with the industry as commercial events, scientific journals and magazines and professional associations. The second component (Ext_sources_fact_science) corresponds to more scientific and specific pecuniary knowledge (commercial laboratories, private R\&D firms, universities, technological centres and public research centres), see Table for details. In Table it is showed the list of variables representing the stated hypothesis and Table 2 shows the descriptive statistics and correlation matrix of these variables. 
Table 1. Table of variables for the analysis.

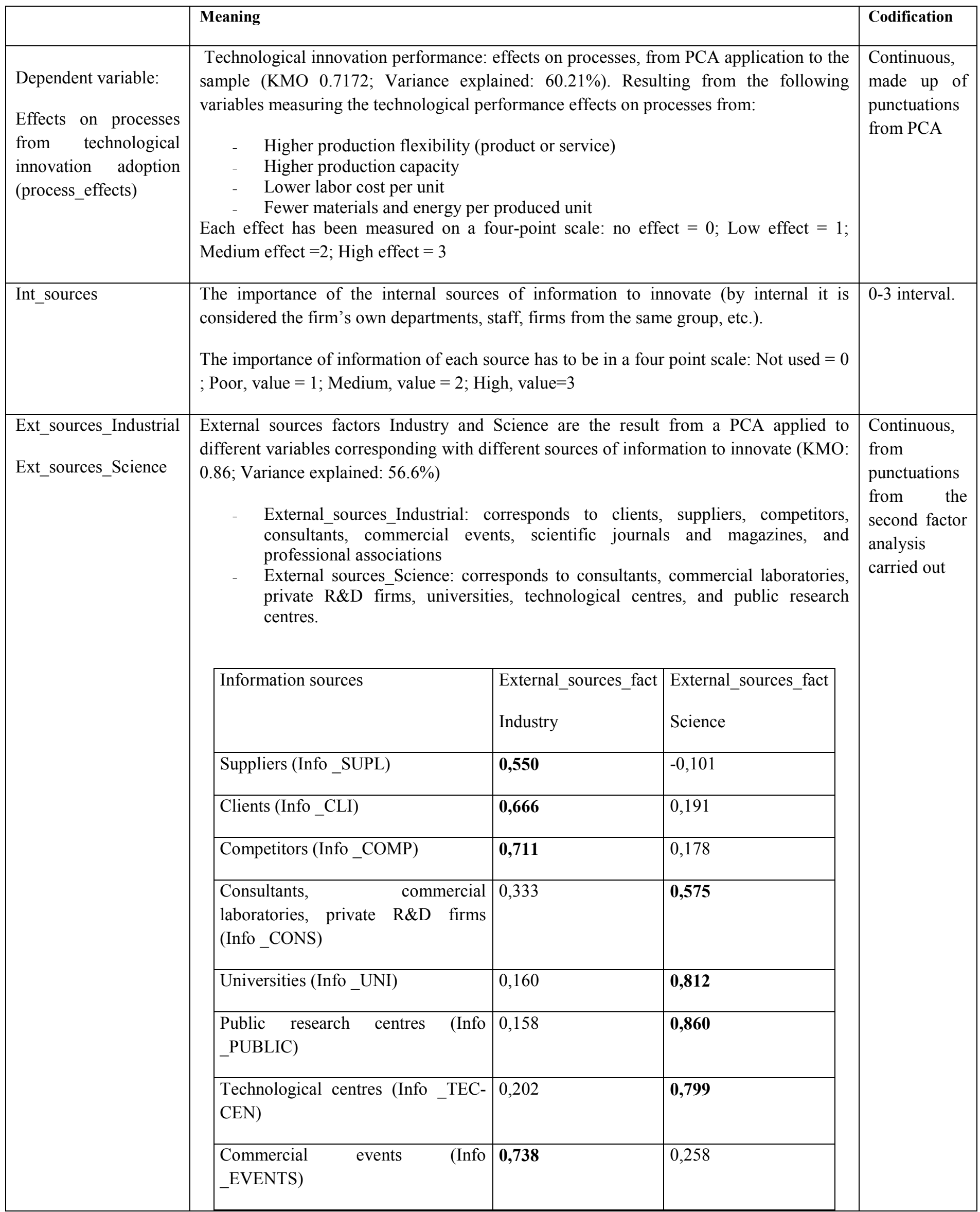




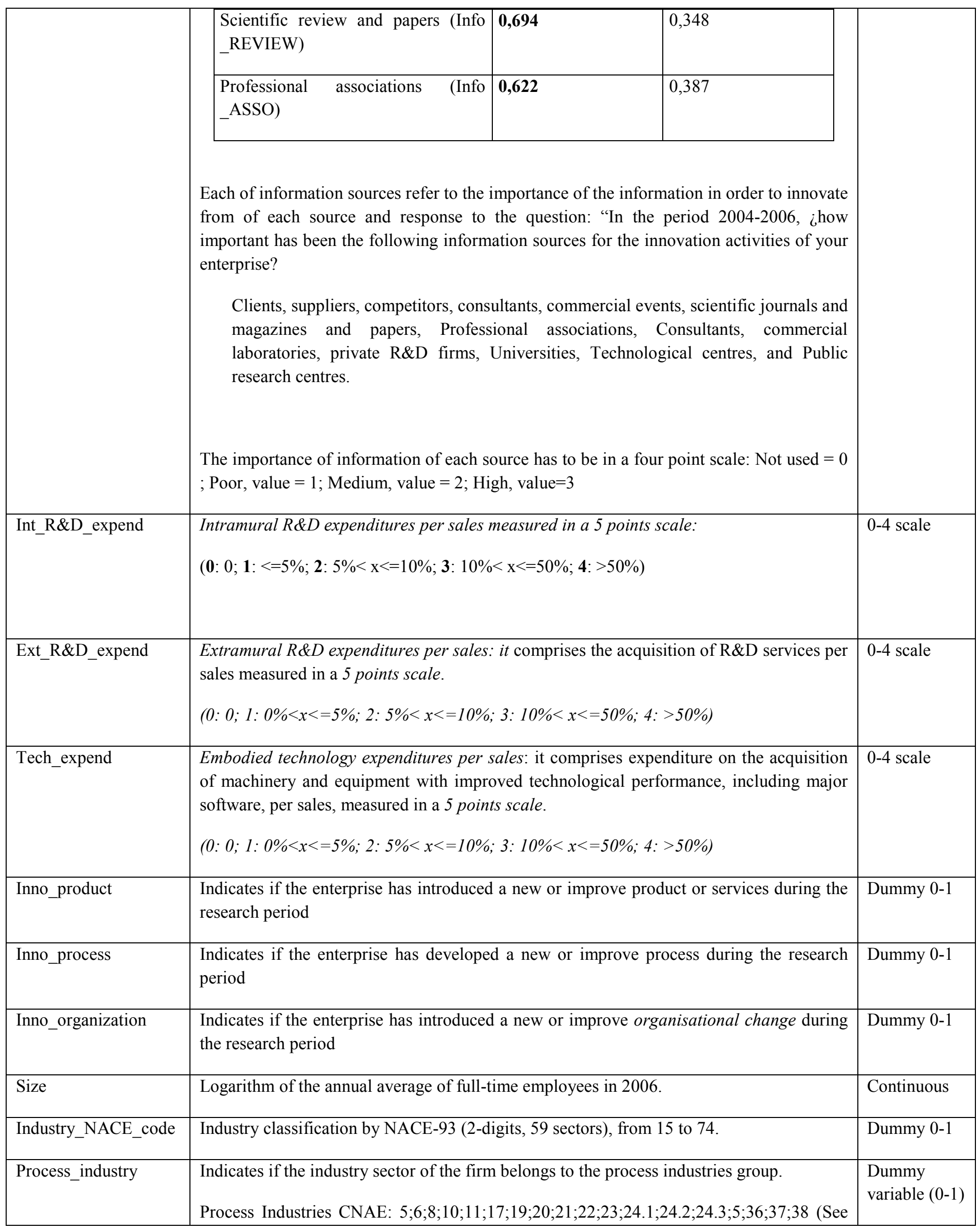




\begin{tabular}{|l|l|l|}
\hline & Lager, 2002) & \\
\hline Inno_problems & $\begin{array}{l}\text { Equal to 1 if one of the four following problems on getting output innovation on the } \\
\text { research period: }\end{array}$ & $\begin{array}{l}\text { Dummy } \\
\text { variable (0-1) }\end{array}$ \\
& $\quad-$ On-going innovation activities at the end of/in 2006 \\
& - On-going innovation activities at the end of/ in 2006, suffering important delays \\
& - Innovation activities abandoned on the early phases & \\
& & \\
\hline
\end{tabular}

Table 2. Descriptive statistics and correlation matrix.

\begin{tabular}{|c|c|c|c|c|c|c|c|c|c|c|c|c|c|c|}
\hline & & Mean & $\begin{array}{l}\text { Std. } \\
\text { Dev }\end{array}$ & 1 & 2 & 3 & 4 & 5 & 6 & 7 & 8 & 9 & 10 & 11 \\
\hline 1 & $\log (\mathrm{SIZE})$ & 3.883 & 0.013 & 1.000 & & & & & & & & & & \\
\hline 2 & group & 0.269 & 0.005 & $0.431^{*}$ & 1.000 & & & & & & & & & \\
\hline 3 & $\begin{array}{l}\text { Int_R\&D_expen } \\
\text { d }\end{array}$ & 0.514 & 0.010 & $-0.267 *$ & $-0.024 *$ & 1.000 & & & & & & & & \\
\hline 4 & $\begin{array}{l}\text { Ext_R\&D_expen } \\
\text { d }\end{array}$ & 0.122 & 0.005 & $-0.161 *$ & $0.028 *$ & $0.439 *$ & 1.000 & & & & & & & \\
\hline 5 & Tech_expend & 0.311 & 0.008 & $-0.183 *$ & $-0.101 *$ & -0.014 & $0.026^{*}$ & 1.000 & & & & & & \\
\hline 6 & Int. sources & 2.192 & 0.011 & $0.074 *$ & $0.127^{*}$ & $0.225 *$ & $0.091 *$ & $-0.031 *$ & 1.000 & & & & & \\
\hline 7 & $\begin{array}{l}\text { Ext_sources_fact } \\
\text { _Industry }\end{array}$ & 0.000 & 0.011 & $0.057^{*}$ & $0.044^{*}$ & $0.149 *$ & $0.047^{*}$ & -0.007 & $0.233 *$ & 1.000 & & & & \\
\hline 8 & $\begin{array}{l}\text { Ext_sources_fact } \\
\text { _Science }\end{array}$ & 0.000 & 0.011 & $0.097 *$ & $0.142 *$ & $0.273 *$ & $0.210^{*}$ & $-0.072 *$ & $0.150 *$ & 0.000 & 1.000 & & & \\
\hline 9 & $\begin{array}{l}\text { Inno_organizatio } \\
\mathrm{n}\end{array}$ & 0.602 & 0.005 & $0.050^{*}$ & $0.047^{*}$ & $0.106^{*}$ & $0.048 *$ & $-0.046^{*}$ & $0.144 *$ & $0.196^{*}$ & $0.076^{*}$ & 1.000 & & \\
\hline 10 & Inno_product & 0.487 & 0.005 & $0.073 *$ & $0.076^{*}$ & $0.309 *$ & $0.124 *$ & $-0.082 *$ & $0.256^{*}$ & $0.248 *$ & $0.195 *$ & $0.145^{*}$ & 1.000 & \\
\hline 11 & Process_Industry & 0.198 & 0.004 & $-0.039 *$ & $-0.055^{*}$ & $-0.052 *$ & $-0.030^{*}$ & $0.094 *$ & -0.002 & $0.040^{*}$ & -0.018 & $-0.042 *$ & $0.029 *$ & \\
\hline 12 & Inno_problemas & 0.283 & 0.007 & $0.105^{*}$ & -0.015 & $-0.221 *$ & $-0.109 *$ & -0.015 & $-0.075^{*}$ & $-0.036^{*}$ & $-0.098 *$ & -0.008 & $0.555^{*}$ & $0.039 *$ \\
\hline
\end{tabular}

*significant at $\mathrm{p}<0.0$. Source: the authors.

As aforementioned, investments in intra and extramural R\&D activities are also considered. The intramural R\&D expenditures per sales (Int_R\&D_expend) comprise all expenditure on $R \& D$ performed within the firm and the extramural $R \& D$ expenditures per sales (Ext_R\&D_expend) comprise the acquisition of external R\&D services. Additionally the embodied technology expenditures per sales (Tech_expend) reflect the acquisition of advanced machinery, equipment and computer hardware or software. The acquisition of embodied knowledge (Tech_expend variable) comprises expenditure on the acquisition of machinery and equipment including major software, per sales. Following Vega-Jurado et al., (2008) procedure, the Tech_expend variable is measured 
into an ordered 5 points scale to better capture its influence $(0: 0 ; 1: 0 \%<\mathrm{x}<=5 \% ; 2$ : $5 \%<\mathrm{x}<=10 \% ; 3: 10 \%<\mathrm{x}<=50 \% ; 4:>50 \%)$.

The variable Inno product is included to control for the firm's introduction of innovative products, i.e. firms which innovate in product or/and service. This variable is measured as a dummy variable and takes 1 if the firm have introduce a new or improve product or/and service during the period, and 0 otherwise. Thus, this variable reflects the complementary effects between product and process innovation. Similarly, the organizational or management innovation output (Inno_organization) is also considered, capturing whether the firm has introduced new or improve organizational changes during the research period (dummy variable 0-1). Next, the moderation effect from hypothesis 2 is represented by an interaction variable as a result of the multiplication of the new management practices variable and the technology acquisition variable. We use moderated regression (Arnold, 1982) in order to capture the second hypothesis, introducing:

$$
\begin{gathered}
y=a+b_{1} x \\
y=a+b_{1} x+b_{2} Z \\
y=a+b_{1} x+b_{2} z+b_{3} x z
\end{gathered}
$$

where, $\mathbf{b}_{\mathbf{3}} \mathbf{x z}$ captures the moderating term of the hypothesis 2 . See table 2 for descriptive statistics.

Eventually, the work also introduces the sector classification in order to control for industry differences (Industry_NACE_code), including 58 2-digit NACE-93 industry classification as dummies, ranging from the 14 to 74 2-digit NACE-93 codes (59 industries). NACE 55 was selected as baseline for dummies specification. In addition, we also control for the typical "process industries" which are mainly dedicated to the introduction of new processes (see Lager, 2002:22), such as mining, forest or utilities, among others (Process_industry variable). The variable Size (also a control variable) is calculated as the logarithm of the annual average of full-time employees in 2006.

In general, $90 \%$ of the process innovators (8,977 firms) are SMEs. Only 1,774 firms (20\% of the simple) belong to "process industries". $60 \%$ of the process innovators also innovate in organization, i.e., introducing new management practices, and $49 \%(4,369$ 
firms) do the same in product innovation. Therefore, it is observed a preference for accompanying process with organizational innovation.

\subsection{Results and discussion}

\subsubsection{Findings}

The dependent variable is the effects on processes (process_effects), as aforementioned. Our sample is based on a threshold (i.e. whether or not firms innovate on process), our results could suffer from additional sort of selection bias. The only respondents to these questions are the technological innovators, not only the process but also the product innovators. Therefore left censoring may arise when firms in do not accomplish process innovations but product innovation and also claimed that from that product innovation introduction some process effects has been obtained. In order to tackle this problem we run a Heckman's two-stage selection model where, in the first stage, the inverse Mills ratio is obtained from a Probit regression (to predict whether or not a firm innovates on process) using all available observations in the population (28,649 firms). For the second stage, the inverse Mill ratio is included, as an additional variable, to explain the variation in innovation performance of the selected sample $(8,977$ firms, the process innovators). See table 3.

Table 3 Two-step Heckman procedure to control for selection problems.

\begin{tabular}{|c|c|c|c|c|}
\hline & $\begin{array}{l}\text { Probi } \\
\text { (INNO_F }\end{array}$ & $\begin{array}{l}\text { model } \\
\text { ROCESS) }\end{array}$ & \multicolumn{2}{|c|}{$\begin{array}{l}\text { OLS Model } \\
\text { Process_effect } \\
\text { (dependent } \\
\text { variable) }\end{array}$} \\
\hline & Coef. & Std. Err. & Coef. & Std. Err. \\
\hline Constant & $-1.695 * *$ & 0.059 & -0.801 & 0.122 \\
\hline $\log (\mathrm{SIZE})$ & $0.157 * *$ & 0.009 & $0.040 * *$ & 0.010 \\
\hline Group & $0.061 * *$ & 0.024 & -0.037 & 0.024 \\
\hline Int_R\&D_expend & 0.019 & 0.015 & -0.002 & 0.014 \\
\hline Ext_R\&D_expend & $0.058 *$ & 0.025 & -0.016 & 0.022 \\
\hline Tech_expend & $0.987 * *$ & 0.027 & $0.141 * *$ & 0.023 \\
\hline
\end{tabular}




\begin{tabular}{|c|c|c|c|c|}
\hline Inno_organization & $0.847 * *$ & 0.019 & $0.112 * *$ & 0.032 \\
\hline Inno_product & $0.786^{* *}$ & 0.023 & 0.008 & 0.032 \\
\hline process_industry & -0.148 & 0.136 & & \\
\hline inno_problems & $-0.467 * *$ & 0.024 & & \\
\hline Int. sources & & & $0.157 * *$ & 0.010 \\
\hline Ext_sources_fact_Industry & & & $0.343^{* *}$ & 0.010 \\
\hline Ext_sources_fact_Science & & & $0.096^{* *}$ & 0.010 \\
\hline Inv Mill & & & 0.018 & $\mathbf{0 . 0 5 0}$ \\
\hline Industry_NACE_code & \multicolumn{2}{|c|}{ Yes } & \multicolumn{2}{|c|}{ Yes } \\
\hline $\mathrm{N}$ & \multicolumn{2}{|c|}{28649} & \multicolumn{2}{|c|}{8977} \\
\hline chi2 & \multicolumn{2}{|c|}{10,901} & & \\
\hline R2 & \multicolumn{2}{|c|}{0.306} & \multicolumn{2}{|c|}{0.2221} \\
\hline Adjusted $\mathrm{R}^{2}$ & & & \multicolumn{2}{|c|}{0.2178} \\
\hline Error & & & \multicolumn{2}{|c|}{0.00} \\
\hline F & & & \multicolumn{2}{|c|}{52.01} \\
\hline
\end{tabular}

The specification used to predict the probability to innovate in process (Inno_process) includes the following variables: Int_R\&D_expend, Ext_R\&D_expend, Tech_expend, Inno_product, Inno_Organization, Size, Group, Industry_NACE_codes, Process_industry and Inno_problems (the latter related with facts which hamper innovation in process).

In table 3 the dependent variable measures the innovation performance as the process effects from the introduction of new processes on firms (higher production flexibility; higher production capacity; lower labor cost per unit; fewer materials and energy per produced unit). In this particular case, the inverse Mill ratio turns out to be nonsignificant $(\mathrm{p}>5 \%)$ suggesting that the sample selection (process innovators firms) is not an issue for the Process_effects variable.

Table 4. OLS Model. Dependent variable: Process_Effects.

\begin{tabular}{|l|l|r|l|r|l|r|}
\hline & \multicolumn{3}{|l|}{ Specification 1 } & \multicolumn{2}{l|}{ Specification 2 } & \multicolumn{2}{l|}{ Specification 3 } \\
\hline & Coef. & Std. Err. & Coef. & Std. Err. & Coef. & Std. Err. \\
\hline Intercept & $-0.763^{* *}$ & 0.068 & $-0.557^{* *}$ & 0.043 & $-0.751^{* *}$ & 0.068 \\
\hline $\log$ (SIZE) & $0.038^{* *}$ & 0.009 & $0.033^{* *}$ & 0.009 & $0.038^{* *}$ & 0.009 \\
\hline Group & -0.039 & 0.024 & -0.045 & 0.024 & -0.038 & 0.024 \\
\hline Int_R\&D_expend & -0.002 & 0.013 & -0.034 & 0.012 & -0.002 & 0.013 \\
\hline Ext_R\&D_expend & -0.016 & 0.022 & -0.018 & 0.022 & -0.016 & 0.022 \\
\hline Tech_expend & $0.135^{* *}$ & 0.013 & $0.151^{* *}$ & 0.013 & $0.098^{* *}$ & 0.019 \\
\hline Int. sources & $0.157^{* *}$ & 0.010 & $0.1574 * *$ & 0.010 & $0.157^{* *}$ & 0.010 \\
\hline Ext_sources_fact_Industry & $0.343^{* *}$ & 0.010 & $0.350^{* *}$ & 0.010 & $0.343^{* *}$ & 0.010 \\
\hline
\end{tabular}




\begin{tabular}{|c|c|c|c|c|c|c|}
\hline Ext sources fact Science & $0.096 * *$ & 0.010 & $0.104 * *$ & 0.010 & $0.096 * *$ & 0.010 \\
\hline Inno_organization & $0.102 * *$ & 0.020 & $0.086 * *$ & 0.020 & $0.081 * *$ & 0.021 \\
\hline Inno_product & -0.001 & 0.021 & 0.018 & 0.021 & -0.002 & 0.021 \\
\hline Inno_organization_x_Tech_expend & & & & & $0.065^{*}$ & 0.026 \\
\hline Industry_NACE_code & yes & & & & \multicolumn{2}{|c|}{ yes } \\
\hline Process_Industry & & & 0.038 & 0.024 & & \\
\hline $\mathrm{R}^{2}$ & 0.222 & & 0.2071 & & 0.2227 & \\
\hline Adjusted $\mathrm{R}^{2}$ & 0.218 & & 0.2061 & & 0.2187 & \\
\hline Error & 0 & & 0 & & 0 & \\
\hline $\mathrm{F}$ & 53.1 & & 212.87 & & 52.48 & \\
\hline
\end{tabular}

Level of significance: $1 \%(* *)$. Sample 8,977 firms which introduced at least new processes (these firms may also introduce new products or management practices) (Industry_NACE_code), including n-1 2-digit NACE-93 industry classification as dummies, ranging from the 14 to 74 codes. Code 55 is the baseline. The variable Industry_CNAE_code has effect on the dependent variable. Industry dummies and their coefficients are not reported to save space but are available upon request. $\mathrm{N}=8923$. In addition Process_industry control for typical process industries, as aforementioned in table 1. VIF tests are also conducted and results are fine (available upon request)

According to table 4 (process_effects as dependent variable), which contains the OLS results, the three specifications offer a good fit (adjusted $\mathrm{R}^{2}$ ranging from 0.20 to 0.21 ).

The results in table 4, corresponding to Specification 1, indicate that the investment in internal R\&D activities (Int_R\&D_expend) to innovate do not influence the process effects. This result is repeated in all subsequent specifications. In fact, the coefficients are negative, although they are not statistically significant. Similarly, in all specifications, the variable Ext_R\&D_expend does not work, meaning that the acquisition of $R \& D$ from external sources does not render any process returns from process innovation strategies. The result is also observed in the rest of specifications. On the contrary, there is one key variable which reflects the acquisition of embodied knowledge, Tech_expend which does contribute to increase process innovation performance (coefficient $0.135,0.151$ and 0.98 in specifications 1 to 3 , respectively; all of them significant at $\mathrm{p}<0.01$ ). Then, the variable Inno product, which is negative in all specifications (except for the second) and statistically insignificant, indicates that the realization of product innovation strategies do not contribute to improve process innovation effects, that is, product innovation activities are neutral and do not influence the effects on process. On the contrary, the Inno_organization variable, which addresses whether the company has also introduced organizational or management innovation activities, does contribute positively to improve process innovation performance, as the positive and significant coefficient shows in each specification $(0.102,0.086$. 0.081, respectively, $\mathrm{p}<0.01)$. The latter result suggests that the accomplishment of organizational innovation activities does contribute to improve effects on processes from new processes introduction, that is, the organizational and process innovation 
activities are complementary. Regarding the sources of information within a firm's search strategies, which benefit process innovation performance, the results indicate in the three specifications that the internal sources of knowledge improve process innovation performance (Int_sources, 0.157, 0.1574, 0.15732, respectively, p<0.01), indicating that there is important knowledge disperse within a firm which can be used deployed to improve process innovation performance positively. In addition, the external sources of knowledge variables indicate that sourcing external sources of knowledge from industrial agents (i.e., the value chain; Ext_sources_fact_Industry) and from science sources (i.e., universities and R\&D centers; Ext_sources_fact_Science) are both positive and significant (in all specification, $\mathrm{p}<0.01$ ), meaning that there are returns and gains in process innovation performance from the sourcing of external knowledge, and especially from the industry sources, due to the larger coefficients showed in the table 4 (for instance, in specification 1, 0.343 in Industry, compared to 0.096 in Science, both significant at $\mathrm{p}<0.01)$. The control for the specific "process industries" does not yield any effect in the effects on processes but the general industry effect (Industry_NACE_code variable) is important and significant, showing inter-industry heterogeneity.

The control variable, $\log$ Size, is positive in all specifications (with 0.038 value in most of the specifications; $\mathrm{p}<0.01$ ), indicating that the larger the company, the better the process innovation performance. Lastly, the interaction shows important results. Thus, the acquisition of embodied knowledge is positively moderated, that is, there are complementarities, by the introduction of new management practices, i.e., organizational innovation (Inno_organization_x_Tech_expend), pointing out that an improvement in process innovation performance is obtained from combining the acquisition of embodied knowledge with co-adopting simultaneously organization innovation activities at the firm (specification 3, 0.065 at $\mathrm{p}<0.01$ ).

In order to isolate the effects on process of simultaneous co-adoption of product and process activities by firms, we restrict the sample $(8,977)$ to only "pure" process innovators, that is, firms which only introduced new processes and not new products (4,608 firms). This is our second sample and whatever effect on either products or processes is caused solely by the introduction of new processes. Put differently, we restrict the technological innovation to just process innovators. We also conducted selection process control by running a two-step Heckman procedure. Two-step 
Heckman procedure is used in order to control for selection problems in the subsample of the pure process innovators, when measuring effects on process. There is not found any selection problem, that is, the Inv. Mill is insignificant (Inv Mill's ratio 0.33; $\mathrm{p}>0.05$ ). The 4,608 firms which only introduced new processes show a similar pattern of innovation to the previous sample $(8,977$ process innovators which some also have introduced new products). In order to isolate the pure process innovators, we construct a new dependent variable following a similar procedure as the aforementioned, getting a single component from a PCA $(59.9 \%$ of the variance explained and $\mathrm{KMO}=0.7015)$ for the reduce $(4,608)$ sample. In table 5 , the results showed a similar pattern of innovation for the pure process innovators $(4,608)$ compared to the process innovators $(8,977)$. Basically, and in line with the previous findings, it is observed that R\&D activities (both internal and external) do not influence any process performance. Similarly, the acquisition of embodied knowledge (Tech_expend variable) does yield significant and positive returns on the effects on processes $(0.123,0.137,0.085$ respectively in all three specifications, $\mathrm{p}<0.01)$. In line with previous results, the search strategies are also positive and significant. That is, the external sources of knowledge (from the industry and from the science sources) are both significant and positively related to effects on processes. The size effect is also positive and significant (first and third specification, 0.032 and $0.031, \mathrm{p}<0.05)$ and the Group variable is negative and significant, indicating that the pure process innovators do not yield any effect from belonging to an industrial group. Finally, the introduction of new management practices (Inno_organization variable) is positively significant $(0.075,0.058,0.0453$, respectively, $\mathrm{p}<0.01)$. In addition, the interaction effect (Inno_organization X Tech_expend variables) is also positive and significant $(0.082, \mathrm{p}<0.05)$. The effects from the industry are significant (Industry_NACE_code variable) and also the effect from the specific process industries (specification 2, $0.0138 \mathrm{p}<0.05$ ). See table 5 .

Table 5. OLS Model. Dependent variable: Process_Effects.

\begin{tabular}{|l|l|l|l|l|l|r|}
\hline & \multicolumn{5}{|l|}{$\begin{array}{l}\text { Firms which only introduce new processes (without co-adoption } \\
\text { of product innovation objective): "pure" process innovators }\end{array}$} \\
\hline & Specification 1 & \multicolumn{1}{|c|}{ Specification 2 } & \multicolumn{2}{|l|}{ Specification 3} \\
\hline & Coef. & Std. Err. & Coef. & Std. Err. & Coef. & Std. Err. \\
\hline constant & $-0.570^{* *}$ & 0.0824 & $-0.351^{* *}$ & 0.0578 & $-0.552^{* *}$ & 0.0826325 \\
\hline log (SIZE) & $0.032^{*}$ & 0.0131 & 0.021 & 0.0130 & $0.031^{*}$ & 0.0131 \\
\hline group & $-0.078^{*}$ & 0.0346 & $-0.079 *$ & 0.0341 & $-0.076^{*}$ & 0.0346 \\
\hline Int_R\&D_expend & -0.002 & 0.0236 & -0.032 & 0.0222 & -0.002 & 0.0236 \\
\hline Ext_R\&D_expend & 0.039 & 0.0407 & 0.037 & 0.0405 & 0.039 & 0.0407 \\
\hline Tech_expend & $0.123^{* *}$ & 0.0170 & $0.137^{* *}$ & 0.0168 & $0.085^{* *}$ & 0.0228 \\
\hline Int. sources & $0.152^{* *}$ & 0.0122 & $0.153^{* *}$ & 0.0123 & $0.152^{* *}$ & 0.0122 \\
\hline
\end{tabular}




\begin{tabular}{|c|c|c|c|c|c|c|}
\hline Ext sources fact Industry & $0.381 * *$ & 0.0138 & $0.386 * *$ & 0.0138 & $0.380 * *$ & 0.0138 \\
\hline Ext_sources_fact_Science & $0.073 * *$ & 0.0158 & $0.085 * *$ & 0.0155 & $0.074 * *$ & 0.0157 \\
\hline Inno_organization & $0.075 * *$ & 0.0269 & $0.058^{*}$ & 0.0267 & 0.0453 & 0.0294 \\
\hline Inno organization $\mathrm{x}$ Tech expend & & & & & $0.082 *$ & 0.0327 \\
\hline Industry_NACE_code & \multicolumn{2}{|c|}{ Yes } & & & \multicolumn{2}{|c|}{ Yes } \\
\hline Process_Industry & & & $0.138^{*}$ & 0.0340 & & \\
\hline $\mathrm{N}$ & \multicolumn{2}{|c|}{4608} & \multicolumn{2}{|c|}{4608} & \multicolumn{2}{|c|}{4608} \\
\hline $\mathrm{R}^{2}$ & \multicolumn{2}{|c|}{0.239} & \multicolumn{2}{|c|}{0.2212} & \multicolumn{2}{|c|}{0.24} \\
\hline Adjusted $\mathrm{R}^{2}$ & \multicolumn{2}{|c|}{0.2311} & \multicolumn{2}{|c|}{0.2195} & \multicolumn{2}{|c|}{0.232} \\
\hline Error & \multicolumn{2}{|c|}{0} & \multicolumn{2}{|c|}{0} & \multicolumn{2}{|c|}{0.000} \\
\hline $\mathrm{F}$ & \multicolumn{2}{|c|}{30.47} & \multicolumn{2}{|c|}{130.54} & \multicolumn{2}{|c|}{30} \\
\hline
\end{tabular}

Dependent variable: process_effects, $(\mathrm{KMO}=0.7015 ; 59.98 \%$ variance) obtained from the 4,608 firms Level of significance: $1 \%\left({ }^{* *}\right) ; 5 \%(*)$. Sample 4,608 firms which only introduced new processes (pure process innovators) and not product (Industry_NACE_code), including n-1 2-digit NACE-93 industry classification as dummies, ranging from the $\overline{14}$ to $\overline{74}$ codes. Code 55 is the baseline. The variable Industry_CNAE_code has effect on the dependent variable. Industry dummies and their coefficients are not reported to save space but are available upon request. $\mathrm{N}=4,608$ In addition Process_industry variable controls for typical process industries, as aforementioned in table 1. VIF control is correct.

All in all, the results of the process innovation strategy and the effects on processes on both samples, i.e., process innovators $(8,977)$ and just pure process innovators $(4,608)$, are pretty similar. Put differently, the R\&D (internal or external) activities do not explain any return on the effects on processes (based on production flexibility, production capacity, lower labor costs or materials and energy reduction). Then, process effects are highly influenced by external sources of knowledge, mainly from the acquisition of embodied knowledge and the knowledge from the industry. In addition, those effects are amplified by engaging simultaneously in the adoption of new management practices, finding a significant and positive relationship between the process innovation strategy and the management activities. Complementary, the combination of the acquisition of embodied knowledge with the introduction of new management practices yields significant returns from process innovation, that is, an interaction effect is captured. Finally, the introduction of new products do not yield any return on the effects on processes.

Nevertheless, the introduction of new processes by process innovators can also yield effects on products. We control for this possibility in Appendix A using the second sample. See Appendix A.

\subsection{2.- Dicussion of results.}


In general, the results point out that the process innovation strategy and its performance on process effects is mainly explained by non $R \& D$ efforts but a highly intensive process of dependence on external sources of knowledge, including formal and pecuniary acquisition of embodied technology and informal sources of knowledge from the industry and other external agents and events (fair trades, congresses, etc.). In short, the results indicate that introducing acquired embodied knowledge, together with the use of external and internal (to the firm) sources of knowledge, and simultaneously adopting new management practices, all in all, increase a firm's process performance from its process innovation strategies, that is, reducing costs and materials per produced unit and improving flexibility and capacity in process/production activities. Neither $R \& D$ efforts, nor the introduction of new products improve the performance on processes. In addition, the interaction variables show a complementary and positive effect, which reflects that the acquisition of embodied knowledge is positively moderated, and effects on processes are amplified, when that acquisition is congruent and synchronous with the introduction of new management practices, following the integration idea of complementarities from the "learning by trying" aforementioned effect. All in all, this results confirm the innovation literature (Arundel et al., 2008; Barge-Gil et al., 2010; Rammer et al., 2009; Heidenreich, 2009).

The evidence about $\mathrm{R} \& \mathrm{D}$ and process innovation adoption is quite controversial, indeed. On the one hand, Reichstein and Salter (2006), Mairesse and Mohnen (2005) and Baldwin et al. (2002) found a positive relationship between process innovation and R\&D intensity. On the other hand, Hervas-Oliver et al. (2011), Huang, Arundel and Hollanders (2010), Barge-Gil et al. (2011) or Rouvinen (2002) found no relationship between firm-level R\&D and process innovation. The reason for this possible nonexisting relationship between $R \& D$ and process innovation is found on the fact that firms innovate through activities which do not require R\&D (following Arundel et al., 2008; European Commission, 2008; Huang et al., 2010; Hervas-Oliver et al., 2011), such as combining existing knowledge in new ways (e.g. Evangelista et al., 2002), through imitation and reverse engineering (Kim and Nelson, 2000) or conducting incremental changes relying on engineering knowledge (Kline and Rosenberg, 1986). As Arundel et al., 2008 points out describing the Innobarometer in 2007: "non- $R \& D$ innovators, compared to $R \& D$ performers, are more likely to focus on process innovation and to source ideas from within the firm from production engineers and 
design staff. The higher prevalence of process innovation among non-R\&D performers suggests that there are more options for developing process innovations without performing $R \& D$." In addition, as Clausen et al., (2011) pointed out analyzing innovation persistence on the long term, process is less persistent, compared to product, less strategic option and is rather based on learning by doing (Pisano, 1997). This confirms literature stressing the fact that process innovation requires less technological advancement and strategic decision-making (Rosenberg, 1982; Thusman and Rosenkopf, 1992). Nevertheless, our results are novel and not really comparable to the previous literature, in the sense that we do not relate $R \& D$ or non-R\&D activities to process innovation adoption, but to new process adoption performance. The subtleties are quite different and thus our findings suggest that the R\&D activities do not yield superior process effects which improve the firm's performance.

Our work is in line with previous studies about sourcing knowledge from external sources. In this line, as evidenced in our results, sourcing knowledge is positively related to the innovation process (e.g., Damanpour et al., 2009), exchanging information with their environments effectively (Tushman, 1977) and sourcing knowledge from internal communications in order to facilitate dispersion of ideas within a communication organization and increases their amount and diversity, which results in cross-fertilization of ideas (Aiken and Hage, 1971; Ross, 1974). All in all, the role of consultants (e.g. Flowers, 2007) and especially the role of suppliers providing knowledge for process innovation (e.g. Cabagnols and Le Bas, 2002; Ettlie et al., 1984; Ettlie and Reza, 1992; Rouvinen, 2002; Voss, 1985) are important. Then, size has been found to be an important driver to explain inducements to process innovation in literature (Cohen and Klepper, 1996; Damanpour, 2010; Klepper, 1996; Nord and Tucker, 1987; Reichstein and Salter, 2006) predicting a positive relationship among them. As Damanpour suggests (2010), researchers generally posit that size has a more positive association with process than with product innovations (e.g. Cohen and Levinthal, 1989; Fritsch and Meschede, 2001; Scherer, 1980), in line with this research's results, contradicting other studies which do not relate innovation and size (e.g. Camisón-Zornoza et al., 2004; Rammer et al., 2009).

Overall, the results confirm the two stated hypothesis, showing the following contributions. First, the introduction of new management practices is positively related to the process adoption performance, that is, the new management innovation practices 
improve effects on processes. These results are in line with the previous organization theory and technology strategy literature (Ettlie, 1988; Nabseth and Ray, 1974; Thompson, 1967). Put differently, it is empirically evidenced that the simultaneous adoption of a more systemic approach to innovation, combining the technical (process) and the organizational system, gives a firm a superior performance. However, this result does not mean a cause-and-effect of one over another, but a positive synergistic gain which is supported in literature. Put differently, literature does not provide a causeeffect logic and following Damanpour et al. (2009, p. 658) it is recognized that the relationship between the technical and the social systems in the social-technical systems theory is a correlative relationship representing a "coupling of dissimilarities" (Damanpour \& Evan, 1984; Scott, 1992). The research also links the disconnected strands of literature using a variety of disciplines in order to construct a more systematic and comprehensive conversation about the technical innovation and the diverse organizational disciplines. In this vein, our conclusions based on the large-scale database are contributing to different streams of the literature. The evidence provided can be framework within the organization theory and strategy strand. In this chain of thought, Milgrom and Roberts (1990) showed how the introduction of new processes using CAD technology pays off best when associated with inventory, marketing or management policies. Similarly, Hayes and Jaikumar (1988) pointed out the need for improving the equipment with adopting also organizational changes, similar findings than Parthasarthy and Sethi $(1992 ; 1993)$ and McDuffie and Krafcik (1992). Following contingency theory, our findings are in line with those of Roberts and Amit (2003) which found evidence about the performance consequences of synchronous innovations. Similarly, our findings are in line with those of Damanpour et al., (2009) which also suggested that the introduction of a diverse set of innovations (service, technological process and managerial) concurrence presents an impact on performance. Finally, the results presented confirm the idea that vindicated that synchronous innovation or optimization of the socio-technical system leads to better performance (Cua et al., 2001; Georgantzas and Shapiro, 1993; Emery, 1990; Rehder, 1989), following the operations management literature. Summarizing, the concentration on either the technical or the organizational solely would result in a low performance level, as Herbst (1974) stated.

Second, we observed an "implementation" or "learning by trying effect", that is, the acquisition of embodied knowledge is positively moderated and, subsequently, the 
effects on processes are amplified, when that acquisition is synchronously complemented with the introduction of new organizational innovations. This result confirms previous literature which suggested that technology is an occasion for structuring and the actual outcomes depend on how the new processes brought from the new technology are coupled with the organization (Barley, 1986; Cohen and Zysman, 1987; Damanpour, 1991; Ettlie and Reza, 1992; Markus and Robey, 1988; McCann and Galbraith, 1981), also reinforcing the aforementioned idea of complementarities.

Finally, the introduction of new products does not yield any return on the effects on processes. Put differently, there is no evidence about the effects that the product innovation activities exert on process innovation activities performance, contradicting a body of literature which claim that there is not sufficient evidence on the separation (Damanpour, 2010; Fritsch and Meschede, 2001; Pisano et al., 1997; Reichstein and Salter, 2006; Walker, 2004) of product or process innovation. In fact, the previous literature has studied the co-adoption of product and process, while our study has gone as step further to assess whether the product innovation exerts or not effects on process adoption. Therefore, introducing new products does yield necessarily effects on the processes. In this vein, our findings pointed out that product innovations are pursued to respond to customers' demand for new products or executives' desire to capture new markets, whereas process innovations are pursued to reduce delivery lead-time or decrease operational costs (Knight, 1967; Martinez-Ros, 2000; Schilling, 2005). On this chain of thought, our results confirmed those of Kraft, (1990) which evidenced that introducing process innovation does not act as a spur to product innovation.

\subsection{Conclusions.}

This work explores the process innovation strategy and sheds light on the process innovation phenomenon using a large-scale database, whose study has been systematically under-researched by scholars (e.g., European Commission, 2008; Hatch and Mowery, 1998) and biased mostly to the study of product innovation. In particular, this study presents an attempt to explore the effects that the process innovation adoption exerts on a firm's performance, emphasizing the role of the potential complementarities when, simultaneously, adopting new organizational methods to integrate the introduction of new processes technologies. Based on 8,977 firms which recorded to 
have introduced at least one new process, and using Spanish CIS data-based innovation survey for 2006, the results, after checking selection by two-step Heckman procedures, suggest that the two stated hypotheses are accepted and the conclusions are as follows.

First, introduction of new management or organizational practices is positively related to the process adoption performance, that is, the new management innovation practices improve the effects on process. This result is in line with the idea of synchronous adoption (Ettlie, 1988), “coupling of dissimilarities" (Trist \& Murray, 1993) or complementarities (e.g., Milgrom and Roberts, 1995).

Second, regarding the second hypothesis, it is observed an important "implementation" effect or "learning by trying" (Fleck, 1994) effect in which the acquisition of embodied knowledge require that the organization is reprocessed to couple the new technology. This result, predicted in literature mainly through case studies and small samples (Fleck, 1994; Flowers, 2007; Leonard-Barton and Deschamps, 1988; Voss, 1988), is confirmed from the evidence of our large sample and thus it is vindicated that the positive combination or synchronous introduction of new embodied knowledge with the organizational innovation in order to integrate or couple organization to the new type of knowledge, showing this co-adoption a positive and complementary effect on process innovation performance and its effects on processes.

Lastly, the research presents implications for scholars and policy makers. First, the policymaking efforts to foster process innovation strategy should: (a) facilitate access to other innovative inputs in addition to $R \& D$; (b) support organizational or management innovation as a complement for implementing the technology and thus enhance process innovation, producing synergies which expand and amplify new process adoption performance; (c) incentive the acquisition of embodied knowledge through technology equipment to counteract the lack of internal resources; (d) promoting networking in order to search knowledge. Second, scholars should also include the effect of process innovation adoption beyond or complementary to the much more studied product innovation phenomena. In particular, scholars should also focus on non-R\&D indicators, due to the facts that the R\&D cannot explain all type of innovation decisions, strategies and their effects. In addition, scholars should also refine and exploit the still under-researched process innovation strategy in other countries and datasets. 
The research has some limitations. The analysis of large-scale databases cannot capture many questions that require direct observational research methods. The sample is set in a technology-follower country (Spain) and it cannot be extended to other more technology advanced nations. Second, As Qian and Li (2003) pointed out, it is impossible to determine causality at a single time point, although the CIS data is lagged when asking questions referring to the period of the last 2 years. Nonetheless, this study assumes that independent variables have a causal relationship with the firm's innovative performance due to the lag period considered between the independent and dependent variables. For future studies, a more in-depth analysis of the role of non R\&D innovators when studying process innovation strategy should be done by especially comparing European Union countries. 


\section{a) Conclusiones de la primera parte de la tesis.}

En la primera parte de la investigación se utiliza la teoría de niveles de gestión para tratar de entender el fenómeno de la innovación de proceso usando también la teoría gestión de innovación y del cambio, así como partes de la teoría de organización industrial y de la economía de de la innovación. Dentro de este fértil marco teórico, la contribución del trabajo es triple. Primero, se dirige al emergente campo de la importancia de los innovadores sin I+D. Segundo, explora y arroja luz sobre la innovación de proceso sobre la cual los académicos han prestado menor atención, sobretodo a la variable d innovación de proceso, usando un mediador para explicar el desempeño de la firma y no simplemente como variable dependiente. Tercero, busca determinar hasta que punto las actividades de innovación de proceso están relacionadas y son por tanto independientes. La combinación de esos objetivos y el contexto en el cual el estudio se basa hacen a este trabajo original y que contribuya a la literatura sobre innovación organizativa. En lugar de predecir solamente los innovadores de proceso o entender las complementariedades entre innovaciones de producto y proceso, este trabajo está basado en entender los drivers que consiguen mejoras de productividad a través de la reducción de costes, flexibilidad y mejora de la capacidad a partir de actividades de innovación de proceso controlando para actividades de I+D y no-I+D. El estudio se basa en datos de la encuesta CIS de 10.755 firmas españolas. España es un país seguidor tecnológico, cuyos niveles de inversión en $\mathrm{I}+\mathrm{D}$ no son altos.

Los indicadores tradicionales de I+D no capturan el impacto total de las actividades de innovación en el desempeño de la empresa, como algunos trabajos previos han evidenciado (ej., Hall et al., 2009; Rammer et al., 2009; Arundel et al., 2008). Por tanto, el desempeño de la innovación de proceso puede ser explicado usando variables no $\mathrm{I}+\mathrm{D}$, tales como nuevas actividades organizativas relativas a las gestión del trabajo y del conocimiento. Todas esas actividades pueden ser incluidas en los niveles de gestión, junto con el entorno de aprendizaje (Damanpour, 1991), los sistemas de gestión del conocimiento (Cebon y Newton, 1999) y la complejidad general y alcance administrativo (Damanpour, 1991) dentro de las actividades de la innovación organizativa. En la literatura de gestión de la innovación, diferentes académicos han trabajado sin considerar la intensidad de I+D (Bougrain and Haudeville, 2002; Freel, 2003, 2007; Muscio, 2007) y confirmando como el proceso de la innovación en contextos de baja y media tecnología puede ser capturado usando actividades no-I $+\mathrm{D}$ 
(ej., Santamaria et al., 2009). Dicho de otra forma, las variables sobre las cuales el estudio se basa están más allá de la $\mathrm{I}+\mathrm{D}$ puertas adentro, y los resultados muestran que "hacer, usar e interactuar" (Jensen et al., 2007) es una forma en que las firmas se basan en los procesos y la experiencia (know-how) en las actividades aguas abajo (marketing, diseño) para innovar (OECD, 2005). Esto principalmente se refiere a los sectores de baja y media tecnología que usan “...la resolución de problemas incrementales y experimentación que tiene lugar en planta y está estrechamente relacionada con la producción más allá de los programas bien definidos de $I+D$..." (Albaladejo and Romijn, 2000:4-5). Así, la innovación no es un esfuerzo exclusivamente tecnológico, sino estratégico desde una perspectiva basada en el mercado (ej., Bessant and Tidd, 2007; Terziovski, 2010).

Por tanto, en contradicción a una larga serie de investigaciones (ej: Reichstein and Salter, 2006; Mairesse and Mohnen, 2005; Baldwin et al., 2002), los esfuerzos de I+D no son importants para explicar los determinantes de una firma para conseguir mejores niveles de productividad realizando esfuerzos de innovación en proceso, confirmando el estudio de (2002). En este caso particular, de un país seguidor tecnológico, este resultado se esperaba dado el porcentaje de firmas en la muestral que no presentan esfuerzos conscientes de I+D (en cualquier forma, gastos de I+D o compra de $\mathrm{I}+\mathrm{D}$ ). Este trabajo introduce una aproximación novedosa midiendo los efectos percibidos de actividades innovadoras en firmas usando variables no-I+D.

Las fuentes de conocimiento externas son positivas y significativas, en línea con otros estudios (Escribano et al., 2009; Barge-Gil, 2010; Vega-Jurado et al., 2008; Reichstein and Salter, 2006; Rouvinen, 2002; Cabagnols and Le Bas, 2002; Von Hippel, 1988). Especialmente cuando diferentes fuentes de conocimiento externas están presentes en varias especificaciones, los proveedores parecen ser la fuente de conocimiento más importante. Este resultado contradice a Bogers (2009) y Von Hippel (1998) y su foco en el cliente y confirma la visión de que los proveedores son conductores clave para los innovadores de proceso porque son la fuente de conocimiento clave cuando nos dirigimos a la innovación de proceso (ej. Reichstein and Salter, 2006), mientras que los clientes son la fuente clave cuando se usan actividades no tecnológicas para la innovación de proceso (ej.: Bogers, 2009). Más investigación se necesita ya que la mayoría de estudios en innovación ni se dirigen a aspectos no tecnológicos ni a actividades de no-I+D. Además, la mayoría de resultados están desviados debido a la 
selección muestral, por ejemplo, la mayoría de artículos emplean la I+D como el mayor inductor, lo cual restringe la muestra y los resultados no pueden ser usados apropiadamente en una muestra $\sin \mathrm{I}+\mathrm{D}$.

Se ha encontrado que el tamaño es un factor importante para explicar los incentivos a la innovación en proceso en la literatura (Damanpour, 2010; Reichstein and Salter, 2006; Keppler, 1996, Cohen and Klepper, 1996; Nord and Tucker, 1987) y para predecir una relación positiva relación. A pesar de las predicciones contradictorias nuestro estudia reporta que el tamaño es importante para conseguir resultados en innovación de proceso a través de las actividades de innovación. Esta idea implica que las firmas grandes tienen mayores oportunidades de mejorar la productividad a través de las reducciones de coste, flexibilidad y capacidad de mejora como innovadores de proceso. Esto contradice a Rammer et al. (2009) que señalaron que existen pocas (si es que existe alguna) barreras relativas al tamaño a la hora de aplicar técnicas de gestión de la innovación de forma exitosa, y que el desempeño de la innovación no está claramente asociado al tamaño (Camison-Zornoza et al., 2004).

Este trabajo no puede contribuir al debate sobre los resultados contradictorios entre los efectos complementarios y sustitutivos de las interacciones (ver Laursen and Salter, 2006; Vega-Jurado et al., 2008).

El rol predicho de complementareidad o interdependencia de innovación de proceso y producto no ha sido confirmada, a pesar de una importante corriente de la literatura (e.g., Damanpour, 2010; Reichstein and Salter, 2006; Pisano, 1997). En cualquier caso, una complementareidad entre producto y proceso no significa que las actividades de I+D son la principal o única medida de las mejoras de productividad a través de las actividades de innovación. Nuestro trabajo introduce actividades de no-I+D (compra de equipo y maquinaria) como mediador para conseguir un mayor efecto de las innovaciones de proceso.

Sin embargo, uno de los puntos más importantes en esta tesis está basada en el hecho de que los esfuerzos de $\mathrm{I}+\mathrm{D}$ y de no-I+D fueron usados para medir los inductores potenciales para explicar un mayor nivel de productividad llevando a cabo actividades de innovación de proceso como parte de los niveles de gestión de la firma. De hecho, dada esta (casi omitida) oportunidad de medir los inductores (input) de la innovación o actividades más allá de la $\mathrm{I}+\mathrm{D}$ es una forma de contribuir a ampliar la literatura para 
entender la innovación con y sin esfuerzos de I+D. En este sentido, Arundel et al. (2008) señalaron que los innovadores "omitidos" (o de no-I+D) no eran apoyados debidamente por la política de innovación, incluso cuando el cambio en el crecimiento de las ventas anuales entre los innovadores I+D y no-I+D ("omitidos") es similar y no hay razón para un sesgo en la política. De hecho, cuando se comparan las empresas que desarrollan $\mathrm{I}+\mathrm{D}$ y las no- $\mathrm{I}+\mathrm{D}$, la mitad las firmas no llevan a cabo $I+D$ y no existe diferencia en el desempeño, medido por un cambio en las ventas (pp.32). De forma similar, la OCDE (OECD, 2010) afirma que: “...las firmas pueden introducir nuevos productos en el mercado sin involucrarse en $I+D$. Nuevos indicadores revelan que en Australia y Noruega la propensión a innovar introduciendo productos nuevos para el mercado es similar tanto si la firma lleva a cabo $I+D$ como sino". Por ejemplo, se cita que en Luxemburgo el 52\% de las compañías que no desempeñaban I+D introducían innovaciones nuevas para el mercado comparado a tan solo un $63 \%$ de los que llevaban a cabo I+D interna. Además, esta idea sobre los innovadores no-I+D está vinculada a los resultados obtenidos en la literatura sobre el tamaño. En nuestra opinión, la mayoría de estudios que miden la innovación cometen importantes errores y el más importante, capaz de distorsionar los resultados es el siguiente: si la muestra está hecha de empresas que llevan a cabo I+D, la mayoría de firmas en la muestra son grandes. Esto puede distorsionar los resultados. En este caso particular, casi el 60\% de las firmas no llevaban a cabo actividades de I+D. Si el estudio hubiese incluido solo a las empresas que hacían $\mathrm{I}+\mathrm{D}$, ¿qué muestra estaríamos mostrando? ¿Cómo serían los resultados y las implicaciones? Incluir las actividades de I+D y de no-I+D para medir la innovación es una forma más equilibrada de entender su efecto. Sin embargo, se necesita más investigación en esta área, especialmente en relación no solo a los innovadores no-I+D sino a las actividades de no-I+D para medir adecuadamente esos innovadores a menudo "omitidos" y que con frecuencia son omitidos en el proceso de selección. Finalmente, como se evidencia en los resultados, los servicios actúan de una forma bastante similar a las firmas manufactureras, y ambos pueden ser medidos con variables similares, confirmando a Forsman y Rantanen (2011) y Gallouj y Savona (2009).

Este trabajo tiene algunas limitaciones. Primera, la muestra se toma en un país tecnológicamente seguidor (España) y no se puede extender a otros estados más avanzados tecnológicamente. Como Qian y Li (2003) señalaron, es imposible determinar la causalidad en un solo momento en el tiempo, aunque este estudio realiza 
la asunción de que las variables independientes no pueden tener una relación causal con el desempeño innovador de la firma, debido a la falta de retraso en el período de tiempo considerado entre algunas de las variables independientes y las dependientes, pero muestra importantes relaciones entre variables. Para futuros estudios, el rol de los innovadores no-I+D debería ser analizado más profundamente, especialmente comparando distintos países de la Unión Europea.

\section{b-) Conclusiones de la segunda parte de la tesis}

La segunda parte de la tesis explora la estrategia de innovación en proceso y arroja luz sobre este fenómeno usando una gran base de datos. El estudio de la innovación en proceso ha estado poco estudiado por los académicos (ej: European Commission, 2008; Hatch and Mowery, 1998) y sesgado mayormente hacia el estudio de la innovación de producto. En particular, este estudio presenta un intento de explorar los efectos que ela adopción de la innovación de proceso ejerce en el desempeño de la firma, enfatizando el rol de las potenciales complementariedades cuando se adopta simultáneamente nuevos métodos organizativos para integrar la introducción de nuevas tecnologías de proceso. Basado en 8,977 firmas que decían haber introducido al menos un nuevo proceso y usando datos de la encuesta CIS española para el 2006, el resultado, después de comprobar el posible sesgo en la selección muestral a través del procedimiento de dos pasos de Heckman, sugiere que las dos hipótesis que se establecen se aceptan y que las conclusiones son como sigue.

Primero, la introducción de nuevas prácticas de gestión o organizativas está positivamente relacionada con el desempeño en la innovación de proceso, es decir, que las nuevas prácticas de gestión de la innovación mejoran los efectos en el proceso. Este resultado está en línea con la idea de la adopción síncrona (Ettlie, 1988), “coupling of dissimilarities" (Trist and Murray, 1993) o complementariedades (Milgrom and Roberts, 1995).

Segundo y relativo a la segunda hipótesis, se observa una importante efecto de implementación o de aprender intentando (Fleck, 1994) en el cual la adquisición de conocimiento incorporado requiere que la organización se reorganice para asumir la nueva tecnología. Este resultado predicho en la literatura principalmente a través de 
casos de estudios y pequeños ejemplos (Fleck, 1994; Flowers, 2007; Leonard-Barton and Deschamps, 1988; Voss, 1988) se confirma a partir de la evidencia de nuestra gran muestra y por tanto establece que una positiva combinación o sincronización en la introducción de nuevo conocimiento incorporado junto con la innovación organizativa en orden a integrar o preparar la organización para el nuevo tipo de conocimiento, mostrando esta co-adopción un efecto positivo y complementario en el desempeño de la innovación de proceso y sus efectos en los procesos.

Por último, la investigación presenta implicaciones para los académicos y los políticos. Primero, los esfuerzos de la política para dar soporte a innovación de proceso debería: (a) facilitar el acceso a otros inputs además de a la I+D; (b) dar soporte organizativo o gestionar la innovación como un complemento para implementar la tecnología y así mejorar la innovación de proceso, produciendo sinergias que expandirán y ampliarán el desempeño en la adopción de nuevos procesos; (c) incentivar la adquisición de conocimiento incorporado a través del equipamiento tecnológico para contrarrestrar la falta de recursos internos; (d) promover el trabajo en red para buscar conocimiento. Segundo, los académicos deberían también incluir el efecto de la adopción de innovación de proceso más allá o complementariamente a la más estudiada innovación de producto. En particular, los académicos deberían centrarse en indicadores no- $\mathrm{I}+\mathrm{d}$ debido al hecho que la $\mathrm{I}+\mathrm{D}$ no puede explicar todos los tipos de decisiones en innovación, sus estrategias y efectos. Además, los académicos deberían también refinar y explotar la estrategia de innovación en proceso todavía poco estudiada en otros países y bases de datos.

La investigación tiene algunas limitaciones. El análisis de grandes bases de datos no puede captura muchas cuestiones que requiere métodos de observación directos. La muestra está basada en un país seguidor tecnológicamente (España) y no puede extenderse a otros estados más desarrollados tecnológicamente. Segundo, como Quan y Li (2003) señalarón, es imposible determinar la causalidad en un único punto del tiempo, aunque los datos CIS están retrasados en algunos aspectos en un período anterior de 2 años. Se asume solo en parte una causalidad, importando más la importancia de las relaciones encontradas. Para futuros estudios, se debería realizar un análisis más en profundidad sobre el papel de los innovadores sin $\mathrm{I}+\mathrm{D}$ comparando distintos países de la Unión Europea, así como un análisis de bases de datos panel para poder estudiar mejor los efectos de causalidad. 


\section{c) Conclusiones generals.}

A partir del trabajo empírico se deducen diversas conclusiones, si bien en la primera parte vemos como la $\mathrm{I}+\mathrm{D}$ y otras actividades innovadoras internas no son significativas para conseguir efectos de innovación en proceso; encontramos que la compra de maquinaria si lo es, también la utilización de fuentes de conocimiento industriales, internas y otras (consultores, ferias, etc.) si influyen en el desempeño de lo que llamamos la productividad percibida. Contradiciendo a una importante corriente de la literatura la innovación en producto no parece moderar positivamente la innovación en proceso para los efectos observados en mejora de procesos. Corroborando una gran corriente en la literatura, el tamaño si parece importar para observar mayores efectos sobre los procesos.

En la segunda parte y a partir de estos hallazgos se estudia como la innovación organizativa modera positivamente los efectos en la innovación en proceso de la compra de maquinaria y equipos. La adecuación de la organización a los nuevos equipos resulta fundamental para observar mayores efectos en aumento de flexibilidad, reducción de costes, reducción de mano de obra y de materiales y energía.

Desde el punto de vista metodológico en la tesis se han tratado cuatro métodos econométricos (estadísticos): análisis factorial de componentes principales, regresión ordinaria por mínimos cuadrados, probit y el cálculo de la inversa del ratio de Mill's siguiendo a Heckman (1978).

Desde el punto de vista de novedad de variables tratadas aparece sobretodo el cálculo de un análisis factorial sobre las variables de los efectos observados en procesos de la innovación, esta novedad nos permite medir el desempeño observado en innovación en proceso y no tan solo estudiar la decisión de innovar en proceso o no.

Como conclusiones interesantes para la política sobre innovación corregimos el sesgo de muchas muestras al incluir además a los innovadores no-I+D, responsables de una parte nada despreciable de las innovaciones.

Estas conclusiones son especialmente interesantes para un país tecnológicamente seguidor como España, con pocas empresas (en \%) que tengan I+D y una mayoría de 
empresas pertenecientes a sectores low-tech, con escasez de recursos internos y innovan en proceso para mejorar su competitividad.

\section{BIBLIOGRAFÍA.}

Abernathy, W.J.; Utterback, J.M. (1978). Patterns of Industrial Innovation. Technology Review, 80(7): 40-47.

Adner R. and Levinthal D. (2001). Demand heterogeneity and technology evolution: Implications for product and process innovation. Management Science, 611-628. 
Ahuja, G.; Katila, R. (2001). Technological acquisitions and the innovation performance of acquiring firms: a longitudinal study. Strategic Management Journal 22 (3): 197-220.

Aiken M.; Hage J. (1971). The organic organization and innovation. Sociology, 5(1): 63.

Albaladejo, M.; Romijn H. (2000) Determinants of innovation capability in small UK firms: an empirical analysis, ECIS Working Papers 00.13, Eindhoven Centre for Innovation Studies, Eindhoven University of Technology.

Amit, R.; Schoemaker, P. (1993). Strategic Assets and Organizational Rent. Strategic Management Journal, 14: 33-46.

Antonelli, C. (1998). Localised Technological Change, New Information Technology and the Knowledge-Based Economy: European Evidence. SI4S Topical Papers, 8, Step Group: Oslo.

Ark, B. van; Inklaar, R.; McGuckin, R.; Timmer, M.P. (2003a). The employment effects of the New Economy: A Comparison of the European Union and the United States. National Institute Economic Review, 184 (1): 70-82.

Ark, B. van; Inklaar, R.; McGckin, R.G. (2003b). ICT and productivity in Europe and United States: where do the differences come from? CESifo Economic Studies, 49 (3): 295-318.

Arundel, A.; Van de Paal, G.; Soete, L. (1995). Innovation strategies of Europe's largest industrial firms, PACEReport. MERIT, University of Limbourg, Maastricht.

Arundel, A.; Bordoy, C.; Kanerva, M. (2008). Neglected Innovators: How Do Innovative Firms that Do not Perform R\&D Innovate? Results of an Analysis of the Innobarometer 2007 Survey No. 215, INNO Metrics Thematic Paper, The Hague.

Asheim, B.T.; Isaksen, A. (1997). Location, agglomeration and innovation: towards regional innovation systems in Norway. European Planning Studies 5 (3): 299-330.

Asheim, B.T.; Gertler, M.S. (2005). The geography of innovation: regional innovation systems. In: Fagerberg, J., Mowery, D.C., Nelson, R.R. (Eds.). The Oxford Handbook of Innovation. Oxford University Press, Oxford, 291-317. 
Atuahene-Gima, K. (1995). An exploratory analysis of the input of market orientation on new product performance: a contingency approach. Journal of Product Innovation Management, 12: 275-93.

Atuahene-Gima, K.; Ko, A. (2001). An Empirical Investigation of the Effect of Market Orientation and Entrepreneurship Orientation Alignment on Product Innovation. Organization Science, 12(1): 54-74.

Baer, M.; Frese, M. (2003). Innovation is not enough: climates for initiative and psychological safety, process innovations, and firm performance. Journal of Organizational Behaviour, 24: 45-68.

Balaz, V. (2003). Knowledge intensive business services in a transition economy. Ekonomicky Casopis, 51: 475-488.

Baldwin, J.; Hanel, P.; Sabourin, D. (2002). Determinants of innovative activity in Canadian manufacturing firms. In A. Kleinknecht and P. Mohnen (eds), Innovation and Firm Performance, pp. 86-111. New York: Palgrave.

Baptista, R.; Swann, P. (1998). Do firms in clusters innovate more? Research Policy, 27: $525-540$.

Barcet, A.; Bonamy, J.; Mayère, A. (1987). Modernisation et innovation dans les services aux entreprises. Commissariat Général du Plan.

Barge-Gil, A. (2010). Cooperation-based innovators and peripheral cooperators: An empirical analysis of their characteristics and behaviour. Technovation, 30: 195-206.

Barge-Gil A., Nieto M. J., Santamaría L., (2011). Hidden innovators: The role of nonR\&D activities. Technology Analysis \& Strategic Management ,23(4), 415-432.

Barney, J. B. (1991). Firm resources and sustained competitive advantage. Journal of Management, 17: 99-120.

Barley, S. R. (1986). Technology as an occasion for structuring: Evidence from observations of $\mathrm{CT}$ scanners and the social order of radiology departments. Administrative Science Quarterly,31: 78-108. 
Barras, R. (1986). Towards a theory of innovation in services. Research Policy, 15: 161-173.

Barras, R. (1990). Interactive innovation in financial and business services: the vanguard of the service revolution. Research Policy, 19: 215-237.

Battisti, G.; Stoneman, P. (2010). How innovative are UK firms? Evidence from the fourth UK community innovation survey on synergies between technological and organizational innovations. British Journal of Management, 21 (1): 187-206.

Baumol, W. (1967). The macroeconomics of unbalanced growth. American Economic Review, 57 (3): 415-26.

Baumol, W. (1985). Productivity Policy and the Service Sector, in Managing the Service Economy: Prospects and Problems, Inman, R.P. (ed.) University Press: Cambridge, 301-317.

Baumol, W. (2000). Services as leaders and the leader of the services. Inaugural Lecture: International conference on the economics and socio-economics of services, Lille, France, 22-23 June.

Bayus, B. (1995). Optimal dynamic policies for product and process innovation. Journal of Operations Management, 12: 173-185.

Becheikh, N.; Landry, R.; Amara, N. (2006). Lessons from innovation empirical studies in the manufacturing sector: A systematic review of the literature from 1993-2003. Technovation, 26(5/6): 644-664.

Becker, S.; Egger, P. (2009). Endogenous product versus process innovation and a firm's propensity to export. Empirical Economics.

Belleflamme, C.; Houard, J.; Michaux, B.; (1986). Innovation and research and development process analysis in service activities. IRES, EEC-FAST report, August

Beneito, P. (2003). Choosing among alternative technological strategies: an empirical analysis of formal sources of innovation. Research Policy, 32: 693-713.

Bessant, J. (2003). High Involvement Innovation: Building and Sustaining Competitive Advantage Through Continuous Change. John Wiley: Chichester, UK. 
Bessant J.; Tidd J. (2007). Innovation and Entrepreneurship. John Wiley: Chichester, UK.

Beugelsdijk, S.; Cornet, M. (2002). A far friend is worth more than a good neighbour: proximity and innovation in a small country. Journal of Management and Governance, 6 (2): 169-188.

Bhoovaraghavan, S.; Vasudevan, A.; Chandran, R. (1996). Resolving the process vs. product innovation dilemma: A consumer choice theoretic approach. Management Science, 42 (2): 232-246.

Birkinshaw J, Hamel G, Mol M. 2008. Management innovation. The Academy of Management Review (AMR) 33 (4): 825-845.

Bitran, G.; Pedrosa, L. (1998). A structured product development perspective for service operations. European Management Journal, 16: 169-89.

Blind, K.; Grupp, H. (1999). Interdependencies between the science and technology infrastructure and innovation activities in German regions: empirical findings and policy consequences. Research Policy, 28: 451-468.

Blundell, R.; Griffith, R.; Van Reenen, J. (1999). Market share, market value and innovation in a panel of British manufacturing firms. Review of Economic Studies, 66: $529-554$.

Bogers, M. (2009). The sources of process innovation in user firms: an exploration of the antecedents and impact of non-R\&D innovation and learning-by-doing. Foray, Dominique (dir.). Ph.D. Thesis. Lausanne: Ecole Polytechnique Fédérale.

Bogers, M.; Lhuillery, S. (2010). The Role of Openness of R\&D, Manufacturing and Marketing in Product and Process Innovation (July 31, 2010). Working Paper.

Bonano, G.; Haworth, B. (1998). Intensity of competiton and the choice between product and process innovation. International Journal of Industrial Organization, 16: $495-510$.

Bougrain, F.; Haudeville, B. (2002). Innovation, collaboration and SMEs' internal research capacities, Research Policy, 31: 735-748. 
Bresand, A.; Nicolaïdis, K. (1988) Les services au cœur de l'économie relationnelle. Revue d'Economie Industrielle, 43: 141-163.

Breschi, S.; Malerba, F.; Orsenigro, L. (2000). Technological regimes and Schumpeterian patterns of innovation. The Economic Journal, 110: 388-410.

Bresson, C.; Townsend, J. (1981). Multivariate models for innovation-Looking at the Abernathy-Utterback model with other data. Omega, 9 (4): 429-436.

Brouwer, E.; Kleinknecht., A. (1997). Measuring the immeasurable: A country's nonR\&D expenditure on product and service innovation. Research Policy, 25: 1235-42.

Brouwer, E.; Budil-Nadvornikova, H.; Kleinknecht, A. (1999). Are urban agglomeration a better breeding place for product innovation? An analysis of new product announcements. Regional Studies, 33 (6): 541-549.

Buesa, M.; Heijsa, J.; Baumert, T. (2010). The determinants of regional innovation in Europe. A combined factorial and regression knowledge production function approach. Research Policy, 39 (6): 722-735.

Cabagnols, A. (1999). The Determinants of the Continuity and Consistency of the Innovative Behaviour of Product and Process Innovators. European Meeting on Applied Evolutionary Economics, 7 - 9 June, 1999, Grenoble, France.

Cabagnols, A.; Le Bas, C. (2002). Differences in the determinants of product and process innovations: The French case, in Innovation and Firm Performance. Econometric Explorations of Survey Data (Alfred Kleinknecht and Pierre Mohnen, eds.). Palgrave, Hampshire and New York.

Cabral, R.; Leiblein, M. J. (2001). Adoption of capital embodied process innovations in industries with learning by doing. Journal of Industrial Economics, 49(3): 269-280.

Cainelli, G.; Evangelista, R.; Savona, M. (2004). The Impact of Innovation on Economic Performance in Services. The Service Industries Journal, 24 : 116-130.

Cainelli, G.; Evangelista, R.; Savona, M. (2006). Innovation and economic performance in services: a firm-level analysis. Journal of Economics, 30: 435-458. 
Caird, S. (1994). How important is the innovator for the commercial success of innovative products in SMEs? Technovation, 14 (2): 71-83.

Camacho, J.A.; Rodriguez, M. (2005). How Innovative are Services? An Empirical Analysis for Spain. The Service Industries Journal, 25: 253-271.

Camison-Zornoza, C.; Lapiedra-Alcami, R.; Segarra-Cipres, M.; Boronat-Navarro, M. (2004). A meta-analysis of innovation and organizational size, Organization Studies, 25: $331-361$.

Campbell, D.T.; Fiske, D.W. (1959). Convergent and discriminant validation bymultitrait multimethod matrix. Psychological Bulletin, 56: 81-105.

Capaldo, A. (2007). Network structure and innovation: the leveraging of a dual network as a distinctive relational capability. Strategic Management Journal, 28(6): 585-608.

Cebon, P.; Newton, P. (1999). Innovation in Firms: Towards a Framework for Indicator Development. Working Paper 99-109, Melbourne Business School.

Celikel-Esser, F., Villalba, E.; Tarantola, S. (2008). The Lisbon strategy and development of metrics to measure innovation in Europe; in Statistics Sweden (ed.) Yearbook on productivity 2007, pp. 7-33. Orebro: Statistics Sweden.

Cesaretto, S.; Mangano, S. (1992). Technological profiles and economic performance in the Italian manufacturing sector. Economics of Innovation and New Technology, 2: $237-256$.

Chandy, R. K.; Tellis, G.L. (2000). The incumbent's curse. Incumbency, size, and radical product innovation. Journal of Marketing, 64: 1-17.

Chuang, Y. C.; Lin, C. M. (1999). Foreign direct investment, R\&D and spillover efficiency: evidence from Taiwan's manufacturing firms. The Journal of Development Studies, 35: 117-37.

Clark, K.B.; Wheelwright, S.C. (1993). Managing New Product and Process Development. The Free Press, New York.

Clausen, T.; Pohjola, M.; Sapprasert, K.; Verspagen, B. (2011). Innovation strategies as a source of persistent innovation. Industrial and Corporate Change. 
Cleff, T.; Rennings, K. (1999). Determinants of environmental product and process innovation - evidence from the Mannheim Innovation Panel and a follow-up telephone survey. European Environment, special issue on integrated product policy, Karl H, Orwat C (eds), 9(5): 191-201.

Cohen S. S.; Zysman J. (1987). Manufacturing matters: The myth of the post-industrial economy. Basic Books, New York.

Cohen, W.; Levinthal, D. (1989). Innovation and learning: the two faces of R\&D. Economic Journal, 99: 569-596.

Cohen, W.; Levinthal, D. (1990). Absorptive capacity: a new perspective on learning and innovation. Administrative Science Quarterly, 35 (1): 128-152.

Cohen, W. M.; Klepper, S. (1996). Size and the nature of innovation within industries: the case of process and product R\&D. Review of Economics and Statistics, 78: 232-243.

Cohen, W.; Nelson, R. (2000). Protecting their Intellectual Assets: Appropriability Conditions and Why US Manufacturing Firms Patent (or Not). Cambridge, MA (USA): National Bureau of Economic Research Doc. Trab. 7552.

Cohen, W.M.; Malerba, F. (2001). Is the tendency to variation a chief cause of progress? Industrial and Corporate Change, 10: 587-608.

Comisión interministerial de ciencia y tecnología. (2007). Plan Nacional de Investigación Científica, Desarrollo e Innovación Tecnológica 2008-2011. Fundación Española para la Ciencia y la Tecnología (FECYT).

Conte A, Vivarelli M. 2005. One or many knowledge production functions? Mapping innovative activity using microdata. IZA: Discussion paper $\mathrm{n}^{\circ} 1878$.

Cooke, P. (1992). Regional Innovation Systems: Competitive Regulation in the New Europe. Geoforum, 23: 365-382.

Cooke, P.; Gómez, M.; Etxebarria, G. (1997). Regional Innovation Systems: Institutional and Organizational Dimensions. Research Policy, 26 (4-5): 475-491.

Cooke, P.; Memedovic, O. (2003). Strategies for Regional Innovation Systems: Learning Transfer and Applications, Vienna: UNIDO Policy Papers. 
Coombs, R.; Miles, I. (2000). Innovation, measurement and services. En Metcalfe, J.S.; Miles, I. (Eds). Innovation Systems in the Service Economy. Measurement and Case Study Analysis, Kluwer Academic, Boston, MA, 85-103.

Coombs, R.; Tomlinson, M. (1998). Patterns in UK company innovation styles: new evidence from the CBI innovation trends survey. Technology Analysis and Strategic Management 10 (3): 295-310.

Crouch, C.; Le-Galés, P.; Trigilia, C. ; Voelzkow, H. (2004). Changing Governance of Local Economies: Responses of European Local Production Systems, Oxford, Oxford University Press.

Crossan, M.M.; Apaydin, M. (2010). A Multi-Dimensional Framework of Organizational Innovation: A Systematic Review of the Literature. Journal of Management Studies, 47(6): 1154-1191.

Cua, K.O.; McKone K.E.; Schroeder, R.G. (2001). Relationships between implementation of TQM, JIT, and TPM and manufacturing performance. Journal of Operations Management 19 (6): 675-694.

Cuervo-Cazurra, A.; Un, C.A. (2007). Regional economic integration and R\&D investment. Research Policy, 36: 227-46.

Damanpour, F. (1991). Organizational innovation-a meta-analysis of effects of determinants and moderators. Academy of Management Journal, 34: 555-90.

Damanpour, F. (2010). An integration of research findings of effects of firm size and market competition on product and process innovations. British Journal of Management, 21: 996-1010.

Damanpour F.; Evan W. M. (1984). Organizational innovation and performance: The problem of organizational lag. Administrative Science Quarterly, 392-409.

Damanpour, F.; Gopalakrishnan, S. (2001). The dynamics of the adoption of product and process innovation in organizations. Journal of Management Studies, 38(1): 45-65.

Damanpour, F.; Aravind, D. (2006). Product and process innovations: a review of organizational and environmental determinants. In J. Hage and M. Meeus (eds), 
Innovation, Science, and Institutional Change: A Research Handbook, pp. 38-66. Oxford: Oxford University Press.

Damanpour, F.; Walker, R. M.; Avellaneda, C. N. (2009). Combinative effects of innovation types and organizational performance: A longitudinal study of service organizations. Journal of Management Studies, 46(4), 650-675

Debackere, K.; Clarysse, B.; Rappa, M.A. (1996). Dismantling the ivory tower: the influence of networks on innovative output in emerging technologies. Technological Forecasting and Social Change, 53: 139-154.

Den Hertog, P. (2000). Knowledge intensive business services as co-producers of innovation. International Journal of Innovation Management, 4(4): 491-528.

De Vries, E. (2006). Innovation in services in networks of organizations and in the distribution of services. Research Policy 35(7): 1037-1051

Dierickx I, Cool K. 1989. Asset stock accumulation and sustainability of competitive advantage. Management science : 1504-1511.

Dierkes, M. (2003). Visions, Technology, and Organizational Knowledge: An Analysis of the Interplay between Enabling Factors and Triggers of Knowledge Generation. En J. de la Motte y Foray, D. Knowledge Management in the Innovation Process (págs. 9-42). Knowledge Management in the Innovation Process.

Dicken, P.; Forsgren, M.; Malmberg, A. (1994). The local embeddness of transnational corporations. En: Amin, A., Thrift, N. (Eds.), Globalization, institutions and regional development in Europe. Oxford University Press, Oxford, pp. 23-45.

Djellal, F.; Gallouj, F. (2001). Patterns of Innovation Organisation in Service Firms: Postal Survey Results and Theoretical Models. Science and Public Policy, 28(1): 57-67.

Dolfsma, W. (2004). The process of new service development - issues of formalization and appropriability. International Journal of Innovation Management. 8 (3): 319-337.

Doloreux, D.; Shearmur, R. (2010). Exploring and comparing innovation patterns across different knowledge intensive business services. Economics of Innovation and New Technology, 99999(1), 1-21. 
Donaldson, L. (1996). For positivist organization theory: Proving the hard core. Sage Publications Ltd.

Dosi, G. 1982. Technological Paradigms and Technological Trajectories: A Suggested Interpretation of the Determinants and Directions of Technical Change. Research Policy 11 (3) $147-162$.

Dosi, G.; Freeman, C.; Nelson, R.; Silverberg, G.; Soete, L. (Eds.), (1988). Technical Change and Economic Theory. Pinter, London.

Dosi, G. (1992). The nature of the innovative process. In Nelson R (ed). Oxford University Press, USA

Dougherty, D. (1992). Interpretive Barriers to Successful Product Innovation in Large Firms. Organization Science, 3(2): 179-202.

Drejer, I. (2002). A Schumpeterian perspective on service innovation. Paper presented at the $9^{\text {th }}$ International Joseph Schumpeter Society Conference, Gainesville, March 2002 .

Drejer, I. (2004). Identifying innovation in surveys of services: a Schumpeterian perspective. Research Policy, 33: 551-62.

Duguay, C. R., Landry S., Pasin F., 1997. From mass production to flexible/agile production. International Journal of Operations \& Production Management, 17(12): 1183-1195.

Dyer J.; Singh, H. (1998). The relational view: cooperative strategy and sources of interorganizational competitive advantage. Academy of Management Review, 23: 660679.

Edquist, C. (1997). Systems of innovations: Technologies, Institutions and Organizations. London: Pinter.

Edquist, C. (2001). Innovation policy-a systemic approach. The Globalizing Learning Economy: 219-238.

Edquist, C.; Hommen, L.; McKelvey, M.D. (2001). Innovation and employment: Process versus product innovation. Edward Elgar Pub. 
Emery, F. (1990). The nine-step model. The Social Engagement of Social Science, A Tavistock Anthology: The Socio-Technical Perspective, 2: 569-579.

Escribano, A.; Fosfuri, A.; Tribo, J. (2009). Managing external knowledge flows: the moderating role of absorptive capacity. Research Policy, 38: 96-105.

Etienne, E.C. (1981). Interactions between R\&D product and process technology. Research Management, 24: 22-27.

Ettlie J. E.; Bridges W. P.; O'keefe, R. D. (1984). Organization strategy and structural differences for radical versus incremental innovation. Management Science, 682-695.

Ettlie, J. E. (1988). Taking charge of manufacturing: How companies are combining technological and organizational innovations to compete successfully. Jossey-Bass Inc., Publishers.

Ettlie, J.E.; Reza, E.M. (1992). Organizational integration and process innovation. Academy of Management Journal, 35: 795-827.

European Commission (2008). European Innovation Scoreboard 2007 - Comparative Analysis of Innovation Performance, PRO INNO Europe/INNO-Metrics, February.

Evangelista, R. (2000). Sectoral patterns of technological change in services. Econonomics of Innovations and New Technologies, 9: 183-221

Evangelista, R.; Perani, G.; Rapiti, F.; Archibugi, D. (1997). Nature and impact of innovation in manufacturing industry: some evidence from the Italian innovation survey. Research Policy, 26: 521-536.

Evangelista, R.; Savona, M. (2002). The Impact of Innovation on Employment in Services: evidence from Italy. International Review of Applied Economics, 16: 309-318.

Evangelista R.; Iammarino S.; Mastrostefano V.; Silvani A. (2002). Looking for regional systems of innovation: Evidence from the italian innovation survey. Regional Studies, 36(2): 173-186.

Evangelista, R.; Savona, M. (2003). Innovation, employment and skills in services. Firm and sectoral evidence. Structural Chance and Economic Dynamics, 14: 449-474. 
Evangelista, R.; Vezzani, A. (2010). The economic impact of technological and organizational innovations. A firm-level analysis. Research Policy, 39 (10): 1253-1263.

Fagerberg, J.; Mowery, D.C.; Nelson, R.R. (Eds.) (2005). The Oxford Handbook of Innovation. Oxford University Press, Oxford

Fagerberg, J.; Srholec, M. (2008). National innovation systems capabilities and economic development. Research Policy, 37: 1417-1435.

Fleck J. (1994). Learning by trying: The implementation of configurational technology. Research Policy, 23(6): 637-652.

Flowers S. (2007). Organizational capabilities and technology acquisition: Why firms know less than they buy. Industrial and Corporate Change, 16(3): 317-346.

Follet MP. 1933. Freedom \& coordination: Lectures in business organization 18681933. Garland Publishing, 1987: New York (originally published in 1949).

Forsman, H.; Rantanen, H. (2011). Small manufacturing and service enterprises as innovators: a comparison by size. European Journal of Innovation Management, 14 (1): 27-50.

Foss, N. J. (1996). Higher-order industrial capabilities and competitive advantage. Journal of Industry Studies, 3: 1-20.

Franke, R.H.; Hofstede, G.; Bond, M.H. (1991). Cultural roots of economic performance: a research note. Strategic Management Journal, 12: 165-173 (Special Issue).

Freel, M. (2000). External linkages and product innovation in small manufacturing firms. Entrepreneurship and Regional Development, 12: 245-266.

Freel, M.S. (2003). Sectoral patterns of small firm innovation, networking and proximity. Research Policy, 32: 751-770.

Freel, M.S. (2006). Patterns of technological innovation in knowledge-intensive business services. Industry and Innovation, 13: 335-358.

Freel, M.S. (2007). Are small innovators credit rationed? Small Business Economics, 28 (1): 23-35. 
Freel, M.; Harrison, R. (2006). Innovation and cooperation in the small firm sector: evidence from “'Northern Britain”, Regional Studies, 40(4): 289-305.

Freeman, C. (1987). Technology policy and economic performance: Lessons from Japan. London: Pinter.

Fritsch, M.; Meschede, M. (2001). Product innovation, process innovation, and size. Review of Industrial Organization, 19: 335-350.

Froehle, C.M.; Roth, A.V. (2007). A resource-process framework of new service Development. Production and Operations Management, 16(2): 169-88.

Gadrey, J.; Gallouj, F.; Weinstein, O. (1994) New Modes of Innovation. How Services Benefit Industry. International Journal of Service Industry Management, 6: 4-16.

Gago, D.; Rubalcaba, L. (2007). Innovation and ICT in service firms: towards a multidimensional approach for impact assessment. Journal of Evolutionary Economics, 17 (1): 25-44.

Gallaher, M.P.; Petrusa, J.E. (2006). Innovation in the U.S service sector. Journal of Technology Transfer, 31, 611-628.

Gallouj, F. (1994). Economie de l'innovation dans les services, Editions L'Harmattan. Logiques économiques, Paris

Gallouj, F. (1998). Innovating in reverse: services and the reverse product cycle. European Journal of Innovation Management 1(3): 123-138.

Gallouj, F. (2002). Innovation in the service economy: the new wealth of nations. Edward Elgar, Cheltenham.

Gallouj, F.; Savona, M. (2009). Innovation in services. A review of the debate and a research agenda. Journal of Evolutionary Economies, 19 (2): 149-172.

Gallouj, F.; Weinstein, O. (1997). Innovation in services. Research Policy, 2: 537-556.

Georgantzas NC, Shapiro HJ. 1993. Viable theoretical forms of synchronous production innovation. Journal of Operations Management 11 (2): 161-183. 
Geroski, P.A. (1990). Innovation, technological opportunity and market structure. Oxford Economic Papers, 42: 586-602.

Gopalakrishnan, S.; Damanpour, F. (1997). A review of innovation research in economics, sociology and technology management. Omega, 25(1): 15-28.

Grant, R.M. (1996). Toward a knowledge-based theory of the firm. Strategic Management Journal, 17: 109-122.

Griliches, Z., (1990). Patent statistics as economic indicators: a survey. Journal of Economic Literature, 28: 1661-1707.

Gulati, R. (1998). Alliances and networks. Strategic Management Journal, 19(4): 293317.

Gulati, R.; Nohria, N.; Zaheer, A. (2000). Strategic networks. Strategic Management Journal, 21(3): 203-215.

Hagedoorn, J. (2002). Inter-firm R\&D partnerships - an overview of patterns and trends since 1960. Research Policy, 31 (4): 477-492.

Hair, J.F.; Black,W.C.; Babin, B.J.; Anderson, R.E.; Tatham, R.L. (2007).Multivariate Data Analysis, 6th ed. New Jersey, Prentice Hall.

Hall, B.H.; Lotti, F.; Mairesse, J. (2009). Innovation and productivity in SMEs: Empirical evidence for Italy Small Business Economics, 33 (1): 13-33.

Hall, L.A.; Bagchi-Sen, S. (2007). An analysis of firm-level innovation strategies in the US biotechnology industry, Technovation, Vol. 27, pp. 4-14.

Hansen, P.A. and G. Serin, 1997. Will low technology products disappear? The hidden innovation processes in low technology industries. Technological Forecasting and Social Change, 55: 179-191.

Hatch N.W.; Mowery D.C., (1998). Process innovation and learning by doing in semiconductor manufacturing. Management Science 44(11): 1461-1477.

Hauknes, J. (1998). Services in Innovation - Innovation in Services, SI4S Final Report, STEP Group. 
Hayes, R.H.; Jaikumar, R. (1988). Manufacturing's crisis: New technologies, obsolete organizations. Harvard business review, 66 (5): 77-85.

Heckman, J.J. (1979). Sample Selection Bias as a Specification Error. Econometrica, 47 (1), 153-161.

Heidenreich, M. (2009). Innovation patterns and location of European low- and medium- technology industries. Research Policy, 38, (3) 483-494.

Helfat, C. E.; Finkelstein, S.; Mitchell, W.; Peteraf, M.; Singh, H.; Teece, D.; Winter, S. (2007). Dynamic Capabilities: Understanding Strategic Change in Organizations. New York: Wiley.

Henderson, R.; Cockburn, I. (1996). Scale, scope and spillovers: the determinants of research productivity in drug discovery. RAND Journal of Economics, 27(1): 32-59.

Herbst, P.G. (1974) Socio-Technical design Strategies in multidisciplinary research. London: Tavistock Publications

Hervas-Oliver, J.L., Garrigos, J.A., Gil Pechuan, I. (2011). Making sense of innovation by $R \& D$ and non $R \& D$ innovators in low technology context: a forgotton lesson for policymakers. Technovation, 31:427-446.

Hipp, C.; Grupp, H. (2005). Innovation in the service sector: the demand for servicespecific innovation measurement concepts and typologies. Research Policy, 34: 517-35.

Hipp, C.; Kukuk, M.; Licht, G.; Muent, G. (1996). Innovation in services: Results of an innovation survey in the German service industries. Paper presented at the Conference on the new S\&T indicators for the knowledge-based economy. OECD: Paris.

von Hippel, E. (1986). Lead users: A source of novel product concepts. Management Science, 32: 791-805.

von Hippel, E. (1988). The Sources of Innovation. Oxford University Press: New York. von Hippel, E. (1998). Economics of product development by users: The impact of 'sticky' local information. Management Science, 44(5): 629-644.

Hofstede, G. (1980). Culture's Consequences: International Differences in WorkRelated Values. Sage, Beverly Hills, CA. 
Holbrook, J.A.; Wolfe, D.A. (2005). The innovation systems research network: a Canadian experiment in knowledge management. Science and Public Policy, 32(2): 109-118.

Hollander, S. G. (1965). The Sources of Increased Efficiency: A Study of DuPont Rayon Plants. MIT Press: Cambridge, MA.

Hollanders, H.; van Cruysen, A. (2008). Rethinking the European Innovation Scoreboard: A New Methodology for 2008-2010, INNO Metrics.

Hollenstein, H. (2003). Innovation modes in the Swiss service sector: a cluster analysis based on firm-level data. Research Policy, 32: 845-63.

Howells, J. (2001). The nature of innovation in services. Innovation and Productivity in Services, 57-82. OECD: Paris.

Howells, J. (2004). Innovation, consumption and services: encapsulation and the combinatorial role of services. The Service Industries Journal, 24 (1): 19-36.

Howells, J. (2006). Where to from here for services innovation? A paper presented at the Knowledge Intensive Services Activities (KISA) Conference, Sydney

Howells, J.; Tether, B. (2004). Innovation and Services: Issues at Stake and Trends, INNO Studies 2001 (ENTR-C/2001), Commission of the European Communities: Brussels-Luxembourg.

Huang, C.; Arundel, A. Hollanders, H. (2008). Non-R\&D innovation of manufacturing firms: theory and evidence from the third European Community innovation survey. Innovation Watch/Systematic report, Brussels: European Commission, DG Enterprise.

Huang, C.; Arundel, A.; Hollanders, H. (2010). How firms innovate: R\&D, non-R\&D, and technology adoption. UNU-Merit Working Paper \#2010-027. Maastricht, United Nations University.

Huergo, E.; Jaumandreu, J. (2004). Firms' age, process innovation and productivity growth. International Journal of Industrial Organization, 22: 541-559. 
Ichniowski, C.; Shaw, K.; Prennushi, G. (1997). The effects of human resource practices on manufacturing performance: A study of steel finishing lines. American Economic Review, 87 (3): 291-313.

Iammarino, S. (2005). An evolutionary integrated view of regional systems of innovation: concepts, measures and historical perspectives. European Planning Studies, 13(4): 497-518.

Jaffe, A.B. (1986). Technological opportunity and spillover of R\&D: evidence from firms, patents, profits and market value. The American Economic Review, 76(15): 984 1001.

Jaffe, A.B. (1988). Demand and supply influences in R\&D intensity and productivity growth. The Review of Economics and Statistics, 70: 431-437.

Jaffe, A.B. (1989). Characterizing the technological position of firms with application to quantifying technological opportunity and research spillovers. Research Policy, 18(2): 87-97.

Jaw, C.; Lo, J.; Lin, Y. (2010). The determinants of new service development: Service characteristics, market orientation, and actualizing innovation effort. Technovation, 30(4): 265-277.

Jelinek, M.; Burstein, M.C. (1982). The production administrative structure: A paradigm for strategic fit. Academy of Management Review: 242-252.

Jensen, M.B.; Johnson, B.; Lorenz, E.; Lundvall, B.A. (2007). Forms of knowledge and modes of innovation. Research Policy, 36(5): 680-693.

Kalantaridis, C.; Pheby, J. (1999). Processes of innovation among manufacturing SMEs: the experience of Bedfordshire. Entrepreneurship and Regional Development, 11: 5778.

Kam,W.P.; Kiese,M.; Singh, A.; Wong, F. (2003). The pattern of innovation in Singapore's manufacturing sector. Singapore Management Review, 25(1): 1-34.

Katila, R.; Ahuja, G. (2002). Something old, something new: a longitudinal study of search behavior and new product introduction. Academy of Management Journal, 45(8): $1183-1194$. 
Kaufmann, A.; Tödtling, F. (2001). Science-industry interaction in the process of innovation: the importance of boundary-crossing between systems. Research Policy, 30: 791-804.

Kearns, A.; Ruane, F. (2001). The tangible contribution of R\&D-spending foreignowned plants to a host region: a plant level study of the Irish manufacturing sector 1980-1996. Research Policy, 30: 227-244.

Keizer, J.A.; Dijkstra, L.; Halman, J.I.M. (2002). Explaining innovative efforts of SMEs. An exploratory survey among SMEs in the mechanical and electrical engineering sector in the Netherlands. Technovation, 22: 1-13.

Kim, L.; Nelson, R. R. (2000). Technology, learning and innovation: Experiences of newly industrializing economies. Cambridge University Press.

Kim, H.E.; Pennings, J.M. (2009). Innovation and Strategic Renewal in Mature Markets: A Study of the Tennis Racket Industry. In: Organization Science, 20(2): 368383.

Kleinknecht, A. (1987). Measuring R\&D in small firms: how much are we missing? The Journal of Industrial Economics. V. 36, n 2 253-256.

Kleinknecht, A.; Reijnen, J.O.N. (1991). More evidence on the undercounting of small firm R\&D, Research Policy, 20: 579-592.

Klepper, S. (1996). Entry, exit, growth, and innovation over the product life cycle. American Economic Review, 86(3): 562-583.

Klevorick, A.; Levin. R.; Nelson, R.; Winter, S. (1995). On the sources of significance of inter-industry differences in technological opportunities. Research Policy, 24: 185205.

Kline, S.J.; Rosenberg, N. (1986). An overview of innovation. En: Landau, R., Rosenberg, N. (Eds.), The Positive Sum Strategy: Harnessing Technology for Economic Growth. National Academy Press, Washington, 275-307.

Knight, K. E. (1967). A descriptive model of the intra-firm innovation process. Journal of Business, 40: 478-496. 
Koberg, C.S.; Uhlenbruck, N.; Sarason, Y. (1996). Facilitators of organizational innovation: the role of life-cycle stage. Journal of Business Venturing, 11: 133-149.

Koch, A.; Stahlecker, T. (2006). Regional Innovation Systems and the Foundation of Knowledge Intensive Business Services. A Comparative Study in Bremen, Munich, and Stuttgart, Germany, European Planning Studies, 14: 123-145.

Koeller, C.T. (1995). Innovation, market structure and firm size: a simultaneous equations model. Managerial and Decision Economics, 16: 259-269.

Koeller, C.T. (1996). Union membership, market structure, and the innovation output of large and small firms. Journal of Labor Research, 17(4): 683-699.

Koschatzky, K. (1999). Innovation Networks of Industry and Business-Related Services - Relations Between Innovation Intensity of Firms and Regional Inter-Firm Cooperation. European Planning Studies, 7: 737-757.

Koschatzky, K.; Bross, U.; Stanovnik, P. (2001). Development and innovation potential in the Slovene manufacturing industry: analysis of an industrial innovation survey. Technovation, 21: 311-324.

Kraft, K. (1990). Are Product- and Process-Innovation Independent of Each Other? Applied Economics, 22: 1029-1038.

Laestadius, S., Pedersen, T., Sandven, T. (2005). Towards a new understanding of innovativeness and of innovation based indicators. In: Bender, G., Jacobson, D., Robertson, P.L. (Eds.), Non-Research-Intensive Industries in the Knowledge Economy. Journal for Perspectives on Economic Political and Social Integration, 11 (1-2), 75122.

Lager, T. (2002) Product and process development intensity in process industry: a conceptual and empirical analysis of the allocation of company resources for the development of process technology, International Journal of Innovation Management, 4, 105-130.

Lager T. (2010). Managing Process Innovation: From Idea Generation to Implementation. World Scientific Publishing Company. 
Lam, A. (2005). Organizational innovation. In J. Fagerberg, D. C. Mowery \& R. R. Nelson (Eds.), (pp. 115-147). Oxford: Oxford University Press.

Lancaster, K.J. (1966). A new approach to consumer theory. Journal of Political Economy 14: 133-156.

Landry, R.; Amara, N.; Lamari, M. (2002). Does social capital determine innovation? To what extent? Technological Forecasting and Social Change, 69: 681-701.

Lanjouw, J.O.; Mody, A. (1996). Innovation and the international diffusion of environmentally responsive technology. Research Policy, 25: 549-571.

Laursen, K.; Salter, A. (2006). Open for innovation: the role of openness in explaining innovation performance among U.K. manufacturing firms. Strategic Management Journal, 27(2): 131-150.

Lee, J. (1995). Small firms' innovation in two technological settings. Research Policy, 24: $391-401$.

Lee, M.; Son, B.; Lee, H. (1996). Measuring R\&D effectiveness in Korean companies. Research Technology Management, 39: 28-31.

Lee, C.; Lee, K.; Pennings, J. (2001) Internal capabilities, external networks, and performance: a study on technology-based ventures. Strategic Management Journal, 22: $615-640$.

Leiponen, A. (2005). Organization of Knowledge and Innovation: The Case of Finnish Business Services, Industry and Innovation, 12: 185-203.

Leiponen, A.; Helfat, C.E. (2010). Innovation objectives, knowledge sources, and the benefits of breadth. Strategic Management Journal, 31 (2): 224-236.

Leonard-Barton D.; Deschamps I., (1988). Managerial influence in the implementation of new technology. Management Science, 1252-1265.

Levin, R.C.; Cohen, W.M.; Mowery, D.C. (1985). R\&D appropiability, opportunity and market structure: new evidence on some Schumpeterian hypotheses. American Economic Review Proceedings 75(2): 20-24. 
Licht, G.; Moch, D. (1999). Innovation and Information Technology in Services. Canadian Journal of Economics, 32 (2): 364-381.

Lim, P.L.L., Garnsey, E., Gregory, M. (2006). Product and process innovation in biopharmaceuticals - a new perspective on development. R\&D Management, 36: 2736.

Lin, P. C.; Huang, D. S. (2008). Technological regimes and firm survival: Evidence across sectors and over time. Small Business Economics, 30: 175-186.

Liu, X.; White, R.S. (1997). The relative contribution of foreign and domestic inputs to innovation in Chinese manufacturing industries. Technovation, 17 (3): 119-125.

Llorca-Vivero, R. (2002). The impact of process innovations on firm's productivity growth: the case of Spain, Applied Economics, 34: 1007-16.

Love, J.H.; Ashcroft, B. (1999). Market versus corporate structure in plant-level innovation performance. Small Business Economics, 13 (2): 97-109.

Love, J.H.; Roper, S. (1999). The determinants of innovation: R\&D, technology transfer and networking effects. Review of Industrial Organization, 15 (1): 43-64.

Love, J.H.; Roper, S. (2001). Location and network effects on innovation success: evidence for UK. German and Irish manufacturing plants. Research Policy, 30: 313332.

Lundvall, B. (1992). National systems of innovation: Towards a theory of innovation and interactive learning. London: Pinter.

Lunn, J. (1987). An Empirical Analysis of Firm Process and Product Patenting. Applied Economics, 19(6): 743-51.

Luria, D. (1987). Technology, work organization, and competitiveness: Automotive subsystem cost reduction, 1986-1992. Industrial Technology Institute, University of Michigan.

MacPherson, A.D. (1998). Academic-industry linkages and small firm innovation: evidence from the scientific instruments sector. Entrepreneurship and Regional Development, 10 (4): 261-276. 
Mairesse, J.; Mohnen, P. (2005). The importance of R\&D for innovation: a reassessment using French survey data, Journal of Technology Transfer, 30(1-2): 183197.

Malecki, E.J. (1997). Technology and Economic Development. Addison Wesley Longman, Harlow.

Máñez, J. A.; Rincón, A.; Rochina, M. E.; Sanchis, J. A. (2005). Productividad e I+D: Un análisis no paramétrico. Revista de Economía Aplicada, 39: 47-86.

Markus, M. L.; Robey, D. (1988). Information technology and organizational change: Causal structure in theory and research. Management Science, 583-598.

Marsili, O., Salter, A. (2006). The dark matter of innovation: Design and innovative performance in Dutch manufacturing. Technology Analysis \& Strategic Management 18, no. 5: 515-34.

Martinez-Ros, E. (2000). Explaining the decisions to carry out product and process innovations: the Spanish case. The Journal of High Technology Management Research, 10 (2): 223-242.

Maskell, P. (2001). Social capital, innovation and competitiveness, en S. Baron, J. Field y T. Schuller (Eds.), Social Capital: Critical perspectives, Oxford, Oxford University Press, pp. 111-123.

McCann, J.; Galbraith, J. R. (1981). Interdepartmental relations. Handbook of Organizational Design, 2: 60-84.

McEvily, B.; Zaheer, A. (1999). Bridging ties: a source of firm heterogeneity in competitive capabilities. Strategic Management Journal, 20: 1133-1156.

Michie, J.; Sheehan, M. (2003). Labor market deregulation, 'flexibility' and innovation. Cambridge Journal of Economics, 27 (1): 123-143.

Miles, I. (2002). Service innovation: towards a tertiarisation of innovation studies. In: Gadrey, J. and Gallouj, F. (Eds.) Productivity, innovation and knowledge in services. Edward Elgar, Cheltenham, 164-196 
Miles, I. (2005). Innovation in services. En Fagerberg, J., Mowery, D.C. and Nelson, R.R. (Eds), The Oxford Handbook of Innovation, Oxford University Press, Oxford, 433-58.

Miles, I.; Kastrinos, N.; Flanagan, K.; Bilderbeek, R.; den Hertog, P. (1995). Knowledge- intensive business services. Users, carriers and sources of innovation. Manchester: PREST.

Milgrom, P.; Roberts, J. (1990). The economics of modern manufacturing: Technology, strategy, and organization. The American Economic Review: 511-528.

Milgrom, P.; Roberts, J. (1995). Complementarities and fit strategy, structure, and organizational change in manufacturing. Journal of Accounting and Economics, 19 (2): 179-208.

Miozzo, M.; Soete, L. (2001). Internationalisation of services: a technology perspective, Technol. Forecast. Soc. Change, 67: 159-185.

Mothe, C.; Thi, T.U.N. (2010). The link between non-technological innovations and technological innovation. European Journal of Innovation Management, 13(3): 313332.

Muller, E. (2001). Innovation interactions between knowledge-intensive business services and small and medium-sized enterprises: an analysis in terms of evolution, knowledge and territories. Heidelberg: Physica-Verlag.

Mumford,M. D.; Scott, G.M.; Gaddis, B; Strange, J.M. (2002). Leading creative people: orchestrating expertise and relationships. Leadership Quarterly, 13: 705-50.

Murovec, N.; Prodan, I. (2008). The influence of organizational absorptive capacity on product and process innovation. Organization - Journal of Management, Informatics and Human Resources, 41(2): 43-49.

Muscio, A. (2007). The impact of absorptive capacity on SME's collaboration. Economics of Innovation and New Technology, 16: 653-668.

Nabseth, L.; Ray G. F.(1974). The diffusion of new industrial processes: An international study. Cambridge University Press. 
Nelson, R.R.; Winter, S.G. (1982). An Evolutionary Theory of Economic Change, Harvard University Press, Cambridge, MA.

Nelson, R. (1993). National systems of innovation: A comparative study. Oxford: Oxford University Press.

NESTA. (2007). National Endowment for Science, Technology and the Arts (NESTA), Hidden Innovation - How Innovation Happens in Six "Low Innovation" Sectors, June. NESTA, London.

Niehaves, B. (2010). Open process innovation: The impact of personnel resource scarcity on the involvement of customers and consultants in public sector BPM. Business Process Management Journal, 16(3): 377-393. Nord W. and Tucker S., 1987. Implementing routine and radical innovations. New York.

Nielsen, A.O. (2001). Patenting, R\&D and market structure: manufacturing firms in Denmark. Technological Forecasting and Social Change, 66: 47-58.

Nieto; M; Quevedo, P. (2005). Absorptive capacity, technological opportunity, knowledge spillovers and innovative effort. Technovation, 25: 1141-57.

Nord, W. R.; Tucker, S. (1987). Implementing Routine and Radical Innovations. Lexington, MA: Lexington Books.

OECD (1990). The Measurement of Scientific and Technological Activities. Proposed Standard Method of compiling and Interpreting Technology Balance of Payments DataBTP Manual. OECD, París.

OECD (1994). Manual de estadísticas de patentes. Paris: Oficina española de patentes y marcas. OCDE, París.

OECD (1995). Canberra Manual, Manual on the measurement of human resources devoted to S\&T. OCDE, Paris.

OECD (2001): The Well-being of Nations, The Role of Human and Social Capital. OECD, Paris. 
OECD (2002). Manual de Frascati, Propuesta de Norma Práctica para Encuestas de Investigación y Desarrollo Experimental de la OECD. Fundación española de ciencia y tecnología.

OECD (2004). The Economic Impact of ICT-Measurement: evidence and implications, OECD, Paris.

OECD; Eurostat (2005). Manual de Oslo, Guía para la recogida e interpretación de datos sobre innovación. OCDE, Paris.

OECD (2009) Innovation in Firms. A microeconomic Perspective. OECD publishing, Paris

OECD (2010). Measuring Innovation, a New Perspective, 2010. OECD Publications, Paris.

Ofek, E.; Sarvary, M. (2003). R\&D, Marketing, and the Success of Next-Generation Products. Marketing Science. Vol. 22, No. 3, Summer 2003, pp. 355-370.

Olazaran, M.; Otero, B. (2009). La perspectiva del sistema nacional/regional de innovación: balance y recepción en España. ARBOR Ciencia, Pensamiento y Cultura. 738: 767-779.

Ornaghi, C. (2006). Spillovers in Product and Process Innovation: Evidence From Manufacturing Firms, International Journal of Industrial Organization, 24: 349-380.

Oyelaran-Oyeyinka, B.; Laditan, G.O.A.; Esubiyi, A.O. (1996). Industrial innovation in sub-Saharan Africa: the manufacturing sector in Nigeria. Research Policy, 25: 10811096.

Pacheco-Pires, C.; Sarkar, S.; Carvalho, L. (2008). Innovation in services - how different from manufacturing? The Service Industries Journal, 28(10): 1339-1356.

Padmore, T. H. (1998). Modelling systems of innovation: an enterprise-centered view. Research Policy, 26: 605-624.

Papadakis, V.; Bourantas, D. (1998). The chief executive officer as corporate champion of technological innovation: an empirical investigation. Technology Analysis and Strategic Management, 10 (1): 89-98. 
Parthasarthy R, Sethi SP. 1992. The impact of flexible automation on business strategy and organizational structure. Academy of Management Review: 86-111.

Parthasarthy R, Sethi SP. 1993. Relating strategy and structure to flexible automation: a test of fit and performance implications. Strategic Management Journal, 14 (7): 529549.

Pasmore W, Francis C, Haldeman J, Shani A. 1982. Sociotechnical systems: A North American reflection on empirical studies of the seventies. Human Relations, 35 (12): 1179-1204.

Pavitt, K. (1984). Sectoral patterns of technical change: towards a taxonomy and a theory. Research Policy, 13: 343-374.

Pavitt, K.; Robson, M.; Townsend, J. (1989) Technological accumulation, diversification and organisation in UK companies. Manage Science, 35: 81-99.

Pérez, C. (1996). Nueva concepción de la tecnología y el sistema nacional de la innovación. Cuaderno del Cendes, 9-33.

Peteraf, M.A. (1993). The cornerstones of competitive advantage: a resource-based view. Strategic Management Journal, 14(3): 179-192.

Pires, C. P. ; Sarkar, S. ; Carvalho, L. (2008). Innovation in services-how different from manufacturing? The Service Industries Journal, 28(10): 1339-1356.

Pisano, G. P. (1994). Knowledge, integration, and the locus of learning: an empirical analysis of process development. Strategic Management Journal, 15, 85-100

Pisano, G. (1997). The Development Factory: Unlocking the Potential of Process Innovation. Harvard Business School Press: Boston.

Pisano G, Shuen A, Teece D. 1997. Dynamic capabilities and strategic management. Strategic Management Journal 18 (7): 509-533.

Porter, M.E. (1990). The Competitive Advantage of Nations. The Free Press, New York. 
Powell, W. W.; Koput, K. W.; Smith-Doerr, L. (1996). Interorganizational collaboration and the locus of innovation: networks of learning in biotechnology. Administrative Science Quarterly, 41(1): 116-145.

Qian, G.; Li, L. (2003). Profitability of small- and medium-sized enterprises in hightech industries: The case of the biotechnology industry. Strategic Management Journal, 24 (9): 881-887.

Rammer, C.; Czarnitzki, D.; Spielkamp, A. (2009). Innovation success of non-R\&Dperformers: substituting technology by management in SMEs. Small Business Economics, 33(1): 35-58.

Raymond, L. and St-Pierre, J. (2010). R\&D as a determinant of innovation in manufacturing SMEs: An attempt at empirical clarification, Technovation, 30: 48-56.

Rehder, R.R. (1989). Japanese transplants: in search of a balanced and broader perspective. Columbia Journal of World Business, 24 (4): 17-28.

Reichstein, T., Salter, A. (2006). Investigating the sources of process innovation among UK manufacturing firms. Industrial and Corporate Change, 15 (4): 653-682.

Rhyne, L.C.; Teagarden, M.B.; Van den Panhuyzen, W. (2002). Technology-based competitive strategies. The relationship of cultural dimensions to new product innovation. The Journal of High Technology Management Research, 13: 249-277.

Ritter, T.; Gemünden, H.G. (2003). Network competence: its impact on innovation success and its antecedents. Journal of Business Research, 56: 745-755.

Roberts, P.W.; Amit, R. (2003). The dynamics of innovative activity and competitive advantage: The case of Australian retail banking, 1981 to 1995. Organization Science: 107-122.

Rochina-Barrachina, M.E.; Mañez J.A.; Sanchis-Llopis J.A. (2010). Process innovations and firm productivity growth. Small Business Economy, 34: 147-166.

Romijn, H.; Albaladejo, M. (2002). Determinants of innovation capability in small electronics and software firms in southeast England. Research Policy, 31: 1053-1067.

Rogers, E. (1995). Diffusion of innovations. The Free Press, New York. 
Roper, S.; Love, J.H. (2002). Product innovation and small business growth: a comparison of the strategies of German, UK and Irish companies. Research Policy, 31: $1087-1102$.

Rosenberg, N. (1982), Inside the Black Box. Cambridge University Press: Cambridge, MA.

Ross, P. F. (1974). Innovation adoption by organizations. Personnel Psychology, 27(1): $21-47$.

Rouvinen, P. (2002). Characteristics of product and process innovators: some evidence from the Finnish innovation survey, Applied Economics Letters, 9(9): 575-580.

Rowley, T.; Behrens, D.; Krackhardt, D. (2000). Redundant governance structures: an analysis of structural and relational embeddedness in the steel and semiconductor industries. Strategic Management Journal, 21: 369-386.

Rubalcaba, L. (2006). Which policy for innovation in services? Science and Public Policy, 33 (10): 745-756.

Rubalcaba, L.; Di Meglio, G.; Visintin, S., Maroto, A.; Gallego, J. (2008). The competitiveness of European services. IAES Working Papers 01/2008.

Rubalcaba, L.; Kox, H. (2007). Business Services in European Economic Growth, Palgrave MacMillan, New York.

RYCIT y OEA. (2001). Manual de Bogotá, Normalización de Indicadores de Innovación Tecnológica en América Latina y el Caribe. COLCIENCIAS/OCYT.

Salter, W.E.G. (1960). Productivity and Technical Change. Cambridge University Press: Cambridge, MA

Salter, A.; Tether, B.S. (2006). Innovation in services: through the looking glass of innovation studies. Background paper for Advanced Institute of Management (AIM) Research's Grand Challenge on Service Science, April 7.

Santamaría, L.; Nieto, M.J.; Barge-Gil, A. (2009). Is there innovation beyond R\&D? The role played by other innovation activities. Universia Business Review, 22: 102-117. 
Santarelli, E.; Sterlacchini, A. (1990). Innovation, formal vs. informal R\&D, and firm size: Some evidence from italian manufacturing firms. Small Business Economics, 2(3): 223-228.

Saviotti, P.P.; Metcalfe, J.S. (1984). A theoretical approach to the construction of technological output indicators. Research Policy, 13: 141-151.

Scherer, F.M. (1965). Firm, size, market structure, opportunity, and the output of patented inventions. American Economic Review, 55: 1097-1125.

Scherer, F. M., (1983). Concentration, R\&D and productivity change. Southern Economic Journal, 50: 221-225.

Schilling, M. A. (2005). Strategic Management of Technological Innovation. New York: McGraw-Hill, Irwin.

Schmidt, T. and Rammer, C. (2007), "Non-technological and technological innovation: strange bedfellows?", Working Paper 07-052, ZEW, Mannheim, available at: $\mathrm{ftp}: / / \mathrm{ftp} . z e w \cdot d e / p u b /$

zew-docs/dp/dp07052.pdf (accessed 12 November 2009).

Schumpeter, J.A. (1934). Theory of Economic Development: An enquiry into Profits, Capital, Interest and the Business Cycle. Cambridge, MA. Harvard University Press.

Schumpeter, J.A. (1942). Capitalism, Socialism and Democracy. Harper, New York.

Scott, W. R. (1992). Organizations: Natural, rational and open systems Englewood Cliffs, NJ: Prentice-Hall.

Shane, S. (1993). Cultural influences on national rates of innovation. Journal of Business Venturing, 8: 59-73.

Simonetti, R.; Archibugi, D.; Evangelista, R. (1995). Product and process innovations: How are they defined? how are they quantified? Scientometrics, 32(1): 77-89.

Sinclair, G., Klepper, S. and Cohen, W. (2000). What's experience got to do with it? Sources of cost reduction in a large specialty chemicals producer. Management Science, 46: $28-45$. 
Sirilli, G.; Evangelista, R. (1998). Technological innovation in services and manufacturing: results from Italian surveys. Research Policy, 27: 881-99.

Skinner, W. (1992). The shareholder's delight: Companies that achieve competitive advantage from process innovation. International Journal Technology Management: 7, 1(3): 41-48.

Smolny, W. (2003). Determinants of innovation behaviour and investment estimates for West-German manufacturing firms. Economics of Innovation and New Technology, 12 (5): 449-463.

Som, O., Dreher, C; Maloca, S. (2010). Innovation patterns of non-R\&D performing firms in the German manufacturing industry. An evolutionary approach to heterogeneity in firms' innovation strategy. International Schumpeter Society Conference 2010 on Innovation, Organization, Sustainability and Crises. Aalborg, June 21-24, 2010

Souitaris, V. (2001). External communication determinants of innovation in the context of a newly industrialised country: a comparison of objective and perceptual results from Greece. Technovation, 21: 25-34.

Souitaris, V. (2002). Technological trajectories as moderators of firm-level determinants of innovation. Research Policy, 31: 877-898.

Sterlacchini, A., (1999). Do innovative activities matter to small firms in non-R\&D intensive industries? An application to export performance. Research Policy, 28: 819832.

Sternberg, R.; Arndt, O. (2001). The firm or the region: what determines the innovation behaviour of European firms? Economic Geography, 77 (4): 364-382.

Stieglitz N, Heine K. (2007). Innovations and the role of complementarities in a strategic theory of the firm. Strategic Management Journal, 28 (1): 1-15.

Storper, M.; Harrison, B. 1991. Flexibility, hierarchy and regional development: The changing structure of industrial production systems and their forms of governance in the 1990s. Research Policy, 20: 407-422. 
Stumpfe, J. (2001). Product design and manufacturing process: dynamic implications for innovation management, in: Presented at the $19^{\text {th }}$ International Conference of the System Dynamics Society, Atlanta, GA, USA, 2001.

Sundbo, J. (1997). Management of Innovations in Services. The Service Industries Journal, 17(3): 432-455.

Sundbo, J. (1998). The organisation of innovation in services. Roskilde University Press, Roskilde, Denmark

Sundbo, J.; Gallouj, F. (2000). Innovation as a loosely coupled system in services. En Metcalfe, J.S; Miles, I. (Eds). Innovation Systems in the Service Economy: Measurement and Case Study Analysis, London: Kluwer Academic Publishing, pp.4368.

Taylor, A. (2010). The Next Generation: Technology Adoption and Integration Through Internal Competition in New Product Development. Organization Science, 21: 23-41.

Taylor, P. J.; Flint, C. (2002). Geografía política: economía-mundo, estado-nación y localidad. Prentice Hall.

Teece, D. (1987) Profiting from technological innovation: implications for integration, collaborating, licensing, and public policy. In D. Teece (ed.) The Competitive Challenge. New York: Harper Collins: 185-219.

Teece, D.J., Pisano, G. and Shuen, A. (1997). Dynamic Capabilities and Strategic Management. Strategic Management Journal, 18: 509-533.

Terziovski, M. (2010). Innovation practice and its performance implications in small and medium enterprises (SMEs) in the manufacturing sector: a resource-based view. Strategic Management Journal, 31: 892-902.

Tether, B.S. (1999). Small firms, innovation and employment creation in Britain and Europe. A question of expectations ..., Technovation, 20: 109-113.

Tether, B. (2002). Who cooperates for innovation, and why. An empirical analysis. Research Policy, 31: 947-967. 
Tether, B.S. (2003). The Sources and Aims of Innovation in Services: Variety between and within Sectors, Economics of Innovation and New Technology, 12: 481-505.

Tether, B.S. (2005). Do services innovate (differently)? Insights from the European innobarometer survey. Industrial Innovation, 12: 153-184

Tether, B.S.; Hipp, C. (2002). Knowledge Intensive, Technical and Other Services: Patterns of Competitiveness and Innovation Compared. Technology Analysis \& Strategic Management, 14: 163-182.

Tether, B. S.; Metcalfe, J. S. (2003). Horndal at Heathrow? Capacity Creation through Cooperation and System Evolution. Industrial and Corporate Change, 12.3: 437-476.

Tether, B. S.; Mina, A.; Consoli, D.; Gagliardi, D. (2005). A Literature Review on Skills and Innovation. How Does Successful Innovation Impact on the Demand for Skills and How Do Skills Drive Innovation? Department of Trade and Industry, London

Tether, B.S.; Howells, J. (2007). Changing understanding of innovation in services. Innovation in services, DTI Occasional Paper No 9, June. 21-60.

Tether, B.S.; Tajar, A. (2008). The organisational-cooperation mode of innovation and its prominence amongst European service firms. Research Policy, 37(4): 720-39.

Thompson, J. D. (1967). Organizations in action. New York: Mc Graw Hill.

Tidd, J. (Ed.), (2000). Measuring Strategic Competencies: Technological, Market and Organisational Indicators of Innovation. Imperial College Press, London.

Tödtling, F.; Trippl, M. (2005). One size fits all? Towards a differentiated regional innovation policy approach. Research Policy, 34: 1203-1219.

Tödtling, F.; Lehner, P.; Trippl, M. (2006). Innovation in knowledge intensive industries: The nature and geography of knowledge links, European Planning Studies, 14: $1035-1058$.

Todorova, G.; Durisin, B. (2007). Absorptive capacity: valuing a reconceptualization. The Academy of Management Review, 32(3): 774-786.

Tomlinson, M. (2000). The contribution of knowledge-intensive services to the manufacturing industry. En Andersen, B.; Howells, J.; Hull, R.; Miles, I.; Roberts, J. 
(Eds). Knowledge and Innovation in the New Service Economy, Cheltenham: Edward Elgar, pp. 36-48.

Trippl, M.; Tödtling, F. (2007). Developing Biotechnology Clusters in Non-high Technology Regions: The Case of Austria. Industry and Innovation, 14 (1): 47-67.

Trist, E.; Murray, H. (1993). The Socio-Technical Perspective. University of Pennsylvania Press: Pennsylvania.

Trist, E.L. (1978). On socio-technical systems. Sociotechnical systems: A sourcebook.San Diego, CA: University Associates.

Turner, S.F.; Mitchell, W.; Bettis, R.A. (2010). Responding to Rivals and Complements: How Market Concentration Shapes Generational Product Innovation Strategy. Organization Science, 21: 854-872.

Tushman, M. L. (1977). Special boundary roles in the innovation process. Administrative Science Quarterly, 587-605.

Uchupalanan, K. (2000). Competition and IT-based Innovation in Banking Services. International Journal of Innovation Management, 4(4): 491-528.

Utterback J.M., Abernathy W. (1975). A dynamic model of process and product innovation. Omega, 6: 639-656.

Uzun, A. (2001). Technological innovation activities in Turkey: the case of manufacturing industry, 1995-1997. Technovation, 21: 189-196.

Vaona, A.; Pianta, M. (2008). Firm size and innovation in european manufacturing. Small Business Economics, 30(3): 283-299.

Vega-Jurado, J.; Gutiérrez-Gracia, A.; Fernández-de-Lucio, I.; Manjarrés-Henríquez, L. (2008). The effect of external and internal factors on firms' product innovation. Research Policy, 37 (4): 616-632.

Veugelers, R. (1997). Internal R\&D expenditures and external technology sourcing. Research Policy, 2: 303-315.

Veugelers, R.; Cassiman, B. (1999). Make and buy in innovation strategies: evidence from Belgian manufacturing firms. Research policy, 28: 63-80. 
Vivarelli, M.; Pianta, M. (ed) (2000). The employment impact of innovation. evidence and policy London: Routledge.

Vivarelli M. and Toivanen O. (1995). The economics of technology and employment: Theory and empirical evidence. Edward Elgar London.

Vonortas N.S., Xue, L. (1997). Process innovation in small firms: case studies on CNC machine tools. Technovation, 17(8): 427-38.

Voss, C. A. (1985). The role of users in the development of applications software. Journal Product Innovation Management, 2(2): 113-121.

Voss, C. A. (1988). Implementation: A key issue in manufacturing technology: The need for a field of study. Research Policy, 17(2): 55-63.

Walker, R. M. (2004). Innovation and organizational performance: Evidence and a research agenda. Advanced Institute of Management Research Working Paper, WP $\mathrm{n}^{\circ} 2$.

Weiss, P. (2003). Adoption of product and process innovations in differentiated markets: The impact of competition. Review of Industrial Organization, 23(3-4), 301314.

Wheelwright, S.C., Clark, K.B. (1992). Revolutionizing product development: quantum leaps in speed, efficiency, and quality. Free Press: New York

White, R. E.; Ruch, W. A. (1990). The composition and scope of JIT. Operations Management Review, 7(3/4): 9-18.

Windrum, P.; Garcia-Goñi, M. (2008). A neo-Schumpeterian model of health services innovation. Research Policy, 37(4): 649-672.

Windrum, P.; Tomlinson, M. (1999). Knowledge intensive services and international competitiveness: a four country comparison. Technology Analysis and Strategic Management, 11, 391-408.

Winter, S. G. (1984). Schumpeterian competition in alternative technological regimes. Journal of Economic Behaviour and Organization, 5: 287-320.

Wolfe, R. A. (1994). Organizational innovation: review, critique, and suggested research directions. Journal of Management Studies, 31: 405-431. 
Womack, J. P.; Jones D. T.; Roos, D. (1990). The Machine that Changed the World. Rawson Associates: New York.

Wong, P.K.; He, Z.L. (2005). A Comparative Study of Innovation Behaviour in Singapore's KIBS and Manufacturing Firms. The Service Industries Journal, 25: 23-42.

Wong, P.K.; Singh, A. (2004). The Pattern of Innovation in the Knowledge-intensive Business Services Sector of Singapore. Singapore Management Review, 26: 21-44.

Wu, W.Y.; Chiang, C.Y.; Jiang, J.S. (2002). Interrelationships between TMT management styles and organizational innovation. Industrial Management and Data Systems, 102 (3/4): 171-183.

Yin, X., Zuscovitch, E., (1998). Is firm size conducive to R\&D choice? A strategic analysis of product and process innovations. Journal of Economic Behavior \& Organization, 35: 243-262.

Zahra, S.A. (1993). New product innovation in established companies: associations with industry and strategy variables. Entrepreneurship Theory and Practice, Winter, 47-69.

Zeng, S.X.; Xie, X.M.; Tam, C.M. (2010). Relationship between cooperation networks and innovation performance of SMEs. Technovation, 30(3): 181-194. 


\section{Appendix A: effects on products from new processes introduction}

As Lager (2002) points out, one of the process development objective is also prompted by the needs or the company's own product development. Therefore, the introduction of new processes not only improves the needs of production but also produce effects on the products. This paper sheds light on it utilizing the second sample. Thus, the work checks also on effects on products (measured through achieving wider range of product or services, increasing the market share or obtaining a higher quality of products or services) generated by introduction of new processes. As done before for the process_effects variable, the same is repeated for product_effects of the process innovators (4,608 sample), taking into account that the introduction of new processes can also affect the product effects, due to their interrelationship. Again, the resulting punctuations from a PCA represent the product effects (by process innovators) dependent variable and are obtained from three different variables from the CIS questionnaire. The Product_effects variable captures the effects on products from the introduction of new processes by pure process innovators. Pure process innovators are used in order to better isolate process development activities while being in line with the research's real and scope. Thus, these checking are done on the 4,609 firms and not in the general sample $(8,977)$ because there are product innovators (which simultaneously 
undertake process activities) and then the product effects are not only influenced by the introduction of new processes. In this line of thought, we also control for selection process for the general sample (8,977 firms), specifically in order to evaluate the product_effects variable in the "pure process innovators" (only technological adoption of process innovation, not product one, that is, 4,609 firms). The Inv Mill is not significant at $5 \%(-0.123, \mathrm{p}>7 \%)$. Therefore, there is not selection process and the OLS for capturing the innovation pattern over the product effects (product_effects variable) is carried out without the Inv Mill ratio. See table A-1 for analyzing pure process innovators and the product effects.

As observed in table A-1, in general, the overall fit is good, (R2 ranging around 0.27 to $0.29, \mathrm{p}<0.01$, in the three specifications) and the general results are pretty similar to the ones showed for process effects, with some key differences. First, in general, there is a similar pattern of innovation regarding the introduction of new management practices and the acquisition of embodied knowledge, together with the effects yielded by the external sources. The acquisition of embodied knowledge (Tech_expend variable) does yield product effects (at $\mathrm{p}<0.01$ ). Then, the introduction of new management practices does influence the product effects (all coefficients positive and significant, $p<0.01$ ). The internal and external sources of knowledge affect in a positive way the product effects (similar to the results obtained for process innovation) and the industry effect is also important, together with the "process industries", which yield a positive effect on the dependent variable $(0.120, \mathrm{p}<0.05)$, confirming Lager (2011) evidence. On the other hand, the differences are as follows. First, the size variable is observed to be negative and significant $(\mathrm{p}<0.01)$ for all specifications. The Group variable is negative and significant at $p<0.05$. Second, the intramural $R \& D$ expenditures are positive and significant in all specifications at $p<0.05$, meaning that the introduction of new processes produce effects on the product performance by investing in internal $R \& D$ activities (Int_R\&D_expend variable). This is a really important result which differ from the previous one observed for process effects in which investment in intra-mural R\&D does not produce any effect on process performance. Third, the interaction effect of introducing new management practices to complement the acquisition of embodied knowledge (Inno_organization x Tech_expend) does not yield any result. See results at A-1.

Table A-1 OLS Model. Dependent variable: Product_Effects 


\begin{tabular}{|c|c|c|c|c|c|c|}
\hline & \multicolumn{6}{|c|}{$\begin{array}{l}\text { Firms which only introduce new processes (not products): } \\
\text { "pure" process inovators }\end{array}$} \\
\hline & \multicolumn{2}{|c|}{ Specification 1} & \multicolumn{2}{|c|}{ Specification 2} & \multicolumn{2}{|c|}{ Specification 3} \\
\hline & Coef. & Std. Err. & Coef. & Std. Err. & Coef. & Std. Err. \\
\hline constant & $-0.304 * *$ & 0.0791 & $-0.111^{*}$ & 0.0556 & $-0.303 * *$ & 0.0794 \\
\hline $\log (\mathrm{SIZE})$ & $-0.033 * *$ & 0.0126 & $-0.043 * *$ & 0.0125 & $-0.033 * *$ & 0.0126 \\
\hline group & $-0.069^{*}$ & 0.0333 & $-0.080^{*}$ & 0.0328 & $-0.069^{*}$ & 0.0333 \\
\hline Int_R\&D_expend & $0.075^{*}$ & 0.0227 & $0.071^{*}$ & 0.0214 & $0.075^{*}$ & 0.0227 \\
\hline Ext_R\&D_expend & 0.063 & 0.0391 & 0.037 & 0.0389 & 0.063 & 0.0391 \\
\hline Tech_expend & $0.106 * *$ & 0.0163 & $0.119 * *$ & 0.0162 & $0.105 * *$ & 0.0219 \\
\hline Int. sources & $0.141 * *$ & 0.0118 & $0.145 * *$ & 0.0118 & $0.141 * *$ & 0.0118 \\
\hline Ext_sources_fact_Industry & $0.409 * *$ & 0.0133 & $0.415^{* *}$ & 0.0133 & $0.408 * *$ & 0.0133 \\
\hline Ext_sources_fact_Science & $0.149 * *$ & 0.0151 & $0.165 * *$ & 0.0150 & $0.149 * *$ & 0.0151 \\
\hline Inno_organization & $0.131 * *$ & 0.0258 & $0.109 * *$ & 0.0257 & $0.131 * *$ & 0.0283 \\
\hline Inno_organization_x_Tech_expend & & & & & 0.001 & 0.0314 \\
\hline Industry_NACE_code & \multicolumn{2}{|c|}{ Yes } & & & \multicolumn{2}{|c|}{ Yes } \\
\hline Process_Industry & & & $0.120 * *$ & 0.0327 & & \\
\hline $\mathrm{N}$ & \multicolumn{2}{|c|}{4608} & \multicolumn{2}{|c|}{4608} & \multicolumn{2}{|c|}{4608} \\
\hline $\mathrm{R}^{2}$ & \multicolumn{2}{|c|}{0.29187} & \multicolumn{2}{|c|}{0.2788} & \multicolumn{2}{|c|}{0.2987} \\
\hline Adjusted $\mathrm{R}^{2}$ & \multicolumn{2}{|c|}{0.2915} & \multicolumn{2}{|c|}{0.2773} & \multicolumn{2}{|c|}{0.2913} \\
\hline Error & \multicolumn{2}{|c|}{0} & \multicolumn{2}{|c|}{0.000} & \multicolumn{2}{|c|}{0.000} \\
\hline $\mathrm{F}$ & \multicolumn{2}{|c|}{41.32} & \multicolumn{2}{|c|}{177.74} & \multicolumn{2}{|c|}{40.450} \\
\hline
\end{tabular}

*significant at $\mathrm{p}<0.01 ; * *$ significant at $\mathrm{p}<0.05$; Dependent variable product_effects, obtained from PCA (0.7013, 74\% of variance explained) on the sample 4,608 firms which only introduced new processes (pure process innovators) and not product; (Industry_NACE_code) including n-1 2-digit NACE-93 industry classification as dummies, ranging from the 14 to 74 codes. Code 55 is the baseline. The variable Industry_CNAE_code has effect on the dependent variable. Industry dummies and their coefficients are not reported to save space but are available upon request. $\mathrm{N}=4,608$ In addition Process_industry variable controls for typical process industries, as aforementioned in table 1. VIF control is correct.

Following our findings it is evidenced that the product effects require the investment in R\&D activities, confirming previous studies (Arundel et al., 2008; OECD, 2010; Huang et al., 2010; Hervas-Oliver et al., 2011) which pointed out that the product innovation 
requires $R \& D$ activities. Finally, the results showed in this appendix have pointed out how different are the effects on products and processes from new process introduction and their respective innovation patterns. Summarizing the Appendix's results, it can be stated that the introduction of new management practices by process innovators also enhance product effects, although it does not leverage the effects from investing in embodied knowledge. Put differently, organizational innovation improves and enhances both product and process objectives, but the "learning by trying" effect from new embodied knowledge acquisition and its effect on product objectives is not leveraged by the organizational innovation. In fact, that effect is only accomplished by process innovators pursuing processes performance or effects. In addition, we can also draw the following conclusions. For the process innovators which also introduce new products, the latter does not improve the effects on products. Similarly, for process innovators, the investments in $R \& D$ does not yield any result on process, but improve the effects on products, that is, process improvement does not require R\&D but product improvement does. 
Apéndice B: Encuesta CIS año 2006, España. 


\section{Identificación}

Modificaciones en la identificación (Cumplimente sólo los apartados sujetos a variación)

Nombre o razón social de la empresa

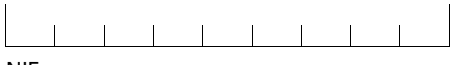

NIF

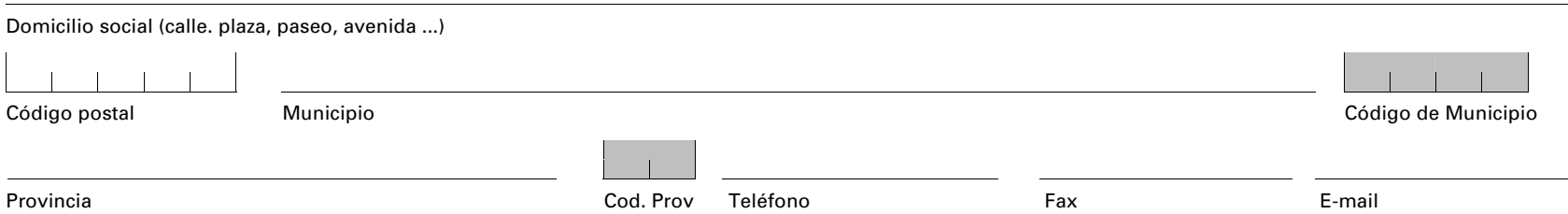

Persona de contacto a quien dirigirse, en caso necesario, para

FIRMA O SELLO DE LA EMPRESA consultas, aclaraciones o modificaciones sobre este cuestionario.

Sr./Sra. D./Dña:

Cargo que ocupa en la empresa:

Teléfono:

Fax:

E- mail:

Página web de la empresa

\section{Naturaleza, características y finalidad}

Esta Encuesta se enmarca dentro del Plan general de estadísticas de ciencia y tecnología propugnado por la oficina de Estadísticas de la Unión Europea (Eurostat). El objetivo de la encuesta es cuantificar las actividades innovadoras de las empresas, entre las que destaca especialmente la realización de I+D y valorar los resultados (innovaciones) y efectos de tales actividades.

\section{Legislación}

Estadística de cumplimentación obligatoria

Secreto Estadístico

Serán objeto de protección y quedarán amparados por el secreto estadístico, los datos personales que obtengan los servicios estadísticos tanto directamente de los informantes como a través de fuentes administrativas (art. 13.1 de la Ley de la Función Estadística Pública de 9 de mayo de 1989 , (LFEP)). Todo el personal estadístico tendrá la obligación de preservar el secreto estadístico (art. 17.1 de la LFEP).

Obligación de facilitar los datos

Las Leyes 4/1990 y 13/1996 establecen la obligación de facilitar los datos que se soliciten para la elaboración de esta Estadística.

Los servicios estadísticos podrán solicitar datos de todas las personas físicas y jurídicas, nacionales y extranjeras, residentes en España (artículo 10.1 de la LFEP).

Todas las personas físicas y jurídicas que suministren datos, tanto si su colaboración es obligatoria como voluntaria, deben contestar de forma veraz, exacta, completa y dentro del plazo a las preguntas ordenadas en la debida forma por parte de los servicios estadísticos (art. 10.2 de la LFEP).

El incumplimiento de las obligaciones establecidas en esta Ley, en relación con las estadísticas para fines estatales, será sancionado de acuerdo con lo dispuesto en las normas contenidas en el presente Título (art. 48.1 de la LFEP).

Las infracciones muy graves serán sancionadas con multas de 3.005,07 a 30.050,61 €. Las infracciones graves serán sancionadas con multas de 300,52 a $\mathbf{3 . 0 0 5 , 0 6} €$. Las infracciones leves se sancionarán con multas de $\mathbf{6 0 , 1 0}$ a $\mathbf{3 0 0 , 5 1} €$ (art. 51.1, 51.2 y 51.3 de la LFEP).

Nota: Este cuestionario está disponible en las distintas lenguas cooficiales de las comunidades autónomas. 


\section{Instrucciones generales}

Unidad de información: la información que se solicita en este cuestionario se refiere a la empresa. Se entiende por empresa a toda unidad jurídica que constituye una unidad organizativa de producción de bienes y servicios, y que disfruta de una cierta autonomía de decisión, principalmente a la hora de emplear los recursos corrientes de que dispone. Desde un punto de vista práctico, y en su caso más general, el concepto de empresa se corresponde con el de unidad jurídica o legal, es decir, con toda persona física o jurídica (sociedades, cooperativas, ...) cuya actividad está reconocida por la Ley, y que viene identificada por su correspondiente Número de Identificación Fiscal (NIF).

Período de referencia: los datos deben referirse al año 2006, salvo que en la pregunta se solicite información referida a otro periodo.

Estructura del cuestionario: el cuestionario se compone de diez apartados:

A. Datos generales de la empresa.

B. Actividades de I+D interna en 2006.

C. Compra de servicios de I+D en 2006.

D. Actividades para la innovación tecnológica realizadas por la empresa en 2006.

E. Innovación de productos y de procesos en el período 2004-2006.

F. Factores que dificultan las actividades de innovación.

G. Derechos de propiedad intelectual e industrial.

H. Ingresos y pagos por tecnología desincorporada en 2006.

I. Innovaciones organizativas.

J. Innovaciones de comercialización.

Forma de anotar los datos: cumplimente los datos claramente. No escriba en las áreas sombreadas. Los datos económicos se solicitan en euros, valorados sin incluir el IVA.

Plazo de remisión: este cuestionario cumplimentado con la información solicitada, debe ser devuelto en un plazo no superior a 15 días.

En este cuestionario, el término producto se utiliza para designar tanto bienes como servicios.

\section{A. Datos generales de la empresa}

\section{A.1 Actividad económica principal}

Actividad principal: la que genera mayor valor añadido o, en su defecto, mayor cifra de negocios.

Descripción:

CNAE-93

Indique, por orden de importancia, los principales productos resultantes de esta actividad:

1.

2.

\section{A.2 Incidencias en el periodo 2004-2006}

Durante el periodo 2004-2006, ¿ha ocurrido en su empresa alguno de los siguientes cambios?

1. Su empresa es de nueva creación

2. Aumento de la cifra de negocios en al menos un $10 \%$, debido a la fusión con otra empresa

3. Disminución de la cifra de negocios en al menos un $10 \%$, debido a la venta o al cierre de la empresa

A.3 Clase de empresa (Señale con un aspa (X) el recuadro que corresponda)

1. Pública

2. Privada nacional

3. Privada con participación de al menos un $50 \%$ de capital extranjero

4. Asociación de investigación y otras instituciones de investigación

\section{A.4 ¿Forma su empresa parte de un grupo de empresas?}

SI $\underset{\Downarrow}{\square}$ NO $\square \Rightarrow$ Pase a la pregunta A.5

- ¿Cuál es la denominación completa del grupo o, en su defecto, de la empresa matriz?

- ¿Cuál es la sede central del grupo? (Escriba el nombre del país)

- ¿Cuál es la relación de su empresa con el grupo?

1. Empresa matriz

2. Empresa filial

3. Empresa conjunta

4. Empresa asociada 


\section{A.5 Resultados económicos}

Consigne el total de ventas comerciales de bienes y servicios, incluidos exportaciones e impuestos, excepto el Impuesto sobre el Valor Añadido (IVA). En el caso de instituciones de crédito se consignarán los intereses a cobrar e ingresos similares. Para empresas de seguros, las primas brutas de seguros firmadas.

Año 2006

Año 2004

(€ sin decimales) (€ sin decimales)

1. Cifra de negocios

1.1 De la cifra anterior, indique el total de exportaciones

(No incluya en exportaciones las entregas intracomunitarias, es decir, entre

países de la Unión Europea, AELC o países candidatos a la UE)

2. Inversión bruta en bienes materiales

\section{A.6 Número medio de empleados}

Año $2006 \quad$ Año 2004

1. Personal remunerado

1.1. De la cifra anterior, indique cuántos de ellos tienen educación superior

2. Personal no remunerado

TOTAL (1+2)

Del total de personal indique el \% de mujeres

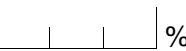

3. ¿Consideraría necesario aumentar la plantilla de la empresa?

$\mathrm{NO} \square \mathrm{SI} \square \Rightarrow$ Indique en cuántas personas

\section{A.7 ¿En qué mercados geográficos vendió su empresa bienes o servicios durante el periodo} 2004-2006? (Señale todos los mercados en los que opera su empresa)

1. Mercado local/autonómico
2. Nacional
3. Otros países de la Unión Europea (UE), AELC o países candidatos a la UE*
4. Todos los demás países

* Se incluyen los siguientes países: Alemania, Austria, Bélgica, Bulgaria, Croacia, Chipre, Dinamarca, Eslovaquia, Eslovenia, Estonia, Finlandia, Francia, Grecia, Hungría, Irlanda, Islandia, Italia, Letonia, Liechtenstein, Lituania, Luxemburgo, Malta, Noruega, Países Bajos, Polonia, Portugal, Reino Unido, República Checa, Rumania, Suecia, Suiza y Turquía.

\section{A.8 Actividades basadas en ciencias y tecnologías biológicas en 2006}

La biotecnología es la aplicación de la ciencia y la tecnología a los organismos vivos, así como a sus partes, productos o modelos, para alterar el material vivo o inerte, con el fin de producir conocimientos, bienes y/o servicios.

1. ¿Realiza su empresa alguna actividad (producción, distribución o venta de productos o servicios, I+D) que emplee o contenga células vivas (levaduras, bacterias, cultivos celulares) o alguna de sus partes activas (proteínas, enzimas, moléculas biológicas, ...)?

SI

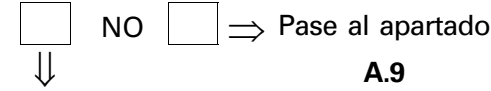

\section{Indique los recursos dedicados a actividades basadas en ciencias y tecnologías biológicas}

La equivalencia a jornada completa (EJC) es la suma del personal que trabaja a dedicación plena con las fracciones de tiempo del personal que trabaja a dedicación parcial en actividades basadas en ciencias y tecnologías biológicas (consultar 1.3 del Anexo)

\begin{tabular}{|c|c|c|c|c|}
\hline \multirow{2}{*}{ Recursos utilizados: } & \multicolumn{2}{|c|}{ Personal } & \multicolumn{2}{|c|}{ Personal en EJC ( 1 decimal } \\
\hline & Total & Mujeres & Total & Mujeres \\
\hline
\end{tabular}

Gastos totales (€ sin decimales)

A.9 Empresas de I+D (Sólo para empresas cuya actividad principal sea la realización de actividades de I+D, asociaciones de investigación y centros tecnológicos)

Indique la actividad principal de la(s) empresa(s) que se benefician de sus actividades de I+D

Descripción: 


\section{B. Actividades de I+D interna en 2006}

Las actividades internas de I+D son trabajos creativos llevados a cabo dentro de la empresa, que se emprenden de modo sistemático con el fin de aumentar el volumen de conocimientos para concebir nuevas aplicaciones, como productos (bienes/servicios) y procesos nuevos o sensiblemente mejorados. (Ver anexo al final del cuestionario).

\section{B.1 ¿Ha realizado su empresa actividades de I+D interna en $2006 ?$}

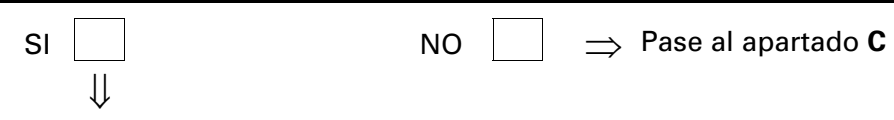

De manera continua

De manera ocasional

Marque sólo una opción

\section{B.2 Organización de la I+D interna en la empresa}

Indique las unidades de su empresa que han realizado actividades de I+D interna en 2006.

1. Departamento o laboratorio específico de I+D

2. Departamento de diseño

3. Departamento de producción

4. Departamento técnico

5. Departamento de control de calidad

6. Departamento de marketing

7. Departamento de informática

8. Otros departamentos (especificar)

\section{B.3 Personal dedicado a actividades de I+D interna en 2006 por ocupación}

La equivalencia a jornada completa (EJC) es la suma del personal que trabaja a dedicación plena con las fracciones de tiempo del personal que trabaja a dedicación parcial en actividades de I+D. (Ver anexo al final del cuestionario).

Ocupación

Personas

EJC (1 decimal)

Total

Mujeres

Total

Mujeres

1. Investigadores (incluye becarios en investigación)

2. Técnicos

3. Auxiliares

TOTAL $(1+2+3)$

De los investigadores del punto 1 , indique los becarios en investigación

\section{B.4 Personal dedicado a actividades de I+D interna en 2006 por titulación, en EJC}

Titulación

1. Doctores universitarios

2. Licenciados, arquitectos, ingenieros y similares

3. Diplomados universitarios, arquitectos e ingenieros técnicos y similares

4. Ciclos formativos de grado superior (Formación profesional específica)

5. Ciclos formativos de grado medio, título de Bachiller y similares

6. Otros estudios

TOTAL $(1+2+3+4+5+6)$. Debe coincidir con B.3

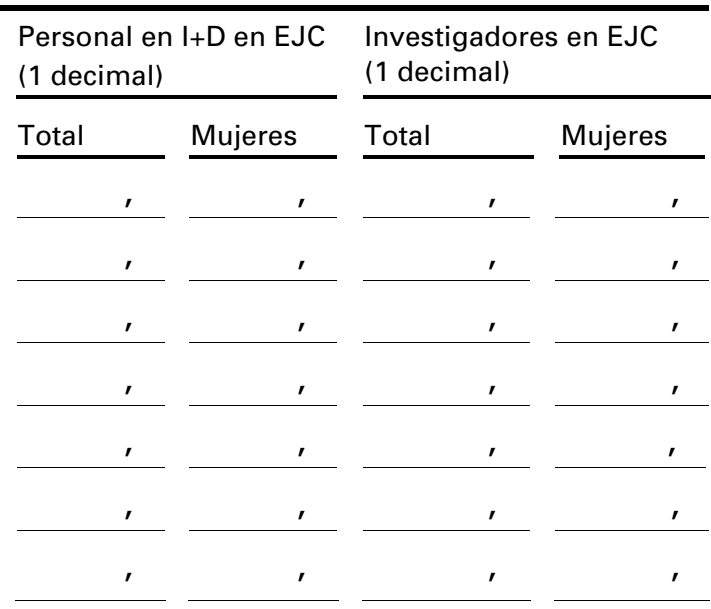




\section{B.5 Distribución del personal en I+D por comunidades autónomas en las que su empresa realiza actividades de I+D interna}

\begin{tabular}{|c|c|c|c|c|c|c|c|c|}
\hline \multirow[t]{2}{*}{ Comunidad autónoma } & \multicolumn{2}{|c|}{ Personal en $\mathrm{I}+\mathrm{D}$} & \multicolumn{2}{|c|}{$\begin{array}{l}\text { Personal en I+D } \\
\text { en EJC ( } 1 \text { decimal) }\end{array}$} & \multicolumn{2}{|c|}{ Investigadores } & \multicolumn{2}{|c|}{$\begin{array}{l}\text { Investigadores en } \\
\text { EJC ( } 1 \text { decimal) }\end{array}$} \\
\hline & Total & Mujeres & Total & Mujeres & Total & Mujeres & Total & Mujeres \\
\hline 1. Andalucía & & &, &, & & & , &, \\
\hline 2. Aragón & & &, & , & & & , & , \\
\hline 3. Asturias (Principado de) & & &, &, & & & , &, \\
\hline 4. Balears (IIles) & & & , &, & & &, & , \\
\hline 5. Canarias & & &, &, & & &, &, \\
\hline 6. Cantabria & & & , & 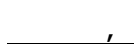 & & & , & , \\
\hline 7. Castilla y León & & & , &, & & &, & , \\
\hline 8. Castilla-La Mancha & & & , &, & & & , & , \\
\hline 9. Cataluña & & &, &, & & & , & , \\
\hline 10. Comunidad Valenciana & & & , &, & & &, &, \\
\hline 11. Extremadura & & &, &, & & &, &, \\
\hline 12. Galicia & & &, &, & & &, &, \\
\hline 13. Madrid (Comunidad de) & & &, &, & & &, & , \\
\hline 14. Murcia (Región de) & & &, &, & & & , & , \\
\hline 15. Navarra (Comunidad Foral de) & & &, &, & & &, &, \\
\hline 16. País Vasco & & &, &, & & &, & , \\
\hline 17. Rioja (La) & & &, &, & & &, &, \\
\hline 18. Ceuta & & & , &, & & & , &, \\
\hline 19. Melilla & & &, &, & & &, & , \\
\hline TOTAL (debe coincidir con B.3) & & & , &, & & &, & , \\
\hline
\end{tabular}

\section{B.6 Gastos en actividades de I+D interna en 2006}

Los gastos de retribuciones serán los correspondientes al total pagado a los investigadores en EJC y al total de técnicos y auxiliares en EJC especificado en B.3. Para el resto de partidas de este apartado se asignará la parte de gasto que corresponda a I+D.

Importe (€ sin decimales)

1. Retribuciones a investigadores en EJC (incluye la retribución de los becarios)

2. Retribuciones a técnicos y auxiliares en EJC

3. Otros gastos corrientes (sin IVA ni amortizaciones)

A. Total gastos corrientes en $I+D(1+2+3)$

A

4. Equipos e instrumentos (sin IVA)

5. Terrenos y edificios (sin IVA)

6. Adquisición de software específico para I+D (incluye licencias)

B. Total gastos de capital en I+D (4+5+6)

B

C. TOTAL $(A+B)$

C

\section{B.7 Becas de investigación}

Estime el importe total de las becas percibidas en el año 2006 por los becarios de investigación consignados en el apartado B.3, independientemente del tipo de beca y del organismo que la haya concedido. Esta cifra debe estar incluida en la retribución a investigadores de la pregunta B.6.

Importe (€ sin decimales)

1. Becas de investigación

\section{B.8 Distribución del gasto corriente en actividades de I+D interna en 2006 por tipo de investigación}

Desglose, en porcentaje, los gastos internos CORRIENTES en I+D de B.6.A según la siguiente clasificación. (No escriba decimales y compruebe que la suma de la columna es $100 \%$ ). (Ver anexo al final del cuestionario).

1. Investigación fundamental o básica

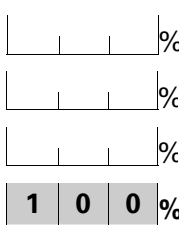

TOTAL 


\section{B.9 Financiación de los gastos en I+D interna en 2006}

Desglose el total de gastos internos en I+D de la pregunta B.6.C según la fuente original de los fondos recibidos para I+D. En el caso de fondos públicos para realizar I+D, deberá distinguirse entre subvenciones (incluidos préstamos a fondo perdido) y contratos (y compras) con la Administración. Los préstamos reembolsables para realizar I+D obtenidos tanto de la Administración como de otras fuentes, se incluirán como fondos propios. En el caso de asociaciones de investigación y de empresas de I+D al servicio de otra(s) empresa(s), las cuotas recibidas de carácter institucional por las que se financian (que no son encargos específicos de $\mathrm{I}+\mathrm{D}$ ) deberán incluirse en fondos propios

Origen de fondos

Importe (€ sin decimales)

\section{A. Financiación a cargo de la propia empresa}

- Fondos propios (incluidos préstamos y cuotas de carácter institucional)

B. Financiación procedente de otras empresas españolas

- De empresas de su mismo grupo

- De otras empresas públicas 3

- De otras empresas privadas y asociaciones de investigación

\section{Financiación pública}

- Subvenciones de la Administración Central del Estado

5

- Contratos con la Administración Central del Estado

6

- Subvenciones de las Administraciones Autonómicas y Locales

- Contratos con las Administraciones Autonómicas y Locales

\section{Otras fuentes nacionales}

- De universidades 9

- De instituciones privadas sin fines de lucro 10

\section{E. Fondos procedentes del extranjero}

- De empresas extranjeras de su mismo grupo

11

- De otras empresas

- De programas de la Unión Europea

12

- De Administraciones Públicas extranjeras 13

- De universidades extranjeras

- De instituciones privadas sin fines de lucro extranjeras

- De otras organizaciones internacionales

16

TOTAL (debe coincidir con B.6.C)

\section{B.10 Distribución del gasto en actividades de I+D interna en $\mathbf{2 0 0 6}$ por objetivo socioeconómico}

Desglose, en porcentaje, los gastos internos en I+D de B.6.C que ha realizado la empresa en 2006 según la finalidad o el objetivo socioeconómico de la investigación. (No escriba decimales y compruebe que la suma de la columna es $100 \%$ ).

1. Exploración y explotación del medio terrestre y de la atmósfera

2.1 Sistemas de transporte y telecomunicaciones

2.2 Otra infraestructura

3. Control y cuidado del medio ambiente

4. Protección y mejora de la salud humana

5. Producción, distribución y utilización racional de la energía

6. Desarrollo de la agricultura, ganadería, selvicultura y pesca

7. Producción y tecnología industrial

8. Estructuras y relaciones sociales

9. Exploración y explotación del espacio

10. Investigación no orientada

11. Otra investigación civil

12. Defensa

TOTAL

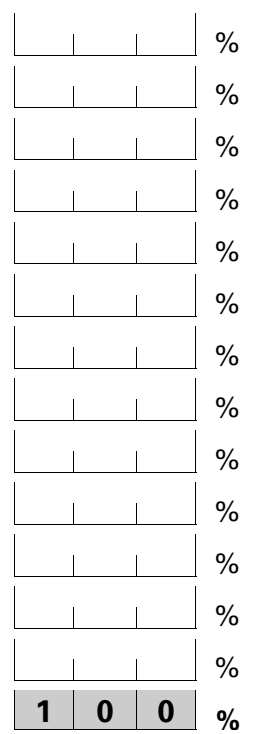

\section{B.11 Actividades de I+D interna previstas para 2007}




\section{Compra de servicios de I+D en 2006}

Son los motivados por la adquisición de servicios de I+D fuera de la empresa mediante contrato, convenio, ... . Se excluyen las cuotas institucionales para financiar a otras empresas, asociaciones de investigación, ... que no signifiquen una compra directa de l+D.

A. Compra de servicios de I+D en España (sin IVA)

Importe (€ sin decimales)

- A empresas de su mismo grupo $\quad 1$

A otras empresas

2

A asociaciones de investigación

3

- A organismos de la Administración Pública

4

- A universidades

A instituciones privadas sin fines de lucro

B. Compra de servicios de I+D en el extranjero (sin impuestos)

- A empresas extranjeras de su mismo grupo

7

A otras empresas extranjeras

8

A organismos de Administraciones Públicas extranjeras

9

- A universidades extranjeras

10

A instituciones privadas sin fines de lucro extranjeras

11

- A otras organizaciones internacionales

12

C. Total compra de servicios de I+D, (I+D externa) (suma de 1 a 12)

\section{Actividades para la innovación tecnológica realizadas por la empresa en 2006}

Una innovación tecnológica, tal y como se define en esta encuesta, es un producto (bien o servicio) nuevo o sensiblemente mejorado introducido en el mercado, o un proceso nuevo o sensiblemente mejorado introducido en la empresa. La innovación se basa en los resultados de nuevos desarrollos tecnológicos, nuevas combinaciones de tecnologías existentes o en la utilización de otros conocimientos adquiridos por la empresa. (Ver anexo al final del cuestionario).

a) Los cambios de naturaleza estética, la mera venta de innovaciones producidas completamente por otras empresas, y los simples cambios de organización o de gestión, no deben incluirse. Se especificarán en el apartado I o en el J.

b) La innovación (producto o proceso) siempre es nueva para la empresa. No es necesario que sea nueva en el mercado en que la empresa opera.

c) En este apartado se solicita información sobre las actividades conducentes a obtener innovaciones tecnológicas.

D.1 En 2006 ¿ha realizado su empresa alguna de las siguientes actividades, con el objetivo de conseguir productos (bienes o servicios) o procesos, nuevos o sensiblemente mejorados, basados en la ciencia, la tecnología y otras áreas de conocimiento? (En caso afirmativo, indique el importe del gasto)

Actividades para la innovación tecnológica

A. I+D interna (Debe coincidir con la pregunta B.6.C)

Trabajos creativos llevados a cabo dentro de la empresa para aumentar el volumen de conocimientos y su empleo para idear productos y procesos nuevos o mejorados (incluido el desarrollo de software).

B. Adquisición de I+D (I+D externa) (Debe coincidir con el total del apartado C) Las mismas actividades que las arriba indicadas pero realizadas por otras organizaciones (incluidas las de su mismo grupo) u organismos públicos o privados de investigación, y compradas por su empresa.

C. Adquisición de maquinaria, equipos y hardware o software avanzados destinados a la producción de productos o procesos nuevos o mejorados de manera significativa (no incluido en I+D pregunta B.6.B).

D. Adquisición de otros conocimientos externos para innovación (no incluido en I+D) Compra o uso, bajo licencia, de patentes o de inversiones no patentadas y conocimientos técnicos o de otro tipo, de otras empresas u organizaciones para utilizar en las innovaciones de su empresa.

\section{E. Formación}

Formación interna o externa de su personal, destinada específicamente al desarrollo o introducción de productos o procesos nuevos o mejorados de manera significativa.

F. Introducción de innovaciones en el mercado Actividades de introducción en el mercado de sus bienes o servicios nuevos o mejorados de manera significativa, incluidas la prospección del mercado y la publicidad de lanzamiento.

G. Diseño, otros preparativos para producción y/o distribución (no incluido en I+D) Procedimientos y preparativos técnicos para realizar productos o procesos nuevos o mejorados de manera significativa, no incluidos en otros apartados.

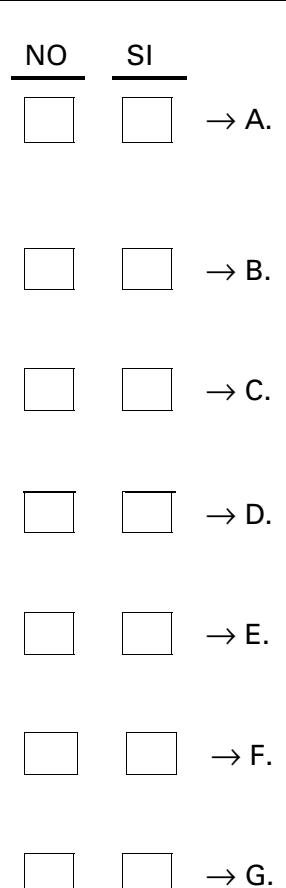

Importe

(€ sin decimales)

$\rightarrow$ A.

$\rightarrow$ B.

$\rightarrow \mathrm{C}$.

$\rightarrow \mathrm{D}$.

$\rightarrow \mathrm{E}$.

$\rightarrow \mathrm{F}$.

$\rightarrow \mathrm{G}$.

$\rightarrow \mathrm{H}$. 


\section{D.2 Gastos en I+D interna y otras actividades de innovación por comunidades autónomas en 2006}

Distribuya el gasto en actividades de I+D y en actividades de innovación tecnológica indicado en las preguntas D.1.A y D.1.H entre las comunidades autónomas donde su empresa realice dichas actividades. Compruebe que los gastos en I+D son menores o iguales que los gastos en innovación tecnológica en cada comunidad autónoma.

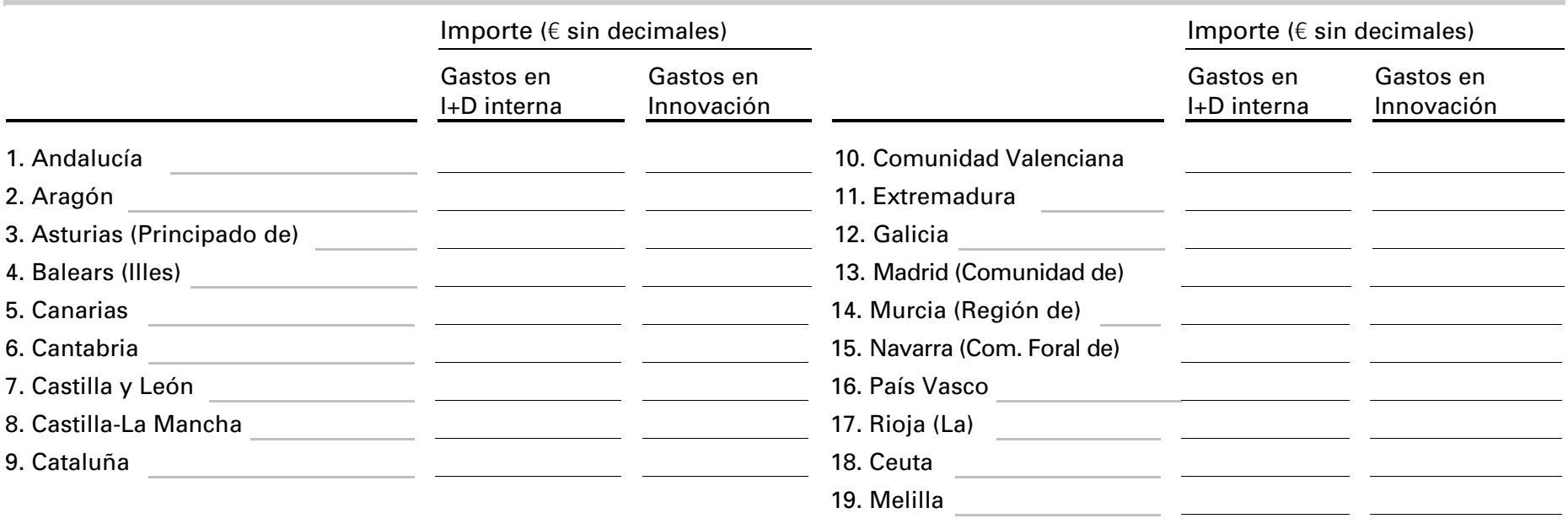

TOTAL (coincide con B.6.C y D.1.H, respectivamente)

D.3 Durante el periodo 2004-2006, ¿recibió su empresa apoyo financiero público (préstamos, subvenciones,...) para actividades de innovación de las siguientes administraciones?

Inclúyase la financiación mediante créditos o deducciones fiscales, subvenciones, préstamos subvencionados y garantías de préstamo. Se excluyen la investigación y otras actividades de innovación, enteramente realizadas mediante contrato para el sector público.

Administraciones locales o autonómicas

Administración del Estado (incluidos los organismos públicos centrales y los ministerios)

La Unión Europea (UE)

En caso de respuesta afirmativa, ¿participó su empresa en el sexto (2003-2006) programa marco de investigación y desarrollo tecnológico de la Unión Europea?

\section{E. Innovación de productos y de procesos en el periodo 2004-2006}

\section{E.1 Innovación de productos (bienes o servicios)}

La innovación de productos consiste en la introducción en el mercado de bienes o servicios nuevos o mejorados de manera significativa con respecto a características básicas, especificaciones técnicas, software incorporado u otros componentes intangibles, finalidades deseadas o prestaciones. (Ver ejemplos en el anexo). Los cambios de naturaleza meramente estética no deben ser tenidos en cuenta, así como la venta de innovaciones completamente producidas y desarrolladas por otras empresas. La innovación (novedad o mejora) debe serlo para su empresa, pero no necesariamente para su sector o mercado. No importa si la innovación la desarrolló inicialmente su empresa o lo hicieron otras.

\section{E.1.1 Durante el período 2004-2006, ¿introdujo su empresa ...}

... bienes nuevos o mejorados de manera significativa? (Se excluyen la mera reventa de bienes nuevos comprados

a otras empresas y las modificaciones unicamente de orden estético)

... servicios nuevos o mejorados de manera significativa?

Si ha respondido NO a ambas preguntas, pase al apartado E.2.

\section{E.1.2 ¿Quién ha desarrollado estas innovaciones de productos? (Seleccione la opción más adecuada)}

Principalmente su empresa o grupo de empresas

Su empresa junto con otras empresas o instituciones

Principalmente otras empresas o instituciones

\section{E.1.3 Breve descripción de la innovación de producto más importante}


... novedad únicamente para su empresa?

... novedad en su mercado?
Su empresa introdujo un bien o servicio nuevo o mejorado de manera significativa del que ya disponían en su mercado sus competidores

Su empresa introdujo un bien o servicio nuevo o mejorado de manera significativa en su mercado antes que sus competidores (puede haberse ofrecido ya en otros mercados)

\section{E.1.5 Impacto económico de las innovaciones sobre la cifra de negocios de 2006}

Desglose, en porcentaje, su cifra de negocios total de 2006 (que consignó en el apartado A.5) según la siguiente clasificación. Escriba la cifra con un decimal y compruebe que la suma de la columna es $100,0 \%$.

1. \% debido a innovaciones en bienes y servicios introducidos en el periodo 2004-2006 que únicamente

fueron novedad para la empresa

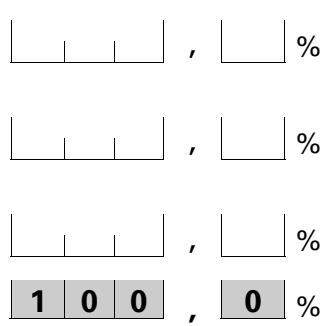

2. \% debido a innovaciones en bienes y servicios introducidos en el periodo 2004-2006 y que representaron

una novedad para el mercado en el que opera la empresa

3. \% debido a bienes y servicios que se mantuvieron sin cambios o sólo experimentaron pequeños cambios

en el periodo 2004-2006 (incluida la reventa de bienes y servicios adquiridos a otras empresas)

Cifra de negocios total en $2006(1+2+3)$

\begin{tabular}{l|l|l|l|l|l|}
$\mathbf{1}$ & $\mathbf{0}$ & $\mathbf{0}$ & $\mathbf{0}$ & $\%$ \\
\hline
\end{tabular}

\section{E.2 Innovación de procesos}

La innovación de proceso consiste en la implantación de procesos de producción, métodos de distribución o actividades de apoyo a sus bienes y servicios que sean nuevos o aporten una mejora significativa. La innovación (novedad o mejora) debe serlo para su empresa, pero no necesariamente para su sector o mercado. No importa si la innovación la desarrolló inicialmente su empresa o lo hicieron otras. Se excluyen las innovaciones meramente organizativas.

\section{E.2.1 Durante el periodo 2004-2006, ¿introdujo su empresa...}

... métodos de fabricación o producción de bienes o servicios nuevos o mejorados de manera significativa?

... sistemas logísticos o métodos de entrega o distribución nuevos o mejorados de manera significativa para sus insumos, bienes o servicios?

... actividades de apoyo para sus procesos, como sistemas de mantenimiento u operaciones informáticas, de compra o de contabilidad, nuevas o mejoradas de manera significativa?

Si ha respondido NO a todas las opciones, pase al apartado E.3.

\section{E.2.2 ¿Quién ha desarrollado estas innovaciones de procesos? (Seleccione únicamente la opción más adecuada)}

Principalmente su empresa o grupo de empresas

Su empresa junto con otras empresas o instituciones

Principalmente otras empresas o instituciones

\section{E.2.3 Breve descripción de la innovación de proceso más importante}

\section{E.3 Actividades de innovación en curso o abandonadas en el periodo 2004-2006}

Recuerde que entre las actividades de innovación se incluyen la adquisición de maquinaria, equipos, software y licencias, las labores de ingeniería y desarrollo, la formación, la comercialización y la investigación y el desarrollo cuando se llevan a cabo de manera específica con el fin de desarrollar o aplicar una innovación de producto o proceso.

1. ¿Cuenta su empresa con alguna actividad de innovación para desarrollar innovaciones de producto

o proceso que estuviera aún en curso a fines de 2006 ?

2. De las actividades que continuaban en curso a fines de 2006, ¿alguna sufrió un retraso importante?

3. En el periodo 2004-2006 ¿alguna de sus actividades o proyectos de innovación fue abandonada

en la fase de concepción?

4. En el periodo 2004-2006 ¿alguna de sus actividades o proyectos de innovación fue abandonada

una vez iniciada la actividad o el proyecto? 


\section{E.4. Fuentes de información para actividades de innovación}

En el periodo 2004-2006, ¿qué importancia han tenido para las actividades de innovación de su empresa cada una de las fuentes de información siguientes?

(Indíquense las fuentes de las que se extrajo información para nuevos proyectos de innovación o que contribuyeron a completar proyectos de innovación en curso)

\section{Fuente de información}

\begin{tabular}{ll} 
Grado de importancia \\
\hline Elevado Intermedio Reducido $\begin{array}{l}\text { No ha sido } \\
\text { utilizada }\end{array}$ \\
\hline
\end{tabular}

Interna

Fuentes del mercado
Dentro de la empresa o grupo de empresas (departamentos, empleados,...)

Proveedores de equipo, material, componentes

o software

Clientes

Competidores u otras empresas de su misma rama de actividad

Consultores, laboratorios comerciales o institutos privados de $\mathrm{I}+\mathrm{D}$

Fuentes institucionales

\section{Otras}

fuentes

\section{Universidades u otros centros de enseñanza superior}

Organismos públicos de investigación

Centros tecnológicos

Conferencias, ferias comerciales, exposiciones, ...

Revistas científicas y publicaciones comerciales/técnicas

Asociaciones profesionales y sectoriales
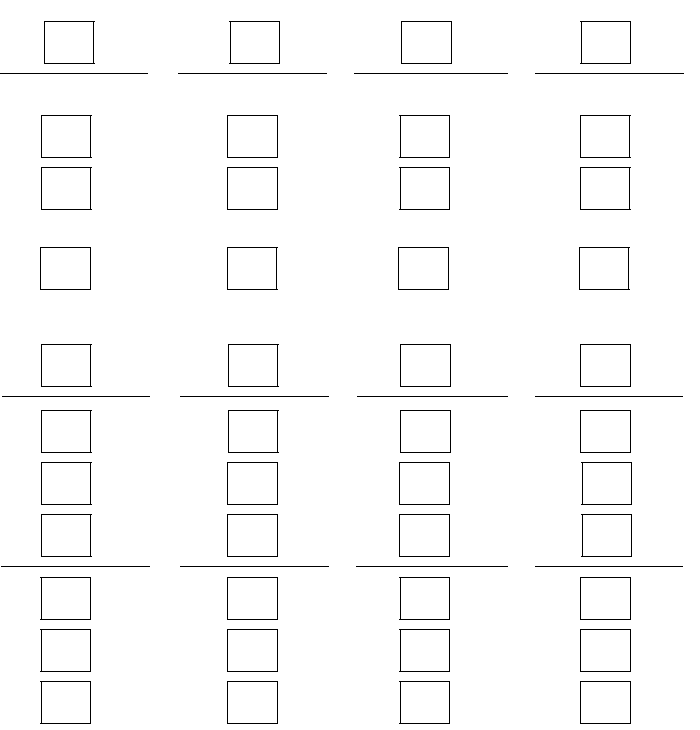

\section{E.5 Cooperación para actividades de innovación}

En el periodo 2004-2006, ¿cooperó su empresa en alguna de sus actividades de innovación con otras empresas o entidades?

La cooperación para la innovación consiste en la participación activa con otras empresas o entidades no comerciales en actividades de innovación. No es necesario que las dos partes extraigan un beneficio comercial. Se excluye la mera subcontratación de trabajos sin cooperación activa.
SI
NO
$\Longrightarrow$ Pase a la pregunta E.6

E.5.1 Indique el tipo de socio con el que cooperó y el país donde está ubicado (Marque las respuestas que procedan)

Tipo de socio con el que cooperó

Su país

$\begin{array}{ll}\begin{array}{ll}\text { Otro país } \\ \text { de Europa* }\end{array} & \text { Unidos }\end{array}$

Los demás 

A. Otras empresas de su mismo grupo

B. Proveedores de equipos, material, componentes o software

C. Clientes

D. Competidores u otras empresas del sector

E. Consultores, laboratorios comerciales o institutos privados de I+D

F. Universidades u otros centros de enseñanza superior

G. Organismos públicos de investigación

H. Centros tecnológicos
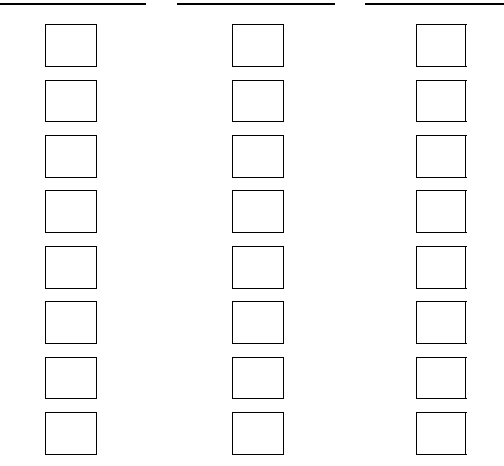

* Se incluyen los siguientes países de la Unión Europea, la AELC o países candidatos a la adhesión a la UE: Alemania, Austria, Bélgica, Bulgaria, Croacia, Chipre, Dinamarca, Eslovaquia, Eslovenia, Estonia, Finlandia, Francia, Grecia, Hungría, Irlanda, Islandia, Italia, Letonia, Liechtenstein, Lituania, Luxemburgo, Malta, Noruega, Países Bajos, Polonia, Portugal, Reino Unido, República Checa, Rumania, Suecia, Suiza y Turquía.

\section{E.5.2 ¿Qué tipo de socio de cooperación considera que ha sido el más valioso para las activida- des de innovación de su empresa?}


El resultado de la actividad innovadora ha podido tener diferentes efectos en su empresa. Señale el grado de importancia de los siguientes efectos:

\begin{tabular}{|c|c|c|c|c|c|}
\hline & & \multicolumn{4}{|c|}{ Grado de importancia } \\
\hline & & Elevado & Intermedio & Reducido & $\begin{array}{l}\text { No } \\
\text { pertinente }\end{array}$ \\
\hline \multirow{3}{*}{$\begin{array}{l}\text { Efectos } \\
\text { para los }\end{array}$} & Gama más amplia de bienes o servicios & & & & \\
\hline & Penetración en nuevos mercados o mayor cuota de mercado & & & & \\
\hline & Mayor calidad de los bienes o servicios & & & & \\
\hline \multirow{4}{*}{$\begin{array}{l}\text { Efectos para } \\
\text { los procesos }\end{array}$} & Mayor flexibilidad en la producción o la prestación de servicios & & & & \\
\hline & Mayor capacidad de producción o prestación de servicios & & & & \\
\hline & Menores costes laborales por unidad producida & & & & \\
\hline & Menos materiales y energía por unidad producida & & & & \\
\hline \multirow{3}{*}{$\begin{array}{l}\text { Otros } \\
\text { efectos }\end{array}$} & Menor impacto medioambiental o mejora en la salud y la & & & & \\
\hline & seguridad & & & & \\
\hline & Cumplimiento de los requisitos normativos & & & & \\
\hline
\end{tabular}

PREGUNTAS A LAS QUE DEBEN RESPONDER TODAS LAS EMPRESAS

\section{F. Factores que dificultan las actividades de innovación}

En el periodo 2004-2006, ¿qué importancia tuvieron los siguientes factores al dificultar sus actividades o proyectos de innovación o influir en la decisión de no innovar?

\begin{tabular}{ll}
\hline $\begin{array}{l}\text { Factores } \\
\text { de coste }\end{array}$ & Falta de fondos en la empresa o grupo de empresas \\
Factores de & La innovación tiene un coste demasiado elevado financiación de fuentes exteriores a la empresa \\
conocimiento & Falta de información sobre tecnología \\
Falta de información sobre los mercados & Dificultades para encontrar socios de cooperación para la \\
innovación & Mercado dominado por empresas establecidas \\
Factores de & Incertidumbre respecto a la demanda de bienes y servicios \\
innovadores & No es necesario debido a las innovaciones anteriores \\
Mo innovar & No es necesario porque no hay demanda de innovaciones
\end{tabular}

\section{G. Derechos de propiedad intelectual e industrial}

\section{G.1. Solicitud y uso de patentes y otros métodos de protección durante el periodo 2004-2006}

En el periodo 2004-2006, ¿ha solicitado su empresa alguna patente para proteger sus invenciones o innovaciones?

SI $\square$ NO $\square \rightleftarrows$ Continue en el apartado G.2

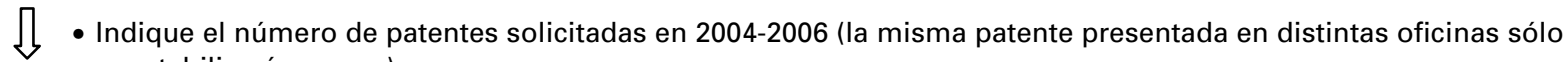
se contabilizará una vez)

- Indique el número de patentes solicitadas en 2004-2006 según el tipo de patente 
En el periodo 2004-2006, ¿ su empresa...

$\begin{array}{lll}\text {... registró algún dibujo o modelo industrial? } & \mathrm{SI} \square \\ \text {... registró alguna marca? } & \mathrm{SI} \\ \text {... reclamó derechos de autor? } & \mathrm{SI}\end{array}$

\section{H. Ingresos y pagos por tecnología desincorporada en 2006}

La tecnología desincorporada incluye los servicios técnicos con contenido tecnológico, patentes, marcas, modelos e inventos y actividades de I+D. Quedan excluidos maquinaria y productos ya sean de alta, media o baja tecnología. Los intercambios con el extranjero deben reunir estas características: a) la operación debe tener un contenido explícitamente tecnológico; b) debe poner en contacto una empresa española con el extranjero; c) la propiedad o el derecho de utilizar la tecnología debe transmitirse bajo condiciones comerciales.

\section{H.1 ¿Ha efectuado su empresa algún intercambio (ingreso o pago) de tecnología desincorpo- rada, con empresas de otros países?}

SI $\square$ NO $\square \rightleftarrows$ Continúe en el apartado I

\section{H.2 Importe de los ingresos y/o pagos de tecnología desincorporada con otros países, por naturaleza de la operación}

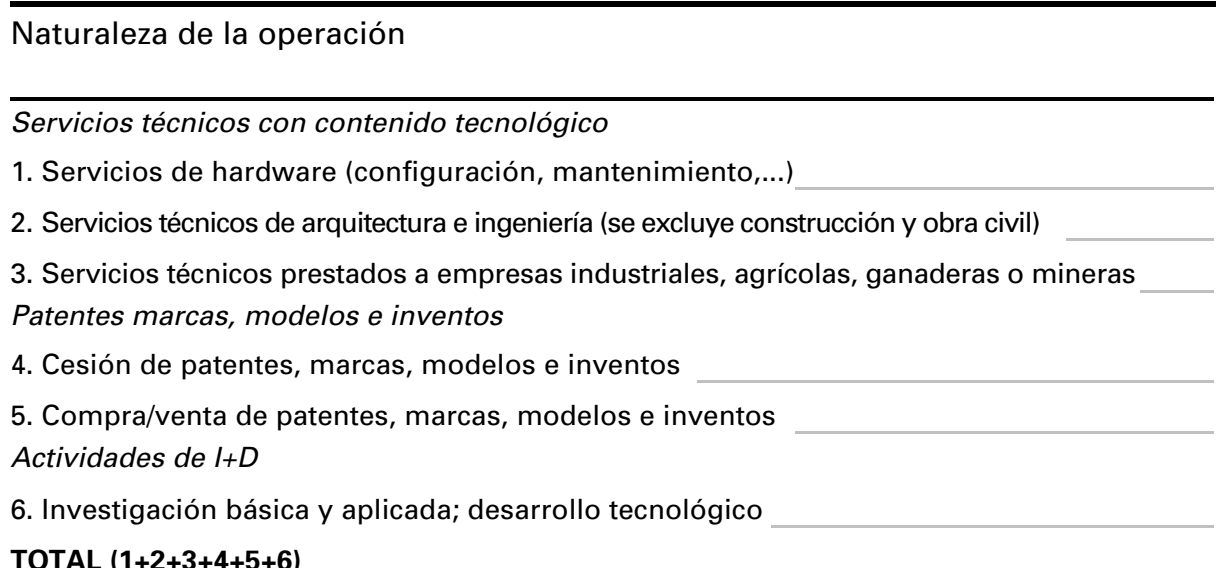

\section{Innovaciones organizativas}

Una innovación organizativa consiste en la implementación de nuevos métodos organizativos en el funcionamiento interno de su empresa (incluyendo métodos/sistemas de gestión del conocimiento), en la organización del lugar de trabajo o en las relaciones externas que no han sido utilizadas previamente por su empresa. Debe ser el resultado de decisiones estratégicas llevadas a cabo por la dirección de la empresa. Excluye fusiones o adquisiciones, aunque estas supongan una novedad organizativa para la empresa.

\section{I.1 Durante el período 2004-2006, ¿introdujo su empresa...}

\begin{tabular}{ll}
$\begin{array}{ll}\text { Ingresos } \\
(€ \sin \text { decimales })\end{array}$ & $\begin{array}{l}\text { Pagos } \\
(€ \sin \text { decimales })\end{array}$ \\
\cline { 1 - 2 } &
\end{tabular}
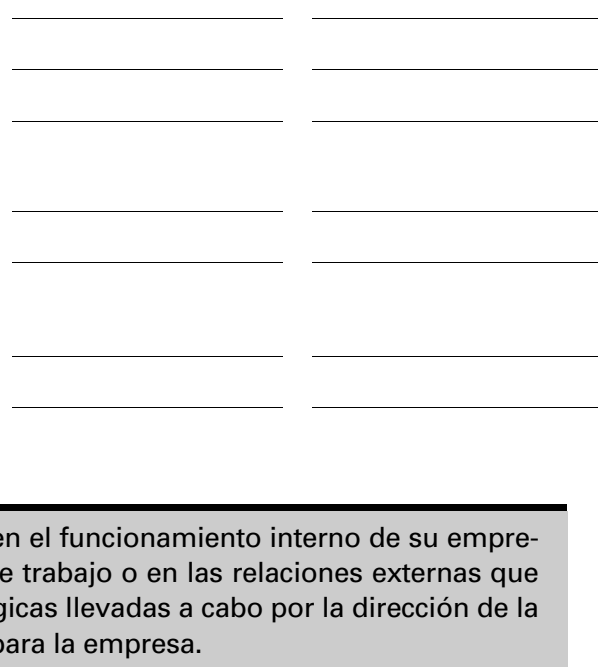

... nuevas prácticas empresariales en la organización del trabajo o de los procedimientos de la empresa? (Por ejemplo la gestión de la cadena de suministro, re-ingeniería de negocios, producción eficiente, gestión de la calidad, sistemas de educación y formación, ...)

... nuevos sistemas de gestión del conocimiento para mejorar el uso o intercambio de información, conocimientos y habilidades dentro de su empresa o para recopilar información externa a su empresa?

... nuevos métodos de organización de los lugares de trabajo en su empresa con el objetivo de un mejor reparto de responsabilidades y toma de decisiones? (Por ejemplo el uso por primera vez de un nuevo sistema de reparto de responsabilidades entre los empleados, gestión de equipos de trabajo, reestructuración de departamentos, ...)

... nuevos métodos de gestión de las relaciones externas con otras empresas o instituciones públicas? (Por ejemplo la creación por primera vez de alianzas, asociaciónes, externalización o subcontratación) 
I.2¿Quién ha desarrollado estas innovaciones organizativas? (Seleccione únicamente la opción más adecuada)

Principalmente su empresa o grupo de empresas

Su empresa junto con otras empresas o instituciones (incluidas consultoras)

Principalmente otras empresas o instituciones (incluidas consultoras)

\section{I.3 Señale el grado de importancia que tuvieron los efectos de las innovaciones organizativas} introducidas por su empresa durante el periodo 2004-2006

Grado de repercusión observado

Reducción del periodo de respuesta a las necesidades de un cliente o proveedor

Mayor calidad de sus bienes o servicios

Menores costes por unidad producida

Mejora de satisfacción del personal o disminución de las tasas de rotación del mismo

Mejora del intercambio de información o de la comunicación dentro de su empresa
Elevado

Intermedio

Reducido

No

pertinente

\section{J. Innovaciones de comercialización}

Una innovación de comercialización es la implementación de nuevas estrategias o conceptos comerciales que difieran significativamente de los anteriores y que no hayan sido utilizados con anterioridad. Debe suponer un cambio significativo en el diseño o envasado del producto, en el posicionamiento del mismo, así como en su promoción y precio. Excluye los cambios estacionales, regulares y otros cambios similares en los métodos de comercialización. Estas innovaciones conllevan una búsqueda de nuevos mercados, pero no cambios en el uso del producto.

\section{J.1 Durante el período 2004-2006, ¿introdujo su empresa...}

... modificaciones significativas del diseño del producto o en el envasado de los bienes o servicios? (Se excluyen los cambios que afectan la funcionalidad del producto o las características del usuario. Dichos cambios de funcionalidad del producto serían innovación de producto)

... nuevas técnicas o canales para la promoción del producto?. (Por ejemplo, el uso por primera vez de un nuevo canal publicitario, fundamentalmente marcas nuevas con el objetivo de introducirse en nuevos mercados, introducción de tarjetas de fidelización de clientes, ...)

... nuevos métodos para el posicionamiento del producto en el mercado o canales de ventas?. (Por ejemplo, el uso por primera vez de franquiciado o licencias de distribución, venta directa, venta al por menor en exclusiva, nuevos conceptos para la presentación del producto, ...)

... nuevos métodos para el establecimiento de los precios de los bienes o servicios?. (Por ejemplo, el uso por primera vez de un sistema de precios variables en función de la demanda, sistemas de descuento, ....). 
J.2 ¿Quién ha desarrollado estas innovaciones de comercialización?

(Seleccione únicamente la opción más adecuada)

Principalmente su empresa o grupo de empresas

Su empresa junto con otras empresas o instituciones (incluídas consultoras)

Principalmente otras empresas o instituciones (incluídas consultoras)

J.3 Señale el grado de importancia que tuvieron los efectos de las innovaciones de comercialización introducidas por su empresa durante el periodo 2004-2006

Grado de repercusión observado

Aumento o mejora de la cuota de mercado

Introducción de productos a nuevos mercados o nuevos grupos de clientes

Aumento de la visibilidad de los productos o negocios

Mejora de la capacidad para responder a las necesidades del cliente
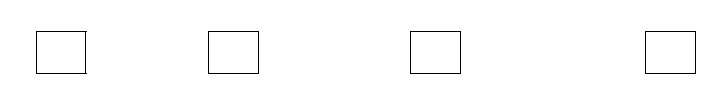

\section{Observaciones:}

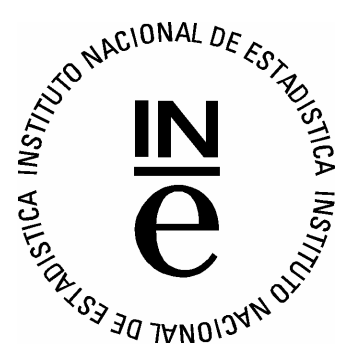




\section{Actividades de Investigación Científica y Desa- rrollo Experimental (I+D)}

\subsection{Definiciones básicas}

La investigación y desarrollo experimental (I+D) comprende el trabajo creativo llevado a cabo de forma sistemática para incrementar el volumen de conocimientos, incluido el conocimiento del hombre, la cultura y la sociedad, y el uso de estos conocimientos para derivar nuevas aplicaciones.

El criterio trabajo creativo llevado a cabo de forma sistemática se satisface por proyectos con objetivos específicos y presupuesto.

El término I+D engloba tres actividades: investigación básica, investigación aplicada y desarrollo experimental:

- La investigación básica consiste en trabajos experimentales o teóricos que se emprenden fundamentalmente para obtener nuevos conocimientos acerca de los fundamentos de fenómenos y hechos observables, sin pensar en darles ninguna aplicación o utilización determinada.

- La investigación aplicada consiste también en trabajos originales realizados para adquirir nuevos conocimientos; sin embargo, está dirigida fundamentalmente hacia un objetivo práctico específico.

- El desarrollo experimental consiste en trabajos sistemáticos basados en los conocimientos existentes, derivados de la investigación y/o la experiencia práctica, dirigidos a la producción de nuevos materiales, productos o dispositivos; al establecimiento de nuevos procesos, sistemas y servicios, o a la mejora sustancial de los ya existentes.

Un criterio para distinguir la I+D de actividades afines es la existencia en el seno de la I+D de un elemento apreciable de novedad y la resolución de una incertidumbre científica y/o tecnológica; o dicho de otra forma, la I+D aparece cuando la solución de un problema no resulta evidente para alguien que está perfectamente al tanto del conjunto de conocimientos y técnicas básicas habitualmente utilizadas en el sector de que se trate.

No constituye I+D aquellas actividades que no contengan un elemento apreciable de novedad, las actividades rutinarias, que no signifiquen la resolución de una incertidumbre científica o tecnológica.

\subsection{Personal en I+D}

Todo el personal empleado directamente en I+D debe ser contabilizado, así como las personas que suministran servicios directamente relacionados con actividades de I+D, por ejemplo, directores, administradores y personal de oficina.

Los investigadores son profesionales que trabajan en la concepción o creación de nuevos conocimientos, productos, procesos, métodos y sistemas y en la gestión de los respectivos proyectos. (Se incluye a los estudiantes postgraduados que desarrollan actividades de I+D).

Los técnicos y el personal asimilado son personas cuyas tareas principales requieren conocimientos y experiencia de naturaleza técnica en uno o varios campos de la ingeniería, de las ciencias físicas y de la vida o de las ciencias sociales y humanidades. Participan en la I+D ejecutando tareas científicas y técnicas que requieren la aplicación de métodos y principios operativos, generalmente bajo la supervisión de investigadores.

Los auxiliares (resto de personal) incluyen los trabajadores, cualificados o no, y el personal de secretariado y oficina, que participan en la ejecución de proyectos de I+D o que están directamente relacionados con la ejecución de tales proyectos.

A continuación se proporciona una lista indicativa (no exhaustiva) de profesionales de cada una de las categorías del personal ocupado en I+D.

\section{- INVESTIGADORES}

Profesionales de Física, Matemáticas e Ingeniería

Físicos, químicos y profesionales relacionados

Matemáticos, estadísticos y profesionales relacionados

Profesionales de informática
Arquitectos, ingenieros y profesionales relacionados

Profesionales de Ciencias de la Vida y de la Salud

Profesionales de ciencias de la vida

Profesionales de ciencias de la salud (excepto enfermería)

\section{Profesionales de la Enseñanza}

Profesionales docentes en Universidades e Instituciones de Enseñanza Superior

\section{Otros profesionales}

Profesionales empresariales

Profesionales de las ciencias jurídicas

Archiveros, bibliotecarios, documentalistas y profesionales de la información

Profesionales de ciencias sociales y relacionados

Gestores de departamentos de investigación y desarrollo

\section{- TÉCNICOS Y PERSONAL EQUIVALENTE}

Profesionales adjuntos de Física e Ingeniería

Técnicos en física e ingeniería

Profesionales adjuntos de informática

Operadores de equipos ópticos y electrónicos

Técnicos y controladores navales y aéreos

Inspectores de seguridad y calidad

Profesionales de seguridad y calidad de vida y profesionales de salud asociados

Técnicos de ciencias de la vida y profesionales asociados relacionados

Nuevos profesionales sanitarios asociados (excepto enfermería)

Otros

Profesionales de Estadística, Matemáticas y otros profesionales asociados relacionados

\section{- OTRO PERSONAL DE APOYO}

Personal de oficina

Trabajadores expertos en agricultura y pesca

Operarios de planta, de maquinaria y ensambladores

Profesionales administrativos asociados

Legisladores, funcionarios y gestores directivos n.c.o.p.

\subsection{Personal en I+D en EJC}

El personal en equivalencia a jornada completa (EJC) es la suma del personal que trabaja a dedicación plena con las fracciones de tiempo del personal que trabaja a dedicación parcial en actividades de $I+D$. Por tanto una persona dedicada a $I+D$ a jornada completa se contabilizará como 1 y una persona que dedica el $20 \%$ de su tiempo a I+D será contabilizada con $0^{\prime} 2$. Si alguien trabaja 3 meses a dedicación plena durante el año se contabilizará como 0'25 pues está una cuarta parte del año. Si una persona está parte del año a dedicación plena y parte a dedicación parcial se hará una estimación de la dedicación anual a I+D con una ponderación ( si está por ejemplo 3 meses a dedicación plena y 9 se dedica en un $20 \%$ a I+D, entonces se calcula: $0^{\prime} 25^{*} 1+$ $0^{\prime} 75^{*} 0^{\prime} 2=0^{\prime} 4$ ).

\subsection{I+D en el desarrollo de software}

Para clasificar como I+D un proyecto de desarrollo de software, se precisa que su realización produzca un progreso científico y/o técnico, y que su objetivo sea el de resolver de forma sistemática una incertidumbre científica y/o tecnológica.

Debe clasificarse en I+D el software que forma parte de un proyecto de I+D, así como las actividades de investigación y desarrollo asociadas a un software si éste constituye un producto acabado.

Los siguiente ejemplos ilustran actividades de I+D en software:

a) La producción de nuevos teoremas o algoritmos en el campo teórico de las Ciencias Computacionales

b) Desarrollo de Tecnologías de la Información al nivel de sistemas operativos, lenguajes de programación, proceso de datos, software de comunicación y herramientas de desarrollo de software 
c) Desarrollo de tecnología de Internet

d) Investigación sobre métodos pare el diseño, desarrollo, uso efectivo y mantenimiento del software

e) Desarrollo de software que produce avances en aproximaciones generales sobre captura, transmisión, almacenamiento, recuperación, manipulación o visualización de información

f) Desarrollo experimental orientado a completar brechas de tecnología de conocimiento, necesario para desarrollar sistemas o programas de software

g) I+D sobre herramientas o tecnologías en áreas específicas de computación (proceso de imagen, representación geográfica de datos, reconocimiento de caracteres, inteligencia artificial y otras áreas).

No constituye I+D las actividades de naturaleza rutinaria que no implican avances científicos o tecnológicos. A modo de ejemplo, no se considera I+D:

a) Desarrollo de aplicaciones de software o de sistemas de información de negocios, utilizando métodos conocidos o herramientas de software ya existente

b) Soporte a sistemas existentes

c) Conversión y/o traducción de lenguajes informáticos

d) Adaptación de programas a usuarios específicos

e) Depuración de errores de sistemas

f) Adaptación del software existente

g) Preparación de documentación de usuarios

\subsection{I+D en actividades de servicios}

Los siguientes criterios deben ser tenidos en cuenta a la hora de identificar proyectos de I+D:

a) Enlaces con laboratorios públicos de investigación

b) El empleo de personal con grado de doctor

c) La publicación de los resultados en revistas o conferencias científicas

d) La construcción de un prototipo o de una planta piloto

\section{A) Ejemplos de I+D en banca y seguros:}

a) Investigación matemática relacionada con análisis de riesgos financieros

b) Desarrollo de modelos de riesgo para políticas de créditos

c) Desarrollo experimental de nuevo software para banca en casa (home banking)

d) Desarrollo de técnicas para investigar el comportamiento del consumidor con el propósito de crear nuevos tipos de cuentas o servicios bancarios

e) Investigación para identificar nuevos riesgos u otras características de riesgos que se necesita tener en cuenta en los contratos de seguros

f) Investigación en fenómenos sociales que tienen impacto en nuevos tipos de seguros (salud, jubilación, etc.), como seguros que cubran a no fumadores

g) I+D relacionada con banca y seguros electrónicos, servicios de Internet y aplicaciones de comercio electrónico

h) I+D relacionada con servicios nuevos o sensiblemente mejorados del sector financiero (nuevos conceptos de cuentas, préstamos, seguros o instrumentos de ahorro)

\section{B) Ejemplos de I+D en otras actividades de servicios:}

a) Análisis de los efectos de cambios económicos y sociales sobre el consumo y actividades de tiempo libre

b) Desarrollo de nuevos métodos para medir las expectativas y preferencias de los consumidores

c) Desarrollo de nuevos métodos e instrumentos para encuestas

d) Desarrollo de procedimientos para el trazado y seguimiento de trayectorias (logística)

e) Investigación sobre nuevos conceptos de viajes y vacaciones

\section{Actividades de Innovación Tecnológica}

\subsection{Definiciones básicas}

Las actividades para la innovación tecnológica están constituidas por todos aquellos pasos científicos, tecnológicos, de organización, financieros y comerciales, incluida la inversión en nuevos conocimientos, destinados a la introducción de productos (bienes o servicios) o procesos nuevos o sensiblemente mejorados.
La I+D constituye únicamente una de esas actividades, y puede llevarse a cabo en diferentes fases del proceso de innovación, no sólo como fuente original de ideas creadoras, sino también como una forma de resolver los problemas que puedan suceder en cualquier etapa hasta su culminación.

Se deben considerar las siguientes actividades para la innovación tecnológica:

1. Actividades de I+D interna

2. Adquisición de I+D (I+D externa)

3. Adquisición de maquinaria y equipo (no incluidos en apartados anteriores)

4. Adquisición de otros conocimientos externos (no incluidos en apartados anteriores)

5. Formación

6. Introducción de innovaciones en el mercado

7. Diseño, otros preparativos para producción o distribución

\subsection{Innovaciones Tecnológicas}

La innovación, tal como se define en esta encuesta, puede ser identificada desde los siguientes puntos de vista:

\subsubsection{INNOVACIÓN EN PRODUCTOS (BIENES O SERVICIOS)}

- La nueva tecnología permite un mejor rendimiento del bien o servicio

- Se consigue una ampliación del rango de productos o servicios Ejemplos: cambio en los materiales de los bienes, introducción de productos ecológicos, utilización de tarjetas con chips, sistemas de tarjetas de cliente, servicios DIAL-IN, banca y seguros electrónicos, servicios relacionados con la Web y el comercio electrónico (salvo la creación de un sitio Web de información sin servicios on line).

\subsubsection{INNOVACIÓN DE PROCESOS}

\subsubsection{Procesos con las siguientes características:}

- mayor automatización o integración

- mayor flexibilidad

- mejora de la calidad

- mejora de la seguridad o del entorno

Ejemplos: selección automática de pedidos, seguimiento automatizado de envíos, comunicación de datos, conexión de sistemas de transporte, sistemas de códigos de barras, proceso óptico de datos, sistemas expertos, software para integración de sistemas, uso o desarrollo de herramientas de software, implantación de sistemas CAD/CAE. La certificación ISO es innovadora únicamente si está relacionada directamente con la introducción de procesos nuevos o mejorados.

\subsubsection{Logística y control con las siguientes características:}

- mayor eficiencia y mejor planificación gracias a nuevas tecnologías - mayor flexibilidad en la distribución

- mejora del control de inventarios

Ejemplos: sistemas de información de gestión, gestión total de la calidad, sistemas de pedidos, sistemas de minimización de stocks, sistemas para el intercambio de productos, logística del transporte, logística asistida por ordenador.

\subsubsection{INNOVACIONES ORGANIZATIVAS}

Una innovación organizativa consiste en la implementación de nuevos métodos organizativos en el funcionamiento interno de su empresa ( incluyendo métodos/sistemas de gestión del conocimiento ), en la organización del lugar de trabajo o en las relaciones externas que no han sido utilizadas previamente por su empresa. Debe ser el resultado de decisiones estratégicas llevadas a cabo por la dirección de la empresa. Excluye fusiones o adquisiciones, aunque estas supongan una novedad organizativa para la empresa.

\subsubsection{INNOVACIONES DE COMERCIALIZACIÓN}

Una innovación de comercialización es la implementación de nuevas estrategias o conceptos comerciales que difieran significativamente de 
los anteriores y que no hayan sido utilizados con anterioridad. Debe suponer un cambio significativo en el diseño o envasado del producto, en el posicionamiento del mismo, así como en su promoción y precio. Excluye los cambios estacionales, regulares y otros cambios similares en los métodos de comercialización. Estas innovaciones conllevan una búsqueda de nuevos mercados, pero no cambios en el uso del producto.

\subsection{Ejemplos de innovaciones específicas por sectores}

\subsubsection{INDUSTRIA MANUFACTURERA}

\section{Innovaciones orientadas a productos:}

a) inclusión de productos ecológicos

b) garantía de por vida de productos nuevos o usados

c) inclusión de servicios:

- soluciones combinadas, por ejemplo, venta del producto incluyendo el mantenimiento

- pruebas, exámenes y certificación de servicios

- provisión de servicios financieros para los clientes (por ejemplo, préstamos, seguros)

d) cambio de materiales en la producción de bienes, (como por ejemplo equipo de montaña resistente al agua respirable)

e) módulos para el área de ciencias de la vida, producidas por bioingeniería

f) introducción de tarjetas con chips

g) utilización de telemática en vehículos de motor

h) vehículos de motor con reducción de contaminantes (por ejemplo, autobuses con gas natural)

i) programas de estabilización electrónica en vehículos de motor

j) nuevo tipo de papel para impresoras específicas

k) nuevos tipos de propelentes para barcos

l) líneas de alto voltaje aisladas con gas

m) mantenimiento remoto

n) cerámica de microondas y filtros de ondas de superficie para la comunicación móvil

El cambio de nombre o de embalaje de bienes existentes como medio para penetrar en otro mercado no es innovación

\section{Innovaciones orientadas a procesos:}

a) digitalización de procesos de imprenta

b) nuevo tipo de cuchillas par la producción de productos de madera

c) nuevo tipo de unidad para la eliminación de agua

d) aplicación en serie de lacas o barnices en polvo para el barnizado de metales

e) nuevos procesos en la producción de ácidos

f) sistemas electrónicos de contratación

g) nuevos sistemas CAD

h) sistemas de distribución de información

i) sistemas interconectados de procesos de datos, redes computacionales

j) introducción de programas de simulación por elementos finitos para la optimización de componentes

k) utilización de comercio electrónico en manufactura

I) retroalimentación directa productor-cliente

m) sistemas de seguimiento de rutas en tiempo real basado en Internet

\subsubsection{COMERCIO MAYORISTA}

\section{Innovaciones orientadas a productos:}

a) inclusión de productos ecológicos en el catálogo de productos

b) garantía de por vida de productos nuevos o usados

c) nuevos tipos de servicios de certificación

d) inclusión de servicios adicionales:

- soluciones combinadas de servicios técnicos y de consultoría

- servicios de comprobación, examen y certificación

e) adopción de servicios financieros:

- pago por teletex

- banca electrónica

- utilización de tarjetas con chips o SMART CARDS que permitan

el pago sin dinero

f) adopción de tareas del sector manufacturero g) consultoría y pedidos desde el punto de venta

h) mantenimiento remoto

i) comercio electrónico

j) sistemas electrónicos de contratación

k) venta directa al consumidor final

\section{Innovaciones orientadas a procesos:}

a) cajas de pago con escáner

b) servicio 24 horas, ampliación de horarios de apertura y admisión

c) desarrollo e introducción de canales de distribución digitales

d) ordenadores portátiles para los comerciales como apoyo a la compra directa

e) sistemas de contratación electrónica

f) etiquetado digital de productos, por ejemplo códigos de barras

g) reconstrucción o reorganización de salas de venta, si esto facilita la compra a los consumidores

h) recepción de pedidos por ordenador con información sobre facturación

i) catálogos electrónicos, p.e. en CD-ROM

j) soluciones basadas en centro de llamadas (call-center)

k) taller de servicio o garaje propio

I) capacitación de $\mathrm{RRHH}$ cualificados para ofrecer servicios de consultoría a los consumidores

m) nuevos sistemas CAD

n) sistemas de distribución de la información

o) sistemas interconectados de procesamiento de datos, softwa-

re de redes computacionales

p) establecimiento de canales de retroalimentación directa entre

el consumidor y el productor

q) centro de atención al cliente para coordinar las solicitudes de los consumidores

\subsubsection{SERVICIOS FINANCIEROS}

\section{Innovaciones orientadas a productos:}

a) servicios financieros nuevos o significativamente mejorados:

- banca on line

- banca por teléfono

b) servicios de seguros nuevos o significativamente mejorados:

- introducción de conceptos de seguros de vida por módulos

- nuevos seguros de invalidez profesional

c) adopción de servicios de seguros por compañías de banca y viceversa

d) adopción de servicios de intermediación inmobiliaria:

- servicios de compraventa de inmuebles

- servicios de valoración de inmuebles

- gestión de propiedad inmobiliaria

e) introducción de sistemas de tarjeta para el pago directo en hospitales

\section{Innovaciones orientadas a procesos:}

a) banca on line

b) herramientas de control por vía telefónica

c) software o redes de ordenadores nuevos o mejorados

d) aplicación de nuevos métodos de diversificación de riesgos

e) archivo de documentos por medios opticoelectrónicos

f) gestión de la oficina sin papel

g) sistemas mejorados de pago con bonificación

h) introducción de política comercial de punto de venta

i) introducción de nuevos métodos de puntuación (rating o scoring)

\subsubsection{OTROS SERVICIOS}

\section{Innovaciones orientadas a productos:}

a) automatización de transacciones con tarjetas de crédito o tarjetas-monedero

b) adopción de tareas del sector manufacturero

c) mantenimiento remoto de software, consultoría a distancia

d) nuevos métodos de análisis estadístico

e) desarrollo de software flexible a medida

f) contratación de servicios medioambientales o energéticos

g) provisión de nuevas aplicaciones multimedia

h) nuevos servicios logísticos

i) sistemas de respuesta por voz 
j) servicios dial-in

\section{Innovaciones orientadas a procesos:}

a) intercambio electrónico de datos

b) realización de proyectos con CAD/CAM

c) banca electrónica

d) herramientas CASE para la creación de software a medida

e) creación automática de documentos

f) mejora de las redes de ordenadores

g) sistemas de gestión de redes

h) sistemas de gestión de llamadas

i) aplicación de métodos termográficos para evaluar sistemas técnicos

j) sistemas de seguimiento de rutas en tiempo real por Internet

k) sistemas de navegación por satélite

I) nuevas herramientas software para la gestión de la cadena de aprovisionamiento

m) introducción de autobuses propulsados con gas natural

n) introducción de autobuses con piso bajo

\subsubsection{INNOVACIONES ORGANIZATIVAS}

- nuevos métodos de organización de rutinas y procesos en desarrollo del trabajo.

- introducción de nuevas prácticas para mejorar el aprendizaje y el conocimiento. Un ejemplo de esto puede ser la creación de un Manual de Buenas Prácticas que sea accesible a toda la empresa. Otro ejemplo es la implantación de sistemas para mejorar el desarrollo y la fidelidad de los trabajadores de la empresa mediante cursos de formación continua.

- introducción de sistemas integrados de ingeniería y desarrollo y producción

- introducción de sistemas integrados de producción y venta

- establecimiento de nuevas vías de relación con otras empresas o instituciones públicas como por ejemplo, acuerdos de colaboración con institutos de investigación, así como nuevas vías de relación con clientes y suministradores, o la subcontración de algunas actividades de la empresa: producción, distribución y servicios auxiliares.

- implementación de estrategias mediante el uso de un software nuevo, encaminadas a fomentar el conocimiento, participando en ello diferentes departamentos de la empresa.

\subsubsection{INNOVACIONES DE COMERCIALIZACIÓN}

- actuaciones dirigidas a una mejor respuesta de las necesidades del cliente, a la apertura de nuevos mercados o a un nuevo posicionamiento de sus productos en el mercado, todo ello con el objetivo final de incrementar las ventas. Deben ser actuaciones nuevas, es decir, no utilizadas con anterioridad en la empresa.

- cambios significativos en el diseño de producto como parte de un nuevo concepto de comercialización.

- introducción de nuevos canales de venta: sistemas de franquicia, venta directa o la concesión de licencias de distribución.

- utilización por primera vez de nuevos medios para la promoción o publicidad de sus productos: inclusión de publicidad dentro de programas de TV, uso de personajes famosos como imagen de la firma, etc.

- cambios significativos en los logos de la firma encaminados a conseguir una nueva imagen de marca

- emisión de "tarjetas de cliente", con ventajas para premiar la fide-

lidad de los clientes de la empresa.

- introduccion de estrategias de precios de acuerdo con la demanda de los productos, por ejemplo, estrategias de bajada de los precios de los artículos menos demandados para impulsar así su venta. Las estrategias de precios cuya única finalidad es diferenciar los precios según segmentos de clientes, por ejemplo, la aplicación de diferentes tarifas en función de la cantidad del producto solicitada por el cliente, no se consideran innovaciones de comercialización.
Diferenciaciones necesarias entre innovaciones organizativas e innovaciones de proceso.

Los cambios que implican las innovaciones organizativas afectan a la organización de los trabajos y la distribución de los recursos humanos de una empresa, mientras que las innovaciones de proceso suponen la implementación de nuevos equipos, maquinaria y software específico.

Diferenciaciones necesarias entre innovaciones de comercialización e innovaciones de producto.

Las innovaciones de comercialización implican cambios de imagen o de acabado final de un producto mientras que las innovaciones de producto implican cambios sustanciales en la propia composición del mismo. Ejemplo: el mero cambio de sabor en un yogur, sería una innovación de comercialización y si al yogur le añadimos algún compuesto vitamínico que enriquece su composición, estariamos ante una clara innovación de producto pues cambia su uso. Si sólo se busca la ampliación del mercado es una innovacion de comercialización. 